Agrupamento híbrido de dados utilizando algoritmos genéticos

Murilo Coelho Naldi 

SERVIÇO DE PÓS-GRADUAÇÃO DO ICMC-USP

Data de Depósito: 19.09.2006

Assinatura:

\title{
Agrupamento híbrido de dados utilizando algoritmos genéticos
}

\author{
Murilo Coelho Naldi \\ Orientador: Prof. Dr. André Carlos Ponce de Leon Ferreira de \\ Carvalho
}

Dissertação apresentada ao Instituto de Ciências Matemáticas e de Computação - ICMC-USP, para avaliação da banca, como parte dos requisitos para obtenção do título de Mestre em Ciências de Computação e Matemática Computacional.

USP - São Carlos

Setembro de 2006 

Este documento foi preparado utilizando-se o formatador de textos ATEX. Sua bibliografia é gerada automaticamente pelo BIBT $\mathrm{EX}$, utilizando o estilo Apalike. O estilo dos títulos dos capítulos foi gentilmente cedido pelo amigo Ronaldo C. Prati.

(C) Copyright 2006 - Murilo Coelho Naldi

Todos os direitos Reservados 



\section{Resumo}

Técnicas de Agrupamento vêm obtendo bons resultados quando utilizados em diversos problemas de análise de dados, como, por exemplo, a análise de dados de expressão gênica. Porém, uma mesma técnica de agrupamento utilizada em um mesmo conjunto de dados pode resultar em diferentes formas de agrupar esses dados, devido aos possíveis agrupamentos iniciais ou à utilização de diferentes valores para seus parâmetros livres. Assim, a obtenção de um bom agrupamento pode ser visto como um processo de otimização. Esse processo procura escolher bons agrupamentos iniciais e encontrar o melhor conjunto de valores para os parâmetros livres. Por serem métodos de busca global, Algoritmos Genéticos podem ser utilizados durante esse processo de otimização. O objetivo desse projeto de pesquisa 1 é investigar a utilização de Técnicas de Agrupamento em conjunto com Algoritmos Genéticos para aprimorar a qualidade dos grupos encontrados por algoritmos de agrupamento, principalmente o $k$-médias. Esta investigação será realizada utilizando como aplicação a análise de dados de expressão gênica.

Essa dissertação de mestrado apresenta uma revisão bibliográfica sobre os temas abordados no projeto, a descrição da metodologia utilizada, seu desenvolvimento e uma análise dos resultados obtidos.

\footnotetext{
${ }^{1}$ Este trabalho conta com apoio financeiro do $\mathrm{CNPq}$
} 



\section{Abstract}

Clustering techniques have been obtaining good results when used in several data analysis problems, like, for example, gene expression data analysis. However, the same clustering technique used for the same data set can result in different ways of clustering the data, due to the possible initial clustering or the use of different values for the free parameters. Thus, the obtainment of a good clustering can be seen as an optimization process. This process tries to obtain good clustering by selecting the best values for the free parameters. For being global search methods, Genetic Algorithms have been successfully used during the optimization process. The goal of this research project ${ }^{2}$ is to investigate the use of clustering techniques together with Genetic Algorithms to improve the quality of the clusters found by clustering algorithms, mainly the k-means. This investigation was carried out using as application the analysis of gene expression data, a Bioinformatics problem.

This dissertation presents a bibliographic review of the issues covered in the project, the description of the methodology followed, its development and an analysis of the results obtained.

\footnotetext{
${ }^{2}$ This work is funded by $\mathrm{CNPq}$
} 



\section{Agradecimentos}

Agradeço ao meu orientador e amigo Prof. Dr. André C. P. L. F. de Carvalho pelos dias de trabalho e dedicação, à Dra. Katti Faceli pela ajuda durante o projeto, ao amigo Marcelo Ubiali Ferracioli pela revisão feita e pelo apoio da minha família e amigos. Também agradeço o CNPq pelo apoio financeiro ao projeto. 



\section{Sumário}

\begin{tabular}{llr}
\hline 1 & Introdução & 1
\end{tabular}

2 Técnicas de Agrupamento 9

2.1 Definição e Aspectos Principais . . . . . . . . . . . . . . . . . . 9

$2.2 \quad$ Preparação dos Padrões $\quad \ldots \ldots$. . . . . . . . . . . . . . . . . . 12

2.3 Medida de Similaridade. . . . . . . . . . . . . . . . . . . . . . 15

$2.3 .1 \quad$ Medidas para atributos binários . . . . . . . . . . . . . 16

2.3 .2 Medidas para atributos nominais e ordinais. . . . . . . . . 16

2.3 .3 Medidas para atributos quantitativos . . . . . . . . . 17

2.3 .4 Medidas para atributos mistos . . . . . . . . . . . . . 20

2.4 Algoritmos de Agrupamento . . . . . . . . . . . . . . . . . . . . . 21

$2.4 .1 \quad$ Algoritmo k-médias . . . . . . . . . . . . . . . . . . 22

$2.4 .2 \quad$ Algoritmos de agrupamento hierárquico . . . . . . . . . . 23

2.4 .3 Redes SOM . . . . . . . . . . . . . . . . . . . . . . . . 24

2.5 Critérios de Validação $\ldots \ldots \ldots$. . . . . . . . . . . . . . 25

2.5 .1 Silhueta . . . . . . . . . . . . . . . . . 25

2.5 .2 Critério de Razão das Variâncias ～. . . . . . . . . . . . . 27

2.5 .3 Rand Corrigido . . . . . . . . . . . . . . . . 27

$2.5 .4 \quad$ Figura de Mérito $\ldots \ldots \ldots \ldots$

2.6 Considerações Finais $\ldots \ldots \ldots$

\begin{tabular}{lll}
\hline & Algoritmos Genéticos & 31
\end{tabular}

3.1 Definição e Aspectos Principais . . . . . . . . . . . . . . . . . . . 32

3.2 Algoritmos Genéticos Paralelos . . . . . . . . . . . . . . . . . 35

3.3 Algoritmos Genéticos Distribuídos . . . . . . . . . . . . . . . . . . 36

3.3 .1 Topologia de migração . . . . . . . . . . . . . . . . . 37

$3.3 .2 \quad$ Escolha dos indivíduos migrantes . . . . . . . . . . . . . . 38

$3.3 .3 \quad$ Freqüência de migração . . . . . . . . . . . . . . . . . . . . 39

3.4 Considerações Finais $\ldots \ldots$. . . . . . . . . . . . . . . . . . 40 
Sumário

4 Técnicas de Agrupamento e Algoritmos Genéticos 41

4.1 Definição e Aspectos Principais . . . . . . . . . . . . . . . . . . . 41

4.2 Representação Utilizada . . . . . . . . . . . . . . . . . . . . . . 43

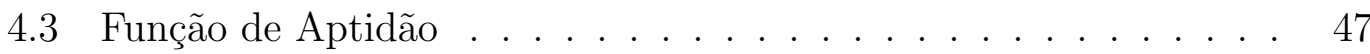

4.4 Operadores Genéticos . . . . . . . . . . . . . . . . . . . 50

$4.4 .1 \quad$ Inicialização . . . . . . . . . . . . . . . . . . 50

4.4 .2 Seleção . . . . . . . . . . . . . . . . . . . 52

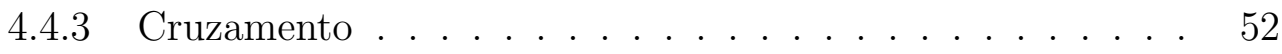

4.4 .4 Mutação . . . . . . . . . . . . . . . . . . 56

4.5 Trabalhos Relacionados . . . . . . . . . . . . . . . . . . . . . . 58

4.5.1 Técnicas particionais em conjunto com AGs . . . . . . . 60

4.5 .2 Redes Neurais em conjunto com AGs . . . . . . . . . . . 70

4.5.3 Técnicas Hierárquicas com AGs . . . . . . . . . . . . . . 77

4.6 Considerações Finais . . . . . . . . . . . . . . . . . . . . . . . . . . . . 84

\begin{tabular}{llr}
\hline 5 & Experimentos & 87
\end{tabular}

5.1 Bases de dados . . . . . . . . . . . . . . . . . . . . . . . . . . . . . 88

5.2 Características do algoritmo utilizado . . . . . . . . . . . . . . . . 89

5.3 Tempo de execução com uso de AG . . . . . . . . . . . . . . . . . 91

5.4 KMGA com função de aptidão baseada em MSE . . . . . . . . . . 93

$5.4 .1 \quad$ Análise do tempo de execução . . . . . . . . . . . . . . . . 96

5.5 KMGA com função de aptidão baseada em VRC . . . . . . . . . . 96

5.5 .1 Tendências dos critérios de validação . . . . . . . . . . . . 97

5.5 .2 Análise do tempo de execução . . . . . . . . . . . . . . . . 100

$5.6 \quad$ KMGA com função de aptidão baseada em Silhueta . . . . . . . . . 101

5.6 .1 Tendências dos critérios de validação . . . . . . . . . . . . 104

5.6 .2 Análise do tempo de execução . . . . . . . . . . . . . . . . 106

5.7 KMGA usando k-médias com múltiplas medidas de dissimilaridade 107

5.7.1 Experimentos feitos com aptidão baseada em VRC . . . . 108

5.7 .2 Experimentos feitos com aptidão baseada em Silhueta . . . 110

5.8 KMGA com função de aptidão baseada em VRC e Silhueta . . . . 112

5.8 .1 Análise do tempo de execução . . . . . . . . . . . . . . . . 114

5.9 KMGA Distribuído . . . . . . . . . . . . . . . . . . . . . . 115

5.10 Estudo do uso de k-médias . . . . . . . . . . . . . . . . . . . . . 121

5.11 KMGA com número de grupos não estabelecido . . . . . . . . . . 125

5.11 .1 CGA . . . . . . . . . . . . . . . 126

$5.11 .2 \mathrm{GCA} \ldots \ldots \ldots \ldots \ldots \ldots$

5.11 .3 KMGA . . . . . . . . . . . . . . . 126 
Sumário

5.11 .4 Experimentos . . . . . . . . . . . . . . . 127

5.12 Análise de desempenho do KMGA e comparação com outras abor-

dagens similares . . . . . . . . . . . . . . . . . . . . 131

5.12 .1 KMGA comparado com abordagens similares . . . . . . 137

5.13 Considerações Finais . . . . . . . . . . . . . . . . . . . . 142

\begin{tabular}{llr}
\hline & Conclusão & 143
\end{tabular} 



\section{Lista de Figuras}

1.1 Estrutura, elementos e representação do DNA . . . . . . . . . . . 2

1.2 Porcesso de medida de expressão de genes por microarray. . . . . 3

$2.1 \quad$ Etapas do processo de Agrupamento . . . . . . . . . . . . . . 11

2.2 Um grupo curvilíneo com distância constante da origem (Jain et al.|, 19990. . . . . . . . . . . . . . . . . . 15

2.3 Exemplo de dendograma (Jain et al 1999$)$. . . . . . . . . . . . 23

3.1 Visão Geral de um Algoritmo Genético . . . . . . . . . . . . . . . 32

3.2 Exemplo de Cruzamento . . . . . . . . . . . . . . . . . . . . 34

3.3 Exemplo de Mutação . . . . . . . . . . . . . . . . . . . . . . . . 34

3.4 Exemplos de AGs paralelos: modelo mestre-escravo (a) e modelo celular $(\mathrm{b}) \ldots \ldots \ldots \ldots \ldots$

$3.5 \quad$ Exemplo de modelo hierárquico utilizando modelo de ilhas no nível superior e modelo celular no nível inferior. . . . . . . . . . . . . 36

3.6 Exemplos de topologias: (1) Salto entre Pedras e (2) Migração Aleatória . . . . . . . . . . . . . . . . . . . . 38

4.1 Cromossomos representando o agrupamento $\{\{A, C, F\},\{B, D, E\}\}$ utilizando as representações: (a)Grupo-Número (b)Matriz (c)Permutaçãa com separador (d) Permutação Gulosa . . . . . . . . . . . . . . . 44

4.2 Cromossomos representando uma matriz contendo centróides . . . 45

4.3 Cromossomo com número variável de grupos . . . . . . . . . . . . 45

4.4 Exemplo de cromossomo para agrupamento hierárquico . . . . . . 46

4.5 Exemplo de cromossomo para redes SOM. . . . . . . . . . . . . 47

4.6 Cromossomo com genes representando os parâmetros P1, P2, P3. 47

4.7 Agrupamentos e suas representações Grupo-Número. . . . . . . . 53

4.8 Intersecções não vazias e um padrão de cromossomo filho. . . . . . 54

\begin{tabular}{|ll}
4.9 & Cruzamento de cromossomos com número indeterminado de grupos 55
\end{tabular}

$5.1 \quad$ Cromossomo representando os grupos $G_{0}, G_{1}$ e $G_{2} . \quad \ldots \ldots$ 
5.2 Tempo de execução total de cada experimento . . . . . . . . . . . 92

5.3 Índices médios obtidos pelo critério $\mathrm{CR}$ para as bases de dados estudadas. . . . . . . . . . . . . . . . . . . . . . . . . . . 92

5.4 Média dos índices dos critérios de validação dos agrupamentos com menor MSE para cada base de dados. . . . . . . . . . . . . . . . . 94

5.5 Tempo de execução total dos algoritmos para cada base de dados. 96

5.6 Média dos índices dos critérios de validação dos agrupamentos com maior VRC para cada base de dados. . . . . . . . . . . . . . . 98

5.7 Tempo de execução total dos algoritmos para cada base de dados. 101

5.8 Média dos índices dos critérios de validação dos agrupamentos com maior Silhueta para cada base de dados. . . . . . . . . . . . . . . 102

5.9 Média da CR obtida pelos experimentos usando diferentes funções de aptidão. . . . . . . . . . . . . . . 103

5.10 Tempo de execução total dos algoritmos para cada base de dados. 106

5.11 Média dos índices dos critérios de validação dos agrupamentos com maior VRC para cada base de dados. . . . . . . . . . . . . . . 109

5.12 Média dos índices dos critérios de validação dos agrupamentos com maior Silhueta para cada base de dados. . . . . . . . . . . . . . . 111

5.13 Média dos índices dos critérios de validação dos agrupamentos com maior aptidão para cada base de dados. . . . . . . . . . . . . . . . 113

5.14 Tempo de execução do algoritmo KMGA com aptidão baseada em Silhueta e aptidão mista para cada base de dados. . . . . . . . . . . 114

5.15 Estrutura do AGD desenvolvido. . . . . . . . . . . . . . . . 115

5.16 CR dos resultados obtidos para a base Gaussiana3. . . . . . . . . 122

5.17 CR dos resultados obtidos para a base Simulado6. . . . . . . . . 123

5.18 CR dos resultados obtidos para a base Pulmão. . . . . . . . . . 123

5.19 CR dos resultados obtidos para a base Leucemia. . . . . . . . . . 124

5.20 CR dos resultados obtidos para a base Proteínas. . . . . . . . . 125

5.21 CR dos resultados obtidos com KMGA para a base Gaussiana3. . 135

5.22 CR dos resultados obtidos com KMGA para a base Simulado6. . . 135

5.23 CR dos resultados obtidos com KMGA para a base Pulmão. . . . 136

5.24 CR dos resultados obtidos com KMGA para a base Leucemia. . . 136

5.25 CR obtida com vários algoritmos de agrupamento para a base Gaussiana3. . . . . . . . . . . . . . . . . . . . . . . . . . 138

5.26 CR obtida com vários algoritmos de agrupamento para a base Simulado6. . . . . . . . . . . . . . . . . 139 
5.27 CR obtida com vários algoritmos de agrupamento para a base Pulmão. . . . . . . . . . . . . . . . . . 139

5.28 CR obtida com vários algoritmos de agrupamento para a base Leucemia. . . . . . . . . . . . . . . . . . 140

5.29 CR obtida com vários algoritmos de agrupamento para a base Proteínas. . . . . . . . . . . . . . . . . . . . . . 140

5.30 Tempo de execução total dos algoritmos. . . . . . . . . . . . . . . 141 



\section{Lista de Tabelas}

$1.1 \quad$ Parte de uma matriz de expressão de genes . . . . . . . . . . . . . 4

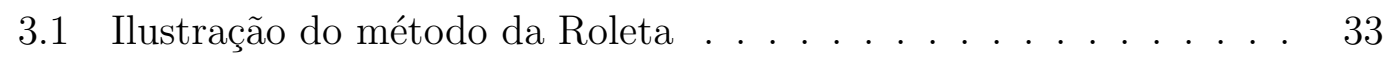

4.1 Principais características dos algoritmos de agrupamento com AG estudados. . . . . . . . . . . . . . . . . . . . 59

$4.2 \quad$ Principais características do AG utilizado por Bezdek et al. . . . . 61

4.3 Principais características do AG utilizado por Murthy. . . . . . . 62

4.4 Principais características do Algoritmo COWCLUS. . . . . . . . . 63

4.5 Principais características do Algoritmo GAG. . . . . . . . . . . 65

4.6 Principais características do Algoritmo KGACLUS. . . . . . . . . 66

4.7 Principais características do Algoritmo HGACLUS. . . . . . . . . 67

4.8 Principais características do Algoritmo SAGA. . . . . . . . . . . . 69

$4.9 \quad$ Principais características do Algoritmo CGA . . . . . . . . . . . . 70

4.10 Principais características do AG utilizado por Tanaka. . . . . . . 71

4.11 Principais características do algoritmo ISOM. . . . . . . . . . . . 73

4.12 Principais características do AG utilizado por Ohtsuka. . . . . . . 75

4.13 Principais características do algortimo GASOM. . . . . . . . . . . 76

4.14 Principais características do Algoritmo GSOMC. . . . . . . . . . . 77

4.15 Principais características do Algoritmo CLUSTERING. . . . . . . 79

4.16 Principais características do Algoritmo utilizado por Greene. . . . 81

4.17 Principais características do Algoritmo utilizado por Ma. . . . . . 82

4.18 Principais características do Algoritmo GCA. . . . . . . . . . . . 84

$5.1 \quad$ Principais características das bases de dados. . . . . . . . . . . 88

5.2 Características do algoritmo KMGA baseado em MSE. . . . . . . 93

5.3 Características do algoritmo KMGA usando VRC. . . . . . . . . . 97

5.4 Porcentual da diferença entre o indivíduo mais apto e a média da população. . . . . . . . . . . . . . . . . . 99 
5.5 Porcentual de agrupamentos cujos critérios se comportaram de forma semelhante ao critério CR. . . . . . . . . . . . . . . . . . . 100

5.6 Características do algoritmo KMGA usando Silhueta. . . . . . . . 101

5.7 Porcentual da diferença entre o indivíduo mais apto e a média da população. . . . . . . . . . . . . . . . . . . 105

5.8 Porcentual de agrupamentos cujos critérios se comportam de forma semelhante ao critério CR. . . . . . . . . . . . . . . . . . . . . . . 105

5.9 Medidas de dissimilaridade utilizadas. . . . . . . . . . . . . . . . . 107

5.10 Diferenças entre o CR médio obtido pelos KMGAs executados nos demes dos AGDs e os obtidos pelos KMGAs executados separadamente. . . . . . . . . . . . . . . . . . 116

5.11 Diferenças $\overline{d_{1}^{\prime}}, \overline{d_{2}^{\prime}}$ e $\overline{d_{3}}$ para as populações obtidas nos demes do AGD1 . . . . . . . . . . . . . . . . . . 118

5.12 Diferenças $\overline{d_{1}^{\prime}}, \overline{d_{2}^{\prime}}$ e $\overline{d_{3}}$ para as populações obtidas nos demes do AGD2. . . . . . . . . . . . . . . . . . . 119

5.13 Diferenças $\overline{d_{1}^{\prime}}, \overline{d_{2}^{\prime}}$ e $\overline{d_{3}}$ para as populações obtidas nos demes do AGD3. . . . . . . . . . . . . . . . . . . 120

5.14 Diferenças $\overline{d_{1}^{\prime}}, \overline{d_{2}^{\prime}}$ e $\overline{d_{3}}$ para as populações obtidas nos demes do AGD4 ........................... 120

5.15 Características dos resultados obtidos com CGA. . . . . . . . . . 128

5.16 Características dos resultados obtidos com GCA. . . . . . . . . . 128

5.17 Características dos resultados obtidos pelo KMGA com aptidão por VRC. . . . . . . . . . . . . . . . . . . . . . . . . 129

5.18 Características dos resultados obtidos pelo KMGA com aptidão por Silhueta. . . . . . . . . . . . . . . . . . . . . . . . . . 129

5.19 Características dos resultados obtidos pelo KMGA com aptidão por VRC e Silhueta. . . . . . . . . . . . . . . . . . . . . . 130

5.20 Características dos resultados obtidos pelo KMGA com aptidão por VRC ou Silhueta. . . . . . . . . . . . . . . . . . . . . . . 130 


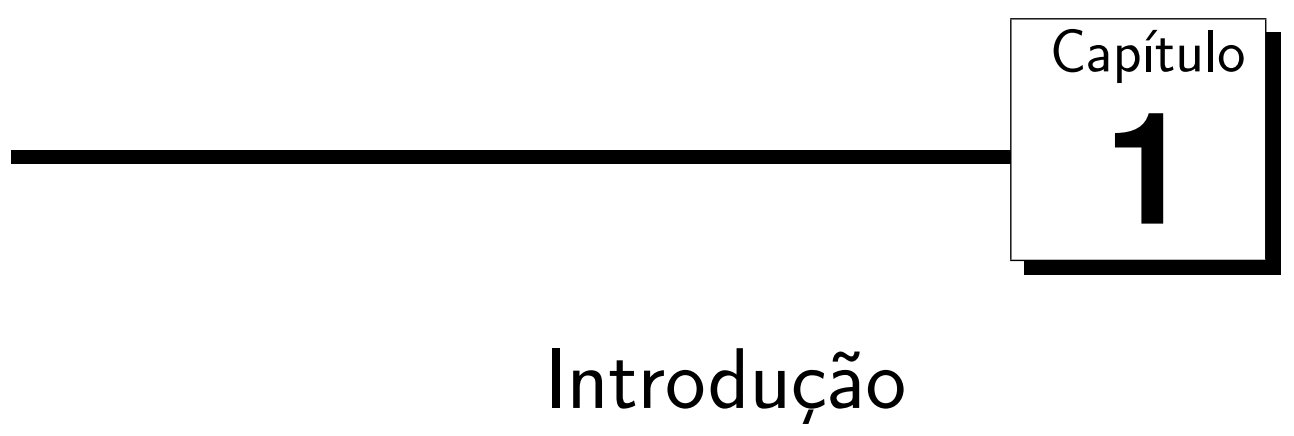

A bioinformática consiste na utilização de técnicas e ferramentas da computação para a resolução de problemas da biologia (Baldi and Brunak, 1998). Essa nova ciência surgiu na última década em função da necessidade de ferramentas sofisticadas para analisar o crescente volume de dados gerado em biologia molecular (Setúbal and Meidanis, 1997). Dentre as análises feitas na biologia molecular, pode ser destacada a análise de expressão de genes.

A expressão de um gene está associada ao processo de produção de proteínas. Proteínas são moléculas grandes compostas de uma ou mais cadeias de moléculas menores chamadas aminoácidos. Existem vários tipos de proteínas desempenhando papel estrutural ou funcional no organismo. A construção da proteína é feita por meio da transcrição de seqüências de ácidos nucléicos de regiões chamadas genes.

Existem dois tipos de ácidos nucléicos, o ácido desoxirribonucléico (DNA) e o ácido ribonucléico (RNA). Os ácidos nucléicos consistem de fitas compostas por uma cadeia de nucleotídeos, sendo que o DNA é composto por uma cadeia (ou fita) dupla e o RNA por uma cadeia única. Os nucleotídeos são formados por um grupo fosfato, um açúcar (desoxirribose no DNA ou ribose no RNA) e uma base nitrogenada. A base nitrogenada pode ser uma adenina $(A)$, uma guanina $(G)$, uma citosina $(\mathrm{C})$, uma timina $(\mathrm{T})$, no caso de DNA, e uracila $(\mathrm{U})$, no caso de RNA.

As cadeias de nucleotídeos são unidas por meio de pontes de hidrogênio entre as bases nitrogenadas. As reações de ponte de hidrogênio que unem as bases nitrogenadas são chamadas de pareamento de bases. A adenina deve parear com timina ou uracila, enquanto a citosina deve parear com guanina. Um cromossomo é constituído por uma molécula de DNA. A Figura 1.1 mostra a estrutura do 
DNA, bem como a representação dos pares e da seqüência de nucleotídeos.

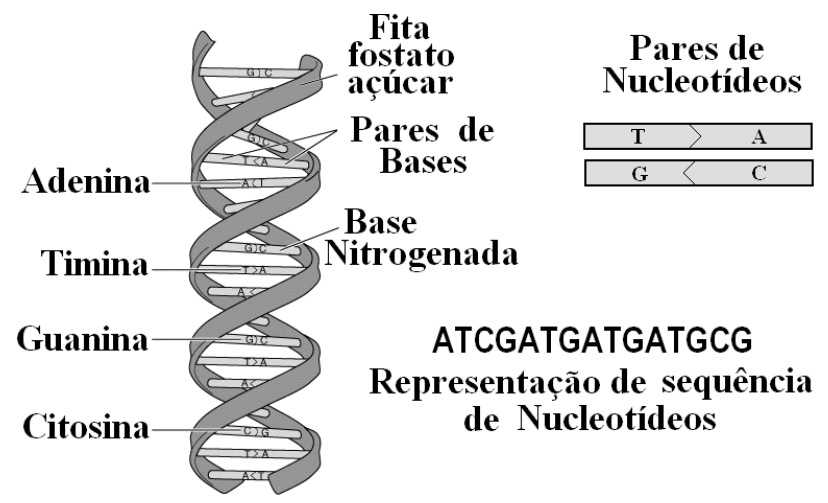

Figura 1.1: Estrutura, elementos e representação do DNA

A produção de proteínas é divida em transcrição e tradução. Na transcrição, uma seqüência de DNA de um gene é transcrita em uma molécula de RNA complementar, ou seja, que é formada por bases nitrogenadas complementares às bases da seqüência do DNA. Essa molécula é chamada de RNA mensageiro (mRNA). Durante essa etapa podem ser formados outros dois tipos de RNA: o RNA transportador (tRNA), que transporta os aminoácidos, e o RNA ribossômico (rRNA), que é parte dos ribossomos.

Durante a tradução, o mRNA irá servir de modelo para a produção de uma proteína. Realizada no interior dos ribossomos, a tradução do mRNA faz com que os aminoácidos transportados pelos tRNAs sejam adicionados, formando uma proteína. Cada aminoácido é conectado em uma trinca de nucleotídeos. $\mathrm{Na}$ maioria das vezes, a proteína pronta passa por algumas modificações para que possa exercer adequadamente suas funções.

O conjunto dos cromossomos de um organismo é chamado de genoma e está presente em todas suas células. ou seja, toda a informação genética necessária ao desenvolvimento e manutenção do organismo está presente em suas células. Entretanto, apenas uma fração reduzida de toda essa informação é utilizada a cada momento, o que faz com que a célula produza diferentes tipos e quantidades de proteínas em um dado instante. A produção de proteínas é controlada por uma série de mecanismos que são ativados/desativados de acordo com informações presentes no DNA, com o tipo de proteína, substâncias presentes na célula e fatores ambientais como temperatura. Esses mecanismos de controle determinam quando, onde e em que quantidade as proteínas são sintetizadas. Mudanças no ambiente da célula, alterações em sua forma ou comportamento, idade, infecção ou doenças são fatores que influenciam nesses mecanismos de controle (Chan et al., 2000). Dentre as doenças, pode ser citado o câncer. 
Embora o produto final da expressão de um gene seja a proteína, a análise do mRNA que gera essa proteína tem um custo menor. O nível de expressão de um gene indica o número aproximado de cópias do mRNA daquele gene presente em uma célula ou amostra (Slonim et al., 2000).

Diversas técnicas têm sido propostas para obtenção da expressão gênica a partir de uma amostra de tecido. Uma das mais conhecidas é a técnica de microarray. Essa técnica é capaz de medir expressões de genes por meio de um processo de hibridização (Murphy, 2002). O processo do microarray consiste em imobilizar seqüências de DNA de maneira organizada em uma superfície sólida, geralmente feita de nylon ou vidro. As seqüências de DNA são previamente conhecidas e fixadas em conjuntos de sondas, um correspondente a cada gene, chamados spots. Dessa maneira, cada spot irá representar um gene conhecido, que é identificado pela sua posição no microarray.

Na utilização do microarray, o mRNA é extraído da amostra de interesse e transformado em uma molécula de DNA complementar (cDNA) marcada de forma radioativa ou fluorescente. Por serem mais estáveis, moléculas de cDNA são hibridizadas no microarray. Cada cDNA se liga a uma sonda complementar no spot correspondente a um gene específico. A abundância de cada mRNA na amostra é capturada de acordo com a quantidade de cDNA que hibridizou em cada spot do microarray. Os níveis de expressão são obtidos por meio de sinais analógicos de absorvência ou fluorescência e digitalizados em seguida. A Figura 1.2 ilustra o processo descrito.

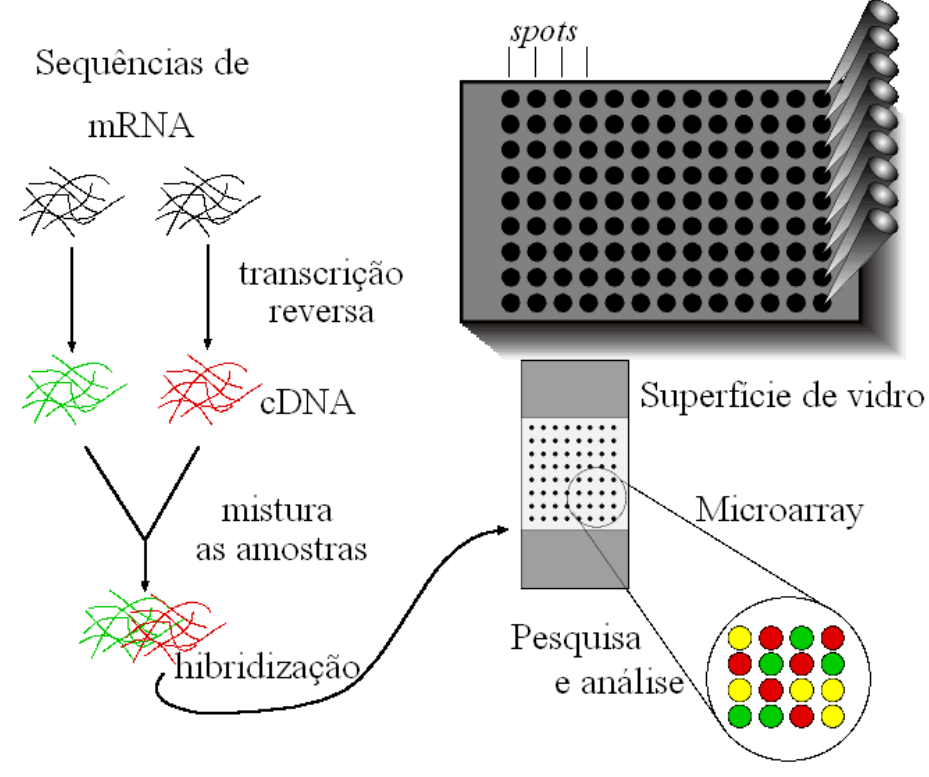

Figura 1.2: Porcesso de medida de expressão de genes por microarray. 
Dois tipos principais de dados são obtidos por meio de microarrays: dados obtidos por cDNA e dados obtidos por microarrays de oligonucleotídeos. Dados provindos de cDNA microarrays representam a razão relativa entre uma amostra de controle e uma amostra de interesse ou entre duas condições a serem comparadas. Dados obtidos de microarrays de oligonucleotídeos correspondem à estimativa de níveis de expressão gênica em condições específicas. O microarray de oligonucleotídeos é construído pela síntese das seqüências de interesse (ologinucleotídeos) no próprio substrato, sendo cada ponto sintetizado, nucleotídeo por nucleotídeo, utilizando uma máscara de luz.

Os dados de expressão de genes são geralmente representados por meio de uma matriz, com linhas representando os genes e as colunas representando as diferentes condições amostrais de onde os genes foram extraídos. Os valores contidos em cada posição dessa matriz representam o nível de expressão de um gene particular em uma amostra. Em geral, as amostras provêm de diferentes experimentos. Uma matriz de expressão, geralmente, é composta por um grande número de genes (milhares) e poucas amostras (dezenas), devido ao alto custo associdado à coleta de dados. Um exemplo típico de matriz de expressão de genes pode ser vista na Tabela 1.1.

Tabela 1.1: Parte de uma matriz de expressão de genes

\begin{tabular}{|lllll|}
\hline GENES & AMOSTRA 1 & AMOSTRA 2 & $\ldots$ & AMOSTRA N \\
GTGAAACCCC & 593 & 372737 & $\ldots$ & 4875 \\
CCTGTAATCC & 507 & 138593 & $\ldots$ & 6851 \\
CCACTGCACT & 461 & 107003 & $\ldots$ & 986 \\
GTGAAACCCT & 244 & 182476 & $\ldots$ & 3257 \\
CACCTAATTG & 209 & 334477 & $\ldots$ & 6895 \\
AGGTCAGGAG & 154 & 59498 & $\ldots$ & 1574 \\
$\ldots$ & $\ldots$ & $\ldots$ & $\ldots$ & $\ldots$ \\
TTGGCCAGGC & 130 & 118194 & $\ldots$ & 2359 \\
\hline
\end{tabular}

Alguns conjuntos de dados de expressão gênica podem precisar passar por diferentes transformações para adequar os dados para sua utilização, dependendo da forma com que os dados foram obtidos.

Para dados obtidos com microarrays também é necessário aplicar algumas normalizações, levando em consideração que as várias fontes de variação sistemática nos experimentos com essas técnicas afetam os níveis de expressão medidos (Yang et al., 2001). Algumas normalizações são feitas nos microarrays individualmente, enquanto outras são feitas na matriz de expressão.

Existem inúmeras análises que podem ser aplicadas a dados de expressão gênica, como filtragens e normalizações, até análises estatísticas para identificação 
de expressões diferentes em diversas condições, identificação de padrões e mineração de dados. Essas análises podem ser aplicadas em conjunto ou individualmente. Porém, a utilização desses métodos para análise tem uma profunda influência na interpretação dos resultados. Portanto, é preciso que haja um entendimento dos métodos utilizados para se fazer um projeto experimental adequado e uma análise significativa dos dados.

Dentre as várias técnicas que podem ser utilizadas para a análise desses dados, algoritmos de agrupamento têm sido cada vez mais utilizados. Agrupamento de dados é a classificação não-supervisionada de padrões (observações, instâncias, exemplos, itens de dados ou vetores de características) em grupos (Jain et al., 1999), sem a necessidade de conhecimento prévio sobre as suas classes ou categorias (Mitchell, 1997). O objetivo dessa classificação é obter grupos que apresentem padrões semelhantes e possam refletir a forma como os dados são estruturados. O aprendizado não-supervisionado é vantajoso para o estudo de problemas da biologia, pois muitos desses problemas estão em estágios iniciais, com pouco conhecimento prévio sobre as possíveis classes existentes nos dados (Zeng et al., 2002). Por esse motivo, várias técnicas de agrupamento vêm sendo utilizadas na bioinformática, em especial na análise de dados de expressão de genes (Golub et al., 1999; Ben-Dor et al., 2001; Ng et al., 2001).

Um agrupamento é formado a partir de um princípio indutivo. Esse princípio indutivo, também conhecido como critério de agrupamento ou função objetivo, consiste em uma forma de selecionar um modelo ou estrutura para representar os agrupamentos que melhor se ajustem a um determinado conjunto de dados. A associação de um princípio indutivo à um conjunto dados gera um problema de otimização. Um algoritmo de agrupamento que tenha como objetivo dividir um conjunto com $n$ objetos $X=x_{1}, x_{2}, \ldots, x_{n}$ em uma coleção de $k$ grupos $G=$ $G_{1}, G_{2}, \ldots, G_{k}$ distintos entre si, de maneira que:

$$
G_{1} \cup G_{2} \cup \ldots \cup G_{k}=X, G_{i} \neq \emptyset, \text { e } G_{i} \cap G_{j}=\emptyset \text { para } i \neq j
$$

Desta forma, o número de maneiras que os $n$ objetos podem ser classificados em um número $k$ de grupos é definido pela Equação 1.1 (Kaufman and Rousseeuw, 1990).

$$
N M(n, k)=\frac{1}{k !} \sum_{i=0}^{k}(-1)^{i}\left(\begin{array}{c}
k \\
i
\end{array}\right)(k-i)^{n}
$$

Portanto, encontrar a melhor partição possível não é uma tarefa fácil, mesmo conhecendo o número de grupos $k$. Porém, esse número raramente é conhecido 
na prática, especialmente na bioinformática. É comum executar um algoritmo de agrupamento várias vezes e, baseado nos resultados, escolher um valor para $k$ que obtenha o agrupamento mais natural possível (Jain et al., 1999). Uma outra alternativa consiste em otimizar $k$ de acordo com um critério numérico, ou seja, efetuar o agrupamento para um grupo de valores, ou de cenários, de $k$. Considerando $c$ cenários distintos, o número de maneiras possíveis de se agrupar $n$ objetos é dado pela Equação 1.2 (Kaufman and Rousseeuw, 1990).

$$
\sum_{i=1}^{c} N M(n, k)
$$

As Equações 1.1 e 1.2 mostram que encontrar uma partição ótima é um problema de complexidade NP-completo (Kaufman and Rousseeuw, 1990). Portanto, tentar encontrar uma solução que represente um ótimo global pode ser uma tarefa computacionalmente custosa.

Na tentativa de reduzir o custo computacional, diversos tipos de algoritmos de agrupamentos vêm sendo desenvolvidos (Ward, 1963; Duda et al., 2001; Haykin, 1999). Porém, muitos desses algoritmos são determinísticos (por serem baseados no método de hill-climbing) e tendem a encontrar soluções em mínimos locais, não necessariamente o mínimo global. Além disso, uma mesma técnica de agrupamento utilizada em um mesmo conjunto de dados pode resultar em diferentes formas de agrupar esses dados. O desempenho de uma técnica depende das características dos dados utilizados, dos diferentes valores de seus parâmetros livres, da seleção do estado inicial e até mesmo da ordem de apresentação dos dados, não existindo uma abordagem melhor do que todas as outras (Zeng et al., 2002). Geralmente, senso comum e conhecimento prévio são utilizados para avaliar os resultados. Porém, na área de bioinformática, esse conhecimento prévio ainda é muito limitado.

Abordagens evolutivas têm se mostrado muito eficientes para a obtenção de soluções globais e têm obtido bons resultados quando aplicadas a problemas de agrupamento (Jain et al., 1999). Dentre essas abordagens é possível destacar os Algoritmos Genéticos (AGs), que vêm sendo utilizados com sucesso em diversas aplicações (Cowgill et al., 1998; Jain et al., 1999; Bayram et al., 2004). AGs são técnicas de Aprendizado de Máquina baseados no processo evolutivo de populações de seres vivos. Esses algoritmos seguem o princípio da seleção natural e sobrevivência dos mais aptos, proposto por Charles Darwin em seu livro "A origem das espécies" (Beasley et al., 1993). Eles utilizam técnicas de busca e otimização para gerar possíveis soluções e combinar as características daquelas que obtiverem melhor desempenho, gerando assim novas soluções a cada geração 
(Balakrishnan and Honavar, 1995). Essa combinação permite às novas soluções obterem, em geral, um desempenho melhor do que os obtidos pelas soluções antecessoras. Ao mesmo tempo, a sua combinação com outras técnicas inserem novas características nas soluções, o que permite ao AG realizar uma busca mais eficiente no espaço de soluções.

Nesse projeto é proposta a investigação e análise da combinação de algoritmos de agrupamento de dados com AGs. Para avaliar o desempenho das combinações investigadas, serão utilizados principalmente bases de dados de expressão gênica.

Essa dissertação está organizada da seguinte forma. O Capítulo 2, Técnicas de Agrupamento, apresenta uma breve descrição dos principais conceitos e técnicas de agrupamento estudados nessa pesquisa. Nele também são apresentadas técnicas para a preparação de padrões, medidas de similaridade e medidas de validação dos agrupamentos resultantes.

O Capítulo 3, Algoritmos Genéticos, aborda as principais características dos AGs como a representação das soluções, a inicialização da população e os operadores genéticos aplicados. Uma variação de AG, os AGs paralelos, também são abordados neste capítulo.

No Capítulo 4. Técnicas de Agrupamento e Algoritmos Genéticos, é feito um estudo sobre a utilização de AGs como técnica de agrupamento e também como ferramenta de otimização de técnicas de agrupamento. Neste estudo são apresentadas diferentes formas de adaptar as principais características dos AGs, descritas no Capítulo 3, para o problema de agrupamento. Ao final é feita a análise de trabalhos relacionados.

No Capítulo 5, Experimentos, os experimentos executados durante o projeto são descritos e o resumo dos resultados obtidos são apresentados. Tais resultados são comparados com outras técnicas de agrupamento, incluindo técnicas descritas no Capítulo 4. Também são listadas as bases de dados utilizadas e analisadas as medidas de validação de agrupamentos.

O Capítulo 6. Conclusão, apresenta um breve resumo das principais características do projeto e as conclusões obtidas pelo estudo dos resultados dos experimentos. Propostas de trabalhos futuros também são apresentadas nesse capítulo. 

Capítulo

2

\section{Técnicas de Agrupamento}

Por serem capazes de classificar os dados de forma não-supervisionada, as técnicas de agrupamento são adequadas para proceder na análise de dados de expressão de genes (Golub et al., 1999; Slonim et al., 2000; Handl et al., 2005). Essas técnicas são capazes de agrupar os padrões de expressão dos genes segundo as suas similaridades ou dissimilaridades (Duda et al. 2001). Desta forma, as técnicas de agrupamento tem como objetivo obter grupos que apresentem padrões semelhantes e possam refletir a forma como os dados são estruturados.

Nesse capítulo é feita uma breve descrição dos principais conceitos e técnicas de agrupamento. Na Seção 2.1 são mostradas algumas definições e os aspectos principais dos algoritmos de agrupamento. Na Seção 2.2 são apresentadas técnicas de seleção e preparação dos padrões para o agrupamento. Na Seção 2.3 são descritas algumas medidas de similaridade utilizadas para quantificar a distância entre os dados e grupos existentes. Na Seção 2.4 são resumidos alguns algoritmos de agrupamento relevantes ao projeto. Na Seção 2.5 são apresentados alguns critérios de validação de agrupamentos. Na Seção 2.6 são discutidas as considerações finais deste capítulo.

\subsection{Definição e Aspectos Principais}

Agrupamento é a classificação não-supervisionada de padrões em grupos, também conhecidos como clusters (Jain et al., 1999). Também é o termo usado para referenciar o conjunto de grupos resultante do processo de agrupamento. O objetivo dessa classificação é obter grupos que apresentem padrões semelhantes e possam refletir a forma como os dados são estruturados. Segundo Barbara (2000), o conceito de grupo ainda não tem uma definição precisa. Segue algumas definições mais recorrentes de grupo: 
- Grupo bem separado: é um conjunto de padrões tal que qualquer padrão em um grupo está mais próximo (ou é mais similar) de outros padrões do grupo do que de qualquer padrão que não pertença a ele. Algumas vezes, um limiar é utilizado para especificar que todos os pontos de um grupo devem estar suficientemente próximos (ou serem mais similares) uns dos outros.

- Grupo baseado em centro: é um conjunto de padrões tal que qualquer padrão em um grupo está mais próximo (ou é mais similar) ao centro do grupo do que ao centro de qualquer outro. O centro de um grupo pode ser um centróide (a média dos pontos do grupo) ou um medóide (o ponto mais próximo da média do grupo). Muitas vezes, o termo similaridade a um elemento ou grupo é substituído por proximidade a um elemento ou grupo.

- Grupo contínuo (vizinho mais próximo ou agrupamento transitivo): é um conjunto de padrões tal que qualquer padrão nele está mais próximo (ou é mais similar) de um ou mais pontos do grupo do que de qualquer padrão que não pertence ao ele.

- Grupo baseado em densidade: é uma região densa de padrões, separada de outros grupos por regiões de baixa densidade. Geralmente essa definição é usada quando os grupos estão irregulares ou se cruzam, e na presença de ruídos e exceções.

- Grupo baseado em similaridade: é um conjunto de pontos que são similares, enquanto pontos de grupos diferentes são dissimilares. Uma variação é definir um grupo como um conjunto de pontos que, juntos, criam uma região com uma propriedade uniforme local, como tamanho ou densidade, por exemplo.

Como descrito no capítulo 1, um grupo é formado a partir de um princípio indutivo, também conhecido como critério de agrupamento ou função objetivo. O princípio indutivo consiste na forma de selecionar um modelo ou estrutura para representar os grupos que melhor se ajustem a um determinado conjunto de dados. Quando um princípio indutivo é aplicado a um conjunto de dados, é gerado um problema de otimização. Na maioria das vezes, esses problemas são intratáveis ou apresentam uma complexidade muito elevada para grandes conjuntos de dados (Estivill-Castro, 2002), como é o caso de dados de expressão gênica. Um exemplo de problema de otimização consiste em dividir um conjunto 
de padrões em número pré-estabelecido de grupos, como foi apresentado na Seção 1 .

Os algoritmos de agrupamento se propõem a solucionar esse problema de otimização. Eles classificam o conjunto de dados de maneira não-supervisionada, ou seja, eles dividem os dados em conjuntos de classes, sem a necessidade de informações prévias sobre esses dados, a não ser para validação. Para isso, esses algoritmos definem uma medida de proximidade e um método de busca para encontrar partições dos dados de acordo com um critério de agrupamento (Jiang et al. 2003). Desta forma, técnicas ou algoritmos de agrupamento são utilizados para explorar as relações entre os dados e avaliar sua estrutura.

Os passos básicos para a construção de um agrupamento estão ilustrados na Figura 2.1 e são resumidos a seguir (Jiang et al., 2003; Jain et al., 1999):

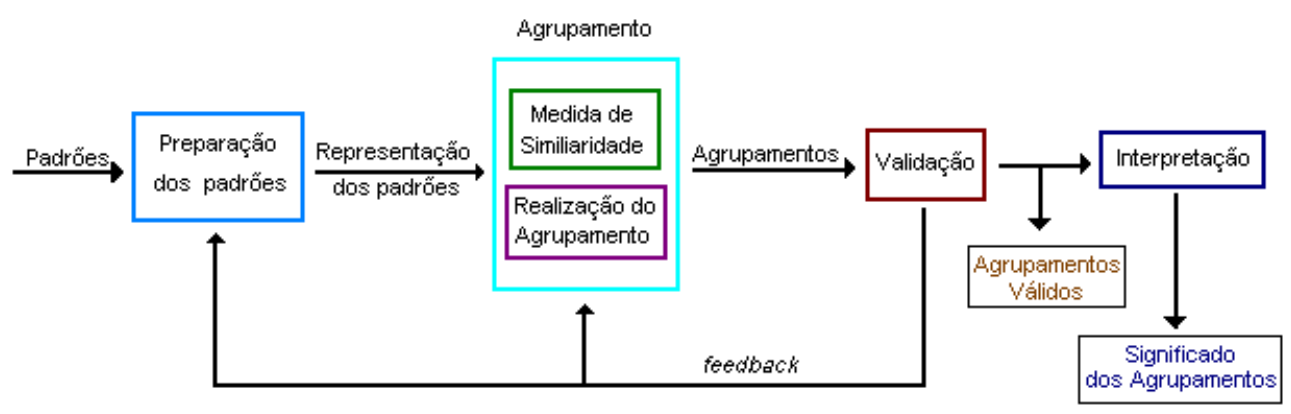

Figura 2.1: Etapas do processo de Agrupamento

1. Preparação dos padrões: Determina como os padrões serão representados. As vezes é aplicado algum tipo de transformação nos dados, como normalizações e seleção e/ou extração de características. A representação de padrões é detalhada na Seção 2.2 .

2. Medida de similaridade: A medida de similaridade é calculada, em geral, por uma função de distância definida entre pares de padrões. É possível incluir na medida de distância aspectos conceituais (qualitativos) ou numéricos (quantitativos). Algumas das principais medidas de distância são descritas na Seção 2.3 .

3. Realização do agrupamento: Consiste aplicar um algoritmo de agrupamento segundo o modelo escolhido, podendo ser realizado de diversas maneiras. Os resultados desta etapa podem ser homogêneos (hard), em que um exemplo pertence ou não-pertence a um dado grupo, ou heterogêneos 
(fuzzy), em que cada exemplo tem um grau de pertinência para cada um dos grupos. Os algoritmos de agrupamento são detalhados na Seção 2.4 .

4. Validação: Se refere à avaliação da validade dos resultados obtidos. Os índices de validação medem a qualidade dos grupos ou estimam o grau em que a estrutura resultante condiz com o conjunto de dados. A estrutura resultante de um agrupamento é válida se não formou-se por acaso e aproxima-se da estrutura natural dos dados. A Seção 2.5 apresenta alguns critérios ou métricas utilizadas para a validação de agrupamentos.

5. Interpretação: Nessa etapa os grupos resultantes são examinados com relação aos seus exemplos, com o objetivo de descrever a natureza do grupo. A interpretação de grupos pode permitir avaliações subjetivas que tenham um significado prático para os grupos. Ou seja, diferentes semânticas podem ser adotadas de acordo com distribuição dos padrões em cada grupo. Dependendo do objetivo do agrupamento, a realização dessa etapa não é necessária.

Outro aspecto relevante é que, devido à diversidade de princípios indutivos e modelos, foram propostos vários tipo algoritmos de agrupamento (Estivill-Castro, 2002). Esses algoritmos podem produzir diferentes agrupamentos a partir de um único conjunto de dados (Zeng et al., 2002). Em alguns casos, o mesmo algoritmo pode produzir agrupamentos diferentes. Isso acaba gerando um problema: Qual o melhor resultado e como obtê-lo?. Segundo Hartigan (1985) "diferentes agrupamentos são corretos para diferentes propósitos, assim, não é possível dizer que um agrupamento é melhor". Além disso, a maioria dos problemas de agrupamento é intratável ou não computável em tempo razoável. As abordagens atualmente disponíveis são freqüentemente baseadas em heurísticas e oferecem apenas uma aproximação de um resultado ótimo (Zeng et al., 2002). Parte disso se deve ao fato de que a maioria dessas abordagens executa uma busca local no espaço de soluções (Jain et al. 1999). Algoritmos de busca global, como AGs, podem ser utilizados para melhorar essa aproximação.

\subsection{Preparação dos Padrões}

A preparação dos padrões determina como eles serão representados no conjunto de dados durante o processo de agrupamento. Os padrões representam os objetos a serem agrupados, podendo ser objetos físicos, como carros ou imóveis, ou noções abstratas, como características sociais de uma população. Padrões são formados 
por vetores de características (atributos) em que cada característica assume um dado valor.

O conhecimento do tipo e escala das características é importante na escolha da medida de similaridade e do algoritmo a serem empregados para definir um agrupamento, bem como na interpretação dos resultados. Uma boa representação dos padrões geralmente permite uma interpretação simples e fácil dos grupos resultantes. Já uma representação pobre pode gerar um agrupamento complexo cuja interpretação é muito difícil ou até impossível. Em virtude disso, por vezes é necessário aplicar algumas transformações nesses padrões como: normalizações, conversão de tipos e a redução do número de atributos por meio de seleção ou extração de características (Jain et al., 1999).

A seleção de características é o processo de identificação do subconjunto mais efetivo dos atributos de entrada disponíveis para descrever cada padrão. A extração de características se refere ao uso de uma ou mais transformações junto aos atributos de modo a salientar características presentes nos dados. Por meio da utilização dessas técnicas é possível encontrar um conjunto de características que melhor representa a similaridade entre padrões.

A maioria das técnicas de agrupamento trabalha com atributos numéricos. Os possíveis tipos de atributos são (Jain et al., 1999; Barbara, 2000):

1. Binários: são atributos que apresentam apenas dois valores. Exemplo: sim/não, verdadeiro/falso.

2. Discretos: representam um número finito de valores. Exemplo: 5 bolas, 7 degraus.

3. Contínuos: podem assumir um número infinito de valores. Exemplo: 45,38 $\mathrm{m}, 68,45 \mathrm{~kg}, \pi$.

Outra característica importante dos atributos é sua escala. A escala de um atributo indica a significância relativa dos números. Ela pode ser qualitativa ou quantitativa (Jain et al., 1999; Barbara, 2000):

\section{Qualitativa}

- Nominal: os valores são apenas nomes distintos. Exemplos: CEP, estado civil.

- Ordinal: os valores apenas refletem uma ordem. Exemplos: Péssimo, Ruim, Bom, Ótimo ou cores ordenadas pelo spectro. 


\section{Quantitativa}

- Intervalo: a diferença entre os valores tem significado, existindo uma unidade de medida. Exemplos: a escala de 1 a 10 para dar notas a atletas, a duração de um evento.

- Relação: os números têm um significado absoluto. Existe um início ou um zero absoluto junto com uma unidade de medida. Exemplos: altura, quantidade de dinheiro, peso, distância.

Algumas vezes os padrões apresentam atributos de escalas diferentes ou a representação dos dados não é adequada para o algoritmo de agrupamento utilizado. Quando os intervalos de valores dos atributos são muito diferentes, um atributo pode dominar o resultado do agrupamento. Nesses casos é necessária a aplicação de algumas transformações antes da utilização desses dados (Barbara, 2000). A investigação das características dos dados e das transformações que podem ser aplicadas pode gerar grupos significativamente melhores.

A investigação das características dos dados e das transformações pode gerar grupos significativamente melhores. Um exemplo é o agrupamento dos pontos da Figura 2.2, onde os padrões formam um agrupamento curvilíneo com distâncias da origem similares. Utilizando uma representação em coordenadas cartesianas, muitos algoritmos de agrupamento produziriam dois ou mais grupos. Entretanto, se fossem utilizadas coordenadas polares para representar os padrões, uma solução de um único grupo poderia ser obtida com maior facilidade (Jain et al., 1999).

Na maioria das vezes os dados são representados por uma matriz de padrões $X_{n \times d}$, onde $n$ é o número de padrões e $d$ é a dimensionalidade, ou seja, o número de atributos em cada padrão. Geralmente, os dados são interpretados como pontos em um espaço de características de dimensão $d$. Essas características são representadas por um conjunto de eixos ortogonais. Cada padrão é visto como um ponto nesse espaço e um grupo como um conjunto de padrões próximos ou que satisfazem uma relação espacial.

Padrões também podem ser representados por uma matriz e o grafo de similaridade ou proximidade. Uma matriz de similaridade contém os valores da similaridade/dissimilaridade entre os padrões do conjunto, dois a dois. Em uma matriz de similaridade $S_{n \times n}$, o valor da similaridade entre dois padrões i e j está representado na linha i e coluna j da matriz, respectivamente. Esse valor é geralmente calculado por uma medida de similaridade. 


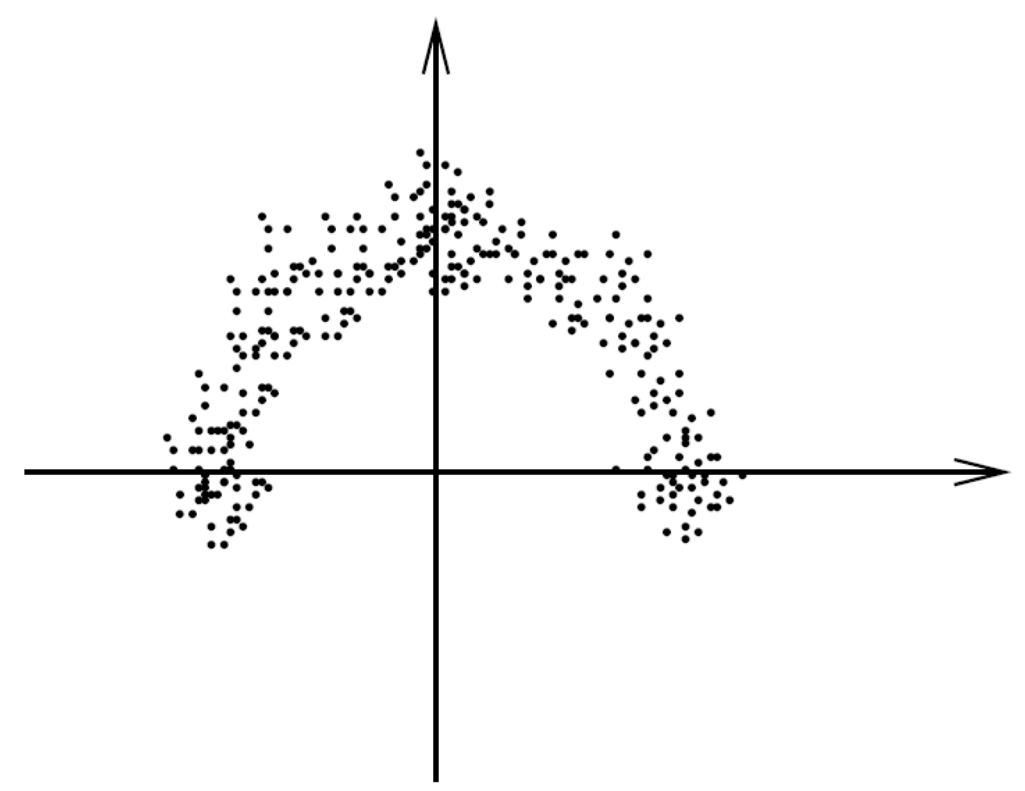

Figura 2.2: Um grupo curvilíneo com distância constante da origem (Jain et al., 1999)

\subsection{Medida de Similaridade}

Como similaridade é fundamental para o conceito de grupo, a medida de similaridade entre dois padrões do espaço de características é essencial para a maioria dos algoritmos de agrupamento. A medida de similaridade a ser empregada deve ser escolhida cuidadosamente devido à grande variedade de tipos e escalas das características. As medidas, em geral, consideram que todas as características contribuem para a proximidade na mesma proporção.

Existem pelo menos três conceitos de similaridade que precisam ser considerados: a similaridade entre padrões, a similaridade entre um padrão e um grupo de padrões e a similaridade entre dois grupos de padrões (He, 1999).

As medidas podem se referir à similaridade ou dissimilaridade, sendo que as mais comuns empregadas em agrupamento calculam a dissimilaridade. A maneira mais convencional de se calcular a dissimilaridade entre dois padrões é através da medida da distância entre eles (Jain et al., 1999).

Para que uma dada medida seja considerada uma medida de proximidade, ela precisa satisfazer algumas propriedades. Dados os padrões $i, j$ e $k$, uma medida $S$ é uma medida de proximidade se satisfaz as três primeiras propriedades a seguir (Gordon, 1999):

1. $S_{i j} \geq 0$, para todo i e $\mathrm{j} ;\{$ positividade $\}$

2. $S_{i i}=0 ;\{$ os pontos são iguais $\}$ 
3. $S_{i j}=S_{j i} ;\{$ simetria $\}$

4. $S_{i j}=0$, somente se $\mathrm{i}=\mathrm{j}$;

5. $S_{i k} \leq S_{i j}+S_{j k}$, para todo i,j e k; $\{$ desigualdade triangular $\}$

Se, além disso, a medida de proximidade satisfaz as propriedades 4 e 5 , ela é considerada uma métrica de proximidade. As medidas de proximidade mais frequentemente utilizadas em problemas de agrupamento são métricas.

Para conjuntos de dados em que todos os atributos são contínuos e a escala é do tipo relação, geralmente são utilizadas distâncias baseadas na métrica de Minkowski, como a distância Euclidiana e a distância de Manhattan. A última é chamada de distância de Hamming quando todos os atributos são binários. Gordon (1999) e Faceli et al. (2005a) apresentam diversas medidas apropriadas para padrões que tenham atributos de um mesmo tipo. Nesta seção, para a descrição de medidas utilizadas para diferentes tipos de atributos, serão considerados dois padrões $i$ e $j$ pertencentes à uma base de dados com dimensionalidade $d$.

\subsubsection{Medidas para atributos binários}

As medidas descritas para atributos binários são derivadas das seguintes informações:

a11: número de atributos com valor 1 para ambos os padrões,

a00: número de atributos com valor 0 para ambos os padrões,

a01: número de atributos com valor 0 para o padrão $i$ e valor 1 para o padrão $j$, a10: número de atributos com valor 1 para o padrão $i$ e valor 0 para o padrão $j$.

Algumas das medidas utilizadas são:

- Coeficiente de Casamento Simples:

$$
S_{i j}=\frac{a_{00}+a_{11}}{a_{00}+a_{11}+a_{01}+a_{10}}=\frac{a_{00}+a_{11}}{d}
$$

- Coeficiente de Jaccard:

$$
S_{i j}=\frac{a_{11}}{a_{11}+a_{01}+a_{10}}=\frac{a_{11}}{d-a_{00}}
$$

\subsubsection{Medidas para atributos nominais e ordinais}

Atributos nominais e ordinais são variáveis categóricas que representam mais de dois estados ou categorias. As medidas de similaridade entre os pares desses 
padrões focalizam a atenção na determinação da contribuição de cada variável. Essas medidas são obtidas pela soma da combinação de todas as variáveis. A seguinte medida é geralmente empregada para este tipo de atributo:

- Similaridade nominal/ordinal geral: baseada nos índices de discordância entre pares de estados dos atributos categóricos, dada pela Equação 2.3. em que $s_{i j m}$ é a soma da contribuição do atributo $m$ dos padrões $i$ e $j$.

$$
S_{i j}=\sum_{m=1}^{d} s_{i j m}
$$

\subsubsection{Medidas para atributos quantitativos}

A medidas mais comuns para esse tipo de dado são as métricas de Minkowski. No entanto, as métricas de Minkowski são sensíveis a variações de escala dos atributos, isto é, atributos representados em uma escala maior tendem a dominar os outros. Outras medidas utilizadas para estes tipos de padrões medem o coseno do ângulo entre dois vetores. O primeiro vetor é medido a partir da origem até os padrões e o outro a partir da média dos dados. É o caso das medidas de separação angular e correlação de Pearson. Essas e outras medidas para atributos quantitativos são descritas a seguir:

- Métricas de Minkowski: as métricas de Minkowski são derivadas da Equação 2.4, de acordo com um valor escolhido para p, com $1 \leq p<\infty$. Como as métricas de Minkowski são sensíveis a variações de escala dos atributos, pode ser aplicada a normalização dos atributos para um intervalo comum, ou outros esquemas de ponderação (Jain et al., 1999) para casos em que alguns atributos são representados em escalar maior.

$$
S_{i j}=\left(\sum_{m=1}^{d}\left|x_{i m}-x_{j m}\right|^{p}\right)^{1 / p}
$$

- $\mathrm{p}=1$ : Distância de Manhattan: também conhecida como distância bloco-cidade, dada pela Equação 2.5 .

$$
S_{i j}=\sum_{m=1}^{d}\left|x_{i m}-x_{j m}\right|
$$

- $\mathrm{p}=2$ : Distância Euclidiana: tem um significado de variância total entre grupos. Uma das medidas de distância mais comuns, é apro- 
priada para conjuntos de dados que possuem grupos compactos ou isolados. É dada pela Equação 2.6 .

$$
S_{i j}=\left(\sum_{m=1}^{d}\left(x_{i m}-x_{j m}\right)^{2}\right)^{1 / 2}
$$

Uma variação da distância euclidiana é a distância euclidiana harmônica, dada pela Equação 2.7. Nessa variação, os atributos dos padrões são somados inversamente, similar a média harmônica.

$$
S_{i j}=\left[\frac{1}{d} \sum_{m=1}^{d}\left(\frac{1}{x_{i m}-x_{j m}}\right)^{2}\right]^{-1 / 2}
$$

- Separação angular: essa medida é calculada através do ângulo formado entre dois vetores, sendo que o primeiro é medido a partir da origem até o padrão e outro a partir da média dos dados. É dada pela Equação 2.8 .

$$
s=\frac{\sum_{m=1}^{d} x_{i m} x_{j m}}{\left(\sum_{m=1}^{d} x_{i m}^{2} \sum_{l=1}^{d} x_{j l}^{2}\right)^{1 / 2}}
$$

A separação angular $s$ assume valores no intervalo $[-1,1]$. A distância angular é calculada por $S_{i j}=1-s$, o que faz com que $S_{i j}$ assuma valores entre 0 e 2. Uma das variações da distância angular é a distância angular absoluta, dada por $S a_{i j}=1-|s|$.

- Coeficiente de correlação de Pearson: é dado pela Equação 2.9, onde $\overline{x_{i}}=\sum_{m=1}^{d} x_{i m} / d$, com valores no intervalo $[-1,1]$. Assim como a medida angular, essa medida é insensível a diferenças na magnitude dos atributos.

$$
r_{p}=\frac{\sum_{m=1}^{d}\left(x_{i m}-\bar{x}_{i}\right)\left(x_{j m}-\bar{x}_{i}\right)}{\left(\sum_{m=1}^{d}\left(x_{i m}-\bar{x}_{i}\right)^{2} \sum_{l=1}^{d}\left(x_{j l}-\bar{x}_{j}\right)^{2}\right)^{1 / 2}}
$$

A distância de Pearson é dada por $S_{i j}=1-r_{p}$, o que faz com que $S_{i j}$ assuma valores entre 0 e 2 . Uma das variações da distância de Pearson é a distância absoluta de Pearson, dada por $S a_{i j}=1-\left|r_{p}\right|$.

- Correlação de Spearman: a correlação de Spearman é uma alternativa não-paramétrica para o coeficiente de correlação de Pearson. Ela é útil por ser mais robusta a dados irregulares (outliers) que a correlação de Pearson. Para calcular a correlação de Spearman $r_{s}$, os atributos dos dados são ordenados segundo seus valores. Em seguida, o coeficiente de correlação de 
Pearson é calculado para os dados, porém a posição dos atributos ordenados é utilizada no lugar dos valores dos mesmos. A distância correspondente a correlação de Spearman é calculada por $S_{i j}=1-r_{s}$.

- Kendall $\tau$ : similar a correlação de Spearman, essa correlação é um exemplo de medida de similaridade não-paramétrica. Porém, no lugar de utilizar a posição dos atributos como o coeficiente de Pearson, essa medida utiliza apenas a relação de atributos no cálculo do $\tau$ (Stuart, 1983). Essa relação pode ser interpretada como a tendência entre duas variáveis possuirem atributos concordantes ou discordantes. Dois pares de atributos $\left(x_{i}, y_{i}\right)$ e $\left(x_{j}, x_{j}\right)$ são concordantes se $x_{i}-x_{j}$ e $y_{i}-y_{j}$ tiverem o mesmo sinal, caso contrário serão discordantes. Se cada padrão tiver $n$ atributos, são possíveis $n(n-1) / 2$ comparações.

Uma maneira simples de medir a relação entre dois padrões é dado pela $S_{i j}=C-D$, onde $C$ é o número de pares concordantes e $D$ o número de pares discordantes. Essa medida é conhecida como Kendall $S$. Se $S$ for positivo, indicará uma relação positiva entre os padrões $i$ e $j$, caso contrário indicará uma relação negativa entre os mesmo. Porém, o valor resultante de $S$ varia com o número de atributos $n$. Para solucionar esse problema, uma normalização pode ser aplicada no resultado $S$, que varia entre $\left[\frac{-n(n-1)}{2}, \frac{n(n-1)}{2}\right]$. O resultado normalizado obtido pela Equação 2.10.

$$
\tau=\frac{2 S_{i j}}{n(n-1)}
$$

Sendo assim, $\tau$ resulta em um valor entre -1 e 1 e a distância correspondente a Kendall $\tau$ é calculada por $S_{i j}=1-\tau$, com valores entre 0 e 2 .

- Distância de Mahalanobis: é dada pela Equação 2.11, em que $C_{n m}$ é o elemento da $n$-ésima linha e $m$-ésima coluna da inversa da matriz de covariância. Esta distância incorpora a correlação entre características e padroniza cada característica para média zero e variância um. A idéia básica desta medida é associar diferentes pesos à diferentes características com base em suas variâncias e a correlação linear entre pares de padrões (Jain et al., 1999). Assume-se implicitamente que as densidades condicionais das classes são unimodais e caracterizadas por um espalhamento multidimensional (Jain et al., 1999). Outras formas de utilização da distância de Mahalanobis são a quadrada e a regularizada. A aplicação dessa medida melhora distorções causadas por correlação linear entre características. 


$$
S_{i j}=\left(\sum_{n=1}^{d} \sum_{m=1}^{d}\left(x_{i n}-x_{j n}\right) C_{n m}\left(x_{i m}-x_{j m}\right)\right)^{1 / 2}
$$

\subsubsection{Medidas para atributos mistos}

Esse tipo de medida é adequado para obter a similaridade entre padrões que contenham características de diferentes tipos, por se adequar a qualquer um dos tipos individualmente.

- Coeficiente de Similaridade Geral: dado pela Equação 2.12, em que $s_{i j m}$ é a contribuição do $m$-ésimo atributo para a similaridade e $w_{i j m}$ é um valor binário que indica se a comparação para a variável $m$ é válida ou não. O valor da contibuição $g_{i j m}$ pode ser definido para atributos de tipos diferentes.

$$
S_{i j}=\frac{\sum_{m=1}^{d} w_{i j m} g_{i j m}}{\sum_{m=1}^{d} w_{i j m}}
$$

Algumas técnicas de agrupamento utilizam a distância entre grupos de objetos. Para isso, várias medidas de dissimilaridade entre grupos se baseiam nos conceitos de centróides $C$, raio $R$, diâmetro $D$, dados pelas equações 2.13, 2.14 e 2.15. respectivamente. $C$ é a média ou mediana dos pontos do grupo, $R$ é distância média dos pontos do grupo ao centróide e $D$ é a distância média entre pares de padrões (pairwise average distance) em um grupo. O número de padrões contidos no grupo é dado por $n$.

$$
\begin{gathered}
C=\frac{\sum_{i=1}^{n} x_{i}}{n} \\
R=\left(\frac{\sum_{i=1}^{n}\left(x_{i}-C\right)^{2}}{n}\right)^{1 / 2} \\
D=\left(\frac{\sum_{i=1}^{n} \sum_{j=1}^{n}\left(x_{i}-x_{j}\right)^{2}}{n(n-1)}\right)^{1 / 2}
\end{gathered}
$$

Dados dois grupos $G_{1}=\left\{x_{i} \mid i=1,2, \ldots n_{1}\right\}$ e $G_{2}=\left\{x_{j} \mid j=n_{1}+1, n_{1}+\right.$ $\left.2, \ldots n_{1}+n_{2}\right\}$, com os respectivos centróides $C_{1}$ e $C_{2}$, podem ser definidas as seguintes distâncias entre dois grupos (Zhang et al., 1996): 
Distância Euclidiana do centróide:

$$
D_{0}=\left(\left(C_{1}-C_{2}\right)^{2}\right)^{1 / 2}
$$

Distância Manhattan do centróide:

$$
D_{1}=\left|C_{1}-C_{2}\right|
$$

Distância inter-grupos:

$$
D_{2}=\left(\frac{\sum_{i=1}^{n_{1}} \sum_{j=n_{1}+1}^{n_{1}+n_{2}}\left(x_{i}-x_{j}\right)^{2}}{n_{1} n_{2}}\right)^{1 / 2}
$$

\section{Distância intra-grupo:}

$$
D_{3}=\left(\frac{\sum_{i=1}^{n_{1}+n_{2}} \sum_{j=1}^{n_{1}+n_{2}}\left(x_{i}-x_{j}\right)^{2}}{\left(n_{1}+n_{2}\right)\left(n_{1}+n_{2}-1\right)}\right)^{1 / 2}
$$

Distância de variação intra-grupo (variance increase): calcula a variação na distância intra-grupo que ocorre quando dois agrupamentos são unidos.

$$
D_{4}=\sum_{z=1}^{n_{1}+n_{2}}\left(x_{z}-\frac{\sum_{l=1}^{n_{1}+n_{2}} x_{l}}{n_{1}+n_{2}}\right)^{2}-\sum_{i=1}^{n_{1}}\left(x_{i}-\frac{\sum_{l=1}^{n_{1}} x_{l}}{n_{1}}\right)^{2}-\sum_{j=n_{1}+1}^{n_{1}+n_{2}}\left(x_{j}-\frac{\sum_{l=n_{1}+1}^{n_{1}+n_{2}} x_{l}}{n_{2}}\right)^{2}
$$

\subsection{Algoritmos de Agrupamento}

Nessa seção são detalhados os algoritmos de agrupamento de potencial interesse para utilização neste trabalho. Em geral, os algoritmos de agrupamento podem ser divididos em exclusivo e não exclusivo (Jain et al., 1999). Um agrupamento exclusivo é uma partição de um conjunto de objetos onde cada objeto pertence exclusivamente a um único grupo. Um agrupamento não exclusivo pode associar um objeto a vários grupos, onde cada exemplo tem um grau de pertinência a cada um dos grupos. Neste trabalho serão estudados algoritmos de agrupamento exclusivos.

Além de relação de exclusividade dos objetos, os algoritmos de agrupamento também podem ser divididos em hierárquicos e particionais, de acordo com a estrutura em que os dados são divididos. A estrutura de um algoritmo hierárquico resulta em uma seqüência aninhada de partições, enquanto os algoritmos particionais resultam em uma única partição dos dados.

A maioria dos trabalhos que relacionam técnicas de agrupamento em conjunto 
com AGs utiliza algoritmos particionais exclusivos (Bezdek et al., 1994; Tanaka et al., 1996; Cole, 1998; Jain et al., 1999; Kivijärvi et al., 2003). Portanto será dada maior ênfase nesse tipo de algoritmo nesse trabalho. Entre os vários algoritmos de agrupamento particionais, podem ser citados os algoritmos $k$-médias (Duda et al., 2001) e o Mapa Auto-Organizável (Self Organizing Map - SOM) (Haykin, 1999).

Existe uma variedade maior de algoritmos de agrupamento na literatura (Jain et al., 1999). Cada um desses algoritmos emprega um critério de agrupamento, que impõe uma estrutura nos dados. Dentre esses, merecem destaque para esse trabalho os algoritmos descritos a seguir.

\subsubsection{Algoritmo k-médias}

A técnica $k$-médias (Duda et al. 2001) particiona o conjunto de dados em $k$ grupos com base em uma medida de similaridade. O algoritmo começa inicializando um conjunto de $k$ centróides para os grupos. Cada padrão pertencente ao conjunto de dados é representado por um ponto em um espaço $d$-dimensional, onde $d$ é o tamanho do vetor de entrada, ou seja, o número de características de cada padrão. A cada interação, um vetor média é computado para cada grupo e os pontos são realocados ao grupo com o vetor média mais próximo, de acordo com a medida de similaridade utilizada. Esse processo é repetido até que os grupos convirjam (o vetor média para cada grupo não mude) ou o número máximo de iterações seja atingido.

O critério de agrupamento do $k$-médias é descrito pela Equação 2.21, em que $C_{i}$ é o centróide do grupo $G_{i}$ e $D\left(x_{j}, C_{i}\right)$ é a distância entre um ponto (padrão) $x_{j}$ e $C_{i}, x_{j} \in G_{i}$. O centróide pode ser a média ou a mediana de um grupo de pontos, dada pela Equação 2.13. O critério do algoritmo é minimizar a distância entre cada ponto e o centróide do grupo ao qual ele pertence, ou seja, minimizar o valor de $E$ dado pela Equação 2.21 para $k$ grupos. Essa função objetivo é minimizada por grupos de formato globular de mesmo tamanho ou grupos bem separados (Halkidi et al., 2001).

$$
E=\sum_{i=1}^{k} \sum_{x_{j} \in G_{i}} D\left(x_{j}, C_{i}\right)
$$

A complexidade do algoritmo é $O(n)$, sendo $n$ o número de padrões. O algoritmo é geralmente executado em um número pequeno de iterações e $k<<n$ (Barbara, 2000). Também deve ser considerado que $n<<d$ na maioria dos casos, sendo $d$ a dimensão dos padrões. O algoritmo é sensível à escolha inicial dos 
centróides e da sua forma de atualização. Dependendo da escolha dos centróides, o algoritmo pode convergir para um ótimo local. Além disso, é restrito a dados em espaços Euclideanos e os grupos encontrados são desbalanceados.

\subsubsection{Algoritmos de agrupamento hierárquico}

Algoritmos hierárquicos (Duda et al. 2001) resultam em uma seqüência aninhada de partições, ou seja, é uma forma de agrupar os dados em que dois exemplos agrupados em um nível continuam fazendo parte do mesmo grupo nos níveis mais altos (ou mais baixos). Eles podem ser divididos em duas abordagens: a aglomerativa e a divisiva. A abordagem aglomerativa começa com $n$ grupos com um único exemplo cada e forma a seqüência de partições aglomerando os grupos a cada nível. A abordagem divisiva começa com um grupo com todos os exemplos e forma a seqüência de partições dividindo os grupos sucessivamente.

No agrupamento hierárquico, as soluções são tipicamente representadas por um dendograma (Jain et al., 1999). Um dendrograma consiste de camadas de nós, cada nó representando um grupo. Algumas linhas conectam os nós, representando grupos aninhados. O corte de um dendrograma na horizontal significa uma partição ou agrupamento em um número específico de grupos. A Figura 2.3 ilustra o processo.

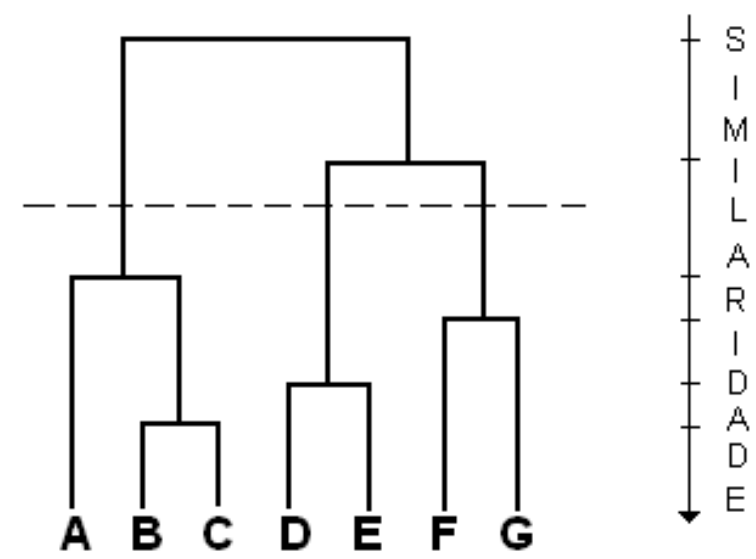

Figura 2.3: Exemplo de dendograma (Jain et al., 1999)

Algumas vantagens do agrupamento hierárquico são a sua flexibilidade em relação ao nível de granularidade, a fácil utilização de qualquer medida de similaridade e por sua aplicação a qualquer tipo de atributo. Porém, o critério de parada é vago e a maioria dos algoritmos não altera os grupos uma vez que esses sejam construídos (Faceli et al., 2005a).

A maioria dos algoritmos hierárquicos utiliza métricas de integração, ou seja, 
métricas que integram os grupos para formar novos grupos. Porém, existem várias outras implementações que visam melhorias, por exemplo, na manipulação de dados com ruídos, obtenção de grupos de diferentes formas, tamanhos e escalabilidade. Existe um grande número de algoritmos hierárquicos. Dentre eles, pode ser destacado o algoritmo BIRCH (Balanced Iterative Reducing and grupoing using Hierarchies) (Zhang et al., 1996; Barbara, 2000).

A principal idéia do algoritmo BIRCH é comprimir os pontos de dados em sub-grupos e depois agrupar esses sub-grupos na memória principal. Com isso, o algoritmo precisa de uma única varredura na base de dados. Sua principal vantagem é a habilidade de lidar com conjuntos de dados muito grandes.

Uma deficiência desse algoritmo é seu baixo desempenho quando os grupos não têm tamanho e forma uniformes. Ele é indicado para dados em espaços vetoriais euclidianos, ou seja, os dados devem ser métricos, ou seja, para os quais médias fazem sentido.

\subsubsection{Redes SOM}

O método Self Organizing Map (SOM) (Haykin, 1999) é uma rede neural não supervisionada baseada em aprendizado competitivo. Os neurônios de saída da rede competem entre si para serem ativados. Nesse tipo de rede, os neurônios são organizados em um reticulado de uma ou duas dimensões. Cada neurônio no reticulado está conectado a todas as entradas da rede.

Esta rede geralmente utiliza uma única camada de neurônios, porém é possível a utilização de múltiplas camadas. Para cada padrão de entrada apresentado à rede, os neurônios computam seus valores de ativação, ativando uma região diferente do reticulado. O neurônio com maior valor de ativação é o vencedor da competição. Esse e outros neurônios situados na sua vizinhança têm seus pesos ajustados. Com o ajuste dos pesos, o valor da resposta do neurônio vencedor à aplicação subseqüente do mesmo padrão de treinamento é melhorada. Assim, os padrões de entrada promovem uma organização topológica dos neurônios da rede. Ainda durante o treinamento, uma região de vizinhança dos neurônios é gradativamente reduzida.

O objetivo da rede SOM é encontrar um conjunto de vetores de referência e associar cada padrão de entrada ao vetor de referência mais próximo. O algoritmo depende da inicialização destes vetores. O resultado é um conjunto de vetores de referência que definem implicitamente os grupos. Uma deficiência da rede SOM é não detectar automaticamente a borda dos grupos.

As redes SOM recebem como entradas atributos numéricos e geram grupo hiper-esféricos. Elas podem utilizar como medida de similaridade a distância 
Euclidiana, produto interno e, no caso de dados de expressão gênica, a medida de correlação de Pearson. Os parâmetros que podem ser otimizados nas redes SOM são a taxa de aprendizado, sua topologia (número de neurônios) e a função de vizinhança (incluindo seus parâmetros).

\subsection{Critérios de Validação}

Para determinar se os grupos são significativos ou não, o resultado do agrupamento é validado para verificar como a solução encontrada representa o conjunto de dados. Se existe similaridade entre os dados de um grupo, o algoritmo é considerado válido. Entretanto, a utilização de parâmetros mais adequados e a escolha de melhores grupos iniciais permitem melhorar a representatividade do agrupamento obtido. A validação do resultado de um agrupamento, em geral, é feita com base em índices estatísticos para avaliar, de uma maneira qualitativa, a qualidade dos grupos encontrados.

(Jiang et al., 2003) citam algumas abordagens comumente empregadas para a validação de dados de expressão gênica. Os trabalhos (Jiang et al., 2003), (Golub et al. 1999) avaliam a qualidade dos grupos com base na idéia de que se grupos supostos refletem a estrutura real, então um preditor de classes construído com base nesses grupos deve ter um bom desempenho. Esses preditores, também conhecidos como critérios de avaliação, podem ser dividos em externos e internos. Os critérios externos comparam os dados do agrupamento gerado com o agrupamento real, também conhecido como gold standart. O agrupamento real é construído com base na intuição ou conhecimento prévio sobre a estrutura real dos dados. Já os critérios internos avaliam o agrupamento resultante a partir de uma heurística, sem nenhum conhecimento externo ao agrupamento analisado. Alguns critérios de avaliação são descritos a seguir.

\subsubsection{Silhueta}

O critério Silhueta (Rousseeuw, 1987) define a qualidade dos agrupamentos com base na proximidade entre os padrões de um determinado grupo e na distância desses padrões ao grupo mais próximo. O critério Silhueta é calculado para cada padrão de um grupo, mostrando quais padrões estão bem situados no mesmo e quais seriam situados melhor em outro grupo. Ele pode ser calculado com medidas de similaridade ou dissimilaridade (Seção 2.3).

Dado um padrão $i$ e um grupo $G$ tal que $i \in G$. Seja $\bar{D}(i, G)$ a dissimilaridade média do padrão $i$ em relação a todos os padrões do grupo $H$, exceto o próprio $i$ caso $G=H$. A silhueta de um padrão empregando dissimilaridade 
resulta da Equação 2.24, sendo que $a$ e $b$ são obtidos pelas equações 2.22 e 2.23 , respectivamente (Faceli et al., 2005b).

$$
\begin{gathered}
a=\bar{D}(i, G) \\
b=\min _{G \neq H} \bar{D}(i, H) \\
s(i)= \begin{cases}1-a(i) / b(i), & a(i)<b(i) \\
0, & a(i)=b(i) \\
a(i) / b(i)-1, & a(i)>b(i)\end{cases}
\end{gathered}
$$

Para se aplicar silhueta empregando similaridade no lugar da dissimilaridade são utilizados $b^{\prime}$, dado pela Equação 2.25, e $s^{\prime}$, dado pela Equação 2.26.

$$
\begin{gathered}
b=\max _{G \neq H} \bar{D}(i, H) \\
s^{\prime}(i)= \begin{cases}1-b^{\prime}(i) / a(i), & a(i)>b^{\prime}(i) \\
0, & a(i)=b(i) \\
b^{\prime}(i) / a(i)-1, & a(i)<b^{\prime}(i)\end{cases}
\end{gathered}
$$

Os resultados obtidos pela silhueta estão no intervalo $[-1,1]$. Se um padrão está bem situado em seu grupo, sua Silhueta será mais próxima de 1, caso contrário será mais próxima de -1 .

Como a Silhueta depende apenas do agrupamento resultante e não do algoritmo de agrupamento empregado, ela pode ser usada para melhorar os resultados de uma análise de grupos ou para comparar os resultados de diferentes algoritmos aplicados ao mesmo conjunto de dados. Para isso, é possível calcular a Silhueta de cada grupo e a largura média da Silhueta, $s(k)=\sum_{i=1}^{n} s(i) / n$, que é o valor médio sobre todos os padrões do conjunto de dados. Quanto maior o valor de $s(k)$, melhor o posicionamento dos padrões dentro dos seus grupos, o que pode ser usado para determinar o melhor número $k$ de grupos, por exemplo.

A Silhueta é apropriada nos casos em que a proporção entre os atributos dos padrões sejam próximas, ou seja, onde nenhum atributo apresente valores muito maiores do que os outros. Ela também é apropriada para agrupamentos com grupos compactos e bem separados (Faceli et al., 2005b). Esse critério obtém melhores resultados com grupos esféricos (Rousseeuw, 1987). Por esses motivos, ele resulta em larguras tendenciosas contra grupos potencialmente sobrepostos, favorecendo agrupamentos disjuntos. 


\subsubsection{Critério de Razão das Variâncias}

O Critério de Razão das Variâncias (VRC, do inglês Variance Ratio Criterion) valoriza a homogeneidade interna e o isolamento externo dos grupos (Calinski and Harabasz, 1974). Esse critério é baseado em duas funções objetivo: a soma da distância quadrática interna dos grupos (WGSS, do inglês within-group sum of squares) e a soma da distância quadrática entre grupos (BGSS, do inglês betweengroups sum of squares) (Duda et al., 2001). Dado um agrupamento, sua WGSS será a soma das distâncias quadráticas entre os padrões contidos em um mesmo grupo, calculada pela Equação 2.27, enquanto sua BGSS será a soma das distâncias quadráticas entre os padrões contidos em grupos distintos, calculada pela Equação 2.28. O critério VRC é resultado da Equação 2.29.

$$
W G S S=\sum_{i=1}^{n} \sum_{j=i+1} S_{i j}
$$

sendo $n$ o número total de padrões da base de dados, com $i$ e $j$ sendo padrões tal que $i \in G$ e $j \in G$, para todo grupo $G$.

$$
B G S S=\sum_{i=1}^{n} \sum_{j=i+1} S_{i j}
$$

sendo $i$ e $j$ padrões tal que $i \in G$ e $j \notin G$, para todo grupo $G$.

$$
V R C=\frac{B G S S}{(k-1)} / \frac{W G S S}{(n-k)}
$$

onde $n$ é o número total de padrões agrupados e $k$ o número de grupos no agrupamento.

Assim como a Silhueta, o critério VRC depende apenas do agrupamento resultante e não do algoritmo de agrupamento empregado. Se utilizada em um agrupamento com número indeterminado de grupos, o VRC ajudará a determinar o número correto de grupos no conjunto de dados, resultando em valores maiores para agrupamentos que se aproximam da forma natural dos dados. Também pode ser utilizado para comparar os resultados de diferentes algoritmos aplicados ao mesmo conjunto de dados.

\subsubsection{Rand Corrigido}

Por ser um critério de validação externo, o Rand Corrigido (CR, do inglês Corrected Rand) compara os dados do agrupamento $A_{e}$, resultante da aplicação de um algoritmo, e o agrupamento real dos dados $A_{r}$. O critério CR é a normalização 
do índice Rand, proposto por Hubert and Arabie (1985), para que ele apresente valores próximos de 0 quando o agrupamento é selecionado ao acaso e 1 quando o agrupamento é idêntico ao agrupamento real (Jain and Dubes, 1988; Gordon, 1999). Esse critério é dado pela Equação 2.30, onde $k_{e}$ é o número de grupos do agrupamento $A_{e}, k_{r}$ é o número de grupos do agrupamento $A_{r}, n_{i}$ é o número de padrões pertecentes ao grupo $G_{i} \in A_{e}, n_{j}$ é o número de padrões pertecentes ao grupo $G_{j} \in A_{r}$ e $n_{i j}$ é o número de objetos comuns aos grupos $G_{i}$ e $G_{j}$.

$$
C R=\frac{\sum_{i=1}^{k_{e}} \sum_{j=1}^{k_{r}}\left(\begin{array}{c}
n_{i j} \\
2
\end{array}\right)-\left[\sum_{i=1}^{k_{e}}\left(\begin{array}{c}
n_{i} \\
2
\end{array}\right) \sum_{j=1}^{k_{r}}\left(\begin{array}{c}
n_{j} \\
2
\end{array}\right)\right] /\left(\begin{array}{c}
n \\
2
\end{array}\right)}{\left[\sum_{i=1}^{k_{e}}\left(\begin{array}{c}
n_{i} \\
2
\end{array}\right)+\sum_{j=1}^{k_{r}}\left(\begin{array}{c}
n_{j} \\
2
\end{array}\right)\right] / 2-\left[\sum_{i=1}^{k_{e}}\left(\begin{array}{c}
n_{i} \\
2
\end{array}\right) \sum_{j=1}^{k_{r}}\left(\begin{array}{c}
n_{j} \\
2
\end{array}\right)\right] /\left(\begin{array}{c}
n \\
2
\end{array}\right)}
$$

Assim como os critérios anteriores, o CR não depende do algoritmo de agrupamento empregado. Esse índice pode comparar o agrupamento resultante com o agrupamento ideal, permitindo determinar a aproximação da numeração correta de grupos e comparar os resultados de diferentes algoritmos aplicados ao mesmo conjunto de dados.

\subsubsection{Figura de Mérito}

O critério Figura de Mérito (FOM, do inglês Figure of Merit) (Yeung et al. 2000), proposto para aplicação em agrupamentos de genes com base no seu nível de expressão em diversos experimentos (Gesú et al., 2005). Esse critério se baseia na tendência dos níveis de expressão dos genes de um determinado grupo serem semelhantes, sendo que o nível de expressão obtido em um experimento é um atributo e cada gene é representado por um padrão. Para que um agrupamento seja significativo, o critério FOM considera que um atributo que não foi empregado na construção do agrupamento apresente valores próximos para padrões do mesmo grupo.

Para calcular o FOM é necessário que um algoritmo de agrupamento seja aplicado em uma base de dados, considerando todos os atributos, exceto um atributo $a$. Esse atributo $a$ é utilizado para estimar o poder preditivo do algoritmo por meio da medida da distância intra-grupo. Quanto maior a similaridade intragrupo sem a utilização do atributo $a$, mais forte é o poder preditivo e melhor o esquema de agrupamento.

Para detalhar o funcionamento deste critério, suponha a construção de $k$ grupos $G_{1}, G_{2}, \ldots, G_{k}$. Seja $x_{i j}$ o atributo do padrão $i$ na posição $j$. Seja $\mu_{G_{n}}\left(x_{i j}\right)$ a média dos atributos $x$ na posição $j$ dos padrões $x_{i}$ pertecentes ao grupo $G_{n}$. 
A figura de mérito para $n$ padrões, sendo $k$ o número grupos e $j$ a posição dos atributos usados na estimativa, é dada pela Equação 2.31.

$$
\operatorname{FOM}(j, k)=\sqrt{\frac{1}{n} \sum_{n=1}^{k} \sum_{x_{i} \in G_{n}}\left(x_{i j}-\mu_{G_{n}}\left(x_{i j}\right)\right)^{2}}
$$

A figura de mérito agregada, dada pela Equação 2.32, pode ser obtida aplicando a Equação 2.31 para cada amostra do conjunto de $z$ amostras. Ela é uma estimativa do poder preditivo total de um algoritmo sobre todas as amostras para $k$ grupos.

$$
\operatorname{FOM}(k)=\sum_{j=1}^{z} \operatorname{FOM}(j, k)
$$

O resultado obtido por FOM tende a diminuir com o aumento do número de grupos k. A Equação 2.33 representa a Equação 2.32 corrigida (Yeung et al., 2000), ou seja, com uma redução dessa tendência.

$$
F O M(k)=\frac{\sum_{j=1}^{z} \operatorname{FOM}(j, k)}{\sqrt{(n-k) / n}}
$$

Como a FOM assume que o atributo excluído contém informações que foram usadas para formar o agrupamento, essa abordagem não é aplicável em conjunto de dados cujos atributos apresentem informações independentes. Ela também não é um critério seguro para comparar agrupamentos com diferentes números de grupos ou obtidos com medidas de similaridade diferentes (Faceli et al., 2005b).

\subsection{Considerações Finais}

Este capítulo apresentou uma visão geral sobre agrupamento de dados, com enfoque nas principais etapas do processo de agrupamento. O capítulo descreveu alguns algoritmos existentes, de maneira a fornecer os elementos necessários para essa pesquisa. Como o conteúdo apresentado nesse capítulo é muito abrangente para o projeto, a pesquisa será focada em agrupamentos particionais exclusivos, especialmente $k$-médias. Também será feito o uso de várias medidas de dissimilaridade descritas nesse capítulo e os agrupamentos resultantes serão avaliados usando critérios de validação apresentadas. 



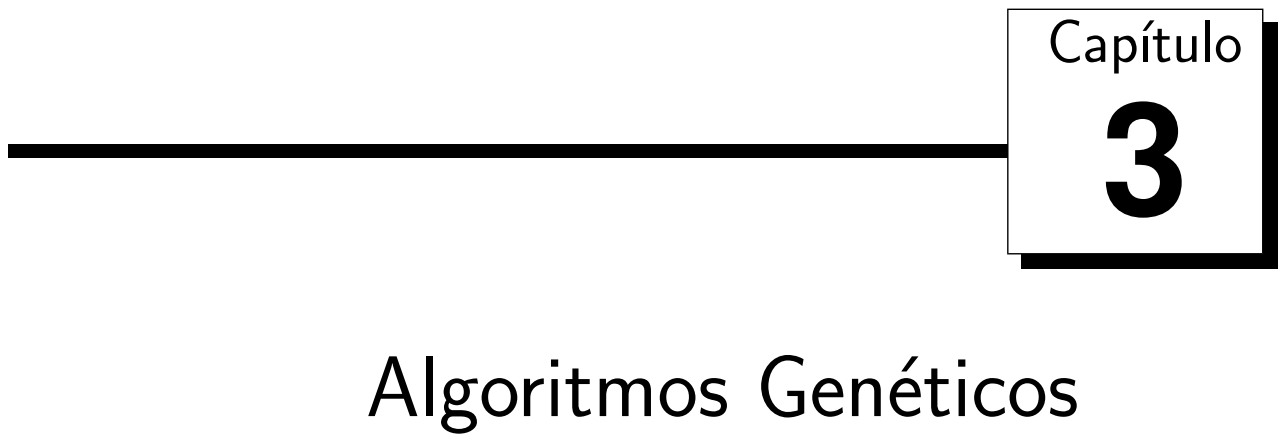

No Capítulo 2 foi visto que algoritmos de agrupamento são ferramentas valiosas para análise exploratória de dados, mineração de dados e reconhecimento de padrões, o que valida seu uso na análise de expressão gênica. Também foi visto que, segundo Hartigan (1985), "diferentes agrupamentos são corretos para diferentes propósitos, assim, não é possível dizer que um agrupamento é melhor". Além disso, foi visto que o desempenho de uma técnica depende das características dos dados utilizados, dos diferentes valores de seus parâmetros livres, da seleção da partição inicial e até mesmo da ordem de apresentação dos dados, não existindo uma abordagem melhor do que todas as outras (Zeng et al., 2002).

Algoritmos Genéticos (AGs) são técnicas de busca global e otimização utilizadas para combinar as características de possíveis soluções que obtiveram bom desempenho, com o objetivo de construir soluções melhores. Esses algoritmos podem ser utilizados em problemas de agrupamento para ajustar os parâmetros livres do algoritmo de agrupamento adotado e para selecionar partição inicial dos dados, entre outros. Em todos esses casos, o objetivo do uso de AGs é o de melhorar o desempenho obtido pelo algoritmo de agrupamento.

Neste capítulo são vistos os principais aspectos dos AGs. Ele está organizado da seguinte forma: na Seção 3.1 é feita uma breve descrição de AGs juntamente com os operadores genéticos utilizados por eles, na Seção 3.2 são mostrados as diferentes abordagens utilizadas para a implementações de AGs paralelos. A Seção 3.3 descreve em mais detalhes uma das abordagens paralelas. Na Seção 3.4 são apresentadas as considerações finais. 


\subsection{Definição e Aspectos Principais}

AGs são técnicas de busca e otimização utilizadas para gerar variações, ou possíveis soluções, combinando as características daquelas que obtiverem melhor desempenho, com o objetivo de produzir novas soluções com desempenho melhor a cada geração (Balakrishnan and Honavar, 1995). Os AGs são baseados na concepção darwiniana de sobrevivência do mais apto e na teoria da seleção natural das espécies (Beasley et al., 1993).

O primeiro passo na construção de um AG é a geração de uma população inicial de $N$ indivíduos ou cromossomos, que representam possíveis soluções do problema a ser resolvido. Durante o processo evolutivo, essa população é avaliada e cada cromossomo recebe uma nota (aptidão), refletindo a qualidade de sua solução para o problema em questão. Em geral, os cromossomos mais aptos são selecionados e os menos aptos são descartados. Os membros selecionados podem sofrer transformações em suas características fundamentais por meio de operadores genéticos como, por exemplo, os operadores de cruzamento e mutação, gerando descendentes para a próxima geração. O processo é repetido até que um critério de parada seja satisfeito. Uma visão geral do funcionamento do AG é apresentada na Figura 3.1 .

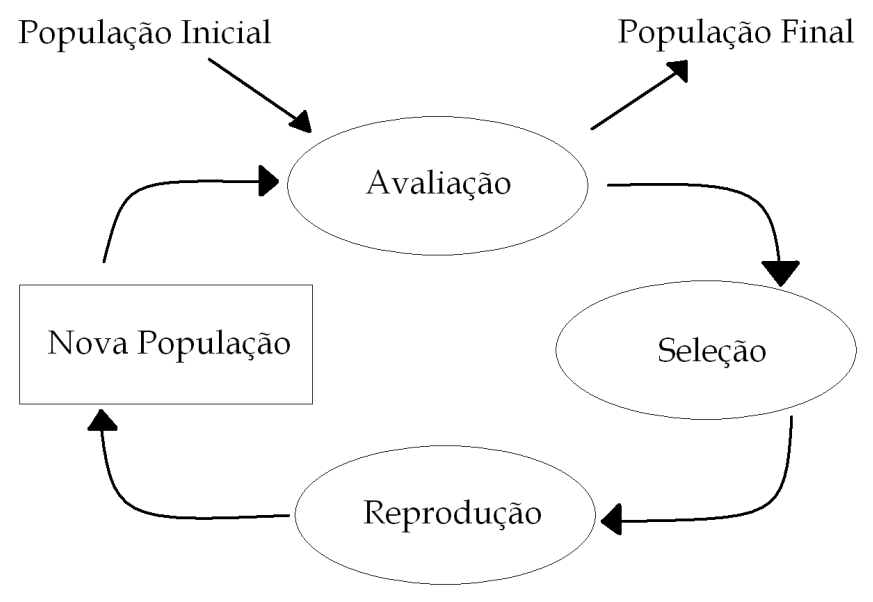

Figura 3.1: Visão Geral de um Algoritmo Genético

A seleção dos cromossomos que passarão para a próxima geração pode ser feita pelo seguinte procedimento: calcula-se a soma das aptidões de todos os cromossomos da população e, em seguida, calcula-se a aptidão relativa de cada cromossomo, que será igual à aptidão desse cromossomo dividida pela soma de todas as aptidões calculadas. Por fim, a probabilidade de um dado cromossomo ser selecionado para a geração posterior é proporcional à sua aptidão relativa. Os indivíduos são selecionados para a próxima geração pode meio de um método 
de sorteio semelhante a uma roleta. Nesse método, cada indivíduo ocupa uma fatia proporcional à sua aptidão relativa na roleta. Cada vez que um indivíduo é selecionado, a roleta é girada e o indivíduo correspondente à fatia apontada é escolhido. Este procedimento é conhecido como Método da Roleta (Tabela 3.1. Este método é repetido até preencher a população intermediária com $N$ cromossomos.

\begin{tabular}{|lllll|}
\hline Si & Indivíduo & Aptidão $\mathrm{f}(\mathrm{Si})$ & Aptidão Relativa \\
S1 & 10110 & 2,23 & 0,14 \\
S2 & 11000 & 7,27 & 0,47 \\
S3 & 11110 & 1,05 & 0,07 \\
S4 & 01001 & 3,35 & 0,21 \\
S5 & 00110 & 1,69 & 0,11 & \\
& & & &
\end{tabular}

Tabela 3.1: Ilustração do método da Roleta

Outros métodos de seleção podem ser utilizados. Um outro método muito utilizado é a seleção por torneio. Segundo Mitchell (1999), a seleção por torneio pode ser implementada da seguinte maneira:

1. A cada seleção, $N$, geralmente 2 , indivíduos da população corrente são escolhidos aleatoriamente

2. Um número entre 0 e 1 é gerado;

3. Se este número for menor que uma constante $p_{s}$ no intervalo $[0,1](0.75$ por exemplo), o indivíduo mais apto é selecionado. Caso contrário, o menos apto é escolhido.

Os operadores de cruzamento e de mutação são os principais mecanismos de busca dos AGs para explorar regiões desconhecidas do espaço de busca. Geralmente, o operador de cruzamento é aplicado a um par de cromossomos retirados da população intermediária, gerando dois cromossomos filhos. Cada um dos cromossomos pai tem seu vetor de características cortado em um ponto, ou seja, uma mesma posição definida aleatoriamente, produzindo dois segmentos de mesmo tamanho. Os segmentos são trocados, gerando dois novos cromossomos. A Figura 3.2 ilustra o comportamento deste operador.

O operador de cruzamento é aplicado com uma dada probabilidade a cada par de cromossomos selecionados. Não ocorrendo o cruzamento, os filhos irão 


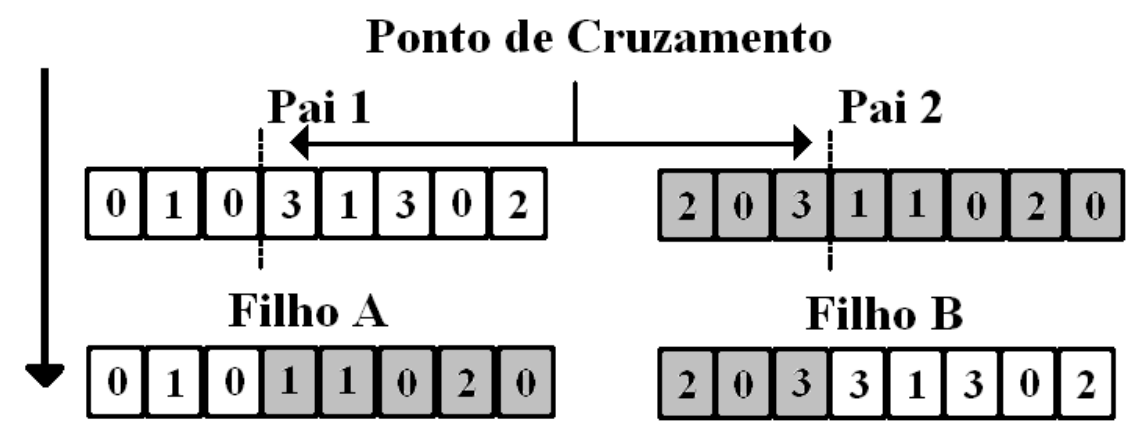

Figura 3.2: Exemplo de Cruzamento

preservar as características dos pais. Esse operador pode ser implementado gerando números aleatórios no intervalo $[0,1]$. Assim, o cruzamento só é aplicado se o número gerado for menor que a taxa de cruzamento.

Após a operação de cruzamento, o operador de mutação é aplicado em cada filho, com uma dada probabilidade, a probabilidade de mutação. O operador de mutação pode alterar o valor de uma ou mais características. A Figura 3.3 apresenta um exemplo desse operador. A mutação aumenta a diversidade dos cromossomos na população. Por outro lado, ela pode destruir informações úteis contidas no cromossomo. Por isso, deve ser utilizada uma taxa de mutação baixa, mas suficiente para assegurar a diversidade da população.

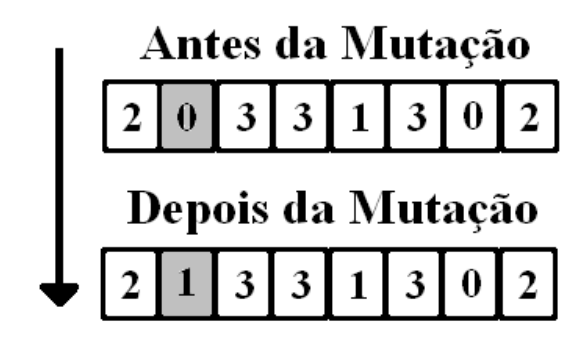

Figura 3.3: Exemplo de Mutação

Após a definição da primeira população, o procedimento se repete até que um critério de parada seja atingido. Quando se conhece a resposta máxima da função de aptidão, pode-se utilizar esse valor como critério de parada do AG. Outros critérios de parada podem ser:

- Atingir um certo número de gerações previamente definido;

- A população convergir (uma porcentagem alta pré-definida dos cromossomos possui um mesmo valor de aptidão);

- Não houver aumento da aptidão durante um número pré-definido de gerações. 
Vale observar que o melhor cromossomo pode ser perdido de uma geração para outra devido ao corte do cruzamento ou à ocorrência de mutação. Portanto, é interessante transferi-lo de uma geração para outra sem alterações. Esta estratégia é denominada elitismo e é muito comum nos AGs tradicionais.

\subsection{Algoritmos Genéticos Paralelos}

Em muitos casos, a função que calcula aptidão para cada indivíduo e os operadores genéticos podem exigir um grande esforço computacional durante a execução do AG. Além disso, a variedade da população durante o processo de busca tende a diminuir devido ao processo de seleção, o que pode gerar a convergência prematura dos cromossomos. Essa convergência poderia dificultar a saída do AG de um mínimo local devido a falta de diversidade entre os cromossomos da população (Chen et al., 2004).

AGs paralelos têm sido investigados para lidar com esses problemas. Dentre as propostas de AGs paralelos, é possível citar três tipos principais abordagens (Cantú-Paz, 1998): mestre-escravo, população única com alta granularidade e múltiplas populações com baixa granularidade.

Nos AGs paralelos mestre-escravo, existe uma única população, como os AGs tradicionais, porém a função de aptidão é calculada em paralelo por diversos processadores. Neles, o mestre armazena toda a população, executa todos os operadores genéticos e envia os indivíduos para os processadores escravos que calculam o valor da função de aptidão para um subconjunto dos indivíduos da população. A Figura 3.4 (a) ilustra esse algoritmo. Nos AGs paralelos de população única com alta granularidade existe uma estrutura espacial que limita a interação entre os indivíduos da população. Os indivíduos podem competir e sofrer cruzamento apenas com os seus vizinhos. Porém, como as vizinhanças se sobrepõe, as soluções são disseminadas por toda população. Esse modelo também é conhecido como modelo celular (Tan et al., 2002). A Figura 3.4 (b) ilustra a estrutura formada por esse tipo de algoritmo.

Um terceiro tipo de AGs paralelos são os de múltiplas populações com baixa granularidade, também conhecidos como AGs Distribuídos (AGDs). Nos AGDs, o conjunto de cromossomos é divido em vários grupos semi-isolados, também chamados demes, contribuindo para a manutenção da variedade dos cromossomos e evitando sua convergência prematura (Chen et al., 2004). Esses demes são associados a AGs independentes, formando ilhas que permitem explorar regiões distintas do espaço de busca, o que faz com o que o algoritmo também seja conhecido por Modelo de Ilhas. 


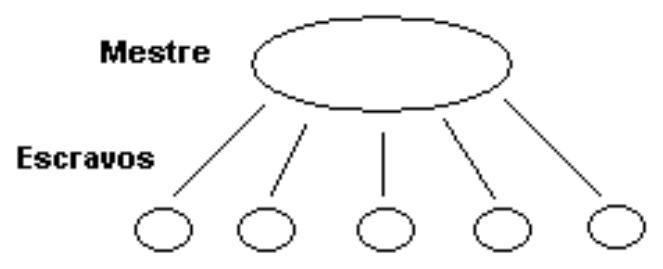

(a)

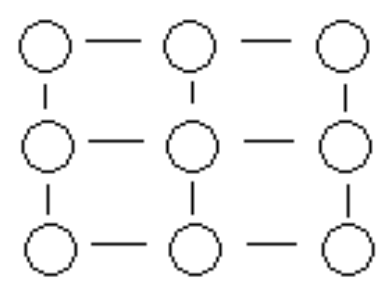

(b)

Figura 3.4: Exemplos de AGs paralelos: modelo mestre-escravo (a) e modelo celular (b)

\subsection{Algoritmos Genéticos Distribuídos}

Algumas implementações de AGDs combinam dois ou mais métodos de paralelismo (Tan et al., 2002; Noda et al., 2002). Esses novos algoritmos híbridos combinam diferentes métodos de uma maneira hierárquica, utilizando um algoritmo em um nível mais alto e outro em um nível mais baixo. Um exemplo de AG hierárquico combina um Modelo de Ilhas no nível superior e o modelo celular no nível inferior, como ilustra a Figura 3.5 .

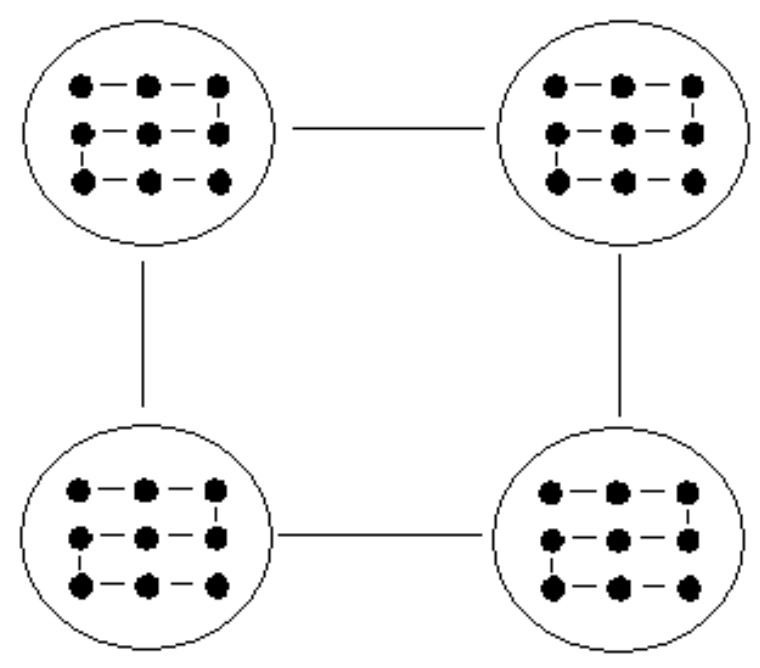

Figura 3.5: Exemplo de modelo hierárquico utilizando modelo de ilhas no nível superior e modelo celular no nível inferior

Levando em consideração a homogeneidade dos demes, os AGDs podem ser divididos em homogêneos e heterogêneos, dependendo se a configuração de parâmetros, operadores genéticos e codificação dos cromossomos ocorre em todos os demes ou não (Noda et al., 2002). Em um AGD homogêneo todas a ilhas 
executam o mesmo AG. Já em um AGD heterogêneo é possível dividir um AG com tarefas grandes e complexas em AGs com tarefas menores e mais simples, mas diferentes entre si.

Um método freqüentemente utilizado para implementar AGDs permite que cada deme seja processado por processadores distintos, paralelamente. Por utilizar populações menores, a convergência é mais rápida. Porém, populações menores podem resultar em soluções de pior qualidade, devido à menor variedade de cromossomos (Cantú-Paz, 2000). Para obter melhores soluções, os AGDs transportam ocasionalmente alguns indivíduos de um certo deme para outro vizinho, em um processo análogo à migração das populações naturais. Diversos tipos de migração foram propostos (Hiroyasu et al., 1999; Tan et al., 2002; Lin et al., 2002; Noda et al., 2002, Chen et al., 2004), cada um controlado por um grupo parâmetros. Isso dificulta a compreensão do efeito causado pelas migrações (Cantú-Paz, 1998), sendo, por isso, um problema em estudo.

Dentre os parâmetros da migração que mais influenciam no resultado do AGDs podem ser citados três: a topologia utilizada para a migração, a escolha dos indivíduos migrantes e a freqüência com que ocorrem as migrações. Uma discussão sobre cada um desses parâmetros é apresentada a seguir.

\subsubsection{Topologia de migração}

A topologia de migração indica a forma como as ilhas do AGD transportam os indivíduos durante a migração. Ela é um fator importante no desempenho do AGD, pois determina a velocidade de propagação de bons indivíduos para outros demes. Em uma topologia muito conectada, os bons indivíduos serão transmitidos rapidamente para todos os demes e estarão presentes em todas as populações. Topologias pouco conectadas fazem com que esses indivíduos demorem a ser transmitidos pela população, o que permite uma maior diversidade. A topologia de migração também influência no tempo de execução do AGD. Quanto maior o número de conexões, maior o custo de comunicação e, conseqüentemente, o tempo de execução.

As topologias de migração podem ser fixas ou dinâmicas. Nos AGDs com topologia fixa, as migrações são sempre efetuadas para as mesmas ilhas. Já nos AGDs de topologia dinâmica, cada migração é geralmente feita para ilhas diferentes. Um exemplo de AGDs de topologia fixa é o modelo de salto entre pedras e um exemplo de AGDs de topologia dinâmica é modelo de migração aleatória (Hiroyasu et al., 1999). No primeiro, a migração dos indivíduos ocorre apenas entre as ilhas vizinhas, enquanto no segundo, a ilha que receberá o indivíduo é escolhida aleatoriamente a cada migração. Essas topologias são ilustradas na 
Figura 3.6 .

(1) Salto entre Pedras

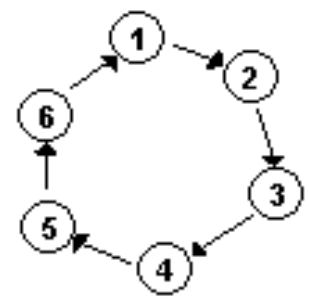

(2) Migração Aleatória

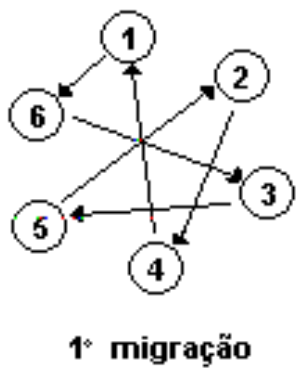

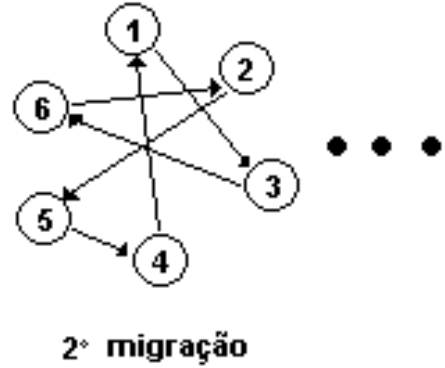

Figura 3.6: Exemplos de topologias: (1) Salto entre Pedras e (2) Migração Aleatória

Cantú-Paz (2000) utiliza uma topologia fixa com conexão total, ou seja, todas as ilhas enviam e recebem indivíduos para/de todas as outras. Alguns tipos especiais de topologia de migração são implementados no caso dos AGDs hierárquicos. Essas topologias variam conforme o tipo de AG paralelo utilizado nos níveis do AGDs hierárquicos, podendo ser fixa ou aleatória para cada um deles. Noda et al. (2002) e Tan et al. (2002) utilizam topologia de migração fixa entre as ilhas.

\subsubsection{Escolha dos indivíduos migrantes}

A escolha dos indivíduos migrantes e a substituição dos mesmos em novas populações afetam consideravelmente a velocidade com que os AGDs convergem. Cantú-Paz (1999) estudou a convergência dos AGDs utilizando os tipos de escolha mais comuns dos indivíduos migrantes: selecionados aleatoriamente ou selecionados entre os melhores indivíduos da população. O indivíduo selecionado pode substituir um indivíduo de outra população, selecionado aleatoriamente ou selecionado entre os piores indivíduos. Os resultados obtidos pelo autor mostram que selecionar para a migração os melhores indivíduos faz com que a velocidade de convergência da população aumente em relação à seleção aleatória.

Deve ser levado em consideração se o indivíduo selecionado será copiado ou movido para a nova população. Mover o indivíduo pode fazer com que a população que o envia retroceda várias gerações de aprimoramento em termos de aptidão. Efetuar uma cópia, por outro lado, pode fazer com que indivíduos com alta aptidão dominem várias populações (Noda et al., 2002).

O número de indivíduos selecionados varia em diferentes trabalhos. Hiroyasu et al. (1999) seleciona um número aleatório de indivíduos para migração. Isso 
que faz com que as populações alterem de tamanho a cada migração, pois, para algumas populações, o número de indivíduos enviados pode ser diferente número de indivíduos recebidos. Chen et al. (2004) utilizam uma migração caótica e uma seleção aleatória. Porém, os indivíduos trocam de população ao invés de serem substituídos, o que faz com que as populações mantenham um tamanho fixo.

Denzinger and Kidney (2003) propuseram a utilização da diversidade junto com a aptidão no processo de escolha dos indivíduos para migração. Os autores calculam para cada indivíduo uma medida de qualidade por meio da Equação 3.1. em que $p_{a p t}$ e $p_{\text {div }}$ são pesos pré-estabelecidos para a aptidão e a diversidade respectivamente e $n$ é o tamanho da população total. São selecionados para a migração o melhor indivíduo juntamente com $m-1$ indivíduos com as medidas de qualidade mais altas, sendo $m$ o número de indivíduos que serão migrados. Esses indivíduos substituem os piores indivíduos da população que os recebe.

$$
\text { qual }(\text { ind })=p_{\text {apt }} \times \frac{\operatorname{apt}(\text { ind })}{\operatorname{apt}\left(\text { ind }_{\text {melhor }}\right)}+p_{\text {div }} \times \frac{\operatorname{apt}\left(\text { ind }_{\text {melhor }}\right)-\operatorname{apt}(\text { ind })}{n}
$$

Noda et al. (2002) implementaram um AGD hierárquico cujo programa é fragmentado em agentes responsáveis pela execução de AGDs de topologia fixa (homogêneos e heterogêneos). Os autores utilizam uma política de migração orientada a conhecimento, que permite aos agentes receber informações sobre os agentes vizinhos. Esse conhecimento é utilizado como base para a tomada de decisão durante a migração, permitindo escolher quantos e quais agentes devem ser migrados. As vezes é necessário efetuar uma adequação do indivíduo em migração, no caso de AGDs heterogêneos. Essa adequação consiste em modificar as características do cromossomo migrante de modo a alterar representação utilizada, mas sem modificar o agrupamento representado.

Tan et al. (2002) propuseram um AGD hierárquico baseado em comunidades formadas por conjuntos de AGs. Durante a migração, os $m$ indivíduos mais aptos de todos os AGs são selecionados e migrados para todas as populações por meio dessas comunidades.

\subsubsection{Freqüência de migração}

A freqüência de migração determina quando a migração ocorrerá. Há dois tipos de freqüência utilizados em AGDs: síncronas e assíncronas. As migrações síncronas ocorrem dentro de um certo intervalo de tempo ou depois de um número prédefinido de gerações (Hiroyasu et al., 1999). Já as migrações assíncronas ocorrem sempre que um determinado evento acontece, por exemplo, a população convergir 
para uma solução (Cantú-Paz, 2000; Chen et al., 2004).

\subsection{Considerações Finais}

Este capítulo apresentou uma visão geral sobre a teoria e construção de AGs e AGDs. Foram apresentadas várias estruturas desses algoritmos, assim como diferentes operadores genéticos e seus parâmetros, fornecendo os elementos necessários para sua pesquisa e utilização nesse trabalho.

Nessa pesquisa será priorizado o uso de AGs tradicionais, pois estabelecer representações e operadores para esse tipo de AG são trabalhos com maior desenvolvimento na literatura. O estudo de AGDs oferece vantagens em máquinas com arquiteturas paralelas, além de preservar um conjunto maior de características em várias populações. Porém, seu uso em agrupamento de dados é quase inexistente na literatura e nem sempre é possível ter acesso a arquiteturas paralelas. Além disso, faltam heurísticas para analisar indivíduos resultantes de diferentes demes e desenvolvê-las não é o foco desta pesquisa. 


\section{Capítulo 4 \\ Técnicas de Agrupamento e Algoritmos Genéticos}

No Capítulo 2, foi visto que algoritmos de agrupamento são ferramentas valiosas na análise exploratória de dados, mineração de dados e reconhecimento de padrões, o que valida seu uso na análise de expressão gênica. No Capítulo 3 foi visto que AGs são técnicas de otimização e busca global utilizadas para combinar as características de possíveis soluções de bom desempenho, gerando soluções potencialmente melhores.

Neste capítulo é feito um estudo sobre a utilização de AGs para a otimização de técnicas de agrupamento e análise de alguns trabalhos relacionados. Nele são detalhadas as principais características de um AG utilizado em problemas de agrupamento. Ele é dividido da seguinte forma: a Seção 4.1 contém definições importantes e os aspectos principais de técnicas que utilizam agrupamentos em conjunto com AGs; na Seção 4.5 são descritos exemplos de modelos que utilizaram AGs em conjunto com algoritmos de agrupamento; na Seção 4.6 são apresentadas as considerações finais e uma discussão sobre os parâmetros utilizados tanto para os algoritmos de agrupamento quanto para os AGs.

\subsection{Definição e Aspectos Principais}

Abordagens evolutivas têm se mostrado muito eficientes para a obtenção de soluções para problemas de agrupamento (Jain et al., 1999). Dentre essas abordagens, AGs são bastante utilizados, principalmente em problemas de agrupamento em $k$ grupos em que o valor de $k$ é previamente conhecido (Belew and Booker, 1991; Raghavan and Birchand, 1979; Bezdek et al., 1994).

AGs têm se destacado na solução de problemas de agrupamento porque (Cow- 
gill et al., 1998; Jain et al., 1999; Bayram et al., 2004):

1. Executam uma busca global pelas melhores soluções, enquanto a maioria dos procedimentos conhecidos de agrupamento executa uma busca local.

2. Utilizam procedimentos de busca probabilísticos ao invés de regras determinísticas.

3. Procuram por uma população de soluções em paralelo, permitindo evitar mínimos locais.

4. Utilizam princípios evolutivos, o que permite que as soluções evoluam em direção a um ponto de ótimo.

5. A função objetivo do algoritmo de agrupamento e a função de aptidão do AG correspondente são suficientes para influenciar a direção da busca.

6. Podem obter não apenas uma, mas um grupo de potenciais soluções em potencial para um dado problema.

Diversos métodos de adaptação de AGs foram propostos para solucionar problemas de agrupamento. Na maioria deles, as soluções candidatas ao problema são codificadas em cromossomos, que representam os indivíduos de uma determinada geração, como definido no Capítulo 3 .

Dentre as semelhanças entre algoritmos de agrupamento e AGs, merece destaque a relação entre as funções objetivo e de aptidão. A função objetivo de um algoritmo de agrupamento pode ser utilizada como função de aptidão do AG. Uma adaptação pode ser necessária, pois, na maioria das vezes, a função objetivo deve ser minimizada para obter bons resultados, ou seja, as soluções que apresentam menores valores para função objetivo devem receber as maiores notas de aptidão.

Em seguida, os cromossomos sofrem a ação de operadores genéticos como seleção, cruzamento (recombinação) e mutação. A maneira com que esses operadores são utilizados varia muito nas implementações propostas, pois cada implementação pode utilizar uma representação distinta da outra. Diferentes algoritmos de agrupamento têm sido utilizados em conjunto com os AGs. As características do AG variam de acordo com o algoritmo utilizado e as variáveis a serem otimizadas. Alguns exemplos de implementações serão apresentados na Seção 4.5 .

Ainda são objetos de estudo definir boas representações dos agrupamentos por meio de cromossomos, definir funções de aptidão adequadas à resolução do problema, adaptar os operadores genéticos e encontrar parâmetros adequados 
ao algoritmo de agrupamento. Esses aspectos são discutidos em detalhes nas próximas seções.

\subsection{Representação Utilizada}

Para a otimização de um algoritmo de agrupamento por AGs, é necessário que as soluções para o problema possam ser representadas por cromossomos. Algumas das alternativas utilizadas na literatura para representar o problema com um número fixo de agrupamentos são (Cole, 1998):

- Representar os objetos a serem agrupados como genes do cromossomo e indicar o grupo a que pertencem por meio do valor desses genes. Esse tipo de representação é conhecido como Grupo-Número.

- Representar o agrupamento por meio de uma matriz binária, onde as linhas representam os grupos e as colunas representam os objetos. Esse tipo de representação é conhecido como matriz.

- Representar os objetos por meio do valor dos genes e o grupo a que eles pertencem por meio da sua posição no cromossomo. Esse tipo de representação é conhecido como permutação.

- Representar apenas os centróides (Equação 2.13) de cada grupo como os genes contidos no cromossomo. Essa representação é conhecida como representação por centróide.

A representação Grupo-Número é uma das mais utilizadas para AGs em problemas de agrupamento (Raghavan and Birchand, 1979; Murthy and Chowdhury, 1996; Cowgill et al., 1998; Hruschka et al., 2004). Nessa representação, os cromossomos são compostos por vetores de tamanho $N$, com $N$ igual ao número de padrões. Cada elemento ou gene representa um padrão e o valor contido nele indica o grupo ao qual ele pertence. Essa representação pode ser visualizada na Figura 4.1 (a).

Bezdek et al. (1994) utilizam como cromossomo uma matriz binária $M_{k \times n}$, onde cada coluna representa um objeto a ser agrupado e cada linha um grupo. Se um objeto $x_{i}$ pertencer ao grupo $c_{j}$, então o conteúdo da posição $M(i, j)$ será 1, caso contrário, o mesmo será 0 . Neste caso, $\sum_{j=1}^{k} M(i, j)=1$ e $\sum_{i=1}^{n} M(i, j) \geq 1$, ou seja, cada objeto pode pertencer a apenas um grupo (agrupamento exclusivo) e nenhum grupo pode estar vazio. Bezdek et al. (1994) também utilizaram essa 
representação para agrupamentos não exclusivos. Nesse caso, a matriz era composta por números reais contendo a pertinência de cada objeto em cada grupo. Essa representação pode ser vista na Figura 4.1 (b).

Um outro tipo de representação utiliza o valor dos genes para codificar os padrões e a posição dos padrões no cromossomo para identificar a que grupo pertencem. Como os diferentes indivíduos representam diferentes permutações dos padrões, esta codificação é denominada codificação por permutação. Existem duas variações para essa representação: permutação com separadores e permutação gulosa.

Permutação com separadores (Belew and Booker, 1991) utiliza valores que não representam objetos para separar um grupo do outro, como mostrado na Figura 4.1 (c).

Belew and Booker (1991) também propõem outra representação que necessita de buscas locais, também conhecida como permutação gulosa, que utiliza os $k$ primeiros genes como sementes para gerar $k$ grupos, ou seja, cada um dos $k$ primeiros padrões pertence a um grupo distinto e serão utilizados como sementes do mesmo. Cada um dos padrões restantes é adicionado no grupo cuja semente apresenta a similaridade mais alta com ele, na ordem que aparecem na permutação. A permutação gulosa é ilustrada na Figura 4.1.(d).

A Figura 4.1 apresenta diferentes codificações para o agrupamento $\{\{A, C, F\}$, $\{B, D, E\}\}$. Neles, os grupos são nomeados como 1 e 2 e os objetos são nomeados por letras entre $A$ e $E$.

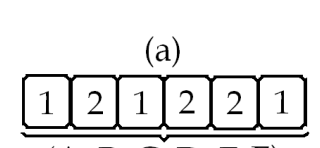

$(\mathrm{A}, \mathrm{B}, \mathrm{C}, \mathrm{D}, \mathrm{E}, \mathrm{F})$

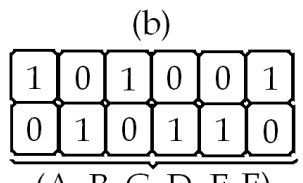

$(A, B, C, D, E, F)$

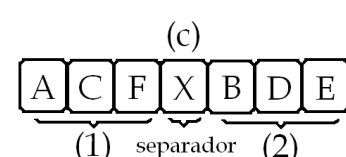

(1) separador (2) (d)

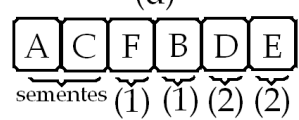

Figura 4.1: Cromossomos representando o agrupamento $\{\{A, C, F\},\{B, D, E\}\}$ utilizando as representações: (a)Grupo-Número (b)Matriz (c)Permutação com separador (d) Permutação Gulosa

Uma outra forma muito utilizada para representar partições consiste em compor um cromossomo com os centróides de cada grupo (Hall et al., 1999; Kivijärvi et al. 2003). Nesse caso, uma matriz $M_{d \times k}$ de valores numéricos representa uma partição, em que $d$ é a dimensão dos objetos da base de dados e $k$ é o número de grupos formados. Cada coluna contém o centróide $c$ de um grupo e cada linha representa a posição do mesmo na dimensão $d$ correspondente. Em alguns casos, os autores utilizam a mesma abordagem, porém optam por utilizar meióides ao invés de centróides (Pan et al. 2003, Ma, 2005). É importante ressaltar a 
diferença entre centróides e meióides. Um centróides é o ponto central ou média de um grupo de valores e o meióide é o padrão mais próximo desse ponto. Essa representação pode ser visualizada na Figura 4.2, em que um conjunto de $k$ centróides de $x$ dimensões é apresentado.

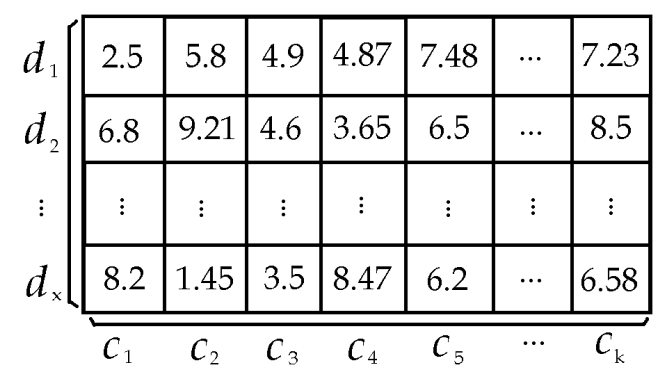

Figura 4.2: Cromossomos representando uma matriz contendo centróides

Quando o número de grupos é fixo, um cromossomo que não seja capaz de representar todos os grupos deve ser tomado como inválido ou infactível. Um exemplo seria um cromossomo que represente grupos e não inclua todos grupos possíveis. Outros exemplos seriam cromossomos que, compostos de permutação com separadores, tenham separadores a mais, falta de separadores ou separadores em posição inválida. Para evitar que esses cromossomos sejam gerados, é utilizada alguma heurística ou verificação da validade dos cromossomos.

Em alguns casos, não é possível saber a quantidade correta de grupos a serem formados para um determinado conjunto de padrões. É possível solucionar esse problema de várias formas, entre elas: fazer com que o número de grupos seja definido pela função de aptidão, executar o AG em um determinado número de cenários ou utilizar um algoritmo hierárquico. Outras representações foram propostas para implementar essas soluções (Tseng and Yang, 2001; Garai and Chaudhuri, 2004, Greene, 2003). Uma delas adiciona a uma das representações já apresentadas a quantidade de grupos (Hruschka et al., 2004). Um exemplo desse novo cromossomo, usando representação Grupo-Número, pode ser visto na Figura 4.3 .

\section{Cromossomo}

\begin{tabular}{|l|l|l|l|l|l|l|l|l|l|l|l|}
\hline 2 & 1 & 2 & 2 & 1 & 5 & 3 & 4 & 4 & 1 & 3 & 5 \\
Grupo-Número
\end{tabular}

Figura 4.3: Cromossomo com número variável de grupos

Uma outra forma de agrupar para um número indefinido de grupos consiste em utilizar algoritmos hierárquicos em conjunto com AGs. Por exemplo, utilizando 
um método que divide o conjunto de dados em $m$ grupos iniciais (Tseng and Yang, 2001; Garai and Chaudhuri, 2004). Esses métodos podem ser vistos com mais detalhes na Seção 4.5.3.

Para que as partições sejam aglomeradas, é necessário um procedimento para dividir o conjunto de dados em $m$ grupos iniciais. Cada um desses grupos $\left\{B_{1}, B_{2}, \ldots B_{m}\right\}$ é representado por um gene no cromossomo binário. Se o valor do gene correspondente a um grupo for 1, esse grupo continuará a existir nos níveis superiores. Caso o valor do bit correspondente seja 0 , os objetos desse grupo serão adicionados aos grupos mais próximos cujo valor seja 1. A Fig. 4.4 ilustra essa representação.

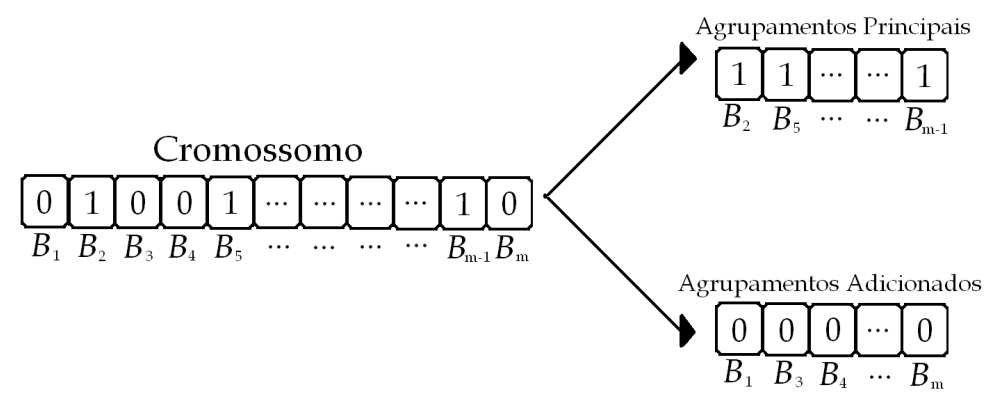

Figura 4.4: Exemplo de cromossomo para agrupamento hierárquico

É possível ainda que o AG seja utilizado apenas para avaliar e selecionar agrupamentos hierárquicos previamente formados, especialmente no caso de algoritmos divisivos (Greene, 2003). Neste caso, cada indivíduo da população é representado por um grupo contendo todos os objetos, que pode ser dividido em outros grupos. Por sua vez, cada novo grupo gerado pode ser novamente dividido, o que produz vários níveis de agrupamento, como no dendograma ilustrado pela Figura 2.3. A construção desses objetos pode ser vista com maior detalhamento na Seção 4.5 .3 .

AGs também podem ser utilizados para encontrar valores para alguns parâmetros livres nas redes SOM como a taxa de aprendizado, a topologia da rede (número de neurônios), os pesos da rede e a função de vizinhança (incluindo seus parâmetros). Esses parâmetros são representados por genes no cromossomo, podendo ser compostos por números reais ou binários. Um exemplo deste cromossomo é ilustrado na Figura 4.5 .

Ao selecionar uma representação para um dado problema, é necessário levar em consideração o tipo de dado a ser agrupado, o conhecimento prévio do número de grupos a serem formados e a complexidade de algumas funções necessárias, como algoritmos de busca (no caso da permutação) e do cálculo da 


\begin{tabular}{|c|c|c|c|c|c|}
\hline \multicolumn{3}{|c|}{ Pesos } & $\begin{array}{c}\text { Taxa de } \\
\text { Aprendizado }\end{array}$ & $\begin{array}{l}\text { Número de } \\
\text { Neurônios }\end{array}$ & $\begin{array}{l}\text { Função de } \\
\text { Vizinhança }\end{array}$ \\
\hline 2.5 & 5.8 & 4.9 & \multirow{2}{*}{0.15} & \multirow{2}{*}{19.7} & \multirow{2}{*}{4.21} \\
\hline 7.23 & |3.32 & 36.0 & & & \\
\hline
\end{tabular}

Figura 4.5: Exemplo de cromossomo para redes SOM.

vizinhança entre os padrões (no caso da representação gulosa e por centróides). Para os algoritmos que não utilizam um número fixo de grupos, é necessário que o número de grupos representados pelo cromossomo seja o mesmo que o indicado, não apresentando nenhum grupo inválido ou vazio. No caso da utilização de algoritmos hierárquicos aglomerativos, é necessário que haja um pré-particionamento dos dados em grupos para serem aglomerados pelo AG.

Todas as representações citadas nessa seção apresentam algum nível de redundância, ou seja, é possível que múltiplos cromossomos apresentem o mesmo resultado. Essa redundância cresce exponencialmente a medida que cresce o número de padrões a serem representados. Os parâmetros utilizados pelos algoritmos de agrupamento também podem ser otimizados pelos AGs. Isso pode ser feito adicionando novos genes que codifiquem esses parâmetros dentro do cromossomo, como mostra a Figura 4.6. Esses genes serão tratados pelo AG durante a sua execução.

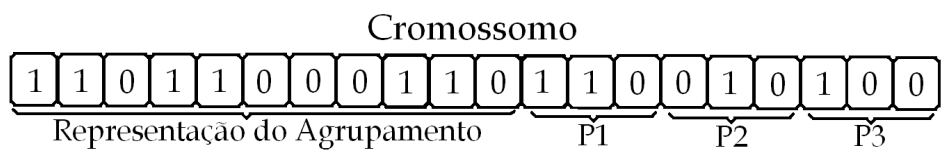

Figura 4.6: Cromossomo com genes representando os parâmetros P1, P2, P3.

\subsection{Função de Aptidão}

A cada geração, os AGs selecionam os melhores indivíduos para criar uma nova população. Para a seleção, é importante atribuir uma nota, avaliação ou valor de aptidão a cada cromossomo. O valor de aptidão é dado por uma função de aptidão, que é definida de acordo com os objetivos do algoritmo de agrupamento utilizado. Geralmente, a meta do algoritmo de agrupamento é minimizar o resultado de uma função objetivo. Nesses casos, a função de aptidão é baseada na função objetivo do algoritmo de agrupamento. Assim, é comum atribuir valores de aptidão maiores aos indivíduos que apresentarem os menores resultados da função objetivo. 
A função objetivo utilizada pelo algoritmo $k$-médias é a minimização de uma medida de proximidade, geralmente da soma quadrática das distâncias Euclidianas entre os objetos contidos nos grupos e seus centróides (Hall et al., 1999; Maulik and Bandyopadhyay, 2000), definida pela Equação 2.6. Essa medida captura a variância total entre grupos e é apropriada para conjuntos de dados que possuem grupos esféricos e compactos ou isolados.

Quanto maior a soma das distâncias Euclidianas, menos compacto é o agrupamento e menor é o seu valor de aptidão. Muitas funções de aptidão utilizam a distância Euclidiana como base, buscando minimizá-la, como a Minimum Squared Error (MSE) (Raghavan and Birchand, 1979; Kivijärvi et al., 2003). Dado um agrupamento $P=\left(p_{1}, p_{2}, \ldots, p_{n}\right)$ e um conjunto de centróides $C=\left(c_{1}, c_{2}, \ldots, c_{k}\right)$, o MSE pode ser calculado por meio da Equação 4.1.

$$
e(P, C)=\frac{1}{n k} \sum_{i=1}^{n} d\left(x_{i}, c_{p i}\right)^{2}
$$

onde $n$ é o número de padrões a serem agrupados, $k$ é o número de grupos, e $d\left(x_{i}, c_{p i}\right)$ é a distância Euclidiana entre o objeto $x_{i}$ e o centróide do grupo que o contém. Nesse caso, a aptidão $A$ do indivíduo $j$ pode ser calculada pela Equação 4.2 .

$$
A_{j}=\frac{1}{1+e\left(P, C_{j}\right)}
$$

A função de aptidão proposta em Cowgill et al. (1998) minimiza a taxa do critério VRC, privilegiando o isolamento externo do grupo e homogeneidade interna. Se utilizada em um agrupamento com um número indeterminado de grupos, a função de aptidão baseada em VRC ajudará a determinar o número correto de agrupamentos no conjunto de dados, produzindo valores maiores para agrupamentos que se aproximam da forma natural dos dados. Essa função é dada pela Equação 2.29.

Também para os casos em que o número de grupos não é determinado, Hruschka et al. (2004) utiliza uma função de aptidão baseada em silhueta (Rousseeuw, 1987), calculada pela Equação 2.24. Nesse caso, a aptidão de cada indivíduo é dada pela média do cálculo da silhueta dos padrões agrupados. Quanto maior a média, maior será a aptidão do indivíduo.

Quando o número de grupos é definido, a função de aptidão pode ser utilizada para evitar cromossomos com agrupamentos degenerados, ou seja, agrupamentos com grupos vazios. Hall et al. (1999) utilizam uma penalização para esses cromossomos. Se um agrupamento apresentar $b$ grupos vazios, ele é avaliado pela 
função objetivo 4.3 .

$$
\bar{e}(A)=e(A)+b \times e(A)
$$

Como a função de aptidão é inversamente proporcional a função objetivo do algoritmo agrupamento, esses indivíduos são penalizados de uma forma proporcional ao número grupos vazios que apresentam, reduzindo a chance de serem escolhidos. Esse cálculo é válido para funções objetivo baseadas em dissimilaridade.

Tseng and Yang (2001) utilizam como função de aptidão o cálculo das distâncias entre os padrões de um grupo e a distância entre o grupo e os demais. O cálculo da aptidão $A$ do indivíduo $j$ é ilustrado na Equação 4.4, na qual $G_{i}$ representa o grupo $i, D_{\text {inter }}$ a distância entre o grupo $G_{i}$ e os outros grupos, $D_{\text {intra }}$ a distância entre os padrões do grupo $C_{i}$ e $w$ uma constante que serve para variar a influência de $D_{\text {inter }}$ ou $D_{\text {intra }}$. As distâncias inter-agrupamentos e intraagrupamentos são medidas utilizando as equações 2.18 e 2.19, respectivamente.

$$
\operatorname{Fitness}\left(A_{j}\right)=\sum_{i=1}^{k}\left(D_{\text {inter }\left(C_{i}\right)} * w-D_{\text {intra }\left(C_{i}\right)}\right)
$$

Para a representação hierárquica utilizada por Greene (2003), a aptidão dos indivíduos é calculada de duas maneiras. Como o resultado do algoritmo é um conjunto de partições hierárquicas, os grupos dos níveis superiores são formados pela combinação dos grupos dos níveis inferiores. A primeira maneira é calcular a soma da aptidão média dos grupos nesse indivíduo com a média das distâncias entre os centróides desses grupos. Caso o grupo não seja formado por outros grupos, é calculada a soma do número de elementos contidos no grupo com a taxa de detalhe do grupo, dado pela diferença entre dois atributos do grupo: seu raio atual e o raio máximo permitido para ele.

No caso das redes SOM, a aptidão é geralmente dada pela média das diferenças entre a quantidade de padrões de cada grupo recebidas por cada neurônio da rede. Desta forma, quanto maior a diferença dos padrões de grupos distintos em um neurônio, maior é a aptidão do mesmo e, conseqüentemente, da rede (Tanaka et al., 1996). Outras formas de validação de agrupamentos podem ser utilizadas para redes SOM, como a média da soma dos quadrados das distâncias entre os padrões e o representante do grupo mais próximo (Ma, 2005).

Como visto, existem vários métodos para avaliar agrupamentos, por causa das diferentes medidas de validação de agrupamentos existentes, como pôde ser visto na Seção 2.5. Se essas técnicas têm como objetivo avaliar o agrupamento 
resultante e não os algoritmos de agrupamento utilizados, é possível comparar o desempenho de algoritmos distintos utilizando uma mesma medida de validação. Isso permite ao AG utilizar algoritmos de agrupamento distintos em uma mesma população.

\subsection{Operadores Genéticos}

Os operadores genéticos são os responsáveis pela transferência do código genético de uma geração para outra. São eles que determinam as variações que podem ocorrer nos cromossomos a cada geração. Como foi descrito na Seção 3, os principais operadores genéticos são inicialização, seleção, cruzamento e mutação dos cromossomos. A seguir, é apresentada uma discussão sobre esses tópicos.

\subsubsection{Inicialização}

Ao gerar uma população inicial, é importante que os indivíduos possam abranger o maior espaço de busca possível. A inicialização também deve levar em conta o tipo de representação utilizada, de maneira que os cromossomos iniciais sejam válidos. Um método de se inicializar uma geração é produzir aleatoriamente os valores assumidos pelos cromossomos. Outros tipos de inicialização podem usar de heurísticas para obter uma população inicial que facilite tanto a convergência do AG para uma solução ótima, quanto reduza o tempo de execução. A seguir, são feitas algumas considerações sobre a inicialização de populações para algumas das representações consideradas na Seção 4.2 .

\section{Grupo-Número}

A forma mais comum de se inicializar um cromossomo quando se utiliza o valor do gene para indicar a que grupos o padrão pertence é gerar esses valores aleatoriamente. Porém, essa abordagem pode gerar cromossomos que não representam todos os grupos. A população deve ser verificada e os cromossomos inválidos substituídos. Também é possível penalizar esses cromossomos aumentando o valor da função objetivo, como mostra a Equação 4.3 .

\section{Matriz Binária}

Uma das formas de inicializar uma matriz de valores consiste em preencher todas as colunas com zeros em todas as posições e depois escolher aleatoriamente uma linha por coluna para receber o valor 1 , indicando que aquele objeto pertence ao grupo correspondente à linha. No caso de agrupamentos não exclusivos, valores aleatórios podem ser utilizados para preencher as colunas, desde que sejam satisfeitas as condições $\sum_{j=1}^{k} M(i, j)=1$ e $\sum_{i=1}^{n} M(i, j) \geq 1$, para $k$ grupos e $n$ padrões. 


\section{Permutação com separador}

Belew and Booker (1991) geram a população inicial dividindo aleatoriamente os padrões em cada grupo de maneira que nenhum fique vazio. Em seguida, a posição desses padrões no agrupamento é permutada e os cromossomos são criados a partir do resultado dessas permutações.

\section{Permutação Gulosa}

Para essa representação, Belew and Booker (1991) utilizam uma escolha aleatória dos padrões para gerar a população inicial, evitando objetos repetidos.

\section{Utilizando Centróides}

Cromossomos que representam centróides podem ser inicializados de duas formas: a posição inicial dos centróides pode ser escolhida aleatoriamente (Hall et al., 1999) ou obtida pelos grupos resultantes da utilização de algum algoritmo de agrupamento (Ward, 1963).

\section{Número variável de grupos}

É feita da mesma forma que as outras representações. Porém, o número de grupos representados em cada cromossomo é importante para o cálculo da aptidão ou mesmo para possibilitar o reconhecimento desses grupos. Muitas vezes, é necessário calcular esse número, mesmo que o número de grupos não esteja no cromossomo. Se esse número não estiver contido no cromossomo, talvez seja necessário conferi-lo.

\section{Representação Hierárquica}

A maioria dos algoritmos hierárquicos necessita de algum tipo de processamento antes que os indivíduos possam ser definidos. No caso dos algoritmos hierárquicos aglomerativos, é preciso que haja a divisão dos padrões do conjunto de dados em grupos iniciais, para que possam ser agrupados posteriormente (Tseng and Yang, 2001; Garai and Chaudhuri, 2004). Esse processo pode ser visto em detalhes na Seção 4.5.3. Em seguida, os agrupamentos formados irão compor os cromossomos da população inicial. Esses cromossomos são representados por vetores binários cujos valores são inicializados aleatoriamente.

No algoritmo desenvolvido por Greene (2003), a adição de padrões em um grupo pode gerar sua segmentação em grupos menores. Ao inicializar a população, o autor organiza os padrões do conjunto de dados de maneira aleatória e seleciona o primeiro padrão, adicionando-o ao primeiro grupo. Os outros padrões são adicionados na seqüência em que foram organizados, podendo causar a sua segmentação (Seção 4.5.3). O processo é repetido para cada indivíduo, permitindo 
uma variedade grande de agrupamentos, uma vez que os padrões são adicionados sempre de maneira aleatória.

\section{Redes SOM}

Os parâmetros e pesos utilizados pela rede SOM recebem valores inicias aleatórios, dentro de um intervalo previamente definido.

\subsubsection{Seleção}

Os cromossomos são selecionados de acordo com sua aptidão relativa. Sendo assim, a seleção está diretamente ligada à função de aptidão, independente da representação utilizada. O método da roleta, torneio ou qualquer outro método de seleção pode ser utilizado. Utilizar elitismo possibilita preservar as melhores soluções para as gerações futuras.

Belew and Booker (1991) e Bezdek et al. (1994) utilizam métodos de seleção por ranking. Belew and Booker (1991) utilizam um método de seleção que escolhe apenas dois indivíduos a cada iteração. Esses indivíduos geram um filho que substitui o pior membro da geração. A escolha dos indivíduos é feita com probabilidade linear entre $b / P$ para o melhor membro e $(2-b) / P$, na qual $P$ é o tamanho da população e $b$ é um valor de bias pré-estabelecido.

Bezdek et al. (1994) organizam os indivíduos da geração em ordem de aptidão e selecionam os $R$ melhores indivíduos. Deste conjunto, são selecionadas as duplas que irão se reproduzir. Depois da reprodução, os cromossomos filhos são inseridos na população e os indivíduos com os piores resultados são retirados.

Greene (2003) utiliza o método da roleta padrão para selecionar os indivíduos que serão utilizados como pais. Garai and Chaudhuri (2004) selecionam os pais aleatoriamente na população.

\subsubsection{Cruzamento}

O operador de cruzamento ou recombinação deve ser escolhido com cuidado para cada tipo de representação utilizada. Cuidados devem ser tomados para que durante o cruzamento não sejam gerados cromossomos inválidos. Para isso, heurísticas têm sido desenvolvidas para possibilitar operadores mais sensíveis ao contexto (Belew and Booker, 1991; Greene, 2003). A seguir, são feitas algumas considerações sobre tipos de cruzamento para cada uma das representações citadas na Seção 4.2 .

\section{Grupo-Número}

Raghavan and Birchand (1979) utilizam o operador de cruzamento de um ponto padrão (Capítulo 3), o que pode fazer com que o operador gere resultados de 
aptidão inferior. Por exemplo, supondo um conjunto composto pelos padrões $\{\mathrm{A}, \mathrm{B}, \mathrm{C}, \mathrm{D}, \mathrm{E}, \mathrm{F}\}$ cujo agrupamento ótimo seja $\{\mathrm{A}, \mathrm{B}, \mathrm{C}\}$ e $\{\mathrm{D}, \mathrm{E}, \mathrm{F}\}$ para dois grupos. A representação grupo-número para esse agrupamento poderia ser 111000 e 000111. Aplicando o cruzamento, o resultado poderia ser 111111 e 000000 , muito inferior ao anterior.

Problemas como esse motivaram a definição de melhores representações e operadores de cruzamento. Belew and Booker (1991) comparam três operadores de cruzamento para esse tipo de representação: cruzamento de um ponto, uniforme e baseado em margens. Também é aplicado rejeição e reenumeração ao operador de cruzamento. Rejeição consiste em excluir cromossomos considerados inválidos e reenumeração consiste em reenumerar os pais canonicamente antes do cruzamento, permitindo uma maior sensibilidade ao contexto. Assim, essa reenumeração atribui os números dos grupos seguindo ordem em que eles estão dispostos no cromossomo, impedindo a ocorrência de redundância.

No cruzamento uniforme, todos os cromossomos filhos são gerados e apenas um cromossomo válido é selecionado. O cruzamento uniforme é repetidamente aplicado até que o cromossomo filho contenha todos os grupos ou um número máximo de iterações seja alcançado.

O cruzamento baseado em margens constrói os cromossomos filhos por meio da combinação das margens dos cromossomos pais. Dois padrões estão conectados pela mesma margem se estiverem no mesmo grupo em ambos os pais. Por exemplo, considere os agrupamentos e suas respectivas representações ilustradas na Figura 4.7:

\begin{tabular}{|c|c|c|c|c|c|c|}
\hline Agrupamentos & & pre & ese & nta & çõ & \\
\hline$\{\{\mathrm{A}\},\{\mathrm{C}, \mathrm{D}, \mathrm{E}\},\{\mathrm{B}, \mathrm{F}\}\} \longrightarrow$ & 1 & 3 & 2 & 2 & 2 & 3 \\
\hline & & & & & & $\mathrm{F}$ \\
\hline$\{\{\mathrm{C}\},\{\mathrm{B}, \mathrm{D}, \mathrm{F}\},\{\mathrm{A}, \mathrm{E}\}\} \longrightarrow$ & 3 & 2 & 1 & 2 & 3 & 2 \\
\hline
\end{tabular}

Figura 4.7: Agrupamentos e suas representações Grupo-Número.

Os cromossomos filhos são inicializados com os conjuntos de intersecções não vazias desses grupos até que o número correto de grupos seja gerado. As intersecções e um possível filho para os agrupamentos da Figura 4.7 podem ser visualizados na Figura 4.8, na qual o cromossomo filho recebe $\{C, D\}$ do cromossomo pai $1,\{A, E\}$ do cromossomo pai 2 e $\{B, F\}$ de ambos cromossomos pais. 


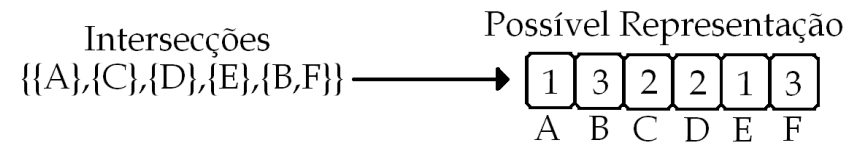

Figura 4.8: Intersecções não vazias e um padrão de cromossomo filho.

\section{Matriz Binária}

Bezdek et al. (1994) efetuam uma troca de colunas, movendo o padrão de grupo. A coluna e o número de colunas são selecionados aleatoriamente.

\section{Permutação com separadores e gulosa}

As técnicas mais comuns de cruzamento para permutação com separadores cruzam repetidamente os cromossomos pais até que os filhos contenham todos os $k$ agrupamentos, ou seja, sejam válidos (Belew and Booker, 1991). Um tipo de cruzamento para a permutação gulosa consiste em cruzar os padrões que representam os centróides entre os cromossomos.

\section{Utilizando Centróides}

Para esse tipo de representação podem ser aplicados os tipos comuns de cruzamento, como o simples (um ponto) ou o duplo (dois pontos). Kivijärvi et al. (2003) utilizaram um conjunto com seis métodos distintos de cruzamento, descritos a seguir:

1. Cruzamento aleatório de vários pontos: metade dos grupos são selecionados aleatoriamente de cada pai para formar o cromossomo filho.

2. Cruzamento baseado na distância do centróide: os grupos mais próximos do centróide do conjunto de padrões são retirados de um cromossomo pai, e os mais afastados são retirados do outro pai.

3. Cruzamento com as maiores partições: os centróides dos grupos com maior número de padrões são selecionados.

4. Cruzamento de pares de vários pontos: os grupos dos pais são comparados de entre si de maneira que cada grupo de um cromossomo pai tenha o seu reespectivo no outro. Em seguida, um deles é selecionado e copiado no filho.

5. Cruzamento de pares de um ponto:Como cruzamento de pares em vários pontos, porém a primeira metade de grupos é retirada de um pai e a outra metade do outro. 
6. Cruzamento de pares com o vizinho mais próximo: os pais são combinados em uma unica solução e os grupos mais próximos são unidos 2 à 2 .

O cruzamento com as maiores partições, o de pares de um ponto e o de pares com o vizinho mais próximo, são determinísticos. Assim, a solução será sempre a mesma para uma determinada dupla $c_{a}$ e $c_{b}$ de cromossomos pais. O método a ser usado é escolhido durante a execução do AG.

\section{Número variável de grupos}

Hruschka et al. (2004) utiliza uma troca de grupos para esse tipo de representação. Primeiro, são selecionados $c$ grupos do cromossomo pai 1 e os padrões contidos nesses grupos são copiados para o cromossomo pai 2. Os padrões que restaram dos grupos de 2 alterados pelo cruzamento são inseridos nos grupos mais próximos. O processo é repetido invertendo-se a ordem dos cromossomos pais para gerar um segundo filho. Um exemplo é ilustrado na Figura 4.9, onde os grupos 2 e 3 foram selecionados do cromossomo 1 e copiados para o cromossomo 2. Os genes que foram afetados pela mudança ganham valor 0 no filho 1 e são adicionados aos grupos mais próximos posteriormente.

\begin{tabular}{|c|c|c|c|c|c|c|c|c|c|c|c|c|c|c|c|c|c|c|c|}
\hline \multicolumn{20}{|c|}{ Cromossomos Pais } \\
\hline P1- & & 1 & 2 & 3 & 2 & 4 & 5 & 1 & 2 & 5 & 4 & 3 & 2 & 5 & 3 & 3 & 4 & 2 & 4 \\
\hline & & 2 & 1 & 2 & 3 & 3 & 2 & 1 & 2 & 4 & 4 & 2 & 3 & 2 & 2 & 1 & 3 & 2 & 1 \\
\hline $1-$ & & 1 & 2 & 3 & 2 & 4 & 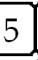 & 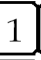 & 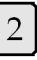 & 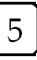 & 1 & 3 & 2 & 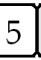 & & 3 & 4 & 2 & 4 \\
\hline & & 2 & 2 & 3 & 2 & 3 & 2 & 1 & 2 & 4 & 4 & 3 & 2 & 2 & 3 & 3 & & 2 & 1 \\
\hline \multicolumn{20}{|c|}{ Cromossomo Filho } \\
\hline & & 0 & 2 & & 2 & & & & & 4 & 4 & 3 & & & & & & 2 & \\
\hline
\end{tabular}

Figura 4.9: Cruzamento de cromossomos com número indeterminado de grupos

\section{Representação Hierárquica}

Operadores de cruzamento foram propostas também para representações hierárquicas. Por exemplo, Greene (2003) utiliza um cruzamento guloso direcionado pela aptidão dos grupos que formam o cromossomo. Seja $k_{0}$ o número de grupos do primeiro cromossomo, $k_{1}$ o número de grupos do segundo cromossomo e $\bar{k}$ a média entre $k_{0}$ e $k_{1}$. São selecionados os $\bar{k}$ grupos que apresentem a aptidão mais alta entre os dois cromossomos. Esses são os grupos que formarão os cromossomos filhos. Por serem conjuntos matemáticos, os grupos selecionados podem conter o 
mesmo padrão duas vezes ou não conter alguns padrões, o que os torna cromossomos inválidos. Um pós-processamento evita cromossomos inválidos sorteando o padrão comum entre os grupos ou incluindo o padrão que falta do grupo mais próximo.

Tseng and Yang (2001) utilizam cruzamento em dois pontos, que consite em selecionar um par de cromossomos e gerar dois números aleatórios $p$ e $q$ no intervalo $[1, m]$, onde $m$ é o tamanho dos cromossomos. Os trechos entre esses pontos são trocados entre os cromossomos. Garai and Chaudhuri (2004) propuseram o algoritmo HCMA para combinar e formar novos grupos durante as gerações. Esse algoritmo seleciona dois indivíduos da população e efetua cruzamento de um ponto entre eles, gerando dois cromossomos filhos.

\section{Redes SOM}

A maioria das implementações utilizando redes SOM efetua cruzamento de um ou dois pontos. Tanaka et al. (1996) selecionam dois cromossomos pais e trocam os valores contidos nos genes alelos, ou seja, genes que correspondam ao mesmo padrão. Esse operador é aplicado com probabilidade $p_{c}$ para cada dupla de genes alelos.

\subsubsection{Mutação}

O operador de mutação é responsável pelo aumento da diversidade da população. Quando AGs são utilizados para otimizar algoritmos de agrupamento, o operador de mutação geralmente tem o efeito de mover um padrão de um grupo para outro. A seguir, são descritos alguns dos operadores e mutação que podem ser utilizados para cada tipo de representação citada (Seção 4.2).

\section{Grupo-Número}

Para esse tipo de representação, a mutação altera o valor do grupo no cromossomo. Belew and Booker (1991) alteram cada gene do cromossomo com probabilidade $P_{m u t}=\frac{1}{n}$, no qual $n$ é o número de padrões contidos no grupo. Isso é feito apenas se o padrão não for o único padrão de um determinado grupo, pois não haveria o grupo caso a alteração fosse efetuada.

\section{Matriz Binária}

Nesse tipo de representação, basta trocar um padrão para um grupo novo, ou seja, a posição do bit 1 é modificada na coluna. É necessária uma verificação para evitar grupos vazios após a mutação. 


\section{Permutação com separadores e gulosa}

Para permutação, Belew and Booker (1991) selecionam dois padrões aleatoriamente, extraem esses padrões do cromossomo e depois troca a posição deles. É necessário verificar os separadores nos cromossomos, para permutação com separador, evitando a geração de cromossomos inválidos.

\section{Utilizando Centróides}

Uma das formas mais simples de executar mutação nessa representação consiste em alterar os valores dos centróides para novos valores aleatórios (Hall et al. 1999; Maulik and Bandyopadhyay, 2000). Outra forma é a substituição de um centróide por um padrão selecionado aleatoriamente da base de dados (Kivijärvi et al. 2003). Porém, essas alternativas podem sobrepor o centróide de outro grupo, fazendo com que, dependendo do algoritmo utilizado, uma verificação seja necessária.

\section{Número variável de grupos}

Hruschka et al. (2004) utiliza dois operadores de mutação distintos: elimina aleatoriamente um grupo colocando seus padrões nos grupos mais próximos; e divide um grupo selecionado aleatoriamente em dois novos grupos, um com os padrões mais próximos do centróide original e outro tendo como centróide o padrão mais afastado do centróide original.

\section{Representação Hierárquica}

A mutação proposta por Greene (2003) retira um grupo do agrupamento e adicionao posteriormente. Isso pode alterar a estrutura dos grupos anteriores, pois o grupo retirado pode fazer parte de um grupo maior. Segundo o autor, o método utilizado é estocástico e gradual, o que possibilita uma maior sensibilidade ao contexto. Estocástico porque existe uma probabilidade de que ela ocorra e gradual porque essa probabilidade é reduzida a medida que a aptidão do cromossomo aumenta.

Tseng and Yang (2001) utilizam mutação bit-a-bit, aplicada a cada bit do cromossomo. Garai and Chaudhuri (2004) também utilizam mutação bit-a-bit, com probabilidade $\eta=\eta_{0} * t$, sendo $\eta_{0}$ a probabilidade de mutação inicial e $t$ o número de gerações até o momento.

\section{Redes SOM}

A mutação dos parâmetros da rede SOM é geralmente feita alterando o valor dos dados contidos nos genes. Isso pode ser feito bit-a-bit ou gerando um novo valor válido para o parâmetro a ser alterado. 


\subsection{Trabalhos Relacionados}

Existem várias formas de representar soluções e cada uma delas pode apresentar diferentes características. Uma grande variedade de funções de aptidão e operadores genéticos continuam a ser propostos, com propósitos que vão desde aumentar o desempenho do próprio AG até obter um melhor resultado para uma aplicação específica.

Nessa seção são apresentadas várias implementações que combinam algoritmos de agrupamento com AGs. Essas implementações foram divididas de acordo com três tipos de algoritmos de agrupamento utilizados com os AGs: particionais (incluindo $k$-médias), redes neurais (em especial redes $\mathrm{SOM}$ ) e algoritmos de agrupamento hierárquico, descritos na Seção 2.4. Cada um desses algoritmos utiliza métodos de agrupamento diferentes e por isso apresentam características distintas que podem ser aprimoradas pelos AGs. As principais características dessas diferentes implementações estão descritas na Tabela 4.1 e são apresentadas em maiores detalhes nas seções 4.5.1 4.5.2 e 4.5.3. 


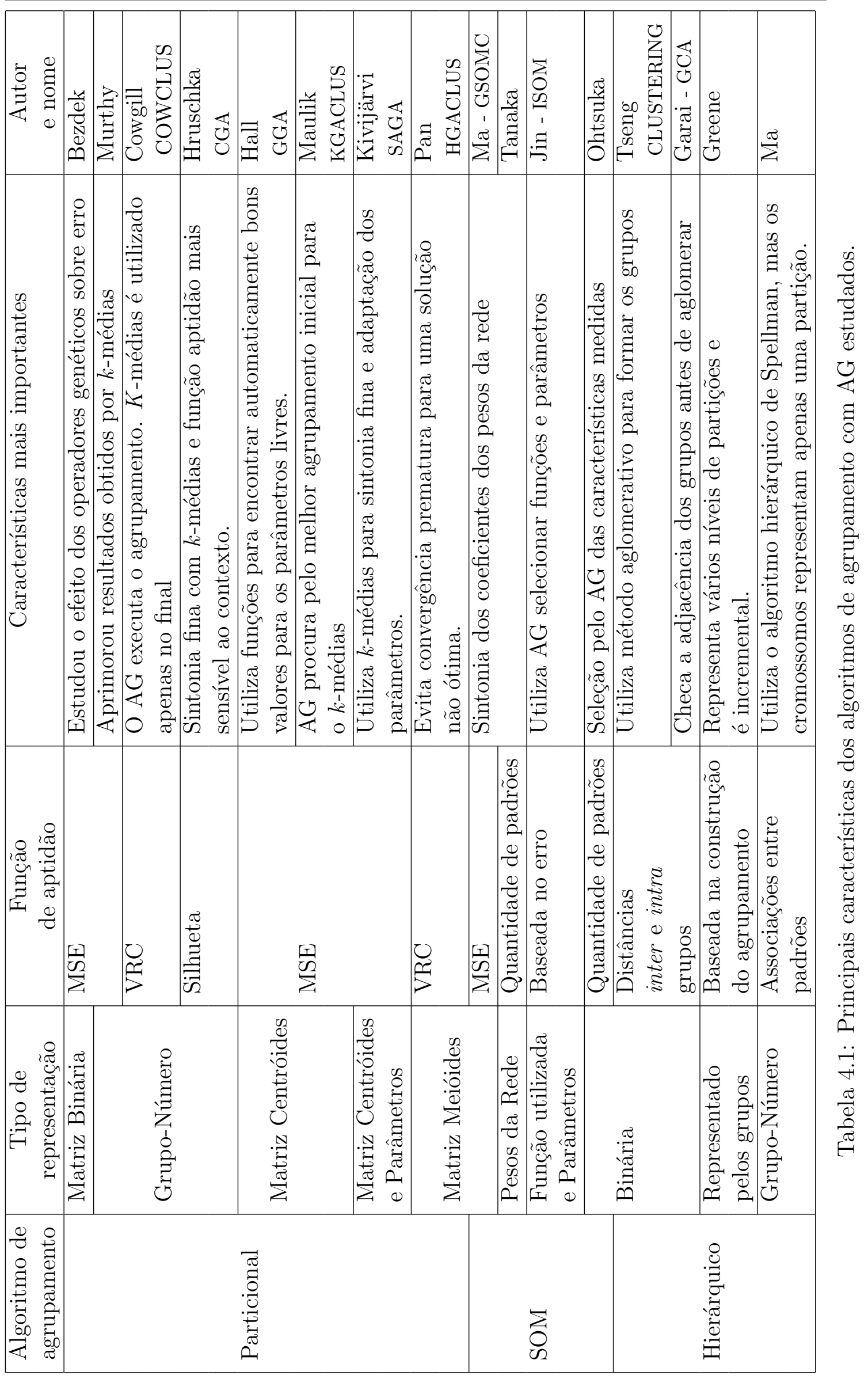




\subsubsection{Técnicas particionais em conjunto com AGs}

Conforme apresentado na Seção 2.4, as técnicas particionais dividem o conjunto de dados em $k$ grupos com base em uma medida de similaridade. As características desses algoritmos mais sensíveis ao aprimoramento feito pelos AGs são a escolha dos grupos iniciais, o método utilizado para atualizar os centróides a cada geração e o balanceamento de padrões entre os grupos.

Várias implementações utilizando AGs baseados em algoritmos particionais têm sido propostas, um dos primeiros trabalhos foi publicado por Bezdek et al. (1994). Os autores utilizaram a representação do tipo matriz (Seção 4.2). Com o objetivo de aprimorar a escolha inicial dos grupos, eles utilizaram dois tipos de inicialização:

- No primeiro, os padrões são divididos na mesma proporção entre os grupos.

- No segundo, os valores dos centróides são copiados aleatoriamente de um padrão da base de dados. Isso é feito para todos os atributos de cada centróide. Em seguida, os padrões são adicionados no grupo de centróide mais próximo.

Cada um dos agrupamentos representados pelos indivíduos é avaliado pela Equação 4.5

$$
J=0.5 \times \sum_{i=1}^{k} n_{i} s_{i},
$$

em que $k$ é o número de grupos, $n_{i}$ é o número de elementos do grupo $G_{i}$ e

$$
s_{i}=\frac{1}{n_{i}^{2}} \times \sum_{y=1}^{n_{i}} \sum_{j=1}^{n_{i}}\left\|x_{y}-x_{j}\right\|^{2}
$$

com $x_{y}$ e $x_{j}$ sendo posições de elementos contidos no grupo $G_{i}$.

Para o agrupamento e comparação dos resultados, Bezdek et al. (1994) utilizaram um banco de dados com 150 padrões de Íris, divididos em 3 classes de mesmo tamanho. Os resultados obtidos foram comparados com o algoritmo $k$ médias utilizando três medidas de distância diferentes: euclidiana, mahalanobis e diagonal (Bezdek et al., 1994). Como o número de grupos foi fixo, o critério utilizado para comparação verificava a quantidade de padrões agrupados corretamente. Na maioria dos experimentos, a técnica baseada em AG apresentou um MSE menor.

Bezdek et al. (1994) também estudaram o efeito dos operadores de cruzamento e mutação em seu algoritmo. Eles mantiveram a mesma população inicial e 
utilizaram diferentes valores para os parâmetros desses operadores. Além disso, a freqüência de mutação foi variada. Não houve efeito positivo relevante na taxa de erro e pouco efeito no aumento da aptidão. Isso levou os autores a concluir que o erro obtido pelo método utilizado é mais sensível à população inicial do que aos parâmetros dos operadores utilizados. As principais características do algoritmo podem ser vistas na Tabela 4.2 .

\begin{tabular}{|l|l|}
\hline Algoritmo de Agrupamento & Particional Exclusivo. \\
\hline Tipo de Representação & $\begin{array}{l}\text { Matriz binária representando um padrão no } \\
\text { grupo. }\end{array}$ \\
\hline População Inicial & Aleatória e parcialmente aleatória. \\
\hline Função de Aptidão & Baseada na densidade dos grupos. \\
\hline Seleção & Seleção por torneio. \\
\hline Cruzamento & $\begin{array}{l}\text { Troca de colunas (troca o padrão de grupo), } \\
\text { com a coluna e o número de colunas } \\
\text { selecionados aleatoriamente. }\end{array}$ \\
\hline Mutação & $\begin{array}{l}\text { Há a troca de um padrão para um grupo novo, } \\
\text { ou seja, a posição do bit 1 é trocada na coluna. }\end{array}$ \\
\hline Elistismo & $\begin{array}{l}\text { Os melhores indivíduos são adicionados na nova } \\
\text { população, juntamente os indivíduos resultantes } \\
\text { do cruzamento, para complementar o número } \\
\text { de indivíduos faltantes. }\end{array}$ \\
\hline Comparação dos Resultados & Avaliação da técnica foi feita contra $k$-médias. \\
\hline Detalhes & $\begin{array}{l}\text { Estudou o efeito dos operadores genéticos sobre } \\
\text { o erro. }\end{array}$ \\
\hline
\end{tabular}

Tabela 4.2: Principais características do AG utilizado por Bezdek et al.

Uma das características mais importantes dos AGs é a sua capacidade de evitar ficar preso em ótimos locais. Tendo em vista essa característica, Murthy and Chowdhury (1996) implementaram uma versão simples de AG particional. Essa implementação difere da implementação de Bezdek et al. (1994) no tipo de representação utilizado, sendo que os autores optaram pela representação GrupoNúmero (Seção 4.2).

Para avaliar o algoritmo, os autores construíram três bases de dados artificiais e utilizaram também uma base de óleo não refinado utilizada por Johnson and Wichern (1982). O principal resultado obtido ao avaliar as bases foi verificar que o AG conseguiu encontrar agrupamentos semelhantes a estrutura real em todos os experimentos executados, pesquisando um número muito menor de agrupamentos do que os possíveis. Os autores também conseguiram, com o uso de AG, aprimorar alguns resultados obtidos por $k$-médias. As principais características desse algoritmo podem ser vistas na Tabela 4.3 . 


\begin{tabular}{|l|l|}
\hline Algoritmo de Agrupamento & Particional. \\
\hline Tipo de Representação & Grupo-Número. \\
\hline População Inicial & Aleatória. \\
\hline Função de Aptidão & $\begin{array}{l}\text { Soma dos quadrados da distância Euclidiana } \\
\text { entre os membros do grupo. }\end{array}$ \\
\hline Seleção & Roleta. \\
\hline Cruzamento & Cruzamento simples. \\
\hline Mutação & $\begin{array}{l}\text { Há a troca de um padrão para um grupo } \\
\text { novo. }\end{array}$ \\
\hline Elistismo & $\begin{array}{l}\text { O melhor indivíduo é adicionados a nova } \\
\text { população somente se sua aptidão for maior que } \\
\text { a menor aptidão dos indivíduos da população. }\end{array}$ \\
\hline Comparação dos Resultados & Avaliação da técnica foi feita contra $k$-médias. \\
\hline Detalhes & Aprimorou resultados obtidos por $k$-médias. \\
\hline
\end{tabular}

Tabela 4.3: Principais características do AG utilizado por Murthy.

Assim como a maioria das técnicas utilizadas nos primeiros experimentos de agrupamento com AGs, as técnicas utilizadas por Bezdek et al. (1994) e Murthy and Chowdhury (1996) tendem a procurar soluções ótimas tendo em vista apenas a distância dos padrões aos centróides de seus grupos. Já Cowgill et al. (1998) tinham como objetivo encontrar a melhor separação e coesão dos grupos possíveis, por meio do isolamento externo do grupo e sua homogeneidade interna. Eles utilizaram AG para minimizar o VRC dos agrupamentos, descrito na Equação 2.29 .

Cowgill et al. (1998) também apresentam as vantagens do seu algoritmo, o COWCLUS, em relação ao método de Ward (1963). Um dos diferenciais do trabalho, segundo os autores, consiste no fato de que nenhum algoritmo de agrupamento determinístico (hill-climbing) é utilizado durante a execução do AG. Essa característica foi importante na redução do custo computacional do algoritmo. O algoritmo $k$-médias é utilizado apenas para melhorar os indivíduos mais aptos da última geração, se esses forem passíveis de melhora. Os autores chamam essa estratégia de "local improvement".

O trabalho foi comparado com o Método de Ward (1963) e duas versões do algoritmo $k$-médias: a primeira com os centróides iniciais escolhidos pelo algoritmo de Ward (1963) ( $k$-médias - W) e a segunda com os centróides iniciados aleatoriamente ( $k$-médias - R). A maioria dos métodos obteve bom desempenho na classificação das bases de dados estudadas, exceto o $k$-médias (R). Quando a medida de validação utilizada foi o VRC, COWCLUS obteve 97,53\% dos melhores resultados, o que é esperado uma vez que o algoritmo busca por soluções com 
índices altos para essa medida.

As principais características do algoritmo COWCLUS podem ser visualizadas na Tabela 4.4.

\begin{tabular}{|l|l|}
\hline Algoritmo de Agrupamento & Particional exclusivo baseado em VRC. \\
\hline Tipo de Representação & Grupo-Número. \\
\hline População Inicial & Aleatória. \\
\hline Função de Aptidão & Variance Ratio Criterion (VRC). \\
\hline Seleção & Seleção com probabilidade $p_{r}=\frac{(b+1-r)}{b(b+1) / 2}$. \\
\hline Cruzamento & Cruzamento simples. \\
\hline Mutação & $\begin{array}{l}\text { Substituição por um número aleatório de } \\
\text { um agrupamento válido. }\end{array}$ \\
\hline Elistismo & $\begin{array}{l}\text { O melhor indivíduo é adicionados a nova } \\
\text { população. }\end{array}$ \\
\hline Comparação dos Resultados & $\begin{array}{l}\text { Trabalho foi comparado com o Método de } \\
\text { Ward, } k \text {-médias (W), } k \text {-médias(R). }\end{array}$ \\
\hline Detalhes & $\begin{array}{l}\text { Uma variação utiliza } k \text {-médias para } \\
\text { aprimorar os melhores indivíduos da } \\
\text { última geração. }\end{array}$ \\
\hline
\end{tabular}

Tabela 4.4: Principais características do Algoritmo COWCLUS.

Apesar das experiências bem sucedidas em agrupamento de dados, a utilização de AGs nessas tarefas ainda apresenta algumas dificuldades. A ação dos operadores genéticos aplicados durante a execução do AG pode gerar particições degeneradas, ou seja, partições que contenham grupos vazios. Além disso, utilizar AGs como técnicas de agrupamento demanda a escolha de bons valores para os vários parâmetros livres, como taxas de cruzamento, mutação, critério de parada, tamanho da população e o número indivíduos a serem selecionados.

Na tentativa de solucionar esses problemas, Hall et al. (1999) dão continuidade ao trabalho feito por Bezdek et al. (1994), utilizando AGs como algoritmos particionais exclusivos e não exclusivos. Assim como no trabalho de Bezdek et al. (1994), a população do AG é composta por indivíduos representados por matrizes, porém contendo apenas os centróides de cada grupo. A função objetivo a ser minimizada também é semelhante à utilizada por Bezdek et al. (1994). Para $k$-médias exclusivo, o valor da função objetivo é dado pela Equação 4.7.

$$
R(V)=\sum_{i=1}^{n} \min \left\{D_{1 i}, D_{2 i}, \ldots, D_{k i}\right\}
$$

em que $D_{G i}\left(c_{G}, i\right)$ é a medida da distância Euclidiana do padrão $i$ para o centróide $c_{G}$, pertencente ao grupo $G$, e $n$ é o número de padrões a serem agrupados. 
Para evitar partições degeneradas, os autores utilizam o termo de penalização dado pela Equação 4.3 , descrito na Seção 4.3 .

Como para $k$-médias não exclusivo, a função de aptidão é dado pela Equação 4.8 .

$$
R_{m}(V)=\sum_{i=1}^{n}\left(\sum_{G=1}^{k} D_{G i}^{1 /(1-m)}\right)^{1-m}
$$

para $k$ agrupamentos. O termo $m$ é o grau de pertinência do padrão $i$ ao agrupamento $G$ e $D_{G} i\left(c_{G}, i\right)$ é a medida da distância do padrão $i$ para o centróide $c_{G}$, que pode ser Euclidiana ou Diagonal (Bezdek et al., 1994).

Antes de passarem pelo processo de seleção por torneio, os indivíduos são transformados em seqüências binárias no código cinza, em que dois números consecutivos diferem em apenas um bit. Os autores afirmam que utilizar essas seqüências aumenta a convergência e o desempenho do AG, em alguns casos.

Logo após a seleção, os operadores de cruzamento e mutação são aplicados com probabilidade $p_{c}$ e $p_{m}$ respectivamente, sendo o cruzamento feito em dois pontos e a mutação feita bit-a-bit, invertendo o valor do bit.

Os autores utilizam algumas heurísticas para tentar encontrar bons valores para os parâmetros livres. Um número alto de indivíduos selecionados para torneio pode levar a uma convergência rápida para um mínimo local. Por isso, o número de indivíduos selecionados pelo AG é inicialmente baixo (2 indivíduos). Porém, nas últimas 50 gerações, essa quantidade é aumentada (10 indivíduos). As probabilidades de cruzamento e de mutação variam de acordo com a aptidão de cada indivíduo. Tomando $f_{\max }$ como a maior aptidão da população, $\bar{f}$ a aptidão média entre os indivíduos da população, $f$ a aptidão do cromossomo filho prestes a sofrer mutação e $f^{\prime}$ a maior aptidão entre os dois cromossomos prestes a sofrer cruzamento, as probabilidades de cruzamento e mutação são dadas pelas Equações 4.9, 4.10, 4.11, e 4.12.

$$
\begin{gathered}
p_{c}=c_{1}\left(f_{\max }-f^{\prime}\right) /\left(f_{\max }-\bar{f}\right), f^{\prime} \geq \bar{f}, \\
p_{c}=c_{3}, f^{\prime}<\bar{f} \\
p_{m}=c_{2}\left(f_{\max }-f\right) /\left(f_{\max }-\bar{f}\right), f \geq \bar{f}, \\
p_{m}=c_{4}, f<\bar{f}
\end{gathered}
$$

com $c_{1}, c_{2}, c_{3}$ e $c_{4}$ constantes e $\leq 1.0$.

Para testar o algoritmo, Hall et al. (1999) realizaram experimentos com seis 
bases de dados distintas, dentre elas: a base Íris utilizada por Bezdek et al. (1994); algumas bases artificiais; imagens de ressonância magnética e uma base com a imagem Lenna. Os autores afirmam que as partições resultantes dos agrupamentos guiados por AGs são idênticos aos obtidos por $k$-médias exclusivo e não exclusivo quando recebem a melhor inicialização possível. Durante o experimento, os autores utilizaram $k$-médias exclusivo sobre as partições obtidas pelo algoritmo guiado por AG antes de convergir e os resultados obtidos foram bons, inclusive para AGs com populações pequenas.

Os resultados obtidos com AG com parâmetros adaptativos não mostraram um aumento significativo na aptidão dos indivíduos e o tempo de execução foi 2,5 vezes maior. A utilização de valores reais nos cromossomos mostrou uma redução de tempo de execução de cada geração em relação à utilização de valores binários. Porém, o número de gerações necessárias para a convergência da população foi maior, o que fez com que o algoritmo não apresentasse uma economia significativa de tempo. A tabela 4.5 apresenta as principais características do algoritmo GAG utilizado por Hall et al. (1999).

\begin{tabular}{|c|c|}
\hline Algoritmo de Agrupamento & Particionais exclusivos e não exclusivo. \\
\hline Tipo de Representação & Matriz contendo os centróides dos agrupamentos. \\
\hline População Inicial & Os valores iniciais são escolhidos aleatoriamente. \\
\hline Função de Aptidão & $\begin{array}{l}\text { Média das somas das distâncias Euclidiana e } \\
\text { Diagonal. }\end{array}$ \\
\hline Seleção & Torneio. \\
\hline Cruzamento & Duplo. \\
\hline Mutação & bit-a-bit. \\
\hline Elistismo & $\begin{array}{l}\text { Os dois membros mais aptos vão para a próxima } \\
\text { geração. }\end{array}$ \\
\hline Comparação dos Resultados & k-médias exclusivo e não exclusivo. \\
\hline Detalhes & $\begin{array}{l}\text { Utilizou funções para encontrar automaticamente } \\
\text { bons valores para os parâmetros livres. }\end{array}$ \\
\hline
\end{tabular}

Tabela 4.5: Principais características do Algoritmo GAG.

Vários trabalhos semelhantes aos anteriores foram realizados, dentre eles os algoritmos GKMCA (Wu et al., 2003) e KGACLUS (Maulik and Bandyopadhyay, 2000). Algumas diferenças em relação aos operadores de cruzamento e seleção foram feitas, porém características como a utilização de matriz de centróides, utilização de distância Euclidiana como medida de dissimilaridade, operadores de cruzamento e mutação continuam semelhantes aos dos experimentos publicados anteriormente.

O algoritmo KGACLUS é utilizado como critério de comparação por alguns 
trabalhos, dentre eles Pan et al. (2003). Ele foi utilizado para agrupar 7 bases de dados, sendo que 4 são formados de dados artificiais, divididos de 2 a 9 grupos, e três formados de dados reais contendo dados de Vowel, Íris e óleo não-refinado (Johnson and Wichern, 1982). É importante ressaltar que, segundo os autores, os resultados obtidos pelo algoritmo KGACLUS foram semelhantes aos resultados obtidos por $k$-médias com a melhor inicialização. Os detalhes do algoritmo utilizado podem ser vistos na Tabela 4.6.

\begin{tabular}{|l|l|}
\hline Algoritmo de Agrupamento & Particional exclusivo \\
\hline Tipo de Representação & Matriz contendo os centróides dos agrupamentos. \\
\hline População Inicial & $\begin{array}{l}\text { Os valores iniciais são retirados de uma padrão } \\
\text { da base de dados aleatoriament. }\end{array}$ \\
\hline Função de Aptidão & Média da Soma da Distância Euclidiana. \\
\hline Seleção & Roleta. \\
\hline Cruzamento & Simples. \\
\hline Mutação & Altera o valor do cromossomo. \\
\hline Elistismo & $\begin{array}{l}\text { Os dois membros mais aptos vão para a } \\
\text { próxima geração. }\end{array}$ \\
\hline Comparação dos Resultados & Com $k$-médias exclusivo. \\
\hline Detalhes & \\
\hline
\end{tabular}

Tabela 4.6: Principais características do Algoritmo KGACLUS.

Pan et al. (2003) afirmam que um dos problemas dos algoritmos de agrupamento que utilizam AG é a convergência prematura para uma solução não ótima. Por isso, desenvolveram o algoritmo HGACLUS (Hybrid GA based Clustering), que utiliza um método de esfriamento durante a fase de seleção. Esse método evita que poucos indivíduos das populações iniciais dominem rapidamente a população. Ele é alterado conforme a execução do algoritmo, permitindo uma maior diferenciação dos indivíduos nas últimas gerações, quando as aptidões ficam muito próximas. Esse método é calculado utilizando a Equação 4.14 e é utilizado durante a seleção de indivíduos, quando a aptidão é calculada pela Equação 4.13 .

$$
p\left(c_{i}\right)=\frac{\exp \left(f\left(c_{i}\right) / T(g)\right)}{\sum_{h=1}^{p} \exp \left(f\left(c_{h}\right) / T(g)\right)},
$$

em que $f\left(c_{i}\right)$ é o cálculo da VRC, dada pela Equação 2.29, para o cromossomo $c_{i}, p$ é o tamanho da população e

$$
T(g)=\frac{G-g}{G} T_{0}, g=0,1, \ldots, G-1,
$$

em que $\mathrm{G}$ é o total de gerações, g é o número da geração atual e $T_{0}$ é o valor 
da temperatura $T$ inicial.

Assim como o algoritmo COWCLUS (Cowgill et al., 1998), HGACLUS utiliza função de aptidão baseada em VRC (Equação 2.29). Porém, a representação utilizada é a matriz de centróides dos grupos, como no algoritmo KGACLUS (Maulik and Bandyopadhyay, 2000).

Os resultados dos experimentos obtidos foram comparados com $k$-médias, PAM, KGACLUS e COWCLUS. Os valores obtidos pelas medidas VRC e silhueta (Equação 2.24) foram utilizados como critério de avaliação. Apesar dos algoritmos COWCLUS e KGACLUS terem obtido bons resultados em relação à $k$ médias e PAM, esses convergiram prematuramente em comparação ao algoritmo HGACLUS, que obteve valores de VRC maiores. A principais características desse algoritmo podem ser vistas na Tabela 4.7.

\begin{tabular}{|l|l|}
\hline Algoritmo de Agrupamento & Particional baseado em VRC. \\
\hline Tipo de Representação & Matriz contendo os meióides dos agrupamentos. \\
\hline População Inicial & $\begin{array}{l}\text { Os valores iniciais são retirados de uma padrão } \\
\text { da base de dados aleatoriament. }\end{array}$ \\
\hline Função de Aptidão & Variance Ratio Criterion (VRC). \\
\hline Seleção & Stocastic Universal Sampling. \\
\hline Cruzamento & $\begin{array}{l}\text { Cruzamento uniforme (cada gene é escolhido } \\
\text { aleatoriamente de um dos pais). }\end{array}$ \\
\hline Mutação & $\begin{array}{l}\text { Substituição por um número aleatório de um } \\
\text { agrupamento válido. }\end{array}$ \\
\hline Elistismo & O membro com maior aptidão é transferido. \\
\hline Comparação dos Resultados & Com $k$-médias, PAM, KGACLUS, COWCLUS. \\
\hline Detalhes & $\begin{array}{l}\text { Os critérios de validação VRC e silhueta são } \\
\text { utilizados. }\end{array}$ \\
\hline
\end{tabular}

Tabela 4.7: Principais características do Algoritmo HGACLUS.

Kivijärvi et al. (2003) aplicaram $k$-médias para executar sintonia fina no algoritmo que eles desenvolveram, o algoritmo SAGA. A sintonia fina é executada para cada indivíduo antes dele ser adicionado a uma população, diferentemente do algoritmo COWCLUS (Cowgill et al., 1998), em que $k$-médias é executado apenas nos indivíduos da última geração. Isso fez com que o algoritmo convergisse em menos gerações, mas resultou em um aumento no seu custo computacional.

Além disso, os valores dos parâmetros livres do algoritmo variam durante a execução do SAGA, permitindo a utilização de valores mais apropriados. A representação utilizada é composta pelo conjunto de centróides adicionados dos valores de parâmetros do AG. A aptidão dos indivíduos é proporcional ao MSE do agrupamento que ele representa, dada pela Equação 4.1, e a seleção é feita pelo 
método da roleta. Kivijärvi et al. (2003) utilizaram seis operadores distintos de cruzamento, descritos na Seção 4.4.3. O operador a ser utilizado é representado por um parâmetro no cromossomo.

Para que não haja perda de variação genética, são aplicados operadores como mutação e ruído. O operador de mutação substitui cada um dos centróides do cromossomo com probabilidade $p_{m}$ por um padrão selecionado aleatoriamente da base de dados. O operador de ruído adiciona um vetor com valores aleatórios entre $[-v, v]$ a cada centróide, para um valor de variação $v$ reduzido em tempo de execução. Depois da aplicação dos operadores genéticos, $k$-médias é utilizado para fazer a sintonia fina das novas soluções.

Parâmetros livres, como o operador de cruzamento $\gamma$, a probabilidade de mutação $p_{m}$ e a variação de ruído $v$, devem ser estimados para cada conjunto de dados, para permitir um melhor desempenho do algoritmo. A adaptação dos valores desses parâmetros é feita durante a execução do próprio AG, uma vez que os parâmetros citados se encontram no final do cromossomo. Esses parâmetros são obtidos dos cromossomos pais durante a construção de um novo cromossomo e são utilizados para a aplicação dos operadores genéticos no restante do cromossomo, ou seja, no vetor de centróides.

Alguns testes foram realizados com o algoritmo SAGA e os resultados foram comparados com os algoritmos $k$-médias, splitting method with local repartitioning (Fränti et al., 1997a), método de Ward (Ward, 1963), Stochastic Relaxation (Zeger and Gersho, 1989), busca local aleatória (Fränti and Kivijärvi, 2000) e um AG (Fränti et al., 1997b). A função objetivo utilizada foi o MSE das partições criadas por cada algoritmo. As bases utilizadas eram compostas de dados de imagens, na maioria dos casos, formando até 256 agrupamentos (um para cada cor utilizada). O MSE do algoritmo SAGA foi menor do que dos algoritmos comparados. Como houve uma diferença pequena entre os resultados dos algoritmos SAGA e AG, a adaptação dos parâmetros livres contribuiu muito pouco para a redução do MSE. A utilização de $k$-médias no algoritmo SAGA causou uma redução do número de gerações. As principais características desse algoritmo podem ser visualizadas na Tabela 4.8 .

Hruschka et al. (2004) propuseram algumas melhorias nos AGs para problemas de agrupamento. No algoritmo proposto, o número de grupos não é fixo, ou seja varia durante a execução. A representação utilizada é a Grupo-Número, com o número de grupos no final do cromossomo, o que faz com que não seja necessário percorrer o cromossomo em busca desta informação. A população inicial é gerada de forma que o número de grupos seja selecionado aleatoriamente 


\begin{tabular}{|l|l|}
\hline Algoritmo de Agrupamento & AG em conjunto com $k$-médias. \\
\hline Tipo de Representação & $\begin{array}{l}\text { Conjunto de centróides adicionados de valores } \\
\text { para os parâmetros livres. }\end{array}$ \\
\hline População Inicial & $\begin{array}{l}k \text { objetos são selecionados da base de dados } \\
\text { aleatoriamente para formar os cromossomos. }\end{array}$ \\
\hline Função de Aptidão & MSE baseada na distância Euclidiana. \\
\hline Seleção & Roleta \\
\hline Cruzamento & Utiliza 6 métodos de Cruzamento distintos. \\
\hline Mutação & $\begin{array}{l}\text { Substitui um centróide por um objeto } \\
\text { selecionado aleatoriamente da base de dados. }\end{array}$ \\
\hline Elistismo & $\begin{array}{l}\text { O membro com maior aptidão é transferido de } \\
\text { geração. }\end{array}$ \\
\hline Comparação dos Resultados & $\begin{array}{l}\text { A comparação com } k \text {-médias, SLR, Ward's, SR, } \\
\text { Randomised local search e AG simples. }\end{array}$ \\
\hline Detalhes & $\begin{array}{l}\text { Utiliza } k \text {-médias para sintonia fina e o parâmetros } \\
\text { livres sofrem adaptação durante a execução. Tem } \\
\text { custo computacional maior. }\end{array}$ \\
\hline
\end{tabular}

Tabela 4.8: Principais características do Algoritmo SAGA.

em um intervalo pré-definido. Em seguida, os objetos da base de dados são adicionados aleatoriamente aos grupos e os seus cromossomos são validados.

A função objetivo utilizada é baseada em silhueta (Rousseeuw, 1987), como descrita na Seção 4.3, e a seleção é feita pelo método da roleta.

Nessa implementação, o cruzamento é feito tendo como base os grupos dos cromossomos pais, como descrito na Seção 4.4.3. e utiliza dois operadores de mutação, descritos na Seção 4.4.4.

O indivíduo com maior aptidão da geração anterior é copiado para a próxima geração. O processo é repetido até que a população convirja. Alguns aprimoramentos foram feitos no algoritmo desde a primeira versão, sendo eles:

1. A utilização do algoritmo $k$-médias, que é aplicado em cada indivíduo no início de cada geração.

2. A aplicação de uma medida de similaridade baseada em centróides, o que faz com que não haja mais a necessidade de armazenar as matrizes de dissimilaridade.

3. A utilização de uma função objetivo mais sensível ao contexto, dada por $s(i)=\frac{b(i)}{a(i)+\varepsilon}$, em que $\varepsilon$ é o termo utilizado para evitar problemas quando $a(i)$ for 0 .

A principais características do algoritmo CGA utilizado por Hruschka et al. (2004) podem ser vistas na Tabela 5.15 . 


\begin{tabular}{|l|l|}
\hline Algoritmo de Agrupamento & Algoritmo que utiliza Silhueta \\
\hline Tipo de Representação & Grupo-Número, com o número de agrupamentos \\
\hline População Inicial & Aleatóriamente \\
\hline Função de Aptidão & Baseado em Silhueta \\
\hline Seleção & Roleta \\
\hline Cruzamento & Feito por troca de agrupamentos entre os pais \\
\hline Mutação & $\begin{array}{l}\text { Utiliza dois operadores: o primeiro elimina } \\
\text { aleatoriamente um agrupamento e o segundo } \\
\text { divide um agrupamento selecionado } \\
\text { aleatoriamente em dois novos agrupamentos }\end{array}$ \\
\hline Elistismo & O membro com maior aptidão é transferido \\
\hline Comparação dos Resultados & $\begin{array}{l}\text { A comparação de resultados foi feita entre as } \\
\text { variações do algoritmo }\end{array}$ \\
\hline Detalhes & $\begin{array}{l}\text { Foram implementados alguns aprimoramentos, } \\
\text { incluindo a utilização do algoritmo } k \text {-médias }\end{array}$ \\
\hline
\end{tabular}

Tabela 4.9: Principais características do Algoritmo CGA

\subsubsection{Redes Neurais em conjunto com AGs}

As redes SOM não detectam automaticamente as bordas dos grupos dos agrupamentos resultantes, o que impossibilita uma representação direta dos grupos nos cromossomos utilizados pelos AGs. Apesar disso, AGs podem ser utilizados para aprimorar outras características importantes dessas redes. Nessa seção são apresentados alguns trabalhos que utilizaram AG para aprimorar a rede SOM e seus detalhes mais importantes.

Tanaka et al. (1996) utilizaram SOM supervisionado, em conjunto com AGs, para tentar extrair informações internas contida em uma base de dados com possíveis pacientes de diabetes. Neste trabalho, AGs são utilizados para a sintonia dos coeficientes dos pesos da rede. Eles modificam o algoritmo SOM canônico de duas maneiras:

1. Informação categórica é adicionada ao vetor de treinamento por meio de um parâmetro fixo $p$. Esse parâmetro é utilizado no aprendizado supervisionado do SOM e seu valor está contido no cromossomo.

2. Elementos do vetor de treinamento também utilizam pesos, que são selecionados pelos AGs. A avaliação do vetor de pesos é feita pela habilidade de classificação do SOM representado pelo cromossomo.

O método utilizado por Tanaka et al. (1996) tem como objetivo fazer discriminações na malha do SOM. Cada indivíduo corresponde a uma rede SOM treinada ciclicamente $T$ vezes na construção de cada população, sendo que o valor de $T$ é 
previamente determinado. Em seguida, cada rede é avaliada pela quantidade de padrões de cada classe que foram recebidas por cada neurônio da rede. Quanto maior a diferença entre a quantidade de padrões de classes distintas, maior a aptidão do indivíduo. A Tabela 4.10 apresenta as principais características do algoritmo.

\begin{tabular}{|l|l|}
\hline Algoritmo de Agrupamento & SOM utilizando distância Euclidiana. \\
\hline Tipo de Representação & $\begin{array}{l}\text { Cada gene representa um peso da rede, } \\
\text { sendo que para cada gene são utilizados 3 bits. }\end{array}$ \\
\hline População Inicial & Aleatória. \\
\hline Função de Aptidão & $\begin{array}{l}\text { Feita pela quantidade de instâncias que cada } \\
\text { neurônio da rede recebeu de cada classe. } \\
\text { Quanto maior a diferença dos padrões } \\
\text { maior é a aptidão. }\end{array}$ \\
\hline Seleção & Torneio. \\
\hline Cruzamento & $\begin{array}{l}\text { São selecionados dois cromossomos pais e depois } \\
\text { os pesos contidos nos genes são trocados entre } \\
\text { si com probabilidade } p \text {, para cada dupla } \\
\text { de genes alelos. }\end{array}$ \\
\hline Mutação & Inverte o valor de cada bit com probabilidade $p_{m}$. \\
\hline Elitismo & O melhor candidato de cada geração é copiado. \\
\hline Comparação dos Resultados & Comparação com MLP Backpropagation. \\
\hline Detalhes & Nenhum \\
\hline
\end{tabular}

Tabela 4.10: Principais características do AG utilizado por Tanaka.

Jin et al. (2003) afirmam que existem três caminhos principais para se otimizar uma rede $\mathrm{SOM}$ :

1. Modificando a estrutura da rede, inserindo ou retirando neurônios da camada de saída.

2. Amenizando o critério de competição, por meio de um novo termo que inibe os neurônios que vencem com muita freqüência ou baseando a competição no produto interno.

3. Aprimorando a regra de aprendizado da rede.

Jin et al. (2003) integram todos esse mecanismos por meio de uma nova regra de aprendizado, formando o integraded SOM (ISOM). Segundo os autores, um ISOM eficiente deve ter uma boa coordenação entre otimização local dos SOMs tradicionais, a otimização global dos coeficientes pelo AG e o valor de uma constante de elasticidade utilizada para atualizar os pesos da rede. O AG deve ser responsável pela seleção dos melhores valores para esses parâmetros. 
Depois da inicialização, um AG é utilizado para evoluir bons esquemas de aprendizado, representados por indivíduos. O algoritmo de treinamento de uma rede neural SOM é obtido pela aplicação do esquema de aprendizado selecionado pelo AG. Em seguida, as redes treinadas são usadas para solucionar um número de pequenos problemas e, por meio do resultado obtido, estimar o valor da aptidão do esquema correspondente. O valor de aptidão de cada indivíduo é dado pela Equação 4.15 .

$$
\text { Aptidao }=3-\text { media }(\text { Qualidade })-\operatorname{varincia}(\text { Qualidade })
$$

sendo que

$$
\text { Qualidade }=\left(\text { resultado }- \text { resultado }{ }^{\prime}\right) / \text { resultado }^{\prime}
$$

em que resultado é o resultado obtido pelo indivíduo e resultado' é o melhor resultado possível ou ótimo global. Como a aplicação utilizada por Jin et al. (2003) foi o problema do caixeiro viajante, resultado é o espaço percorrido pelo caixeiro no caminho representado pelo indivíduo e resultadó é o caminho mais curto. Para aplicar o algoritmo em um problema de busca com o ótimo global desconhecido, basta modificar ou criar uma nova função de aptidão.

Os $Q$ indivíduos distintos com as melhores aptidões são armazenados. O processo de evolução é repetido até que o critério de parada seja satisfeito, nesse caso um número $T$ fixo de iterações seja alcançado. Os esquemas de aprendizado armazenados são analisados em um conjunto de problemas de larga escala. No final, o esquema que obtiver a melhor aptidão nos problemas de validação é retornado como o ISOM evoluído.

Os resultados obtidos são comparados com outras três implementações: o SOM expandido, redes elásticas convexas, e o algoritmo FLEXMAP e conseguiu melhorias na redução do espaço percorrido pelo caixeiro com relação a essas implementações.

As principais características do algoritmo utilizado podem ser vistas na Tabela 4.11 .

AGs não precisam ser necessariamente utilizados para melhorar a topologia das redes SOM ou mesmo encontrar bons valores para os parâmetros livres das redes. Eles também pode ser utilizados para selecionar as características que serão utilizadas pelos SOMs durante o processo de agrupamento, descartando as restantes. 


\begin{tabular}{|l|l|}
\hline Algoritmo de Agrupamento & SOM. \\
\hline Tipo de Representação & Inclui o tipo de fórmula utilizado e parâmetros. \\
\hline População Inicial & Aleatória. \\
\hline Função de Aptidão & Baseado na média e variância da qualidade. \\
\hline Seleção & Roleta. \\
\hline Cruzamento & $\begin{array}{l}\text { Utiliza dois tipos de cruzamento: o primeiro é } \\
\text { o cruzamento simples e o segundo gera um valor } \\
\text { aleatório perto do valor contido entre cada } \\
\text { par de alelos e utiliza esse valor no filho. }\end{array}$ \\
\hline Mutação & $\begin{array}{l}\text { Modifica o valor antigo para um novo dentro do } \\
\text { domínio. }\end{array}$ \\
\hline Elistismo & Os 30 melhores indivíduos são poupados. \\
\hline Comparação dos Resultadosticas & $\begin{array}{l}\text { Compara com o SOM expandido, redes elástic } \\
\text { convexas, e o algoritmo FLEXMAP. }\end{array}$ \\
\hline Detalhes & $\begin{array}{l}\text { Taxa de cruzamento foi de 0.99, de mutação foi } \\
\text { de 0.01, a população tinha 100 indivíduos e o } \\
\text { número máximo de gerações foi de 6000. }\end{array}$ \\
\hline
\end{tabular}

Tabela 4.11: Principais características do algoritmo ISOM.

Ohtsuka et al. (2002) utilizaram redes SOM em conjunto com AGs para detectar confusão em amostras de sangue. As redes SOM selecionam elementos, entre 15 presentes em uma tabela, denominada CBC (Complete Blood Count), para detectar confusão em amostras de sangue. Segundo os autores, é possível que a utilização de todos os elementos da tabela CBC não ajude a detectar confusão, ou seja, um SOM treinado utilizando todos os elementos da tabela CBC como pesos nem sempre obtém a melhor detecção. Por isso, AGs são utilizados para selecionar os elementos a serem utilizados na detecção de confusão nas amostras de sangue.

Os cromossomos utilizados são formados por 15 bits que representam a utilização ou não de cada um dos 15 elementos da tabela CBC. Em seguida, são gerados SOMs correspondentes à cada um dos indivíduos. A atualização dos pesos dessas redes é definida pelos elementos contidos no cromossomo. A aptidão de cada indivíduo é dada pela Equação 4.17.

$$
\text { Fit }=\frac{1}{\sum_{i=1}^{R} \sum_{j=1}^{C} H_{i j}}
$$

com $R$ e $C$ sendo o número de linhas e colunas de neurônios do SOM respectivamente, e 


$$
H_{i j}=\left\{\begin{array}{l}
N D_{i j}^{*}: N D_{i j} \geq N D_{i j}^{*} \\
N D_{i j}: N D_{i j}<N D_{i j}^{*}
\end{array}\right.
$$

sendo $N D_{i j}^{*}$ o número de padrões de entrada com confusão que ativaram o neurônio e $N D_{i j}$ o número de padrões normais que o ativaram. Se a maior aptidão dos indivíduos de uma geração for maior que o critério de parada para o aprendizado, o indivíduo é selecionado e utilizado para treinar um mapa maior (versão final do SOM).

Para avaliar os resultados obtidos, foram utilizadas três métricas: sensibilidade, especifícidade e eficiência, que são dadas pelas Equações 4.19 4.20 4.21, respectivamente.

$$
\begin{gathered}
\text { Sensibilidade }=\frac{N_{T P}}{N_{T P}+N_{F N}} \times 100 \\
\text { Especificidade }=\frac{N_{T N}}{N_{F P}+N_{T N}} \times 100 \\
\text { Eficiencia }=\frac{N_{T P}+N_{T N}}{N_{T P}+N_{F N}+N_{F P}+N_{T N}} \times 100
\end{gathered}
$$

em que $N_{T P}, N_{T F}, N_{T N}$ e $N_{F N}$ são os números de verdadeiros positivos, falsos positivos, verdadeiros negativos e falsos negativos, respectivamente.

Os resultados mostraram que as redes que tiveram os elementos de detecção selecionados por AGs obtiveram maior eficiência e sensibilidade, especialmente quando os dados de entrada não foram utilizados para treinamento. Porém, houve redução na especificidade.

As principais características do algoritmo podem ser visualizadas na Tabela 4.12 .

Outra maneira de utilizar AGs em conjunto com redes SOM é permitir que o AG faça uma seleção dos objetos contidos na base de dados, enquanto as redes SOM modelam os grupos. É o caso de problemas complexos, como os QSAR/QSPR, que modelam os relacionamentos das propriedades/atividades de descritores nos sistemas biológicos. Bayram et al. (2004) utilizam SOMs para agrupar os objetos da base de dados de acordo com os descritores e a propriedade alvo, gerando um modelo denominado QSAR/QSPR, enquanto o AG seleciona os descritores a serem incluídos no modelo.

Para representar esse modelo, Bayram et al. (2004) utilizam um cromossomo binário, em que o bit 1 indica que o descritor correspondente está inserido no modelo e 0, o contrário. Além disso, um vetor binário contendo a classe a qual 


\begin{tabular}{|l|l|}
\hline Algoritmo de Agrupamento & SOM utilizando distância Euclidiana. \\
\hline Tipo de Representação & $\begin{array}{l}\text { Cromossomos binário contendo } 15 \text { genes, } \\
\text { representando um dos elementos da tabela CBC. }\end{array}$ \\
\hline População Inicial & Aleatória. \\
\hline Função de Aptidão & $\begin{array}{l}\text { A função de aptidão baseada na quantidade de } \\
\text { instâncias que cada neurônio da rede recebeu de } \\
\text { cada classe. Quanto maior a diferença dos } \\
\text { padrões maior é a aptidão. }\end{array}$ \\
\hline Seleção & Roleta. \\
\hline Cruzamento & Simples. \\
\hline Mutação & bit-a-bit (bitwise). \\
\hline Elistismo & $\begin{array}{l}\text { Sim. O cromossomo com menor aptidão é } \\
\text { descartado, o cromossomo com maior aptidão é } \\
\text { levado para a próxima geração. }\end{array}$ \\
\hline Análise dos Resultados & $\begin{array}{l}\text { Compara os resultados com SOM utilizando } \\
\text { os } 15 \text { elementos da tabela CBC. }\end{array}$ \\
\hline Detalhes & $\begin{array}{l}\text { Com a utilização do AG, autor altera o cálculo } \\
\text { da distância Euclidiana para receber o vetor de } \\
\text { características, fazendo que o calculo seja feito } \\
\text { apenas entre as características selecionadas pelo } \\
\text { vetor. }\end{array}$ \\
\hline
\end{tabular}

Tabela 4.12: Principais características do AG utilizado por Ohtsuka.

cada descritor pertence é anexado ao vetor de descritores para ser utilizado no treinamento supervisionado do SOM.

As características mais importantes do algoritmo utilizado por Bayram et al. (2004) podem ser visualizadas na Tabela 4.13 .

Outra forma de utilizar AGs com redes SOM consiste em selecionar padrões que possam representar os grupos, uma vez que as redes SOM não detectam automaticamente as bordas dos grupos resultantes. Ma (2005) desenvolveu um AG para selecionar padrões da base de dados para representar grupos. O cromossomo utilizado pelo AG é composto de um vetor de inteiros de tamanho k, em que k é o número de grupos representados. Cada inteiro indica o padrão que será usado como representante do grupo, de maneira similar ao uso de meióides. Um a um, os padrões restantes são adicionados aos grupos cujo representante apresente a menor distância Euclidiana ao padrão.

Em seguida, os valores dos atributos dos padrões representantes são utilizados como pesos sinápticos pelos neurônios do SOM. O tamanho da população é igual ao número de padrões dividido pelo número de agrupamentos. Isso tem como objetivo permitir a utilização da maioria dos padrões como representativos. 


\begin{tabular}{|l|l|}
\hline Algoritmo de Agrupamento & SOM. \\
\hline Tipo de Representação & $\begin{array}{l}\text { Binária, representando os descritores e a classe } \\
\text { a que eles pertencem. }\end{array}$ \\
\hline População Inicial & Aleatória. \\
\hline Função de Aptidão & $\begin{array}{l}\text { Percentual da classificação correta dos dados } \\
\text { de treino. }\end{array}$ \\
\hline Seleção & Método da Roleta. \\
\hline Cruzamento & $\begin{array}{l}\text { Os cromossomos pais são divididos em partes } \\
\text { nas posições de alelos escolhidos aleatorimente, } \\
\text { e depois as partes são trocadas. }\end{array}$ \\
\hline Mutação & $\begin{array}{l}\text { Inverte os bits de alelos selecionados } \\
\text { aleatoriamente. }\end{array}$ \\
\hline Elistismo & $\begin{array}{l}5 \% \text { melhores indivíduos vão para a próxima } \\
\text { geração. }\end{array}$ \\
\hline Comparação dos Resultados & $\begin{array}{l}\text { Obteve melhores resultados do que SOM simples } \\
\text { e PLS. Apesar disso, o autor afirma que } \\
\text { GASOM acabou tendo overfitting aos dados } \\
\text { de treino, obtendo pouca generalização. }\end{array}$ \\
\hline Detalhes & Utiliza treinamento supervisionado para o SOM. \\
\hline
\end{tabular}

Tabela 4.13: Principais características do algortimo GASOM.

A aptidão dos indivíduos é obtida por meio da soma dos quadrados das distâncias entre todos os padrões e o representante do agrupamento mais próximo. Esse cálculo é feito utilizando a Equação 4.22 .

$$
f(C)=\frac{1}{\operatorname{sqrt}\left(\sum_{i=1}^{n}\|i-y(i)\|^{2}\right)}
$$

em que $C$ é o cromossomo, $n$ o número de padrões da base de dados, e $y(i)$ uma função que retorna o padrão representante mais próximo de $i$.

Ma (2005) utiliza redes SOM para a detecção de intrusão em sistemas por meio de arquivos de log do sistema operacional UNIX. Ele teve dificuldades em agrupar esses dados, devido aos diferentes tipos de dados e escalas, que foram divididos em 4 categorias: boolean, string, count e rate. A análise dos resultados obtidos mostram que o desempenho do algoritmo depende muito do conjunto inicial de soluções, assim como o algoritmo $k$-médias.

Um Principais características do algoritmo GSOMC implementado por Ma (2005) podem ser vistas na Tabela 4.14 . 


\begin{tabular}{|l|l|}
\hline Algoritmo de Agrupamento & SOM utilizando distância Euclidiana. \\
\hline Tipo de Representação & $\begin{array}{l}\text { Cada alelo representa o meióide de um } \\
\text { agrupamento. }\end{array}$ \\
\hline População Inicial & $\begin{array}{l}\text { Aleatório. Porém, dois indivíduos devem ser } \\
\text { diferentes. }\end{array}$ \\
\hline Função de Aptidão & $\begin{array}{l}\text { Soma dos quadrados das distâncias entre todos } \\
\text { os padrões e o representante de agrupamento } \\
\text { mais próximo. }\end{array}$ \\
\hline Seleção & Não especificada. \\
\hline Cruzamento & Simples. \\
\hline Mutação & $\begin{array}{l}\text { Substitui um representante por outro que não } \\
\text { tenha sido utilizado na população inicial, para } \\
\text { permitir a utilização de novos representantes. }\end{array}$ \\
\hline Elistismo & Não especificado. \\
\hline Comparação dos Resultados & Não especificada. \\
\hline Detalhes & $\begin{array}{l}\text { Pára depois que a população convergir ou o } \\
\text { algoritmo executar um determinado número } \\
\text { de gerações. }\end{array}$ \\
\hline
\end{tabular}

Tabela 4.14: Principais características do Algoritmo GSOMC.

\subsubsection{Técnicas Hierárquicas com AGs}

Os algoritmos hierárquicos tradicionais são deterministicos, uma vez que diferentes execuções do algoritmo para uma mesma base de dados geram sempre o mesmo resultado. Desta forma, não é possível utilizar AG para selecionar os agrupamentos gerados por essas técnicas. A maioria dos algoritmos que utilizam AGs com técnicas hierárquicas o faz modificando parâmetros dessas técnicas ou a própria técnica. Em alguns casos, os próprios AGs executam a divisão hierárquica da base de dados. Em outros, essas técnicas são aplicadas em situações específicas, como no agrupamento de uma fração do conjunto de dados.

Uma abordagem utilizada por Tseng and Yang (2001) utiliza um método que divide o conjunto de dados em $m$ grupos iniciais e depois os agrupa de maneira aglomerativa. Inicialmente, é calculada a distância do vizinho mais próximo para cada par de padrões $d\left(p_{i}\right)=\min _{j \neq i}\left\|p_{j}-p_{i}\right\|$ e, em seguida, a média dessas distâncias $d_{a v}$. Os padrões são vistos como nós de um grafo e os elementos da matriz de adjacência $A$ são calculados conforme a Equação 4.23 .

$$
A(i, j)=\left\{\begin{array}{cc}
1 & s e\left\|p_{i}-p_{j}\right\| \leq d_{a v} \\
0 & s e\left\|p_{i}-p_{j}\right\|>d_{a v}
\end{array}\right.
$$

Com o grafo formado, é possível encontrar os componentes conectados e formar $m$ grupos $\left\{B_{1}, B_{2}, \ldots B_{m}\right\}$ contendo esses componentes. Esses grupos são 
representados por cromossomos compostos por vetores binários de tamanho $m$. Os valores contidos nesses vetores são determinados aleatoriamente no início da primeira geração. Se o valor do bit correspondente a um grupo for 1, esse grupo continuará a existir na partição. Caso o valor do bit correspondente for 0 , o grupo deixará de existir e os padrões contidos nele serão adicionados à outros grupos cujo valor indicado pelo cromossomo seja 1. A Figura 4.4 da Seção 4.2 ilustra esse tipo de representação.

Em seguida, esses cromossomos recebem uma nota de aptidão baseada nas distâncias inter e intra grupos, como descrito na Seção 4.3. O cruzamento consiste em selecionar um par de cromossomos, a partir da sua aptidão, e dividi-los em dois pontos aleatórios. O segmento entre os pontos é trocado entre os cromossomos com probabilidade de cruzamento $p_{c}$. A mutação é feita bit-a-bit, com probabilidade $p_{m}$.

Tseng and Yang (2001) utilizaram esse algoritmo, nomeado CLUSTERING, em 3 bases de dados, sendo 2 delas artificiais e 1 real. Em seguida, os resultados obtidos foram comparados com os algoritmos $k$-médias, single-link (Dubes and Jain, 1976) e complete-link (Dubes and Jain, 1976). O algoritmo CLUSTERING obteve bons resultados ao agrupar bases de dados com grupos de diferentes densidades, ao contrário dos métodos single-link e complete-link. A utilização do algoritmo CLUSTERING resultou em grupos cuja média das distâncias entre os padrões e o centróide do grupo é menor, quando o número de grupos obtidos pelos algoritmos foi o mesmo. O algoritmo $k$-médias não obteve bons resultados na maioria dos experimentos, mesmo quando o número de agrupamentos era previamente conhecido.

Um resumo das principais características do algoritmo CLUSTERING pode ser visto na Tabela 4.15.

No algoritmo CLUSTERING, não é possível visualizar os vários níveis de partições que um agrupamento hierárquico apresenta, apenas a partição ou agrupamento representado pelo cromossomo. Greene (2003) utiliza um algoritmo hierárquico divisivo que permite visualizar as partições formadas anteriormente. Cada indivíduo é composto de um único grupo contendo todos os padrões da base. Neste algoritmo, um grupo pode ser formado de outros grupos, o que o caracterizaria como um grupo segmentado. Um grupo segmentado pode ser formado por outros grupos segmentados, criando assim uma hierarquia.

Os autores utilizam orientação a objetos para representar os grupos, ou seja, cada grupo é uma instância da classe grupo. Os grupos contêm a lista de características dos objetos que estão contidos nele. Além disso, cada grupo possui 


\begin{tabular}{|c|c|}
\hline Algoritmo de Agrupamento & Agrupamento por AG utilizando aglomeração. \\
\hline Tipo de Representação & Binária, representando os agrupamentos iniciais. \\
\hline População Inicial & Aleatória. \\
\hline Função de Aptidão & $\begin{array}{l}\text { Baseadas nas distâncias inter e intra } \\
\text { grupos. }\end{array}$ \\
\hline Seleção & Não especificada. \\
\hline Cruzamento & $\begin{array}{l}\text { Duplo. Dois pontos aleatórios e o segmento } \\
\text { entre os pontos é trocado. }\end{array}$ \\
\hline Mutação & bit-a-bit. \\
\hline Elistismo & O melhor indivíduo é copiado. \\
\hline Comparação dos Resultados & k-médias, single-link e complete-link. \\
\hline Detalhes & $\begin{array}{l}\text { Utiliza método aglomerativo para formar } \\
\text { os grupos. }\end{array}$ \\
\hline
\end{tabular}

Tabela 4.15: Principais características do Algoritmo CLUSTERING.

os atributos "raio atual", que consiste na distância máxima de qualquer elemento ao centróide do grupo, e "raio máximo", que consiste no raio atual máximo que um grupo pode ter. O raio máximo que um grupo filho pode ter é sempre uma fração do raio do grupo pai, porém sempre maior que uma constante previamente determinada. O tamanho do raio máximo dos grupos filhos influencia na quantidade de grupos que um grupo pai pode possuir, como pode ser visto mais a diante. Ao inicializar a população, Greene (2003) organiza os padrões da base de dados de maneira aleatória e seleciona o primeiro padrão que vai ser adicionado ao grupo inicial. Os outros padrões são adicionados no grupo na seqüência em que foram organizados, podendo causar a segmentação do grupo caso seu raio atual seja maior que o raio máximo dos grupos filhos a serem construídos. Se o grupo que recebe o novo padrão é segmentado, o padrão é inserido no grupo filho com centróide mais próximo (sorteio no caso de empate). Porém, se o raio máximo dos grupos filhos for maior ou igual ao raio atual do grupo pai, a estrutura é descartada pois os grupos filhos podem sobrepor o grupo pai. A adição de padrões pode ser vista por meio do seguinte pseudocódigo:

O processo é repetido até que todos os padrões sejam adicionados ao grupo principal. Essa função também permite adicionar novos padrões à hierarquia, mesmo depois do agrupamento final ser encontrado.

AGs são utilizados para selecionar uma população de grupos. Como pode ser visto no pseudocódigo apresentado, a aptidão dos grupos é calculada durante o processo de adição de padrões. A aptidão dos indivíduos é calculada de duas maneiras distintas. Se o conjunto for segmentado, a função de aptidão é calculada pela soma das médias de aptidão dos grupos que o compõe com a distância 


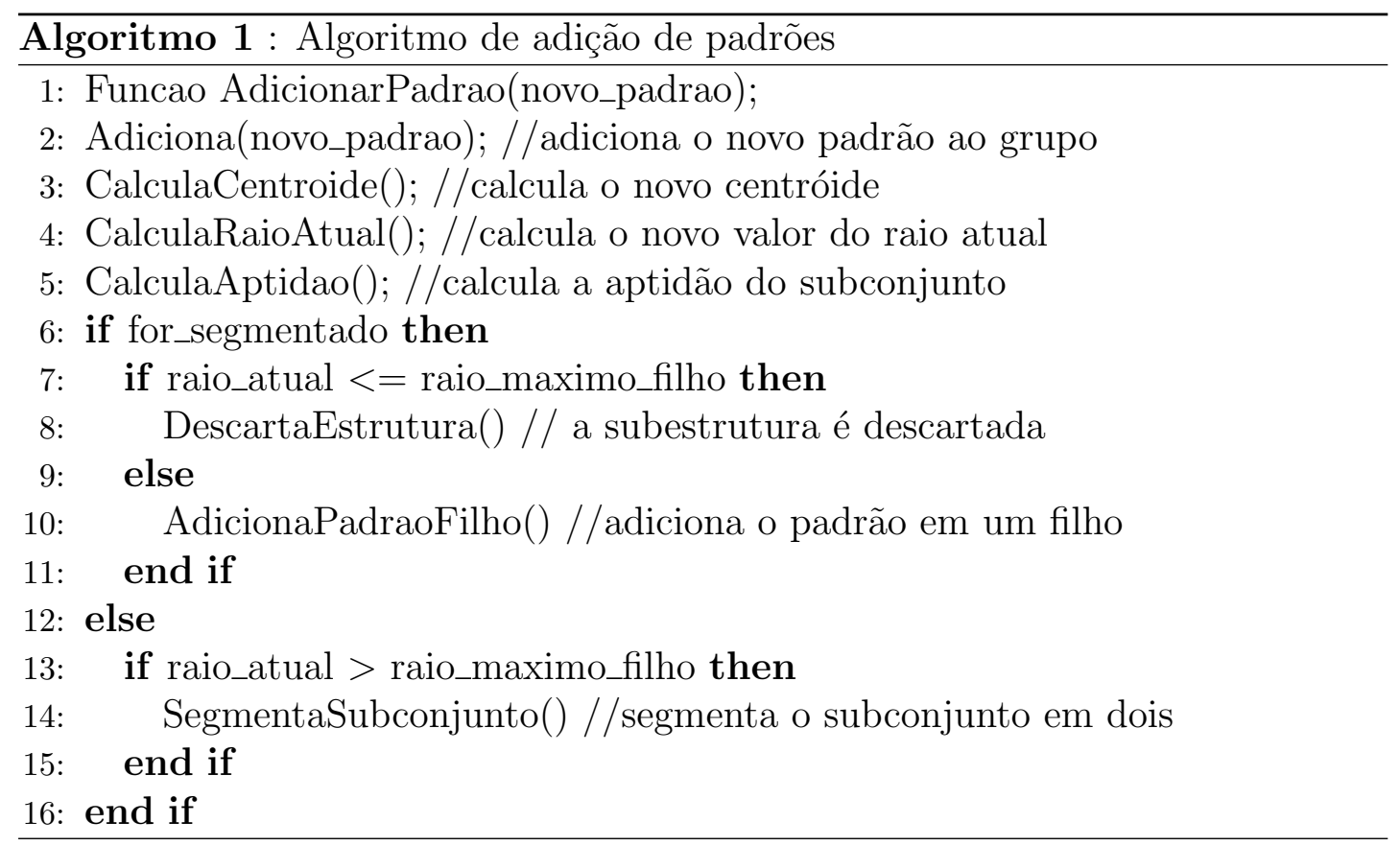

média entre os centróides desses grupos. Caso ele não seja segmentado, a aptidão é calculada pela soma dos elementos contidos no grupo com a diferença entre o raio atual e o raio máximo do mesmo. Os dois indivíduos com as maiores taxas de aptidão são copiados para a próxima geração. Os outros indivíduos são selecionados pelo método da roleta e, em seguida, são aplicados operadores de cruzamento e mutação, descritos na Seção 4.4 .

Greene (2003) aplica o algoritmo em dados com características nominais, ou seja, características cujos valores pertencem a um conjunto discreto simples, sem nenhuma estrutura adicional (cor,sexo,etc). Os experimentos foram realizados com bases de dados do repositório da UC-Irvine para aprendizado de máquina. Os objetos contidos nas bases foram agrupados corretamente. O autor ainda não comparou os resultados com outros algoritmos utilizados na base porque afirma não ter detalhes suficientes para fazê-lo. As principais características do algoritmo podem ser vistas na Tabela 4.16 .

Uma outra implementação consiste em utilizar o algoritmo hierárquico aglomerativo de Spellman (Eisen et al., 1998) em conjunto com AGs. Ma and Chan (2003) utiliza essas técnicas para agrupar genes coexpressos por meio de sua expressão gênica. Essas técnicas são utilizadas para tratar o ruído nos dados, obtidos de origem biológica (durante a análise biológica das sequiências) e técnica (durante a extração dos dados). As técnicas de agrupamento ajudam a identificar as estruturas reais dos dados, enquanto o AG efetua uma pesquisa global pelas melhores partições no espaço de busca. 


\begin{tabular}{|l|l|}
\hline Algoritmo de Agrupamento & Agrupamento Hierárquico Divisivo. \\
\hline Tipo de Representação & Objetos representam os grupos. \\
\hline População Inicial & Aleatória. \\
\hline Função de Aptidão & Baseadas na aptidão dos grupos filhos. \\
\hline Seleção & Roleta. \\
\hline Cruzamento & $\begin{array}{l}\text { Guloso, direcionado pela aptidão dos grupos } \\
\text { que formam o indivíduo. }\end{array}$ \\
\hline Mutação & $\begin{array}{l}\text { Consiste em retirar um grupo e adicioná-lo } \\
\text { posteriormente. Baseada na aptidão dos } \\
\text { indivíduos. }\end{array}$ \\
\hline Elistismo & O dois melhores indivíduos são copiados. \\
\hline Comparação dos Resultados & Nenhuma comparação foi feita. \\
\hline Detalhes & $\begin{array}{l}\text { Representa vários níveis de partições e é } \\
\text { incremental. }\end{array}$ \\
\hline
\end{tabular}

Tabela 4.16: Principais características do Algoritmo utilizado por Greene.

Assim como nos algoritmos hierárquicos apresentados anteriormente, é necessário gerar partições iniciais que possam ser representadas pelos indivíduos da primeira geração. Nessa implementação o primeiro conjunto de partições é gerado com as partições resultantes da utilização do algoritmo de Spellman no conjunto de dados.

Cada cromossomo é composto de duas partes: a primeira parte é uma representação grupo-número dos objetos e a segunda parte é uma seqüência contendo os números dos grupos. A similaridade entre os objetos é medida pela correlação de Pearson durante a construção dos grupos.

A função de aptidão utilizada é dividida em dois passos: o primeiro consiste em descobrir associação de padrões no conjunto de treino que sejam estatisticamente significantes e o segundo consiste em classificar todos os objetos contidos no conjunto de teste baseado nas associações descobertas. A aptidão de cada indivíduo é utilizada para a seleção pela Roleta.

A operação de cruzamento obedece ao seguinte processo: um grupo é selecionado aleatoriamente do primeiro pai e substituído pelo grupo com o maior número de objetos em comum no segundo pai. Os objetos do grupo do primeiro pai que estiverem em outros grupos no segundo, são apagados desses grupos. Os objetos que sobraram do grupo substituído são realocados para novos grupos, por meio do algoritmo de Spellman.

Os autores utilizam dois tipos de mutação, com chances iguais. No primeiro, são selecionados $30 \%$ dos objetos para formar um grupo temporário e os $70 \%$ restantes são mantidos. Os objetos no conjunto de temporário são reagrupados 
em novos conjuntos utilizando o algoritmo hierárquico de Spellman. No segundo, são selecionados $30 \%$ dos objetos de cada grupo e são alocados em novos grupos aleatoriamente.

A cada nova geração, apenas os dois indivíduos menos aptos são substituídos e os cromossomos filhos que sejam duplicatas de cromossomos que já existam na população são descartados. Logo, os cromossomos pais e filhos podem coexistir na mesma geração.

Os detalhes do algoritmo utilizado estão descritos na Tabela 4.17.

\begin{tabular}{|l|l|}
\hline Algoritmo de Agrupamento & Agrupamento Hierárquico Spellman. \\
\hline Tipo de Representação & $\begin{array}{l}\text { Grupo-número contendo os números dos } \\
\text { grupos. }\end{array}$ \\
\hline População Inicial & $\begin{array}{l}\text { Gerada pelas partições formadas pelo } \\
\text { algoritmo de Spellman. }\end{array}$ \\
\hline Função de Aptidão & $\begin{array}{l}\text { Consiste em descobrir associações de padrões } \\
\text { estatisticamente significantes e classificar } \\
\text { todos os objetos contidos no conjunto de } \\
\text { teste baseado nessas associações. }\end{array}$ \\
\hline Seleção & Roleta. \\
\hline Cruzamento & $\begin{array}{l}\text { Um grupo é selecionado aleatoriamente de } \\
\text { um dos pais e substituído pelo grupo } \\
\text { com mais objetos em comum do outro. }\end{array}$ \\
\hline Mutação & $\begin{array}{l}\text { Consiste em retirar 30\% dos objetos dos } \\
\text { grupos e adicioná-los posteriormente. }\end{array}$ \\
\hline Elistismo & $\begin{array}{l}\text { Apenas os dois piores indivíduos são } \\
\text { substituídos. }\end{array}$ \\
\hline Comparação dos Resultados & $\begin{array}{l}\text { Apesar de vários testes terem sido aplicados, } \\
\text { nenhuma comparação foi feita. }\end{array}$ \\
\hline Detalhes & $\begin{array}{l}\text { Mesmo utilizando algoritmo hierárquico, } \\
\text { os indivíduos representam apenas um nível } \\
\text { de partição. }\end{array}$ \\
\hline
\end{tabular}

Tabela 4.17: Principais características do Algoritmo utilizado por Ma.

Garai and Chaudhuri (2004) apresentam um algoritmo de agrupamento guiado por AG (GCA) que, como o algoritmo de Tseng and Yang (2001), divide a base de dados em grupos iniciais e depois os aglomera. Porém, o algoritmo utilizado por Tseng and Yang (2001) falha se o agrupamento contém grupos parcialmente ou completamente confinados em outro grupo. Para solucionar esse problema, Garai and Chaudhuri (2004) utilizam um algoritmo de verificação de adjacência nos grupos (ACCA, do inglês Adjacent Cluster Checking Algorithm).

A primeira parte do algoritmo divide os padrões da base de dados em $k$ grupos iniciais utilizando o CDA ( do inglês Cluster Decomposition Algorithm), descrito 
em pseudo-código pelo Algoritmo 2, para uma base de dados $A$ com $n$ padrões.

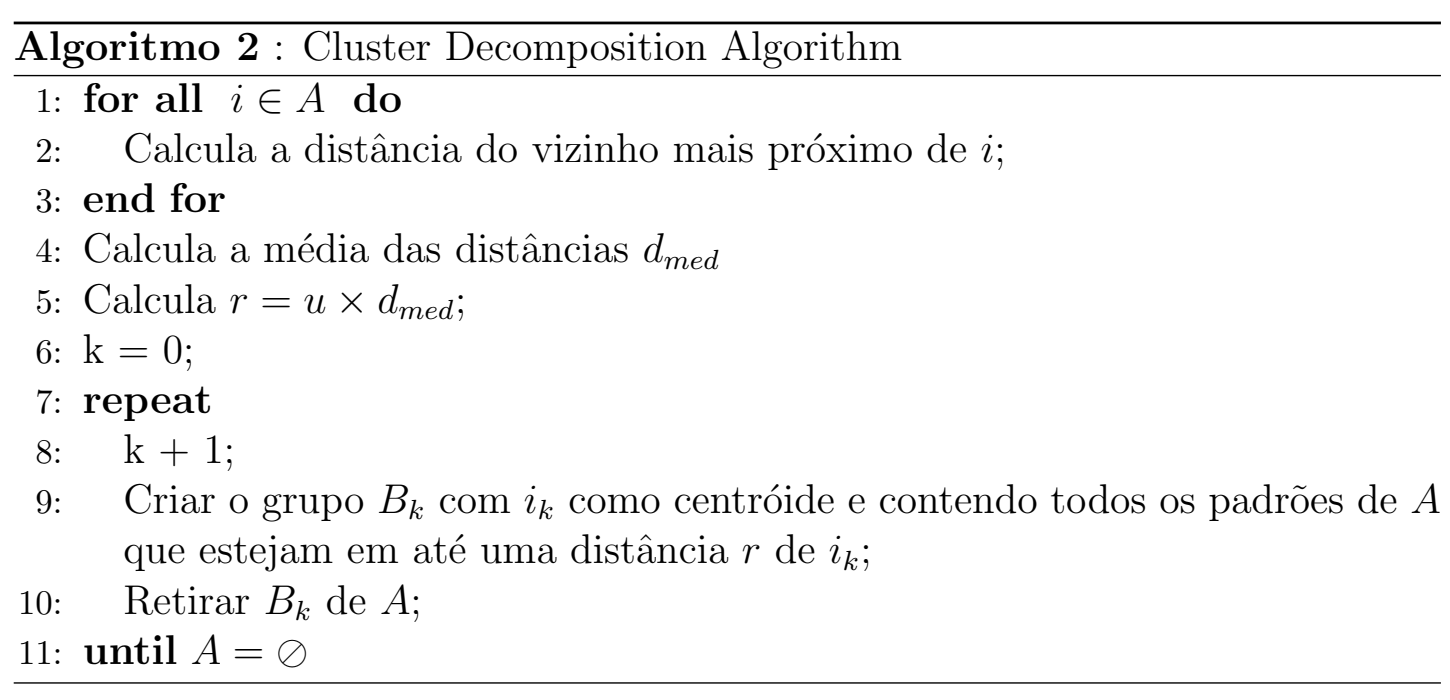

A distância do vizinho mais próximo do padrão $i$ é dada pela Equação 4.24 .

$$
d_{\min }(i)=\min _{i \neq j}\|i-j\|
$$

sendo que $j \in\{1,2, \ldots, n\},\|i-j\|$ é a distância euclidiana entre os dois padrões (Equação 2.6) e a distância mínima média $d_{m e d}$ é calculada por meio da Equação 4.25 .

$$
d_{\text {med }}=\frac{1}{n} \sum_{i=1}^{n} d_{\text {min }}(i)
$$

Em seguida, os grupos iniciais $\left\{B_{1}, B_{2}, \ldots B_{k}\right\}$ são representados por vetores binários, como descrito na Seção 4.2. Os grupos representados por 0 são adicionados pelo algoritmo HCMA (do inglês Hierarchical Cluster Merging Algorithm) aos grupos mais próximos representados por 1. O centróide do grupo formado é calculado pela soma dos centróides dos grupos que o compõem. O algoritmo ACCA é utilizado antes do HCMA para evitar que sejam gerados grupos confinados em outro grupo ou evitar ruídos nos grupos. Esse algoritmo utiliza os limiares $T_{b}$ e $T_{d}$, que representam o número mínimo de objetos em comum aos grupos a serem aglomerados e a diferença de densidade máxima entre os grupos, respectivamente. O ACCA é apresentado em pseudo-código no Algoritmo 3.

A aptidão é calculada utilizando as distâncias inter e intra grupos, descritas na Seção 4.3. Em seguida, os cromossomos são selecionados pelo método da roleta e são aplicados os operadores genéticos de cruzamento simples e mutação bit-abit. O algoritmo é executado até que um número $k$ de grupos seja encontrado ou atingir $G_{m a x}$ gerações. O algoritmo foi aplicado em vários tipos de dados artifici- 


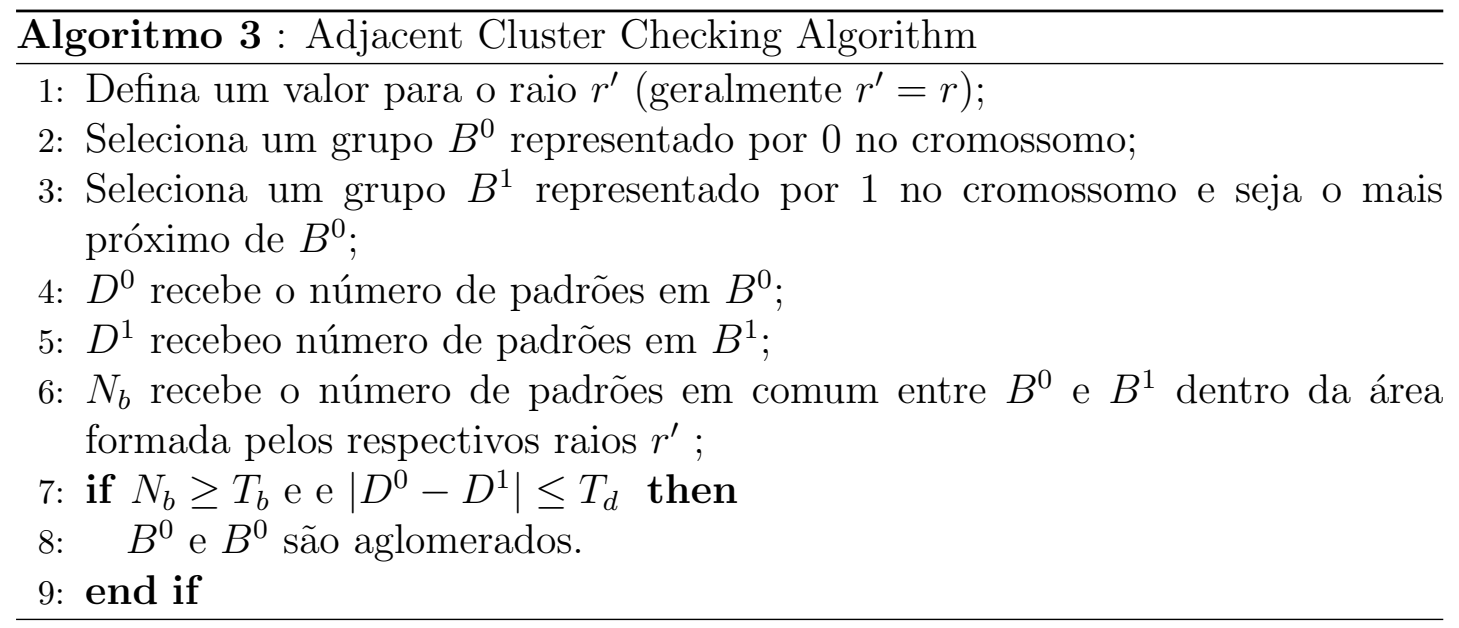

ais, contendo grupos confinados e com ruídos, e a base de dados de padrões Íris. Nos experimentos, eles obtiveram bons resultados. As principais características do algoritmo são apresentadas na Tabela 4.18 .

\begin{tabular}{|l|l|}
\hline Algoritmo de Agrupamento & Agrupamento por AG utilizando aglomeração. \\
\hline Tipo de Representação & Binária, representando os agrupamentos iniciais. \\
\hline População Inicial & Aleatória. \\
\hline Função de Aptidão & $\begin{array}{l}\text { Baseadas na distâncias inter e intra } \\
\text { grupos. }\end{array}$ \\
\hline Seleção & Roleta. \\
\hline Cruzamento & Simples. \\
\hline Mutação & bit-a-bit. \\
\hline Elistismo & Não especificado. \\
\hline Comparação dos Resultados & CURE, DBScan e Chameleon. \\
\hline Detalhes & $\begin{array}{l}\text { Checa a adjacência dos grupos antes de } \\
\text { aglomerar. }\end{array}$ \\
\hline
\end{tabular}

Tabela 4.18: Principais características do Algoritmo GCA.

\subsection{Considerações Finais}

Este capítulo apresentou uma visão geral sobre agrupamento de dados utilizando AGs, enfocando as diversas etapas do processo de representação e aplicação dos operadores genéticos para técnicas de agrupamento e descrevendo alguns dos algoritmos existentes, fornecendo os elementos necessários para a pesquisa em combinação de agrupamentos com AGs proposta neste trabalho.

Vários métodos de utilização de AGs em conjunto com algoritmos de agrupamentos foram descritos. Muitas das implementações utilizam AGs tanto para a escolha de bons grupos iniciais, como para encontrar bons valores para parâmetros livres. Em outras, o próprio AG executa o agrupamento e o resultado obtido 
é avaliado ou reagrupado, posteriormente, por uma técnica determinística. Os AGs também podem ser utilizados para selecionar características do algoritmo de agrupamento ou até mesmo para selecionar padrões mais relevantes para serem utilizados durante o agrupamento. Não existe método definitivo de utilizar os AGs para agrupar dados ou em conjunto com outros algoritmos. O desempenho obtido pela técnica irá variar com o princípio indutivo requisitado para cada exercício de agrupamento.

Um fato relevante a ser citado é que o número de campos e os valores usados para os parâmetros de um agrupamento genético variam consideravelmente com o tipo de algoritmo de agrupamento utilizado, e há pouca documentação justificando a utilização de um valor específico para eles. Dentre esses parâmetros, podem ser citados os parâmetros utilizados pelo próprio algoritmo de agrupamento, taxas de cruzamento, de mutação, além de outros.

Os parâmetros utilizados pelos agrupamentos podem ser otimizados pelo AG. Para isso, eles devem ser representados no cromossomo, variando conforme a representação utilizada. Algumas vezes, devido ao tamanho do cromossomo, a probabilidade de alteração desses parâmetros pode ser baixa. Operadores genéticos podem ser utilizados para alterar os segmentos que contêm as características representadas independentemente. 



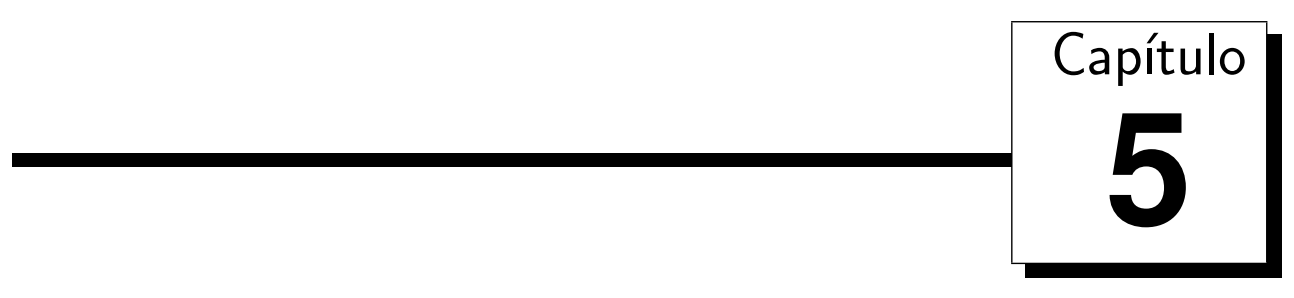

\section{Experimentos}

Nos capítulos 2, 3 e 4 foram apresentados os principais aspectos relacionados a algoritmos de agrupamento, AGs e o uso conjunto de ambas as técnicas. Neste capítulo são apresentados os experimentos executados durante essa pesquisa.

As primeiras duas seções do capítulo apresentam as principais características das bases de dados e do algoritmo desenvolvido durante o projeto. Na Seção 5.1 são descritas as bases de dados utilizadas nos experimentos, boa parte delas compostas de dados de expressão de genes. As principais características do algoritmo KMGA são descritas na Seção 5.2 .

As seções seguintes têm como objetivo descrever os resultados de experimentos exploratórios, utilizados para aprimorar o algoritmo KMGA por meio do estudo de suas características. Na Seção 5.3 é feito um estudo do tempo de execução de um AG simples em comparação com o algoritmo $k$-médias. Várias versões de função de aptidão para o algoritmo KMGA são analisadas nas seções 5.4 , 5.5, 5.6 e 5.8. O uso de múltiplas medidas de dissimilaridade durante a execução do AG é estudado na Seção 5.7. Na Seção 5.9 são descritas as principais características do AGD estudado nesse projeto e os resultados experimentais são avaliados. O uso de técnicas particionais para o ajuste de agrupamentos é analisado na Seção 5.10 .

As últimas duas seções analisam o desempenho do algoritmo KMGA desenvolvido e o compara com o obtido por abordagens similares. O estudo e comparação de algoritmos que executam o agrupamento da base de dados em um número de grupos não estabelecido são feitos na Seção 5.11 . Uma comparação entre os algoritmos desenvolvidos nesse projeto e outros algoritmos descritos na literatura é feita na Seção 5.12 .

As considerações finais do capítulo são feitas na Seção 5.13 . 


\subsection{Bases de dados}

Cinco bases de dados foram utilizadas nos experimentos feitos nesta parte do projeto, sendo que duas são artificiais e três são de expressão gênica, originados da área de bioinformática. Uma das bases artificiais é a Gaussiana3 criada por Monti et al. (2003). Essa base possui 60 padrões gerados artificialmente, formando 3 grupos. Cada padrão contém 600 características, sendo que 200 delas estão diretamente associadas a um único grupo. A segunda base artificial é a Simulado6, também utilizada por Monti et al. (2003), formada por 60 padrões com 600 características cada, que podem ser divididas em 6 grupos, contendo 8 , $12,10,15,5$ e 10 padrões. Cada grupo pode ser identificado por 50 características e as outras 300 são consideradas "ruídos", ou seja, estão distribuídas igualmente nos 6 grupos.

A primeira base de dados de bioinformática é composta por dados de expressão gênica de tecidos com câncer de pulmão (Bhattacharjee et al., 2001; Monti et al. 2003). Inclui 4 classes de câncer de pulmão conhecidas, sendo que uma delas é altamente heterogênea e sua subestrutura é pouco compreendida. A segunda base, St. Jude Leucemia (Yeoh et al., 2002; Monti et al., 2003), possui dados de expressão gênica oriundas de diagnósticos de amostras de medula óssea de pacientes com leucemia aguda, que correspondem a 6 prognósticos de subtipos importantes de leucemia: 43 T-lineage ALL, 27 E2A-PBX1, 15 BCR-ABL, 79 TELAML1, 20 MLL arranjos e 64 "hyperdiploid>50" cromossomos. A terceira base é formada por 27 grupos de proteínas e foi utilizada por Ding and Dubchak (2001).

As principais características das bases de dados utilizadas nos experimentos podem ser vistas na Tabela 5.1. Essa tabela apresenta, para cada base de dados, o número de padrões ( $\sharp$ Pat.), o número de classes $(\sharp C l$.), o número de atributos ( $\sharp$ Atrib.) e a média, o mínimo e o máximo para o número de padrões por classe (med./min./max. ex./classe).

\begin{tabular}{|l|c|c|c|c|}
\hline Base de dados & $\sharp$ Pat. & $\sharp$ Cl. & $\sharp$ Atrib. & $\begin{array}{c}\text { med./min./max. } \\
\text { ex./classe }\end{array}$ \\
\hline Gaussiana3 & 60 & 3 & 600 & $20 / 20 / 20$ \\
Simulado6 & 60 & 6 & 600 & $10 / 5 / 15$ \\
Pulmão & 197 & 4 & 1000 & $49.3 / 17 / 139$ \\
Leucemia & 248 & $2 / 6$ & 985 & $41.3 / 15 / 79$ \\
Proteínas & 698 & $4 / 27$ & 125 & $25.85 / 12 / 77$ \\
\hline
\end{tabular}

Tabela 5.1: Principais características das bases de dados. 


\subsection{Características do algoritmo utilizado}

Dentre as diversas características dos algoritmos descritos no Capítulo 4 , o candidato e o orientador optaram por desenvolver os experimentos utilizando um algoritmo de agrupamento particional com AG e $k$-médias. Um dos principais motivos que levaram a essa escolha foi a estrutura simples dos resultados obtidos por algoritmos particionais, característica não presente nos resultados dos algoritmos hierárquicos e da rede SOM. Outro motivo foi a sensibilidade desses algoritmos a escolha inicial dos grupos, o que permite ao AG uma variabilidade maior de indivíduos e, conseqüentemente, de soluções.

Ao algoritmo utilizado é dado o nome de KMGA e suas principais características são:

- Representação - O cromossomo é composto por duas partes: a primeira parte é um vetor de inteiros usando representação Grupo-Número (Figura 4.1 (a)) e a segunda parte contém o total de grupos e seus centróides. Um cromossomo representando o conjunto $X=\{A-F\}$, particionado nos grupos $G_{0}=\{A, C\}, G_{1}=\{B, D, E\}$ e $G_{2}=\{F\}$, é mostrado pela Figura 5.1 .

\section{Parte 1}

\begin{tabular}{|l|l|l|l|l|l|}
$\mathrm{A}$ & $\mathrm{B}$ & $\mathrm{C}$ & $\mathrm{D}$ & $\mathrm{E}$ & $\mathrm{F}$ \\
\hline 0 & 1 & 0 & 1 & 1 & 2 \\
\hline
\end{tabular}

\section{Parte 2}

\begin{tabular}{|c|c|}
\multicolumn{1}{l}{$k$} & centróides \\
\hline 3 & $c_{1}, c_{2}, c_{3}$ \\
\hline
\end{tabular}

Figura 5.1: Cromossomo representando os grupos $G_{0}, G_{1}$ e $G_{2}$.

A representação Grupo-Número foi escolhida por exigir um menor custo computacional do que representações binárias ou permutações (Hall et al., 1999). O cálculo dos centróides é feito pelo algoritmo $k$-médias e seu armazenamento possibilita o uso de métodos que necessitam destas informações sem que seja necessário o re-cálculo, acelerando o algoritmo.

Uma variação da representação descrita armazena a medida a ser utilizada no cálculo das distâncias entre os padrões. Essa medida é representada por uma letra adicionada à segunda parte do cromossomo.

- Função de Aptidão - Várias funções de aptidão foram implementadas visando um estudo entre o desempenho obtido por cada função. As principais funções de aptidão são baseadas no MSE e nos critérios de validação Silhueta e VRC, descritas na Seção 4.3. A utilização dessas funções varia conforme o experimento. 
A função de aptidão baseada no MSE dos agrupamentos é dada pela Equação 5.1 .

$$
f\left(I_{i}\right)=\alpha-\left(e\left(P, C_{i}\right)-\min _{j=1}^{p} e\left(P, C_{j}\right)\right) \times \frac{\alpha-\beta}{\max _{j=1}^{p} e\left(P, C_{j}\right)-\min _{j=1}^{p} e\left(P, C_{j}\right)}
$$

em que a aptidão dos cromossomos é normalizada entre $[\alpha, \beta]$, com $\alpha$ e $\beta$ pré-definidos, $P$ é o conjunto de dados, $C$ é o conjunto de centróides do indivíduo $I, p$ é o tamanho da população e $e$ é dado pela Equação 4.1. Nos experimentos realizados, as variáveis $\alpha$ e $\beta$ assumiram os valores 100 e 0 , respectivamente. É fácil notar que quanto maior o MSE, menor o valor da aptidão, e que a aptidão do melhor indivíduo é $\alpha$ e a do pior indivíduo é $\beta$. Quando Silhueta e VRC foram utilizadas como função de aptidão, o valor resultante das Equações 2.24 e 2.29 é utilizado diretamente como aptidão.

- Inicialização - Vários métodos de inicialização são apresentados na literatura (Seção 4.4.1). Peña et al. (1999) pesquisaram o uso de quatro métodos distintos de inicialização para o algoritmo $k$-médias e a inicialização aleatória obteve bons resultados quando utilizada em conjunto com AGs. Por esse motivo, a inicialização aleatória foi utilizada nesse algoritmo.

- Seleção - Os métodos de seleção por roleta e torneio, descritos na Seção 3.1 . foram implementados e estudados. O método de torneio é capaz de manter, de maneira estável, múltiplos nichos de soluções e executar, naturalmente e com baixo custo computacional, uma seleção baseada em "rank" Oei et al. 1991). Por esses motivos, o método de torneio foi escolhido como método de seleção. Ele seleciona aleatoriamente dois indivíduos da população, sendo que o indivíduo com maior aptidão tem $t_{1}$ de chance de ser o indivíduo escolhido e o outro descartado, caso contrário o inverso é efetuado. Nos experimentos descritos, $t_{1}=0,8$.

- Cruzamento - Quatro operadores de cruzamento foram utilizados: cruzamento de um simples ponto, cruzamento baseado em margens, cruzamento com número desconhecido de grupos (Hruschka et al., 2004) e cruzamento utilizando centróides. Os três primeiros estão descritos na Seção 4.4 .3 e o cruzamento utilizando centróides é uma variação feita pelo candidato em que os centróides dos cromossomos pais são sorteados e copiados nos cro- 
mossomos filhos. O cruzamento entre dois indivíduos selecionados ocorre com probabilidade $p_{c}$, independentemente do tipo de cruzamento utilizado.

- Mutação - A mutação utilizada altera um padrão de grupo com probabilidade $p_{m}$ para cada padrão.

- $\boldsymbol{K}$-médias - Depois da aplicação dos operadores genéticos, o algoritmo $k$-médias é utilizado para ajustar os grupos representados pelos novos indivíduos. Nos experimentos realizados, o algoritmo $k$-médias utilizou geralmente a distância Euclidiana.

- Critério de parada - O algoritmo pára quando o número máximo de gerações é alcançado, quando os indivíduos apresentarem a mesma aptidão ou quando um número pré-definido de gerações sem aumento na aptidão é executado.

\subsection{Tempo de execução com uso de $A G$}

Uma das maiores críticas ao uso de AGs é o seu tempo de execução e custo computacional. Por isso, o experimento descrito nessa seção foi feito com o objetivo de medir o desempenho obtido pela execução de $k$-médias com os grupos iniciais selecionados por AG e comparar com $k$-médias com grupos iniciais formados aleatoriamente.

Nesse experimento, a população inicial é composta por 10 indivíduos cujos padrões iniciais foram agrupados aleatoriamente. A propabilidade de cruzamento $p_{c}$ foi de 0,5 para cada par de indivíduos selecionados e $p_{m}$ foi 0,01. O número máximo de gerações foi definido como 10. O tamanho da população e o número máximo de gerações foram baixos para avaliar a desempenho obtido pelo AG em uma rápida execução. A função de aptidão é baseada no MSE, como descrito na Seção 5.2 .

O experimento foi executado uma vez com cada um dos três cruzamentos: simples, baseado em margens e utilizando centróides. Cada base de dados foi particionada em agrupamentos de 2 à 10 grupos, com exceção da base Proteínas, que é particionada em até 30 grupos. O número de grupos resultantes de cada experimento é pré-definido, portanto o algoritmo é executado uma vez para cada número de grupos.

Para possibilitar a análise do desempenho do KMGA, o algoritmo $k$-médias foi executado 100 vezes, com grupos iniciais aleatórios, e o agrupamento resultante com menor MSE foi selecionado e armazenado. A execução de ambos os algoritmos foi feita em condições semelhantes e medida em segundos. A Figura 5.2 
apresenta os tempos de execução dos experimentos em segundos, em um gráfico de escala logarítmica.

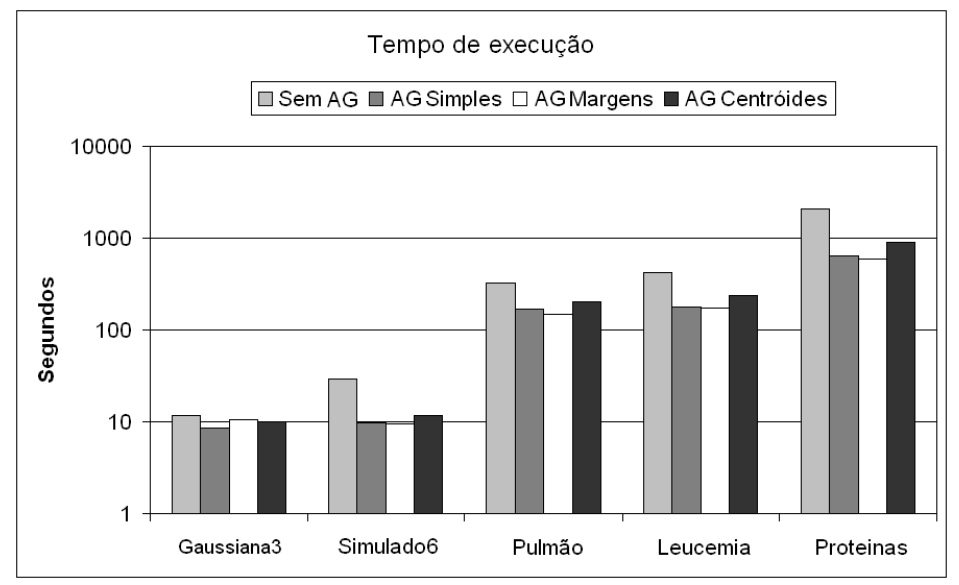

Figura 5.2: Tempo de execução total de cada experimento.

A figura mostra uma redução no tempo de execução quando AGs foram utilizados com os parâmetros descritos. Essa redução ocorreu porque muitas características dos indivíduos são preservadas entre as gerações durante a execução do AG. Desta forma, não é necessário refazer o cálculo dessas características, pois bons grupos encontrados em gerações anteriores não necessitam de muito aprimoramento. O desempenho de cada experimento foi medido utilizando o critério de validação CR, dado pela Equação 2.30, e a média dos índices obtidos é apresentada pela Figura 5.3 .

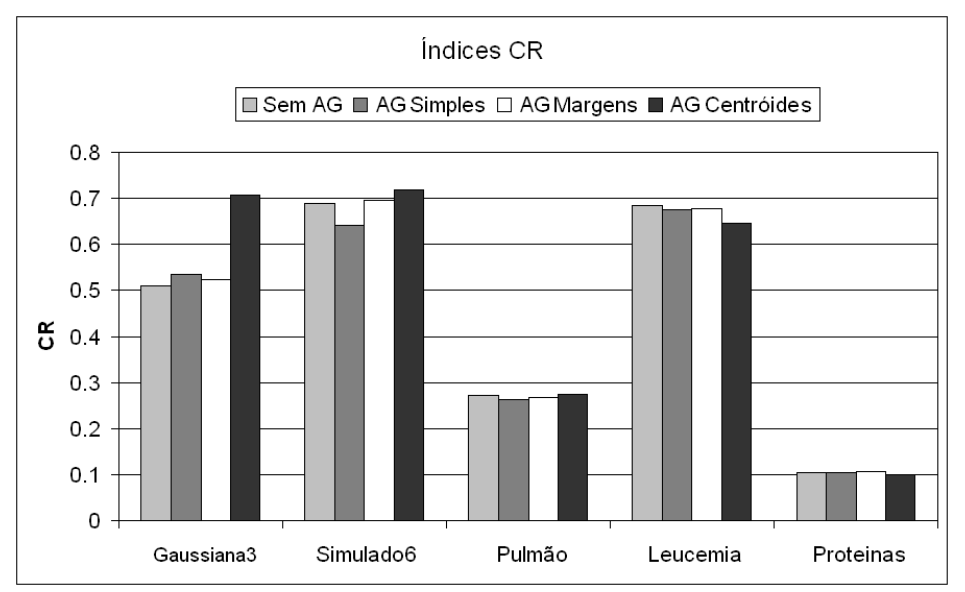

Figura 5.3: Índices médios obtidos pelo critério CR para as bases de dados estudadas.

Nas bases Gaussiana3 e Simulado6 houve um aumento do índice CR na utilização de AGs com cruzamento por margens e centróides. Nos agrupamentos 
em que há a redução desses índices, a diferença está dentro do desvio padrão calculado. Os únicos resultados cujos índices CR e MSE são consideravelmente piores que os índices obtidos por $k$-médias simples foram os resultados do AG com cruzamento simples, que por esse motivo não foi utilizado nos experimentos seguintes.

É necessário destacar o fato que o AG utilizado tem como objetivo aprimorar o MSE do $k$-médias e que a sua redução não implica em um aumento dos valores da CR. Algumas vezes o aumento da CR não ocorre porque grupos mais compactos nem sempre se aproximam dos grupos "reais" da base de dados.

\subsection{KMGA com função de aptidão baseada em MSE}

Com o objetivo de estudar o comportamento do algoritmo KMGA, descrito na Seção 5.2, os experimentos da Seção 5.3 foram feitos com novas características, descritas na Tabela 5.2. O desempenho do algoritmo KMGA foi comparado com o algoritmo $k$-médias, com inicialização aleatória dos grupos.

Nesse experimento, foram utilizados os critérios de validação Silhueta e VRC, descritos na Seção 2.5, foram aplicados aos agrupamentos obtidos. Esses critérios foram escolhidos porque seus resultados dependem apenas do agrupamento e não do algoritmo empregado. Eles também não favorecem resultados formados por mais ou por menos grupos e permitem comparar os resultados de diferentes algoritmos aplicados a um mesmo conjunto de dados.

População composta por 30 indivíduos
Execução máxima de 100 gerações
Aptidão baseada no MSE da distância Euclidiana dos agrupamentos
Elitismo
Seleção por Torneio
Cruzamento por margens e por centróides com 0,5 de chance
Mutação bitwise com 0,05 de chance por gene
Critério de parada de cinco gerações sem melhorias nos resultados

Tabela 5.2: Características do algoritmo KMGA baseado em MSE.

Além da execução do algoritmo KMGA, as bases de dados foram agrupadas com o algoritmo $k$-médias, utilizando distância Euclidiana como medida de dissimilaridade. Os centróides foram calculados com a média aritmética entre os padrões dos grupos. Cada base foi agrupada 100 vezes, com agrupamentos iniciais aleatórios, para cada valor fixo de grupos. O número de grupos variou de 2 a 10, com exceção da base Proteínas, que foi agrupada em até 30 grupos. O agrupamento com menor MSE foi escolhido como o melhor agrupamento encontrado. A Figura 5.4 apresenta a média dos índices dos critérios de validação VRC, 
Silhueta e CR dos agrupamentos com menor MSE, formados por $k$-médias e duas diferentes versões do KMGA, para cada base de dados. Uma das variações utiliza o operador de cruzamento por margens e a outra o cruzamento por centróides. O critério de validação FOM chegou a ser aplicado, mas seu tempo de execução se mostrou proibitivo e, por não ser um critério seguro para comparar agrupamentos com diferentes números de grupos ou obtidos com medidas de similaridade diferentes (Faceli et al., 2005b), foi descartado.

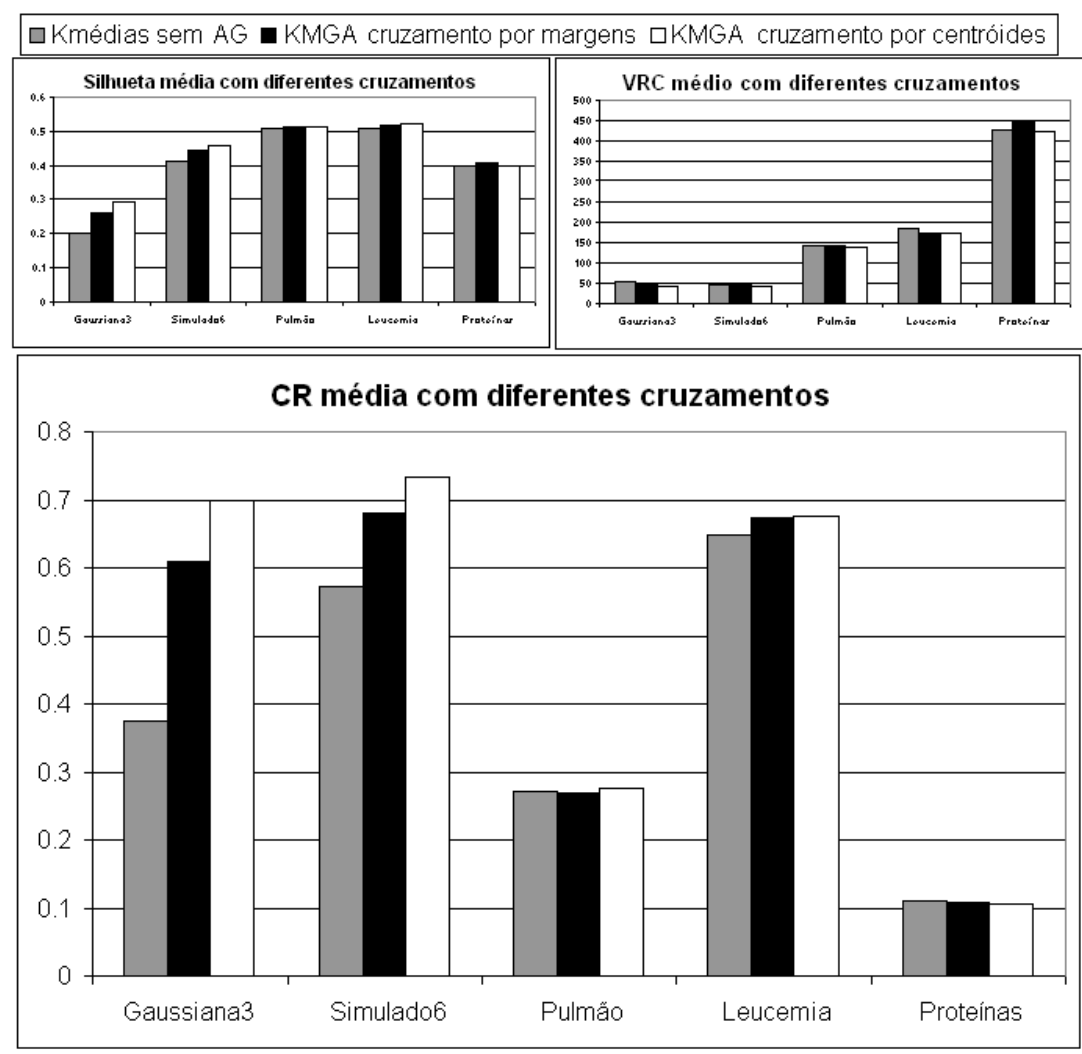

Figura 5.4: Média dos índices dos critérios de validação dos agrupamentos com menor MSE para cada base de dados.

A média do CR resultante do $k$-médias sem a utilização de AG diminuiu em relação ao experimento descrito na Seção 5.3. mesmo sendo executado com as mesmas características e parâmetros. Apesar da seleção aleatória do agrupamento inicial ter obtido um bom desempenho no experimento descrito na Seção 5.3, ela não teve um desempenho semelhante no experimento atual, segundo o critério de validação CR. Além disso, os melhores resultados de ambos os experimentos estão muito acima da média, conseqüência da alta variabilidade do algoritmo. Neste experimento, a diferença entre o melhor resultado e a média dos resultados é proxima de 8,47 vezes o desvio padrão.

Os agrupamentos das bases Gaussiana3 e Simulado6 obtiveram valores altos 
nos critérios de validação utilizados. A utilização de AGs possibilitou um aumento significativo na média da maioria dos critérios utilizados para essas bases. Os agrupamentos obtidos pelo algoritmo KMGA apresentam uma boa redução do desvio padrão dos resultados desses critérios, se comparada com $k$-médias sem AG.

Os resultados obtidos no agrupamento da base de dados Pulmão mostram baixos valores no índice CR, o que indica que os agrupamentos encontrados por $k$-médias não são muito próximos da estrutura real da base. Isso ocorre porque essa base é composta por grupos não esféricos e padrões distantes do seu grupo ou perto de outros. É possível perceber esse fato porque alguns dos resultados obtidos com os menores índices de MSE apresentam CR abaixo da média. Como os índices obtidos com o critério Silhueta foram altos e os valores do critério CR foram baixos, há um forte indício de sobreposições dos grupos. A utilização de AGs, da forma que foi implementada nesse experimento, não obteve melhoras significativas nos critérios de validação utilizados.

Os índices de validação obtidos pelos resultados dos agrupamentos da base Leucemia foram bem diferentes daqueles da base Pulmão. Esses índices foram altos para a maioria dos agrupamentos, o que mostra que a base é composta de grupos semi-esféricos e separados. O algoritmo KMGA obteve um pequeno aumento dos valores dos índices em relação ao $k$-médias, com exceção do critério VRC.

Os melhores índices foram obtidos com 4 e 8 grupos para o critério VRC, entre 4 e 8 grupos para o critério CR e 2 grupos para o critério Silhueta, quando a base de dados Pulmão foi agrupada. Isso demonstra como cada um desses critérios mede aspectos distintos dos agrupamentos. O critério VRC obteve bons índices para os agrupamentos com 4 e 8 grupos, que parecem ser grupos bem compactos e próximos. Já o critério CR obteve bons índices para os agrupamentos entre 4 e 8 grupos, que estão mais próximos do real, que contém 6 grupos. Apesar dos agrupamentos com 9 e 10 grupos dividirem os padrões com estrutura semelhante à real, a quantidade de grupos é maior, o que penaliza o agrupamento quando avaliado pelo critério CR. Por fim, o critério Silhueta obteve um índice mais alto no agrupamento com 2 grupos porque um dos grupos é muito maior que o outro. A predominância de um grupo aumento o valor do índice Silhueta.

A base Proteínas, quando dividida em 27 grupos, mostrou-se de difícil particionamento. Isso ocorre porque o número de grupos é elevado e muitos estão próximos ou sobrepostos. O KMGA não obteve um aumento significativo na maioria dos critérios, com exceção da VRC. O índice do critério CR para o KMGA é 
um pouco menor do que para o $k$-médias, porém a diferença se encontra dentro do desvio padrão.

\subsubsection{Análise do tempo de execução}

A Figura 5.5 apresenta o tempo de execução total de cada algoritmo ao agrupar as bases de dados. Apesar do algoritmo KMGA possuir um tempo de execução maior que o algoritmo $k$-médias, a diferença de tempo entre eles é próxima. Em alguns experimentos, o número de gerações executado pelo KMGA foi pequeno (menos de 20 na maioria dos casos) e por isso sua execução chegou a ser mais rápida que a execução do $k$-médias simples.

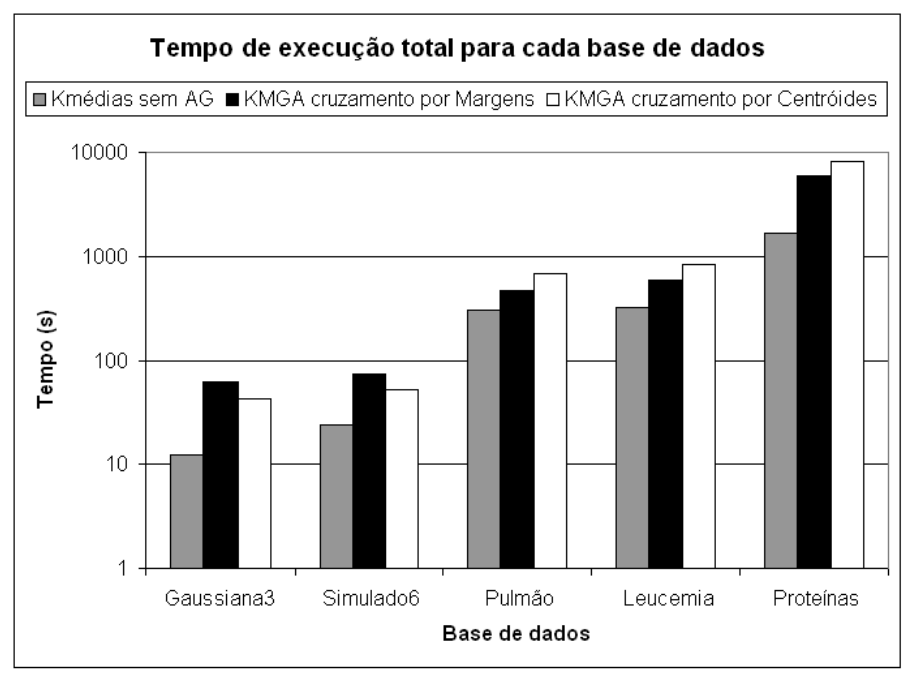

Figura 5.5: Tempo de execução total dos algoritmos para cada base de dados.

\subsection{KMGA com função de aptidão baseada em VRC}

Os experimentos descritos na Seção 5.4 foram repetidos com seleção segundo o critério de validação VRC, descrito na Seção 2.5. O algoritmo KMGA foi utilizado para agrupar cada base de dados descrita na Seção 5.1 em agrupamentos de 2 a 10 grupos, com exceção da base Proteínas, que foi agrupada em até 30 grupos. As características do algoritmo estão descritas na Tabela 5.3 .

Assim como no experimento descrito na Seção 5.4, as bases de dados foram agrupadas com o algoritmo $k$-médias, utilizando distância Euclidiana como medida de dissimilaridade. Os centróides foram calculados com a média aritmética entre os padrões dos grupos. Cada base foi agrupada 100 vezes, com agrupamentos iniciais aleatórios, para cada número de grupos. A diferença entre o experimento atual e o descrito na Seção 5.4 é o fato do agrupamento com maior VRC ser escolhido como o melhor agrupamento encontrado. A Figura 5.6 apresenta a média 


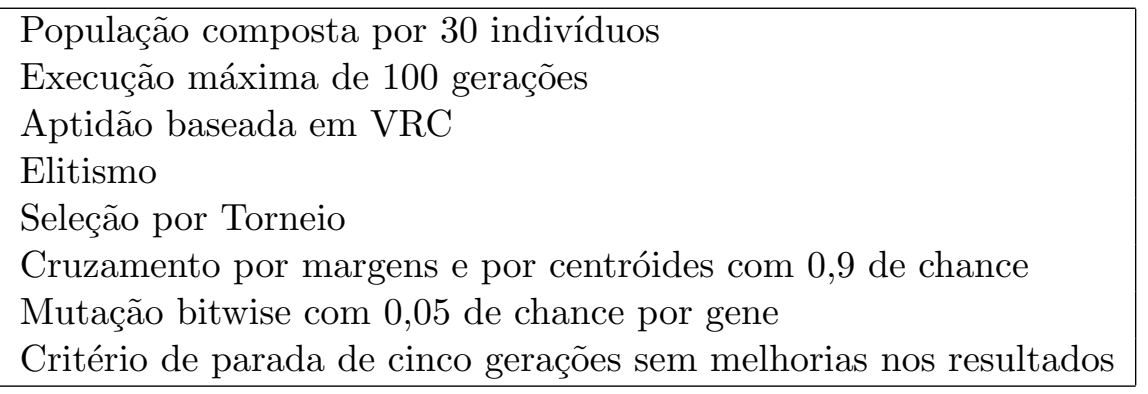

Tabela 5.3: Características do algoritmo KMGA usando VRC.

dos índices dos critérios de validação VRC, Silhueta e CR dos agrupamentos com maior VRC, formados por $k$-médias e as duas versões do KMGA, para cada base de dados.

Os agrupamentos obtidos com a base Gaussiana3 sofreram uma redução no índice CR em comparação com os experimentos anteriores, exceto para o agrupamentos de 3 grupos, que continuou a apresentar o resultado ótimo. Independente do critério de validação escolhido, o algoritmo $k$-médias não apresenta problemas em agrupar conjuntos de dados com grupos esféricos e separados, como esta.

Apesar dos índices CR serem maiores para as bases Simulado6 e Leucemia do que foram para as outras bases, ainda houve redução na maioria dos índices CR comparado ao experimento descrito na Seção 5.4. Os únicos agrupamentos que não tiveram os seus índices CR reduzidos foram os da base Proteínas.

A utilização de uma função de aptidão baseada em VRC possibilitou ao KMGA um aumento considerável na média dos índices obtidos por esse critério de validação em todas as bases, em comparação com $k$-médias. Os índices dos critérios Silhueta e CR também aumentaram em quase todos os agrupamentos feitos pelo KMGA.

Algumas vezes, a média dos índices $\mathrm{CR}$ do conjunto de resultados obtidos foi superior ao CR do resultado que apresenta maior VRC. Isso mostra que outros agrupamentos com estruturas mais próximas do agrupamento real foram encontrados pelo algoritmo aplicado. Porém, esses agrupamentos não foram selecionados por apresentarem um índice VRC menor do que o agrupamento escolhido. Portanto, é de interesse verificar se o agrupamento selecionado, ou seja, o agrupamento com maior VRC, apresenta bons índices $\mathrm{CR}$, o que é feito na Seção 5.5 .1 .

\subsubsection{Tendências dos critérios de validação}

Com o objetivo de evitar que agrupamentos bons fossem descartados, surgiu a necessidade de avaliar se o aumento no índice do critério utilizado para a seleção 

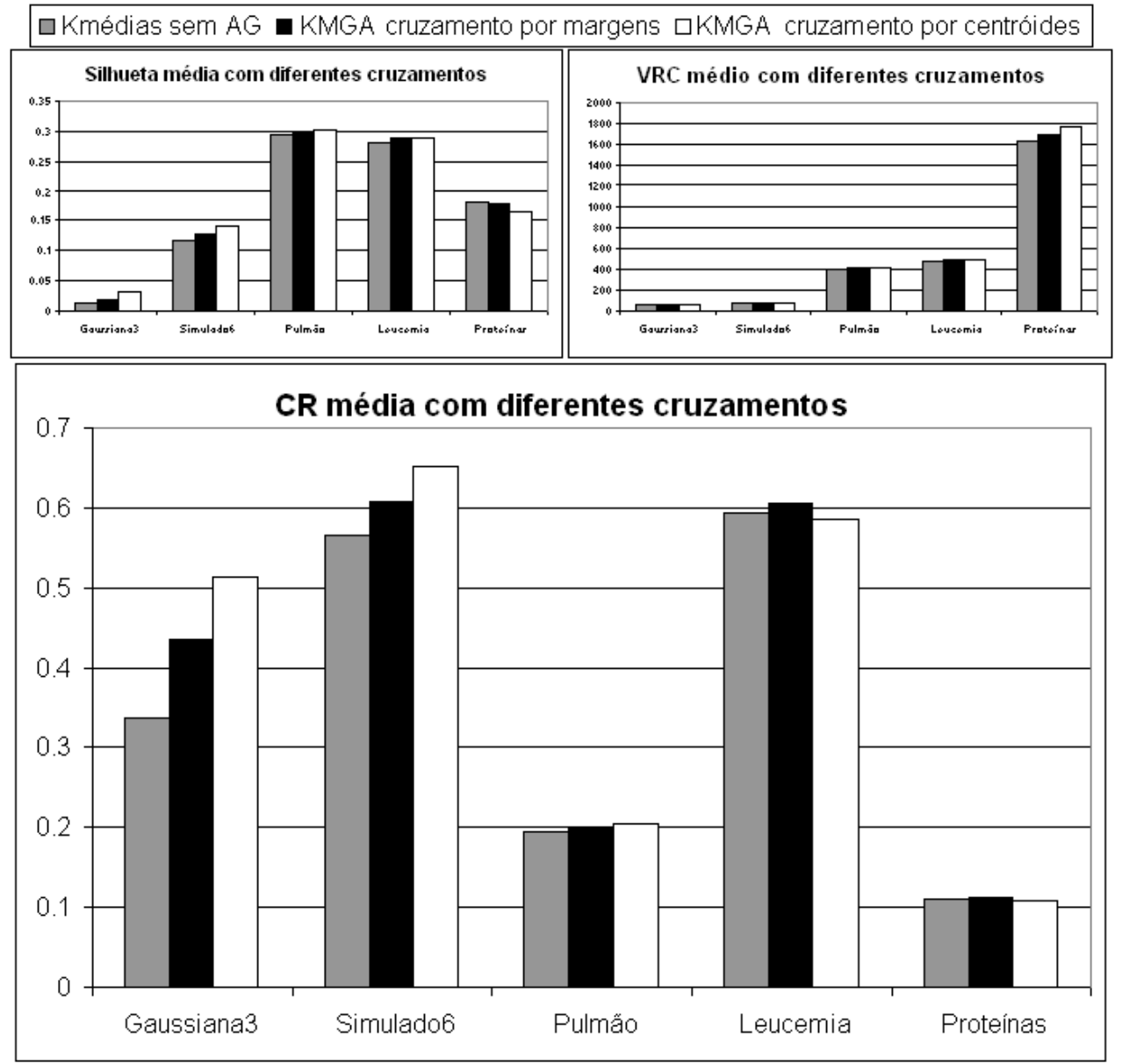

Figura 5.6: Média dos índices dos critérios de validação dos agrupamentos com maior VRC para cada base de dados.

dos agrupamentos também aproximaria a estrutura encontrada da estrutura real. Ao fazer a análise dos resultados, uma comparação simples entre os índices foi feita com o objetivo de encontrar semelhanças e diferenças entre os critérios internos VRC e Silhueta e o critério externo CR.

A comparação consistiu em medir as diferenças do índice de validação obtido pela melhor solução (segundo o critério de seleção) e a média dos índices das outras soluções. Por exemplo, um experimento cujo índice do critério $X$ obtido pelo indivíduo mais apto seja $x_{w}$ e a média dos índices para o mesmo critério obtidos pelos indivíduos da população final seja dada por $\bar{x}=\sum_{i=1}^{p} x_{i} / p$, em que $p$ é o tamanho da população. A diferença entre o índice do melhor indivíduo e a média dos índices é dada por $d_{X}=x_{w}-\bar{x}$. Portanto, se $d_{X}$ for positiva, então houve aumento do índice em relação a média e o experimento tende a obter índices maiores para o critério $X$. Caso $d_{X}$ seja negativa, houve uma redução no índice em comparação com a média e o experimento tende a obter índices 
menores para o critério analisado. Se $d_{X}=0$, o experimento tende a ser neutro quanto aos índices do critério $X$.

A Tabela 5.4 apresenta o porcentual da diferença entre os índices obtidos pelo indivíduo mais apto e a média dos indivíduos, para cada um dos critérios de validação utilizados no experimento descrito nessa seção. Como a quantidade de experimentos feitos para base Proteínas foi aproximadamente três vezes maior que para as outras bases, pois essa foi agrupada em até 30 grupos, o cálculo do porcentual foi feito duas vezes para permitir uma avaliação mais abrangente. O primeiro cálculo considerou todos os agrupamentos do experimento, sem distinção de base de dados, enquanto o segundo aplicou pesos iguais para os conjuntos de agrupamentos de cada base. Como o método de seleção do experimento é baseado no critério VRC, é esperado que haja aumento do índice para a maioria dos casos e nenhuma redução.

\begin{tabular}{|c|c|c|c|c|c|c|}
\hline \multirow{2}{*}{$\begin{array}{l}\text { Critério } \\
\text { utilizado }\end{array}$} & Cálculo & sem & pesos & Cálculo & com & pesos \\
\hline & negativa & positiva & nula & negativa & positiva & nula \\
\hline $\mathrm{CR}$ & $46,67 \%$ & $51,79 \%$ & $1,54 \%$ & $51,57 \%$ & $46,21 \%$ & $2,22 \%$ \\
\hline Silhueta & $67,18 \%$ & $31,28 \%$ & $1,54 \%$ & $64,85 \%$ & $32,91 \%$ & $2,22 \%$ \\
\hline $\mathrm{VRC}$ & $0,00 \%$ & $98,46 \%$ & $1,54 \%$ & $0,00 \%$ & $97,78 \%$ & $2,22 \%$ \\
\hline
\end{tabular}

Tabela 5.4: Porcentual da diferença entre o indivíduo mais apto e a média da população.

Como pode ser visto na Tabela 5.4, grande parte dos agrupamentos com maior VRC selecionados pelo experimento apresentam índices dos critérios CR ou Silhueta abaixo da média. O número de agrupamentos com tendência neutra é igual para todos os critérios, porque provêm de populações com indivíduos semelhantes. Isso ocorreu com apenas três agrupamentos de 2 grupos em bases de dados facilmente divisíveis nessa quantidade de grupos.

Esses resultados possibilitaram verificar se o aumento do critério utilizado durante o experimento se aproximou da estrutura real dos dados ou não. Para isso, as diferenças dos índices obtidos com os critérios VRC e Silhueta foram comparadas com as diferenças dos índices obtidos pelo critério CR. Se o experimento selecionou indivíduos acima da média ou abaixo da média para dois critérios, as diferenças entre o melhor indivíduo e a média calculadas para eles terão o mesmo sinal. Nesse caso, os critérios se comportaram de forma semelhante. A Tabela 5.5 mostra o porcentual de agrupamentos em que os critérios internos utilizados se comportaram de forma semelhante ao critério CR.

Como pode ser visto na Tabela 5.5, o critério Silhueta se comportou de forma semelhante ao critério CR em $60 \%$ dos agrupamentos do experimento (VCR e 


\begin{tabular}{|c|r|c|r|}
\hline $23,08 \%$ & $36,92 \%$ & $30,26 \%$ & $9,74 \%$ \\
\hline VRC e & Somente & Somente & Nenhum \\
Silhueta & Silhueta & VRC & Critério \\
\hline
\end{tabular}

Tabela 5.5: Porcentual de agrupamentos cujos critérios se comportaram de forma semelhante ao critério CR.

Slhueta mais Somente Silhueta), 6,66\% a mais que o critério VRC. O CR se comportou de forma distinta dos outros critérios em quase $10 \%$ dos agrupamentos do experimento, sendo que esses agrupamentos estão divididos entre todas a bases, com exceção da base Leucemia.

\section{Tendências dos critérios em relação ao número de grupos}

A análise do comportamento dos índices obtidos pelos critérios de validação nesse experimento também levou em conta o número de grupos dos agrupamentos validados e como os índices dos critérios reagem à variação desse número. Os critérios VRC e Silhueta apresentaram comportamentos semelhantes para as bases Gaussiana3, Simulado6 e Leucemia. Porém, esse fato não ocorreu para as outras bases de dados agrupadas nesse experimento. A maior diferença entre as três bases descritas e as restantes é que as demais apresentam maior sobreposição dos grupos em sua estrutura real. Além disso, a diferença de comportamento entre os critérios VRC e Silhueta aumenta com número de grupos, sendo que o critério VRC obteve índices maiores, na maioria dos experimentos, com o aumento do número de grupos e o critério Silhueta obteve índices menores com esse aumento.

\subsubsection{Análise do tempo de execução}

Os tempos de execução total do agrupamentos das bases de dados estudas pelos algoritmos KMGA e k-médias com seleção por VRC pode ser visto na Figura 5.7.

O algoritmo KMGA necessitou de mais tempo de execução para agrupar todas as bases de dados, sendo que o cruzamento utilizando centróides exigiu mais tempo que o cruzamento por margens. As maiores diferenças de tempo entre os algoritmos KMGA e $k$-médias ocorreram nas maiores bases: Pulmão, Leucemia e Proteínas.

Os tempos de execução obtidos nesse experimento não são comparáveis aos do experimento com MSE, descrito na Seção 5.4 , porque os experimentos foram executados em máquinas com arquiteturas e sistemas operacionais distintos. 


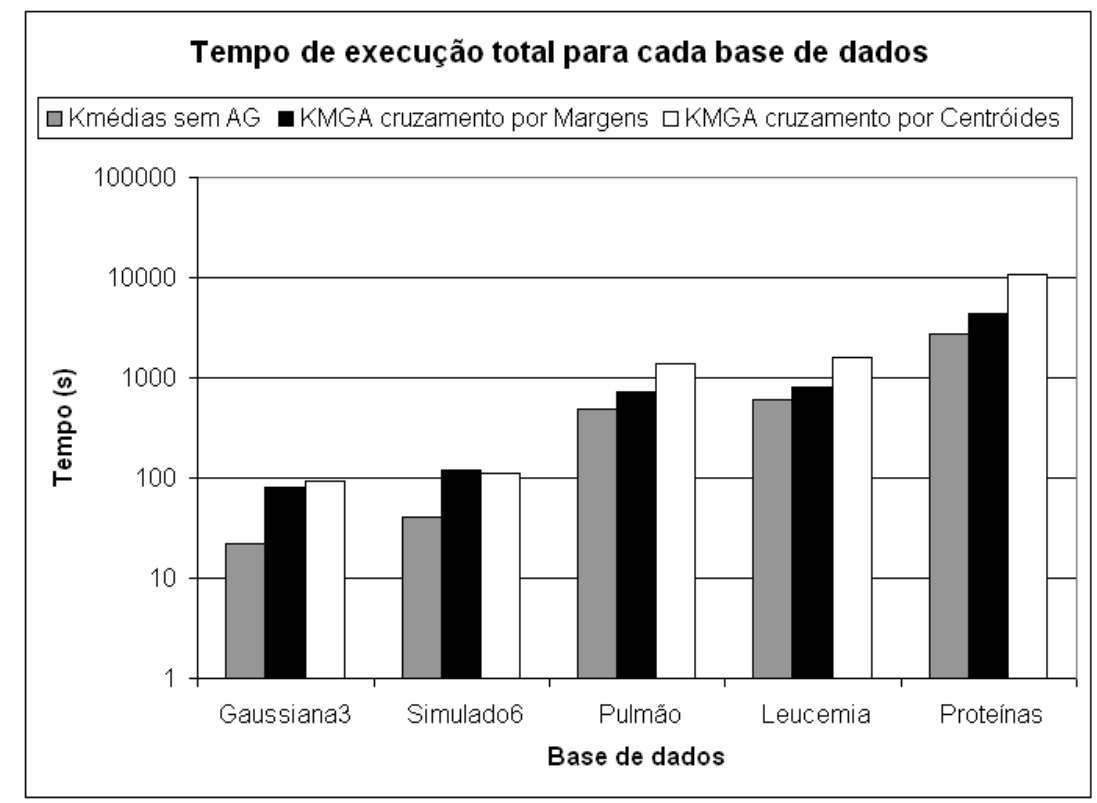

Figura 5.7: Tempo de execução total dos algoritmos para cada base de dados.

\subsection{KMGA com função de aptidão baseada em Silhueta}

Os resultados da análise feita na Seção 5.5.1 mostraram que o critério de validação Silhueta apresenta valores acima da média em grande parte dos agrupamentos próximos da estrutura real dos dados, indicado pelo valor do critério CR acima da média. Um experimento com as mesmas características do experimento descrito na Seção 5.5 foi executado substituindo o critério de validação VRC pelo critério Silhueta. Esse experimento teve por objetivo estudar a utilização de uma função de aptidão baseada no critério de validação Silhueta. As principais características do algoritmo KMGA utilizado estão descritas na Tabela 5.6.

\begin{tabular}{|l|}
\hline População composta por 30 indivíduos \\
Execução máxima de 100 gerações \\
Aptidão baseada em Silhueta \\
Elitismo \\
Seleção por Torneio \\
Cruzamento por margens e por centróides com 0,9 de chance \\
Mutação bitwise com 0,05 de chance por gene \\
Critério de parada de cinco gerações sem melhorias nos resultados \\
\hline
\end{tabular}

Tabela 5.6: Características do algoritmo KMGA usando Silhueta.

Assim como no experimento descrito na Seção 5.4 e 5.5, as bases de dados foram agrupadas com o algoritmo $k$-médias, utilizando distância Euclidiana como medida de dissimilaridade. Cada base foi agrupada 100 vezes para cada valor fixo de grupos, com grupos iniciais aleatórios. No experimento atual, o agrupamento 
com maior Silhueta é selecionado. A Figura 5.8 apresenta a média dos índices dos critérios de validação VRC, Silhueta e CR dos agrupamentos com maior Silhueta, formados por $k$-médias ou KMGA, para cada base de dados.
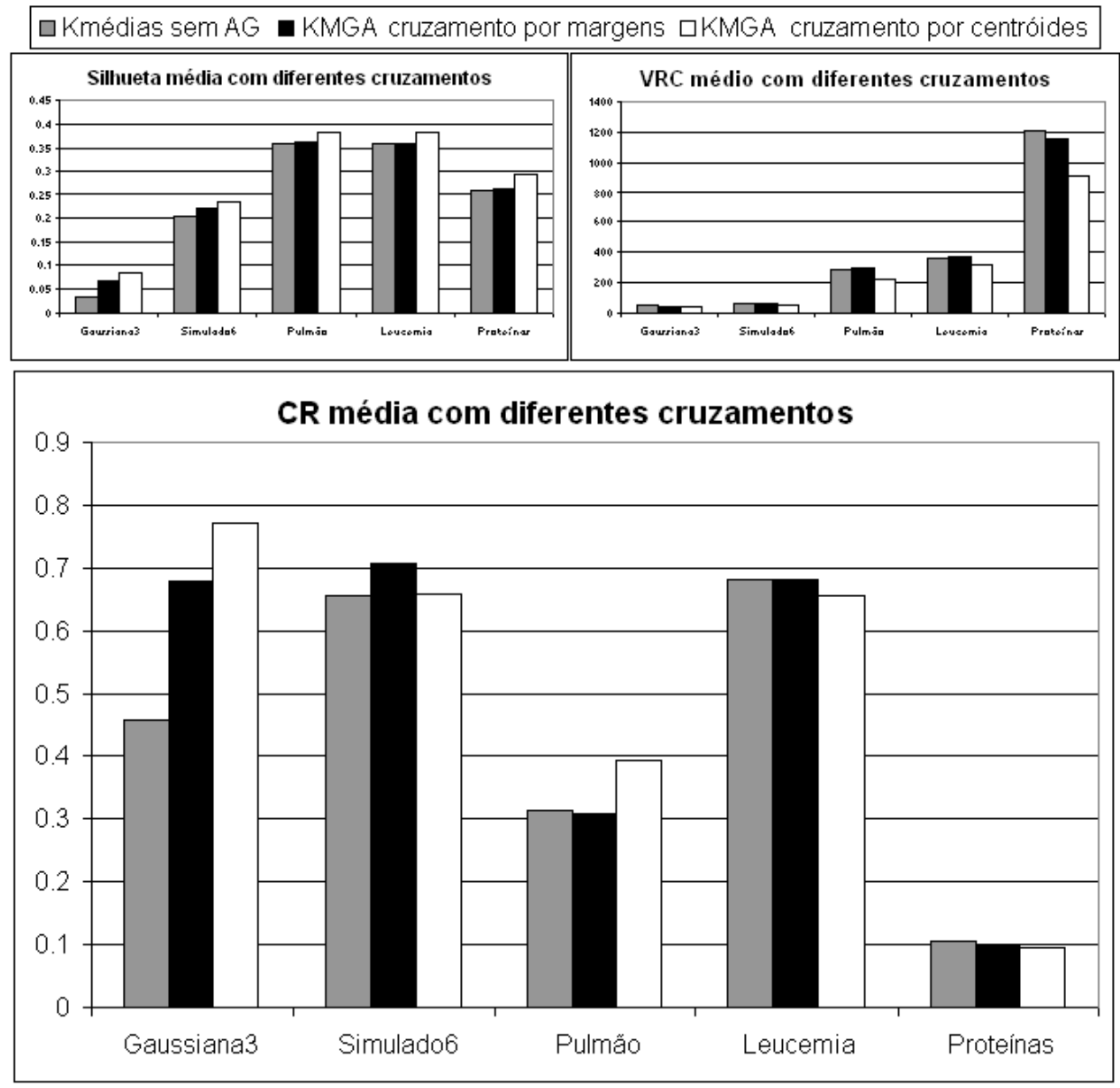

Figura 5.8: Média dos índices dos critérios de validação dos agrupamentos com maior Silhueta para cada base de dados.

As médias dos índices obtidos do critério CR para esse experimento foram maiores do que as obtidas nos experimentos descritos na Seção 5.3, 5.4 e 5.5, com exceção dos resultados do KMGA utilizando cruzamento com centróides para as bases Simulado6 e Leucemia. Os resultados obtidos pelo algoritmo KMGA e cruzamento por centróides foram os que obtiveram maiores índices Silhueta para todas as bases, seguido do KMGA com cruzamento por margens. A única base que não sofreu alteração nos índices obtidos por CR foi Proteínas.

O algoritmo KMGA, especialmente com cruzamento por centróides, apresentou um pequeno aumento nos índices dos critérios Silhueta e CR. O aprimoramento excessivo dos agrupamentos pelo critério Silhueta fez com que surgissem agrupamentos degenerados. Esses agrupamentos não mostram a estrutura real 
dos dados, mas são artefatos da seleção baseada no critério Silhueta. Na maioria dos casos, são agrupamentos com poucos grupos contendo muitos padrões e muitos grupos contendo poucos padrões. A partir desse ponto, refere-se a esse efeito como aglomeração de grupos. Ele foi constatado nos agrupamentos que utilizaram cruzamento com centróides para as bases Simulado6 e Leucemia e obtiveram baixo índice para o critério CR. Também constatou-se que o critério VRC obteve índices muito baixos nos agrupamentos em que há aglomeração de grupos.

A base Pulmão continuou apresentando dificuldades para ser agrupada obedecendo à sua estrutura real, o que reflete nos baixos índices CR. Mesmo assim, houve aumento nos índices do critério em comparação com os experimentos anteriores.

Não houve progresso no agrupamento da base de dados Proteínas, baseado em sua estrutura de 27 grupos. Comparando os experimentos que aprimoram os critérios VRC e Silhueta foi possível constatar que enquanto um aumentou, o outro foi reduzido.

A Figura 5.9 apresenta a média dos índices obtidos com o critério CR para os agrupamentos gerados pelos experimentos utilizando MSE, VRC e Silhueta como função de aptidão, descritos nas Seções 5.4, 5.5 e 5.6, respectivamente.

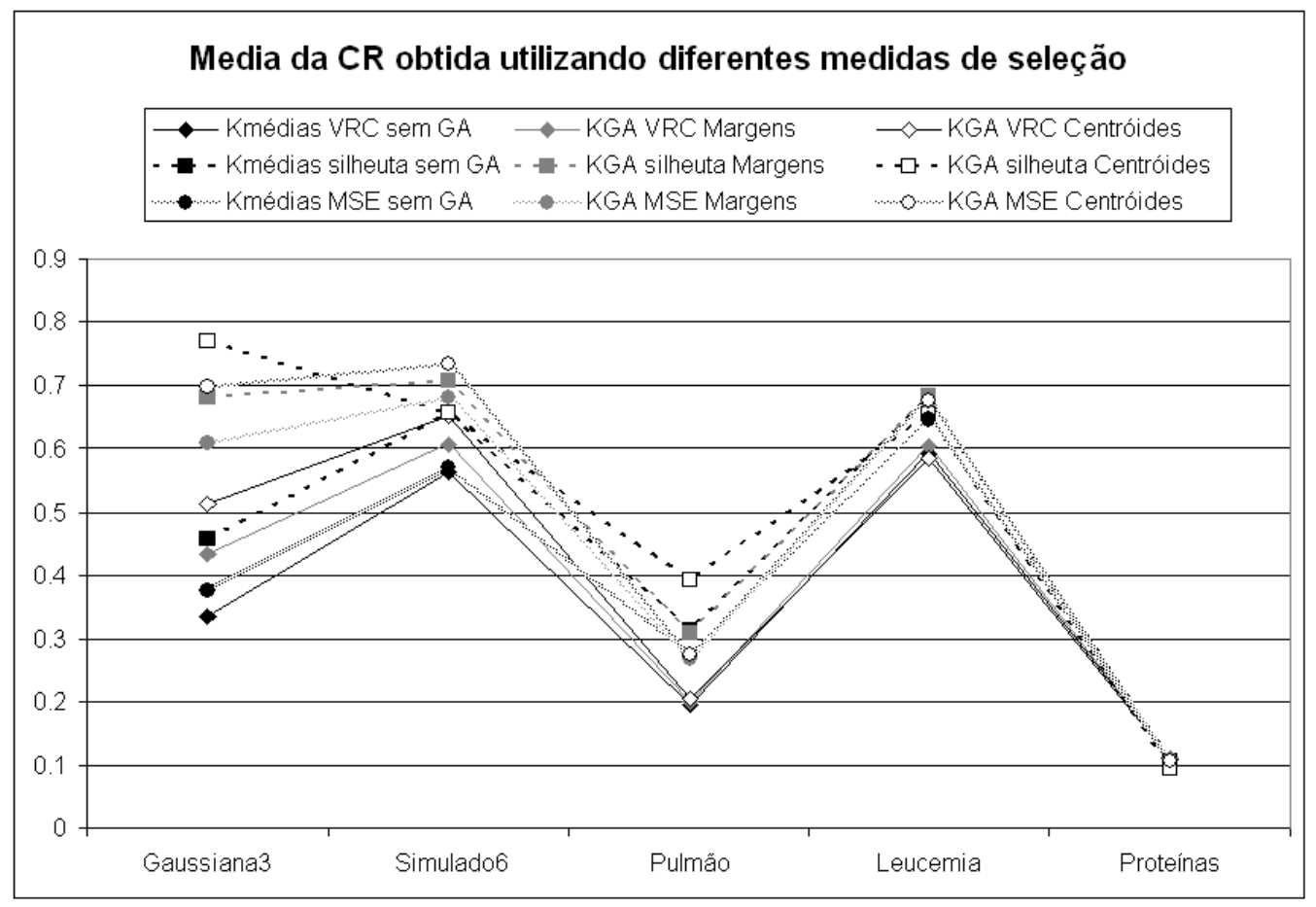

Figura 5.9: Média da CR obtida pelos experimentos usando diferentes funções de aptidão.

Segundo a Figura 5.9, os índices do critério CR obtidos pelos agrupamentos 
selecionados usando o critério Silhueta foram maiores do que os originados de outros experimentos, resultando no melhor desempenho para a maioria dos casos. Apenas os experimentos com cruzamento por centróides obtiveram baixos índices ao agrupar as bases Simulado6 e Leucemia, causados pela aglomeração de grupos. O algoritmo KMGA com função de aptidão baseada em Silhueta e cruzamento por centróides obteve os melhores índices para as bases Gaussiana3 e Pulmão. Ele também apresentou as maiores médias dos índices CR para a base de dados Pulmão.

O segundo melhor desempenho foi obtido pela utilização do MSE como função de aptidão, também usando KMGA com cruzamento por centróides. Esse experimento apresentou a melhor média dos índices do critério CR para a base Simulado6.

Apesar dos agrupamentos selecionados pelo critério VRC não terem obtido uma média de índices tão alta quanto as médias dos outros experimentos, a utilização do critério VRC pode ser importante para detectar o efeito de aglomeração de grupos, causado pela seleção baseada em Silhueta. Os experimentos mostram que o critério VRC resultou em índices baixos para agrupamentos que apresentam esse efeito.

\subsubsection{Tendências dos critérios de validação}

Com o mesmo objetivo do estudo descrito na Seção 5.5.1, houve no experimento atual a necessidade de avaliar se o aumento no índice do critério Silhueta também aproximaria a estrutura encontrada da estrutura real e sua relação com o critério VRC. O mesmo critério de avaliação utilizado para comparar os índices obtidos no experimento com função de aptidão baseada em VRC, descrito na Seção 5.5 . foi utilizado para avaliar as tendências dos critérios no experimento atual. A diferença $d_{X}$ entre os índices dos critérios obtidos pela melhor solução, segundo o critério Silhueta, e as outras soluções foi calculada é utilizada para comparar as tendências entre os critérios. A relação entre essas diferenças é apresentada na Tabela 5.7 .

Como a quantidade de experimentos feitos para base Proteínas foi aproximadamente três vezes maior que para as outras bases, pois essa foi agrupada em até 30 grupos, o cálculo do percentual foi feito duas vezes para permitir uma avaliação mais abrangente. O primeiro cálculo considerou todos os agrupamentos do experimento, sem distinção de base de dados, enquanto o segundo aplicou pesos iguais para os conjuntos de agrupamentos de cada base.

Baseado na Tabela 5.7, foi possível constatar que os índices do critério CR obtidos pelo agrupamento com melhor Silhueta ficaram acima da média, na maioria 


\begin{tabular}{|c|c|c|c|c|c|c|}
\hline \multirow{2}{*}{$\begin{array}{l}\text { Critério } \\
\text { utilizado }\end{array}$} & Cálculo & sem & pesos & Cálculo & $\mathrm{com}$ & pesos \\
\hline & negativa & positiva & nula & negativa & positiva & nula \\
\hline $\mathrm{CR}$ & $38,46 \%$ & $57,95 \%$ & $3,59 \%$ & $27,46 \%$ & $67,87 \%$ & $4,67 \%$ \\
\hline Silhueta & $0,00 \%$ & $96,41 \%$ & $3,59 \%$ & $0,00 \%$ & $95,33 \%$ & $4,67 \%$ \\
\hline VRC & $74,36 \%$ & $25,05 \%$ & $3,59 \%$ & $71,14 \%$ & $24,19 \%$ & $4,67 \%$ \\
\hline
\end{tabular}

Tabela 5.7: Porcentual da diferença entre o indivíduo mais apto e a média da população.

dos experimentos. Quando o cálculo foi feito com pesos iguais para o conjunto de agrupamentos de cada base, os índices do critério CR estiveram acima da média em quase $70 \%$ dos resultados. Isso mostrou que o uso do critério Silhueta resultou em agrupamentos mais próximos da estrutura real dos dados utilizados, na maioria dos casos. Entretanto, os índices obtidos pelo critério VRC para o agrupamento de maior Silhueta foram menores que a média na maioria dos casos.

Nesse experimento, os resultados dos índices obtidos com os critérios VRC e Silhueta também foram comparadas com os resultados dos índices obtidos pelo critério CR. A Tabela 5.8 mostra o porcentual de agrupamentos em que os critérios internos utilizados se comportam de maneira semelhante ao critério CR.

\begin{tabular}{|c|r|r|r|}
\hline $22,05 \%$ & $39,49 \%$ & $34,87 \%$ & $3,59 \%$ \\
\hline VRC e & Somente & Somente & Nenhum \\
Silhueta & Silhueta & VRC & Critério \\
\hline
\end{tabular}

Tabela 5.8: Porcentual de agrupamentos cujos critérios se comportam de forma semelhante ao critério CR.

Ao utilizar uma seleção baseada no critério Silhueta, o número de agrupamentos em que o critério CR não se comportou de maneira semelhante a outros critérios foi reduzido de 9,74\% para 3,59\%. Assim como o terceiro experimento, o critério Silhueta obteve mais resultados em que se comportou de forma semelhante em relação ao critério CR, em comparação com critério VRC. Esses resultados e os analisados na Seção 5.5.1 mostraram que, para as bases de dados estudadas, os agrupamentos com maior índice obtido pelo critério de validação Silhueta se aproximaram mais da estrutura real da base de dados, em média.

\section{Tendências dos critérios em relação ao número de grupos}

Ao avaliar o comportamento do critério Silhueta em relação ao número de grupos, foi constatado que esse critério em geral apresentou índices menores com o aumento do número de grupos. Porém, mesmo com a redução dos índices, os agrupamentos encontrados ainda foram próximos ao agrupamento real. Os outros critérios estudados não apresentaram um comportamento específico em relação 
ao número de grupos para esse experimento.

\subsubsection{Análise do tempo de execução}

A Figura 5.10 apresenta o tempo de execução total dos agrupamentos das bases de dados estudas pelos algoritmos KMGA e $k$-médias, com seleção por Silhueta.

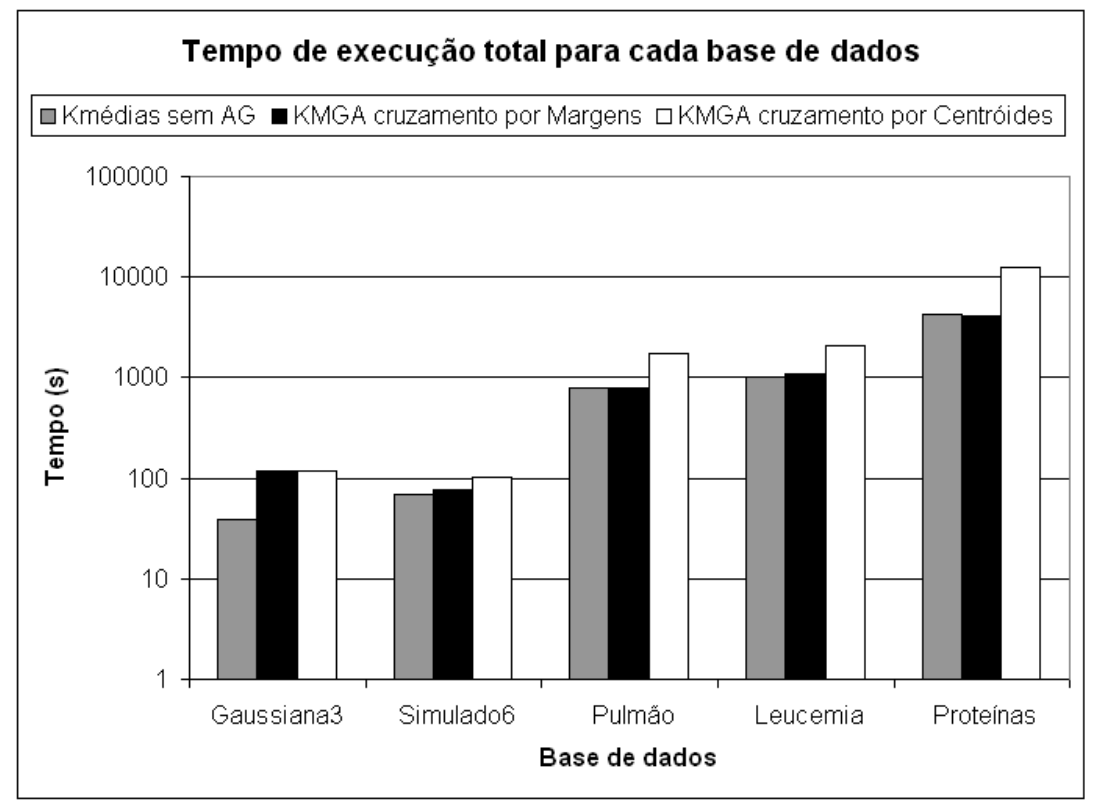

Figura 5.10: Tempo de execução total dos algoritmos para cada base de dados.

Assim como no experimento descrito na Seção 5.5, o algoritmo KMGA necessitou de mais tempo de execução para agrupar todas as bases de dados na maioria dos casos. O algoritmo KMGA utilizando cruzamento por margens obteve um tempo de execução muito próximo ao algoritmo $k$-médias, com exceção das bases Gaussiana3 e Proteínas, cujos tempos de execução do algoritmo KMGA foram maior para a primeira e menor para a segunda.

O algoritmo KMGA com cruzamento utilizando centróides apresentou maior tempo de execução em todas as bases e exigiu até três vezes mais tempo do que os outros experimentos. As maiores diferenças de tempo entre os algoritmos KMGA e $k$-médias ocorreram nas maiores bases: Pulmão, Leucemia e Proteínas.

Esses experimentos foram executados nas mesmas condições que o experimento descrito na Seção 5.4, incluindo máquina e sistema operacional, o que permite uma comparação dos desemepenhos. De acordo com o tempo de execução de cada experimento, apresentados nas Figuras 5.5 e 5.10, os algoritmos selecionados por Silhueta utilizaram um tempo execução maior. Isso era esperado, pois o cálculo da Silhueta dos agrupamentos exige um tempo de processamento maior, uma vez que o cálculo do MSE é feito e armazenado durante a execução 
do $k$-médias.

\subsection{KMGA usando k-médias com múltiplas medidas de dis- similaridade}

O resultado do algoritmo $k$-médias depende da medida de dissimilaridade utilizada durante sua execução, pois diferentes medidas de similaridade podem obter resultados distintos, devido as suas diferentes características, descritas na Seção 2.3. Como cada base de dados pode apresentar uma distribuição estatística diferente, diferentes medidas de similaridade podem fazer com que o algoritmo $k$-médias apresente uma maior flexibilidade para a execução do agrupamento.

Nos experimentos executados nas Seções 5.3, 5.4, 5.5 e 5.6, a medida de dissimilaridade utilizada foi a distância Euclidiana, dada pela Equação 2.6. Nesta seção o algoritmo $k$-médias foi executado com múltiplas medidas de dissimilaridade. As medidas de dissimilaridade utilizadas estão descritas na Seção 2.3 e são representadas por uma letra, ambos listados na Tabela 5.9.

\begin{tabular}{|l|}
\hline Distância Euclidiana (e) \\
Distância Euclidiana harmônica (h) \\
Distância de Manhattan (b) \\
Coeficiente de correlação de Pearson (c) \\
Distância absoluta de Pearson (a) \\
Separação angular (u) \\
Distância angular absoluta (x) \\
Correlação de Spearman (s) \\
Kendall’s tau (k) \\
Distância Mahalanobis (m) \\
\hline
\end{tabular}

Tabela 5.9: Medidas de dissimilaridade utilizadas.

A escolha da medida a ser utilizada é feita de duas formas: aleatoriamente, no caso de $k$-médias simples e para os indivíduos da primeira população do KMGA, ou herdada dos cromossomos de indivíduos pais durante o cruzamento. No KMGA, a medida de dissimilaridade é anexada à segunda parte do cromossomo do indivíduo e é herdada pelos indivíduos filhos com chances proporcionais as aptidões de seus pais. O operador de mutação pode alterar a medida de um indivíduo com a mesma probabilidade de qualquer outro atributo. Caso a mutação aconteça, uma nova medida é escolhida aleatoriamente para substituir a antiga.

Durante os experimentos, as distâncias Euclidiana harmônica e Mahalanobis apresentaram um tempo de execução excessivamente longo, sem melhorias significativas nos resultados. Por esse motivo foram excluídas da seleção. Além disso, a distância Mahalanobis apresenta um desvio padrão maior do que as demais e 
necessita de um número significante de gerações a mais que as outras para obter erros menores (Bezdek et al., 1994). Como o número de atributos dos padrões contidos nas bases é muito alto, o uso dessas medidas se torna proibitivo e os resultados insatisfatórios.

Nos experimentos com múltiplas medidas de similaridade, é necessário que haja uma avaliação comum aos agrupamentos resultantes do uso de diferentes medidas. Não é possível comparar os agrupamentos utilizando o MSE resultante do $k$-médias, pois cada medida retorna valores de diferentes naturezas (distância espacial, distância angular, correlação entre os atributos...) (Faceli et al., 2005a). Portanto, é preciso avaliar o agrupamento resultante, independente da técnica que o construiu.

Os critérios de validação Silhueta, VRC e CR avaliam os agrupamentos resultantes e não as técnicas que os construíram (Faceli et al. 2005b). Logo, são adequados para avaliar os agrupamentos gerados por medidas de dissimilaridade distintas. Porém, por ser externo, o critério CR utiliza o conhecimento da estrutura real dos dados para validar o agrupamento. Se o processo de agrupamento utiliza esse conhecimento, não poderá ser caracterizado como não-supervisionado. Portanto, faz-se necessária a utilização de critérios internos de validação. Por esse motivo, apenas os critérios VRC e Silhueta foram utilizados para selecionar os melhores resultados dos experimentos descritos nessa seção.

\subsubsection{Experimentos feitos com aptidão baseada em VRC}

Os experimentos descritos nas Seções 5.5 e 5.6 foram refeitos com múltiplas medidas de dissimilaridade. Todas as características foram preservadas, exceto pelo número de execuções do $k$-médias sem AG, que subiu de 100 execuções para 300. Essa mudança foi feita em função da maior variedade de indivíduos, com o objetivo de possibilitar uma busca mais abrangente por soluções. Os índices obtidos pelos critérios de validação VRC, Silhueta e CR, para o experimento com função de aptidão VRC, são apresentados na Figura 5.11 .

Os resultados permitem concluir que a utilização de várias medidas de similaridade aumentou o valor do índice do critério VRC, obtido em 52,82\% dos agrupamentos, em comparação com o experimento que usou apenas a distância Euclidiana (descrito na Seção 5.5). A única base de dados em que houve pouco aumento dos índices obtidos por esse critério foi a Proteínas, que se desconsiderada faz com os índices VRC aumentem para 60,18\%. Algumas medidas acabaram predominando entre as utilizadas para algumas bases de dados específicas, ou seja, essas medidas encontraram estruturas mais próximas dessas bases.

Entretanto, 40,51\% dos agrupamentos obtiveram índices do critério VRC me- 

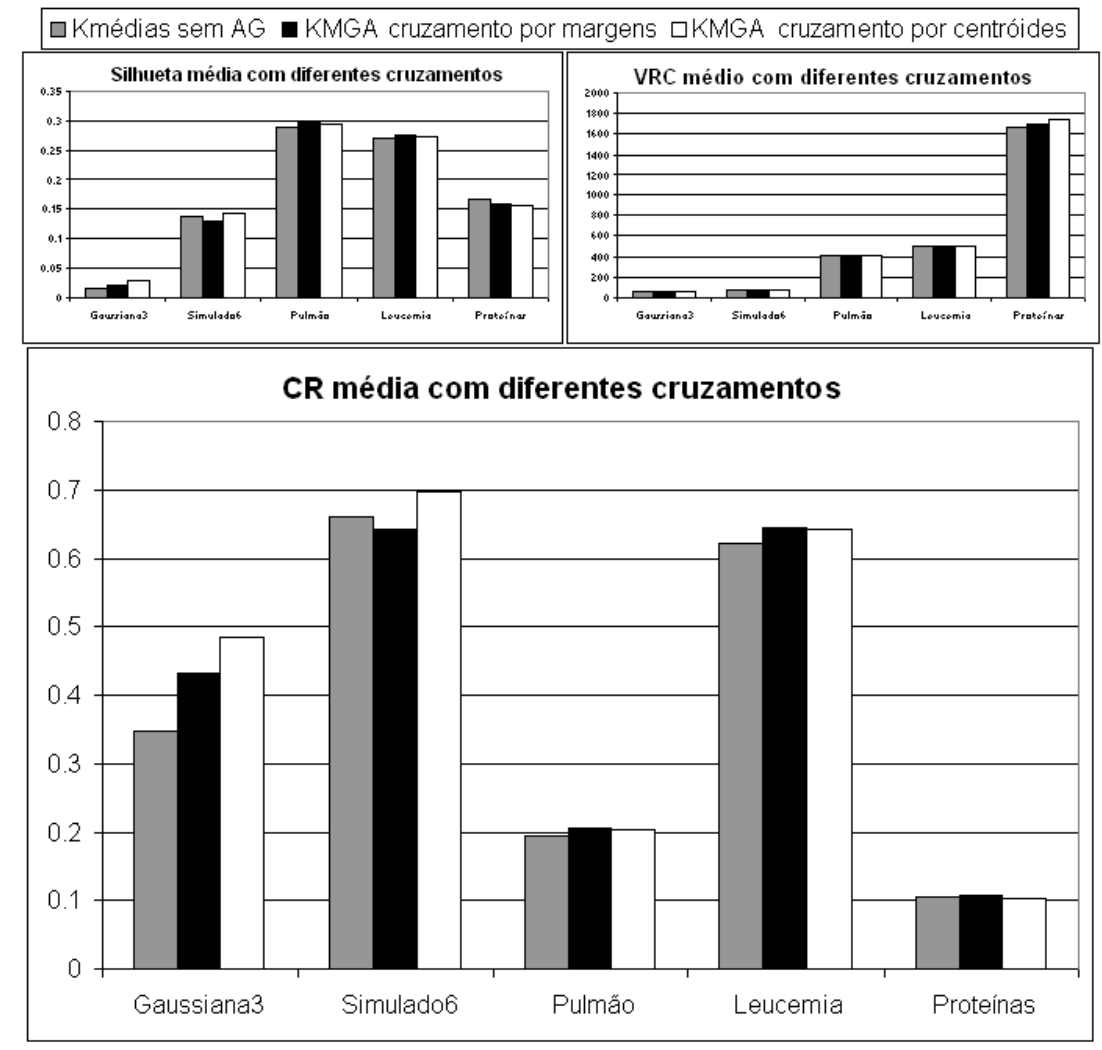

Figura 5.11: Média dos índices dos critérios de validação dos agrupamentos com maior VRC para cada base de dados.

nores que os obtidos pelo experimento que utilizou apenas distância Euclidiana. Ao isolar os resultados do experimento com múltiplas medidas que utilizaram a distância euclidiana, verificou-se que 19,15\% dos índices do critério VRC foram iguais ao experimento descrito na Seção 5.5, 38,30\% foram maiores e 42,55\% foram menores. Dos índices que aumentaram, 38,89\% receberam características transmitidas por operadores genéticos e $61,11 \%$ foram novos agrupamentos, ou seja, criados aleatoriamente. As características transmitidas por operadores genéticos foram obtidas de agrupamentos feitos com diversas medidas de dissimilaridade.

A redução dos índices VRC obtidos com a medida de distância Euclidiana ocorreu por causa da competição entre as várias medidas usadas no experimento. Essa competição reduziu a chance da medida de distância Euclidiana ser utilizada em conjunto com grupos iniciais que gerassem melhores resultados.

Houve um aumento na média do índice obtido por CR em 53,33\% dos agrupamentos em relação ao experimento que utilizou apenas distância Euclidiana. Porém, os agrupamentos resultantes apresentaram uma redução em 46,67\% das médias dos índices CR, se comparado com o mesmo experimento. Essa redução ocorreu em apenas 48,54\% dos experimentos em que houve um aumento simul- 
tâneo no índice VRC. Além disso, houve um aumento na CR em 51,46\% dos agrupamentos em que o índice VRC também aumentou. Esses fatos descartam a possibilidade de uma relação direta entre a redução da CR e o aumento da VRC nesse experimento.

O índice do critério Silhueta sofreu uma redução em 50,76\% dos agrupamentos em relação ao experimento que foi executado apenas com distância Euclidiana. Essa redução ocorreu em 55,33\% dos agrupamentos que tiveram aumento do índice VRC. Mesmo assim, houve um aumento do índice obtido por Silhueta em 43,07\% dos agrupamentos resultantes do experimento atual.

A utilização de várias medidas de dissimilaridade fez com que a variedade dos indivíduos no AG aumentasse. Porém houve uma redução no número de gerações executadas para a maioria dos experimentos.

Quanto à variação do número de grupos, os comportamentos dos índices obtidos por todos os critérios continuaram semelhantes aos do experimento com distância Euclidiana, com poucas variações. De maneira geral, o critério VRC apresentou uma discriminação maior em relação ao número de grupos do que o critério Silhueta, resultando em diferenças maiores entre agrupamentos com números de grupos próximos do número real e agrupamentos distantes do mesmo.

\subsubsection{Experimentos feitos com aptidão baseada em Silhueta}

O critério Silhueta também foi utilizado para selecionar os agrupamentos resultantes do $k$-médias e KMGA com múltiplas distâncias de dissimilaridade. Os índices obtidos pelos critérios de validação VRC, Silhueta e CR para o experimento com função de aptidão baseada em Silhueta são apresentados na Figura 5.12 .

A utilização de múltiplas medidas fez com que os índices obtidos aumentassem com o critério Silhueta em 48,72\% dos agrupamentos, em relação ao experimento que utilizou apenas distância Euclidiana (descrito na Seção 5.6). Dos agrupamentos que apresentaram índices Silhueta maiores, 17,89\% foram obtidos com a distância Euclidiana. Desses, 64,71\% receberam características de outros agrupamentos formados com diversas medidas. A utilização de múltiplas medidas foi responsável pelo aumento dos índices do critério Silhueta em 42,40\% dos agrupamentos, em relação ao experimento com uma única medida. Se a base Proteínas fosse retirada do cálculo, esse aumento subiria para $53 \%$.

Porém, 42,05\% dos índices foram reduzidos e 9,23\% dos agrupamentos continuaram os mesmos para o critério Silhueta. A causa dessa redução é semelhante a do experimento com múltiplas medidas e seleção por VRC, ou seja, a competição entre as várias medidas usadas no experimento. Essa competição reduziu a 


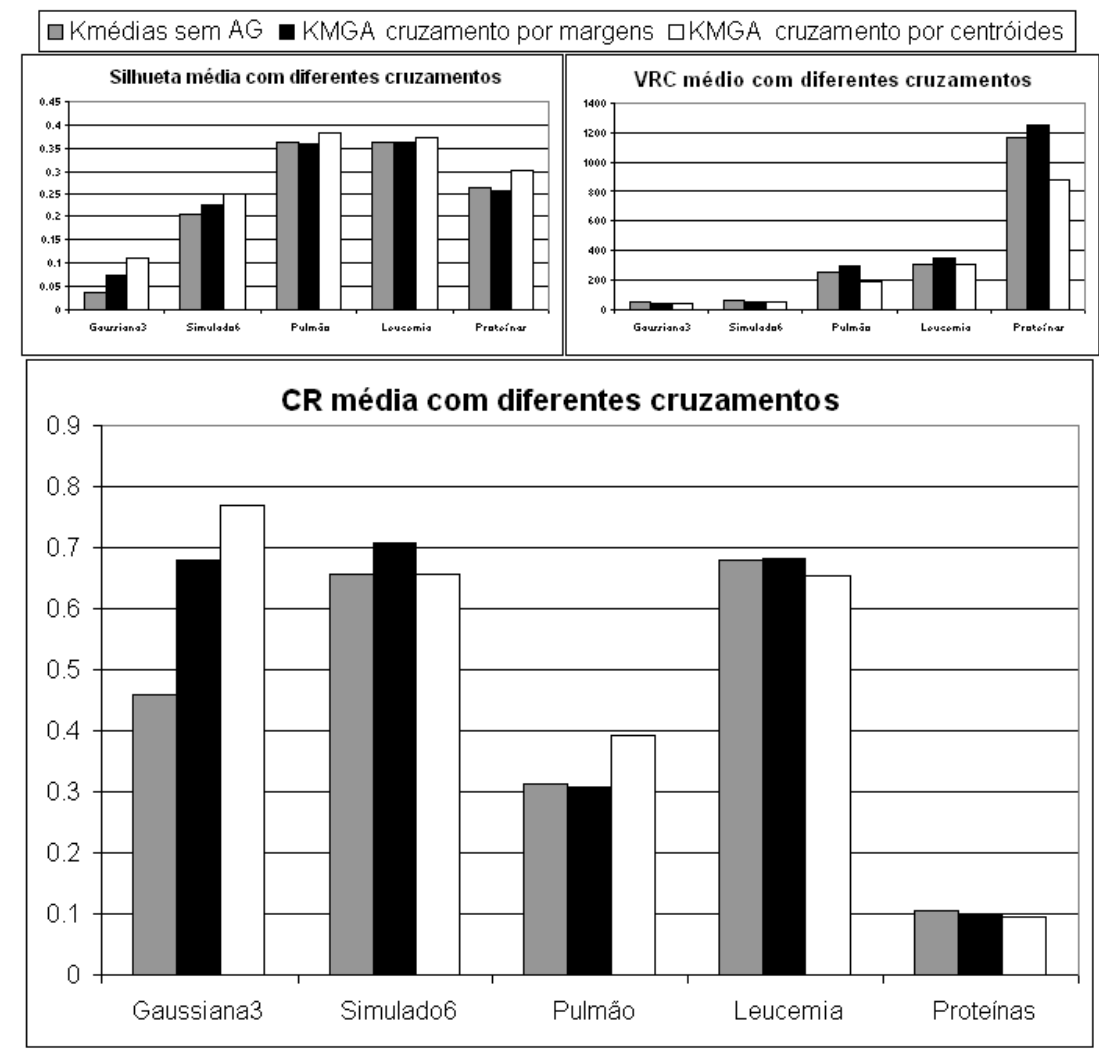

Figura 5.12: Média dos índices dos critérios de validação dos agrupamentos com maior Silhueta para cada base de dados.

chance das medidas de distância serem utilizadas com grupos inicias que gerassem resultados melhores para aquela medida específica.

Assim como no experimento com seleção por VRC, algumas medidas acabaram predominando entre as utilizadas para algumas bases de dados específicas. As medidas de dissimilaridade coeficiente de Pearson, distância Euclidiana e Manhattan foram as que obtiveram melhores resultados para as bases Gaussiana3, Pulmão e Leucemia respectivamente. Essa relação ocorreu em ambos os experimentos. Esses resultados apresentaram índices de validação maiores do que os experimentos em que apenas a medida de distância Euclidiana foi utilizada.

A média dos índices obtidos pelo critério de validação CR ficou muito próxima do experimento feito apenas com uma medida de dissimilaridade. Um total de 44,10\% dos agrupamentos apresentou aumento no índice obtido pelo critério CR, enquanto 45,12\% apresentou redução. Isso ocorreu porque, apesar do aumento dos índices obtido por CR nos agrupamentos das bases Gaussiana3 e Pulmão, houve uma redução dos mesmos para as bases Simulado6 e Leucemia. Essa redução foi causada em grande parte pela aglomeração de grupos, que ocorreu na maioria dos agrupamentos que obtiveram índices muito baixos do critério CR. Esse efeito 
também pode ser observado no experimento que utilizou somente a distância Euclidiana.

O critério de validação VRC obteve índices maiores em 36,41\% dos agrupamentos desse experimento em relação ao executado com distância Euclidiana e índices menores em 53,33\% dos agrupamentos. Desses agrupamentos, 70,19\% apresentaram um aumento nos índices obtidos por Silhueta. O critério VRC resultou em índices baixos nos experimentos em que a seleção por Silhueta apresentou o efeito de aglomeração de grupos.

A utilização de múltiplas medidas de dissimilaridade não demostrou alterações significativas em relação aos índices obtidos pelos critérios de validação, levando em consideração o número de grupos por agrupamentos. Os critérios apresentaram comportamento semelhante ao obtido no experimento com uma medida.

\subsection{KMGA com função de aptidão baseada em VRC e Si- Ihueta}

Como pode ser visto na Seção 5.6, os experimentos feitos com o algoritmo KMGA com aptidão baseada em Silhueta levaram a agrupamentos mais próximos da estrutura real dos dados, segundo o critério CR. Porém, o agrupamento de grande parte dos padrões em um único grupo e a geração de vários grupos pequenos contendo poucos padrões fez com que o índice obtido pelo critério Silhueta fosse alto. Esses agrupamentos não resultam em bons índices quando validados pelo critério VRC.

Para manter o desempenho do algoritmo KMGA com função de aptidão baseada em Silhueta e evitar o efeito de aglomeração de grupos, uma nova função de aptidão mista, baseada em Silhueta e VRC, dada pela Equação 5.2 para um indivíduo $i$, foi investigada.

$$
\operatorname{Apt}(i)=c_{1} * \alpha+c_{2} * \beta
$$

em que

$$
\begin{gathered}
\alpha=\left(\bar{s}(i)-\min _{j=1}^{p} \bar{s}(j)\right) / \max _{j=1}^{p} \bar{s}(j), \\
\beta=\left(V R C(i)-\min _{j=1}^{p} V R C(j)\right) / \max _{j=1}^{p} V R C(j),
\end{gathered}
$$

$c_{1}$ e $c_{2}$ são valores pré-definidos e $p$ é o tamanho da população. O valor de VRC é dado pela Equação 2.29 e $\bar{s}(j)$ é a média da Silhueta dos padrões da base de dados para o agrupamento $j$, calculada por $\bar{s}(j)=\sum_{z=1}^{n} s(z) / n$, em que $n$ é o número de padrões na base de dados e $s(z)$ é dado pela Equação 2.24 . Os valores 
de $\bar{s}(j)$ são normalizados no intervalo [0,2] antes do cálculo de apt $(i)$.

O algoritmo KMGA, com as características descritas na Tabela 5.6, foi executado utilizando a aptidão dada pela Equação 5.2 , com $c_{1}=0,6$ e $c_{2}=0,4$. A Figura 5.13 mostra a média dos índices obtidos pelo experimento que utilizou Silhueta como função de aptidão e pelo KMGA com a função de aptidão baseada em Silhueta e VRC.

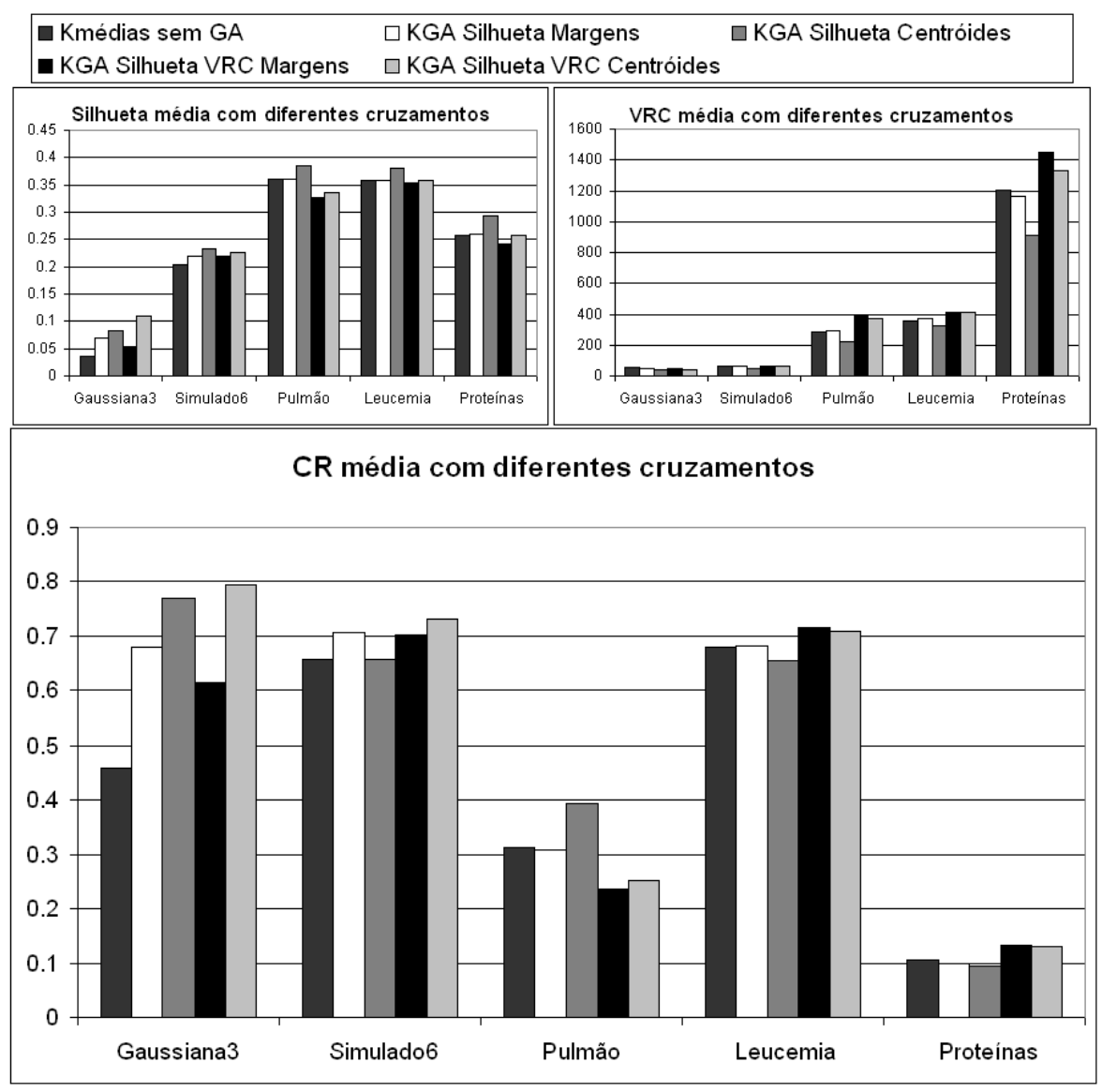

Figura 5.13: Média dos índices dos critérios de validação dos agrupamentos com maior aptidão para cada base de dados.

Assim como apresenta a Figura 5.13, o algoritmo com aptidão mista conseguiu obter as maiores médias do critério CR para quase todas as bases, as exceções foram as bases Gaussiana, para KMGA com margens, e Pulmão, para as duas variações de KMGA. O uso conjunto de VRC na função de aptidão evitou o efeito de aglomeração de grupos que ocorreu no experimento com aptidão baseada somente em Silhueta, nas bases de dados Simulado6 e Leucemia.

Porém, a média dos índices CR, obtidos para as bases Pulmão e Gaussiana3, dos experimentos feitos com cruzamento por margens foi reduzida em comparação com o experimento de aptidão baseada em Silhueta. Foi constatado que essa 
redução não foi consequência do efeito de aglomeração de grupos, mas do uso do VRC na função de aptidão.

Houve queda nos índices Silhueta em comparação com o experimento cuja função de aptidão era totalmente baseada em Silhueta. Contudo, houve aumento da Silhueta média dos agrupamentos gerados pelo algoritmo KMGA com cruzamento por centróides, resultando nos maiores índices do critério até esse ponto da pesquisa. Esses dados indicam que os resultados dos critérios de validação variam não somente com o algoritmo de agrupamento, mas também com a base que é agrupada. Ocorreu um aumento nos índices obtidos por VRC em relação ao mesmo experimento, causado pelo uso do VRC na função de aptidão.

\subsubsection{Análise do tempo de execução}

Os tempos de execução total do KMGA com aptidão baseada em Silhueta e do KMGA com aptidão mista são apresentados na Figura 5.14. Nela é possível ver que, excetuando o KMGA com aptidão mista e cruzamento por centróides para a base Simulado6, os algoritmos executaram em tempos muito próximos.

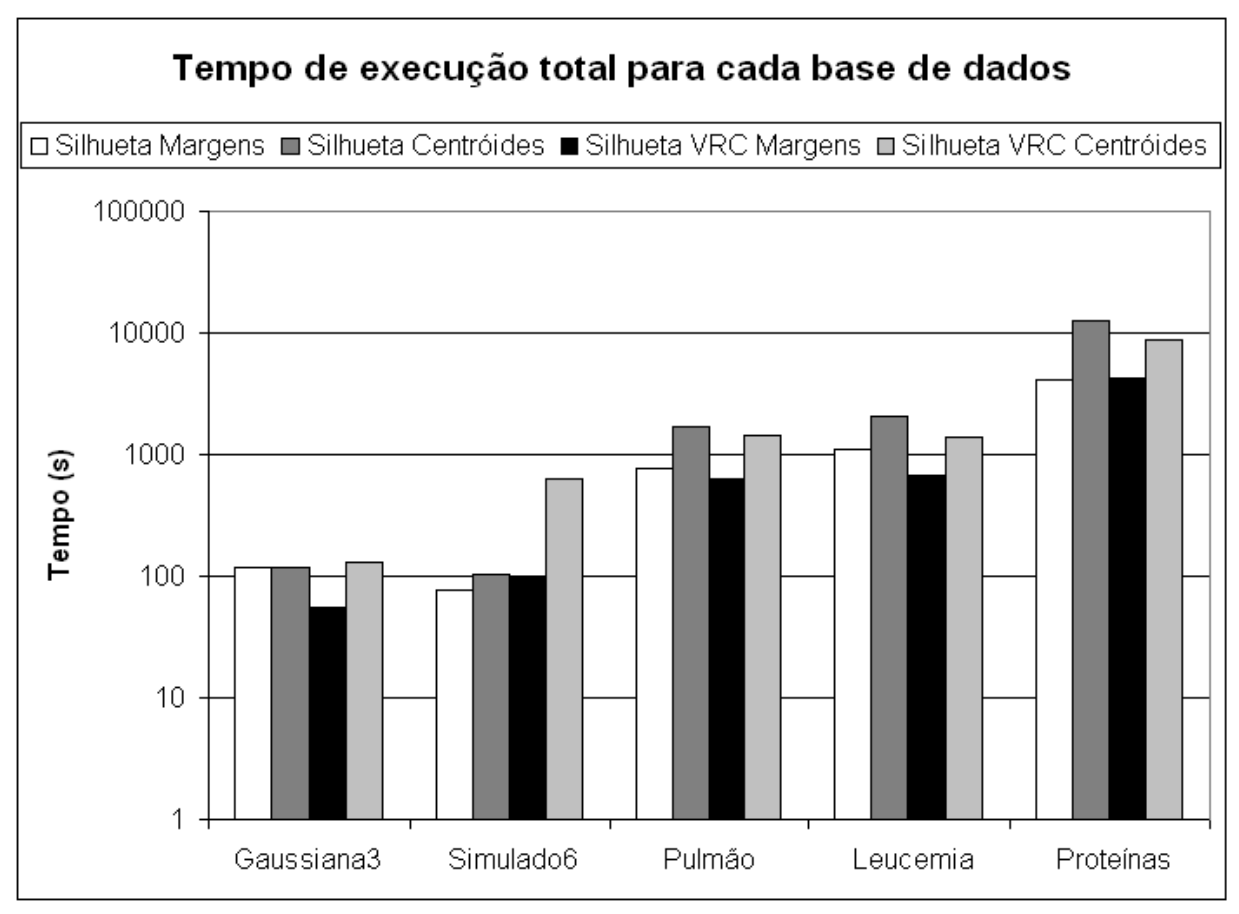

Figura 5.14: Tempo de execução do algoritmo KMGA com aptidão baseada em Silhueta e aptidão mista para cada base de dados.

Algumas vezes, o KMGA com aptidão mista executou em menos tempo que seu equivalente com o algoritmo KMGA com aptidão baseada em Silhueta. O motivo desse resultado foi a redução do número de gerações executadas no total, o número de algoritmos $k$-médias executados e a presença de grupos pouco 
ajustáveis pelo $k$-médias, herdados de outros indivíduos.

\subsection{KMGA Distribuído}

Conforme apresentado na Seção 3.2, AGPs são uma alternativa para aumentar a variedade da população e distribuir o processamento do AG entre vários processadores. Dentre os AGPs, podem ser destacados os AGDs, que são formados por conjuntos de populações executadas em paralelo. Esses algoritmos utilizam um modelo de ilhas em que grupos semi-isolados, chamados demes, executam AGs de forma independente, explorando regiões distintas do espaço de busca.

Durante o projeto, um AGD com demes compostos por versões distintas do algoritmo KMGA foi executado. Neste AGD, a cada nova geração, uma quantidade $m$ pré-definida de cópias de indivíduos migra de um deme para o outro. A escolha dos indivíduos que serão migrados foi feita pelo mesmo processo de torneio, descrito na Seção 5.2. Esses indivíduos substituem outros indivíduos do deme que os recebe, que por sua vez são selecionados entre os perdedores do processo de torneio. A Figura 5.15 ilustra o algoritmo utilizado, em que um algoritmo KMGA é executado em cada deme e as setas indicam a migração de indivíduos. O algoritmo pára quando não houver aumento da aptidão de nenhum KMGA durante um número pré-definido de gerações ou um número máximo de gerações for alcançado. Nesse experimento, esses números são 10 e 100, respectivamente.

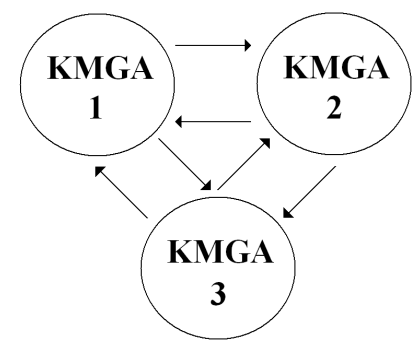

Figura 5.15: Estrutura do AGD desenvolvido.

Quatro AGDs distintos foram executados, sendo dois deles com dois demes e dois com três demes. O AGD1 foi formado por um deme executando KMGA com aptidão baseada em MSE, de forma semelhante ao experimento descrito na Seção 5.4, e um deme executando KMGA com aptidão baseada em Silhueta, semelhante ao experimento descrito na Seção 5.6. O AGD2 foi composto pelos dois demes do AGD1, adicionado de mais um deme executando KMGA com aptidão baseada em VRC, de forma semelhante ao descrito na Seção 5.5. O AGD3 possuiu dois demes, um com algoritmo KMGA com aptidão baseada em VRC e outro com KMGA com aptidão baseada em Silhueta, também de forma semelhante aos experimentos 
anteriores. O último algoritmo, o AGD4, foi formado pelos mesmos demes do algoritmo AGD3 adicionado de um deme com o algoritmo KMGA com aptidão baseada em VRC-Silhueta, como descrito na Seção 5.8 .

A única diferença entre o algoritmo KMGA executado nos AGDs e os descritos nas seções 5.4 5.5, 5.6 5.8 foi que, no KMGA executado nos AGDs, o processo de migração copia 10 indivíduos de um deme para os outros, a cada nova geração. A máquina utilizada para a execução dos AGDs foi um cluster de doze computadores dual XEON 2.0 Ghz, que possibilitou o uso de processos distintos para a execução de cada deme.

Assim como nos experimentos das seções anteriores, os AGDs foram executados 9 vezes, formando populações com indivíduos que representam agrupamentos de 2 à 10 grupos. Os agrupamentos resultantes de cada experimento foram validados com os critérios VRC, Silhueta e CR. Os valores médios do critério CR, para cada base agrupada pelos AGDs, foram comparados com os experimentos equivalentes, descritos nas seções anteriores. A diferença entre o CR médio entre os agrupamentos obtidos pelos KMGAs executados nos demes e seus equivalentes executados separadamente são apresentados na Tabela 5.10. A base de dados Proteínas não foi utilizada nesse experimento.

\begin{tabular}{|c|c|c|c|c|c|}
\hline \multirow{2}{*}{$\begin{array}{l}\text { Base de } \\
\text { dados }\end{array}$} & \multicolumn{2}{|c|}{ AGD 1} & \multicolumn{3}{|c|}{ AGD 2} \\
\hline & MSE & Silhueta & MSE & Silhueta & VRC \\
\hline Gaussiana3 & $-0,07157$ & 0,06581 & $-0,08513$ & 0,05634 & $-0,02399$ \\
\hline Simulado6 & $-0,07157$ & $-0,12169$ & 0,01350 & $-0,10956$ & 0,04982 \\
\hline Pulmão & $-0,00365$ & $-0,05728$ & $-0,00547$ & $-0,06109$ & $-0,13781$ \\
\hline Leucemia & $-0,00269$ & $-0,07422$ & 0,00159 & $-0,17639$ & $-0,05647$ \\
\hline \multirow{2}{*}{$\begin{array}{l}\text { Base de } \\
\text { dados }\end{array}$} & AGD & 3 & \multicolumn{2}{|r|}{ AGD } & 4 \\
\hline & VRC & Silhueta & VRC & Silhueta & VRC-Silhueta \\
\hline Gaussiana3 & 0,01957 & 0,02437 & $-0,00015$ & 0,04283 & $-0,01161$ \\
\hline Simulado6 & 0,06212 & $-0,0471$ & 0,06311 & $-0,13387$ & 0,02395 \\
\hline Pulmão & $-0,0733$ & $-0,00001$ & $-0,15332$ & $-0,00808$ & $-0,12854$ \\
\hline Leucemia & $-0,00651$ & $-0,14206$ & $-0,04213$ & $-0,19203$ & $-0,05175$ \\
\hline
\end{tabular}

Tabela 5.10: Diferenças entre o CR médio obtido pelos KMGAs executados nos demes dos AGDs e os obtidos pelos KMGAs executados separadamente.

Como pode ser visto na Tabela 5.10, a maioria das diferenças obtidas foi negativa, o que indica que os agrupamentos obtidos pelos KMGAs estão mais próximos da estrutura real dos dados em média, ou seja, os índices obtidos pelo critério CR são maiores. Nos experimentos em que a média da CR dos KMGAs executados nos demes foi maior que média dos KMGAs executados separadamente, as diferenças obtidas apresentaram valores muito baixos. Esses fatos mostram que o uso de várias populações com a estrutura do AGD implementado pouco aproxima os 
agrupamentos encontrados do agrupamento real.

O algoritmo KMGA com aptidão baseada em MSE, quando usado nos AGDs, apresentou pouca alteração na CR em relação a versão que executou separadamente. O algoritmo KMGA com aptidão baseada em Silhueta foi o que resultou nas maiores reduções quando executado nos AGDs, seguido do KMGA com aptidão baseada em VRC. As maiores reduções ocorreram nas bases Simulado6 e Leucemia, para o KMGA com aptidão baseada em Silhueta, e Pulmão, para o KMGA com aptidão baseada em VRC. O efeito de aglomeração de grupos foi detectado em alguns agrupamentos resultantes do uso de aptidão baseado em Silhueta.

O uso de várias populações executadas paralelamente em demes possibilita uma variabilidade maior das populações, pois essas recebem indivíduos de outras populações selecionados por funções de aptidão distintas. Com o objetivo de analisar a seleção executada pelos critérios de aptidão, analisar a variabilidade das populações finais e comparar os índices obtidos entre o indivíduo mais apto e indivíduo com melhor CR, o seguinte procedimento foi utilizado:

1. Cada deme executou um algoritmo KMGA, que por sua vez resultou em uma população final. Foi feito o cálculo da média $m$ e do desvio padrão $d p$ dos índices obtidos pelo critério CR para todos os indivíduos das populações finais.

2. Para cada população final, a diferença $d_{1}$ entre o índice CR obtido pelo indivíduo selecionado (indivíduo mais apto), dado por $C R_{a}$, e a média $m$ foi calculada por $d_{1}=C R_{a}-m$. Em seguida, a diferença $d_{1}$ foi divida pelo desvio padrão $d p$, gerando $d_{1}^{\prime}=d_{1} / d p$. Ou seja, $d_{1}^{\prime}$ indica a diferença de CR entre o indivíduo mais apto e a média da população, dada em desvios padrões.

3. Para cada população final, a diferença $d_{2}$ entre o índice CR obtido pelo indivíduo com maior $\mathrm{CR}$, dado por $C R_{b}$, e a média $m$ foi calculada por $d_{2}=C R_{b}-m$. Em seguida, a diferença $d_{2}$ foi divida pelo desvio padrão $d p$, gerando $d_{2}^{\prime}=d_{2} / d p$. Ou seja, $d_{2}^{\prime}$ indica a diferença de CR entre o indivíduo de maior CR e a média da população, dada em desvios padrões.

4. A diferença entre o indivíduo com melhor $\mathrm{CR}$ e o indivíduo com melhor aptidão foi calculada por $d_{3}=d_{2}^{\prime}-d_{1}^{\prime}$, resultando no número de desvios padrões entre os indivíduos. 
5. Como cada KMGA foi executado 9 vezes (uma vez para cada número de grupos), 9 populações finais foram geradas para cada base de dados. Sendo $d_{1 g}^{\prime}, d_{2 g}^{\prime}$ e $d_{3 g}$ as diferenças calculadas para a população de agrupamentos com $g$ grupos, as médias das distâncias calculadas para as populações com agrupamentos de 2 à 10 grupos são dadas por $\overline{d_{1}^{\prime}}=\sum_{g=2}^{10} d_{1 g}^{\prime} / 9, \overline{d_{2}^{\prime}}=\sum_{g=2}^{10} d_{2 g}^{\prime} / 9$ e $\overline{d_{3}}=\sum_{g=2}^{10} d_{3 g} / 9$.

As tabelas 5.11, 5.12, 5.13 e 5.14 mostram os valores das médias $\overline{d_{1}^{\prime}}, \overline{d_{2}^{\prime}}$ e $\overline{d_{3}}$ para as populações obtidas nos demes dos AGDs 1, 2, 3 e 4, respectivamente.

\begin{tabular}{|c|c|c|c|c|c|c|}
\hline \multirow{2}{*}{$\begin{array}{c}\text { Base de } \\
\text { dados }\end{array}$} & KMGA & aptidão & MSE & KMGA & aptidão & Silhueta \\
\hline & $\overline{d_{1}^{\prime}}$ & $\overline{d_{2}^{\prime}}$ & $\overline{d_{3}}$ & $d_{1}^{\prime}$ & $d_{2}^{\prime}$ & $\overline{d_{3}}$ \\
\hline Gaussiana3 & $-0,08316$ & 1,09271 & 1,17587 & 0,97468 & 1,03527 & 0,06059 \\
\hline Simulado6 & 1,03298 & 1,29644 & 0,26346 & 0,23850 & 1,24432 & 1,00582 \\
\hline Pulmão & 0,11182 & 2,28456 & 2,17274 & 1,67359 & 2,63207 & 0,95847 \\
\hline Leucemia & 0,01702 & 1,13117 & 1,11415 & $-0,90655$ & 0,99098 & 1,89754 \\
\hline
\end{tabular}

Tabela 5.11: Diferenças $\overline{d_{1}^{\prime}}, \overline{d_{2}^{\prime}}$ e $\overline{d_{3}}$ para as populações obtidas nos demes do AGD1

A Tabela 5.11 apresenta os valores das diferenças $\overline{d_{1}^{\prime}}, \overline{d_{2}^{\prime}}$ e $\overline{d_{3}}$ obtidas pelo algoritmo AGD1. O KMGA com aptidão baseada em MSE selecionou indivíduos com estruturas pouco semelhantes às estruturas reais, se comparado aos outros indivíduos, para as bases de dados Gaussiana3, Pulmão e Leucemia. Isso é indicado pelos baixos valores de $\overline{d_{1}^{\prime}}$ para essas bases, mostrando que os indivíduos selecionados estão muito próximos da média, ou abaixo dela, como no caso da base Gaussiana3. Os valores de $\overline{d_{2}^{\prime}}$ para essas bases indicam que existem outros indivíduos nas populações que apresentam CR mais alta que o indivíduo mais apto, sendo que todos estão mais de um desvio padrão de diferença da média. A base Pulmão apresentou um valor de $\overline{d_{2}^{\prime}}$ relativamente alto, o que indica que o indivíduo com maior CR é um caso isolado. Para a base Simulado6, o algoritmo KMGA com aptidão baseada em MSE apresentou um bom desempenho, uma vez que o indivíduo escolhido apresenta CR próxima do indivíduo com melhor CR, o que é indicado pelo baixo valor de $\overline{d_{3}}$.

O KMGA com aptidão baseada em Silhueta, que executou no segundo deme do algoritmo AGD1, selecionou indivíduos com bons índices CR para as bases Gaussiana3 e Pulmão, pois suas diferenças $\overline{d_{1}^{\prime}}$ estão acima ou muito próximas do desvio padrão. Assim como o primeiro deme, havia pelo menos um indivíduo com índice CR muito acima da média para a base de dados Pulmão, indicado pela 
distância $\overline{d_{2}^{\prime}}$ alta para essa base. Porém, os valores de $\overline{d_{1}^{\prime}}$ para as bases Simulado6 e Leucemia foram muito baixas, ocasionadas pela seleção de indivíduos com altos índices Silhueta e baixos índices CR, conseqüência do efeito de aglomeração de grupos.

\begin{tabular}{|c|c|c|c|c|c|c|c|c|c|}
\hline Base de & KMGA & aptidão & MSE & KMGA & aptidão & Silhueta & KMGA & aptidão & VRC \\
\hline dados & $d_{1}^{\prime}$ & $d_{2}^{\prime}$ & $\overline{d_{3}}$ & $d_{1}^{\prime}$ & $d_{2}^{\prime}$ & $\overline{d_{3}}$ & $d_{1}^{\prime}$ & $d_{2}^{\prime}$ & $\overline{\overline{d_{3}}}$ \\
\hline Gaussiana3 & $-0,157$ & 1,133 & 1,290 & 1,204 & 1,252 & 0,047 & $-0,980$ & 1,148 & 2,129 \\
\hline Simulado6 & 1,439 & 1,771 & 0,332 & 0,270 & 1,761 & 1,490 & 1,081 & 1,795 & 0,714 \\
\hline Pulmão & 0,413 & 2,319 & 1,906 & 1,407 & 2,596 & 1,188 & $-1,001$ & 2,784 & 3,786 \\
\hline Leucemia & 0,240 & 1,175 & 0,934 & $-1,052$ & 1,378 & 2,430 & $-1,061$ & 1,090 & 2,152 \\
\hline
\end{tabular}

Tabela 5.12: Diferenças $\overline{d_{1}^{\prime}}, \overline{d_{2}^{\prime}}$ e $\overline{d_{3}}$ para as populações obtidas nos demes do AGD2.

A Tabela 5.12 apresenta os valores das diferenças $\overline{d_{1}^{\prime}}, \overline{d_{2}^{\prime}}$ e $\overline{d_{3}}$ obtidas pelo algoritmo AGD2. Nela, as diferenças obtidas no primeiro deme, que executou KMGA com aptidão baseada em MSE, apresentaram um aumento causado pela seleção de indivíduos com CR acima do desvio padrão.

A diferença $\overline{d_{1}^{\prime}}$ no segundo deme, que executou KMGA com aptidão baseada em Silhueta, para base de dados Gaussiana3 aumentou em relação ao AGD1 e se aproximou-se muito da diferença $\overline{d_{2}^{\prime}}$, o que reduziu $\overline{d_{3}}$. Isso indica que o algoritmo selecionou os indivíduos da população com estrutura mais próxima da estrutura real. Houve redução da CR média do experimento em comparação com o deme equivalente do AGD1, como apresenta a Tabela 5.10, fato ocasionado pela migração de indivíduos selecionados por VRC. Esses indivíduos reduziram a CR média da população para a base Gaussiana3, mas não foram selecionados pelo critério Silhueta, o que fez a diferença $\overline{d_{1}^{\prime}}$ aumentar. Também houve um aumento na diferença $\overline{d_{2}^{\prime}}$ da base de dados Simulado6, mostrando que o resultado com maior CR foi um indivíduo isolado, como o selecionado no AGD1. As diferenças para as outras bases para o segundo deme permaneceram semelhantes em relação ao AGD1.

As diferenças $\overline{d_{1}^{\prime}}$ para o terceiro deme, que executou KMGA com aptidão baseada em VRC, foram baixas, sendo a maioria negativa, e as diferenças $\overline{d_{2}^{\prime}}$ foram todas acima de 1,0, ou seja, acima do desvio padrão. Isso mostra que o critério de seleção baseado em VRC não selecionou indivíduos com estruturas mais próximas da real, apesar deles existirem nas populações. A única exceção ocorreu na base Simulado6.

A Tabela 5.13 apresenta os valores das diferenças $\overline{d_{1}^{\prime}}, \overline{d_{2}^{\prime}}$ e $\overline{d_{3}}$ obtidas pelo algoritmo AGD3. Houve um aumento nas diferenças $\overline{d_{1}^{\prime}}$ obtidas pelo KMGA com aptidão baseada em VRC, em especial para a base Gaussiana3. Como ocorreu um aumento na CR média em relação ao AGD2 para a mesma base, como apresenta a Tabela 5.10, o algoritmo KMGA com aptidão baseada em VRC selecionou 


\begin{tabular}{|c|c|c|c|c|c|c|}
\hline \multirow{2}{*}{$\begin{array}{c}\text { Base de } \\
\text { dados }\end{array}$} & KMGA & aptidão & VRC & KMGA & aptidão & Silhueta \\
\hline & $\overline{d_{1}^{\prime}}$ & $\overline{d_{2}^{\prime}}$ & $\overline{d_{3}}$ & $\overline{d_{1}^{\prime}}$ & $\overline{d_{2}^{\prime}}$ & $\overline{d_{3}}$ \\
\hline Gaussiana3 & 0,48385 & 1,59998 & 1,11613 & 0,45766 & 1,74696 & 1,28929 \\
\hline Simulado6 & 1,06502 & 1,67502 & 0,61000 & 0,52984 & 1,62371 & 1,09387 \\
\hline Pulmão & $-0,85387$ & 2,18187 & 3,03575 & 1,77793 & 2,21834 & 0,44040 \\
\hline Leucemia & $-0,51049$ & 1,18357 & 1,69406 & $-1,56911$ & 0,96412 & 2,53323 \\
\hline
\end{tabular}

Tabela 5.13: Diferenças $\overline{d_{1}^{\prime}}, \overline{d_{2}^{\prime}}$ e $\overline{d_{3}}$ para as populações obtidas nos demes do AGD3.

indivíduos com CR maior, sem a presença de indivíduos migrantes da seleção por MSE nessa base. As diferenças $\overline{d_{2}^{\prime}}$ continuam altas para as populações desse deme, acima de 1.0, o que mostra que há indivíduos com estruturas mais próximas das reais das bases que não são selecionados pelo algoritmo.

A diferença $\overline{d_{1}^{\prime}}$ obtidas no segundo deme, que executou KMGA com aptidão baseada em Silhueta, para a base de dados Gaussiana3 foram menores do que as obtidas pelos algoritmos AGD1 e ADG2. As diferenças para as outras bases de dados se mantiveram próximas dos outros AGDs. As diferenças $\overline{d_{1}^{\prime}}$ para a base Pulmão foi alta, o mostra que o algoritmo selecionou indivíduos com CRs bem acima da média para base. O KMGA com aptidão baseada em Silhueta apresentou a diferença $\overline{d_{1}^{\prime}}$ negativa para a base de dados Leucemia, o que indica que o critério selecionou indivíduos com $\mathrm{CR}$ abaixo da média para a base de dados, assim como nos AGDs 1 e 2.

\begin{tabular}{|c|c|c|c|c|c|c|c|c|c|}
\hline Base de & KMGA & aptidão & VRC & KMGA & aptidão & Silhueta & KMGA & aptidão & Mista \\
\hline dados & $d_{1}^{\prime}$ & $d_{2}^{\prime}$ & $\overline{d_{3}}$ & $d_{1}^{\prime}$ & $d_{2}^{\prime}$ & $\overline{d_{3}}$ & $d_{1}^{\prime}$ & $d_{2}^{\prime}$ & $\overline{d_{3}}$ \\
\hline Gaussiana3 & $-0,727$ & 1,233 & 1,961 & 1,292 & 1,382 & 0,090 & 1,261 & 1,293 & 0,032 \\
\hline Simulado6 & 0,990 & 1,490 & 0,499 & 0,244 & 1,777 & 1,533 & 1,183 & 1,601 & 0,417 \\
\hline Pulmão & $-1,090$ & 2,581 & 3,671 & 1,832 & 2,553 & 0,720 & $-0,529$ & 2,496 & 3,025 \\
\hline Leucemia & $-0,911$ & 1,151 & 2,063 & $-1,518$ & 1,028 & 2,546 & 0,250 & 1,031 & 0,780 \\
\hline
\end{tabular}

Tabela 5.14: Diferenças $\overline{d_{1}^{\prime}}, \overline{d_{2}^{\prime}}$ e $\overline{d_{3}}$ para as populações obtidas nos demes do AGD4

A Tabela 5.14 apresenta dos valores das diferenças $\overline{d_{1}^{\prime}}, \overline{d_{2}^{\prime}}$ e $\overline{d_{3}}$ obtidas pelo algoritmo AGD4. Nela, as diferenças obtidas no deme executando KMGA com aptidão baseada em VRC apresentaram resultados muito próximos dos encontrados no experimento AGD2, de modo que o algoritmo selecionou indivíduos com CR abaixo da média para a base de dados Gaussiana3.

O algoritmo KMGA com aptidão baseada em Silhueta também apresentaram resultados muito próximos dos encontrados no experimento AGD2. Apesar do bom desempenho do algoritmo para a base Pulmão, o baixo valor de $\overline{d_{1}^{\prime}}$ encontrado para a base de dados Leucemia mostrou que a função de aptidão seleciona indivíduos com CR abaixo da média, como aconteceu em todos os outros AGDs executados. 
Os resultados apresentados para o KMGA misto que executou no terceiro deme mostraram que o algoritmo foi capaz de selecionar indivíduos com bons índices CR para a maioria das bases de dados. A única exceção foi a base Pulmão, em que o algoritmo selecionou indivíduos com CR abaixo da média da população. Esse resultado refletiu na redução da CR final em comparação com o algoritmo não distribuído, apresentado na Tabela 5.10.

Os AGDs executados nesse experimento mostraram ser eficientes no aumento da variabilidade das populações estudadas, segundo os resultados apresentados. Porém, os critérios utilizados na aptidão dos AGs não foram capazes de selecionar indivíduos da população com estruturas mais próximas da real, na maioria dos casos.

\subsection{Estudo do uso de k-médias}

A utilização de um algoritmo de agrupamento para executar o ajuste fino dos grupos representados pelos cromossomos pode melhorar os resultados obtidos pelo AG, porém exige maior tempo de execução e pode acelerar o AG para uma determinada solução ou grupo de soluções. Para validar o modelo híbrido proposto nesta Dissertação, o KMGA foi comparado com outros algoritmos que combinaram algoritmos de agrupamento particionais, especificamente o $k$-médias, com AGs. Foram comparados os seguintes algoritmos:

1. O algoritmo KMGA com aptidão baseada em MSE, descrito na Seção 5.4 .

2. O algoritmo utilizado por Murthy and Chowdhury (1996), cujas características principais estão descritas na Tabela 4.3. A população foi composta de 30 indivíduos e o algoritmo foi executado com um limite máximo de 1000 gerações ou 100 gerações sem mudança na aptidão.

3. O algoritmo KMGA com VRC como função de aptidão, descrito na Seção 5.5 .

4. Um AG semelhante ao algoritmo KMGA como descrito no terceiro item, mas sem a utilização de $k$-médias para executar o ajuste dos grupos. Ele foi executado com um limite máximo de 1000 gerações ou 100 gerações sem mudança na aptidão.

5. O algoritmo COWCLUS (Cowgill et al., 1998), que utiliza aptidão baseada em VRC e aplica $k$-médias nos resultados obtidos pela última geração do algoritmo. As outras características do algoritmo estão descritas na Tabela 
4.4. O algoritmo executou com população de 30 indivíduos, número máximo de 100 gerações e critério de parada de 10 gerações sem aumento na aptidão.

Esses algoritmos podem ser divididos em dois grupos: algoritmos com função de aptidão baseada em MSE (KMGA MSE e Murthy) e algoritmos com função de aptidão baseadas em VRC (KMGA VRC, AG sem $k$-médias, COWCLUS). Esses algoritmos também diferem na utilização de $k$-médias durante a execução do AG. Os algoritmos KMGA e KMGA VRC aplicam $k$-médias em todos os indivíduos, o algoritmo COWCLUS aplica $k$-médias apenas no indivíduo resultante e os algoritmos AG sem $k$-médias e Murthy não aplicam $k$-médias.

Cada um dos cinco algoritmos foi utilizado para agrupar as bases de dados descritas na Seção 5.1, em agrupamentos de 2 a 10 grupos, com exceção da base Proteínas, que foi agrupada em até 30 grupos. O desempenho dos indivíduos mais aptos da última população de cada algoritmo foram avaliados pelo critério CR, VRC e Silhueta, descritos na Seção 2.5. As figuras 5.16, 5.17, 5.18, 5.19 e 5.20 apresentam gráficos com o resultado do critério CR para cada algoritmo executado.

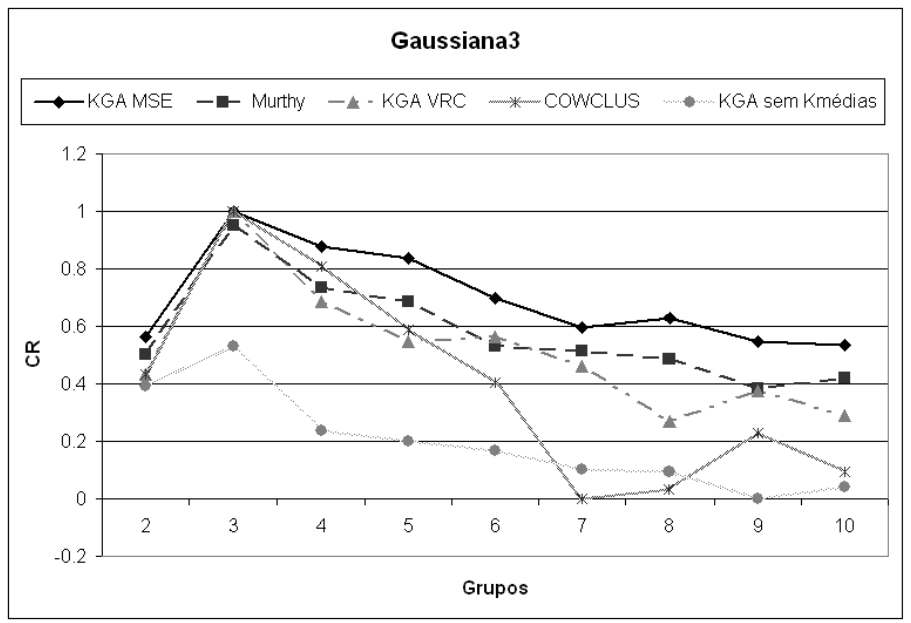

Figura 5.16: CR dos resultados obtidos para a base Gaussiana3.

Como pode ser visto na Figura 5.16, o algoritmo KMGA MSE apresentou os melhores índices CR para todos os números de grupos. Os índices obtidos pela execução do algoritmo utilizado por Murthy ficaram muito próximos dos obtidos pelo KMGA MSE. Ambos os algoritmos utilizam funções de aptidão baseadas em MSE, o que justifica a semelhança do desempenho entre os dois para essa base.

Os três experimentos restantes, com função de aptidão baseados em VRC, apresentam índices menores que os obtidos pelos experimentos com função de 
aptidão baseada em MSE. Os algoritmos que utilizaram $k$-médias com maior freqüência apresentaram um aumento dos índices CR.

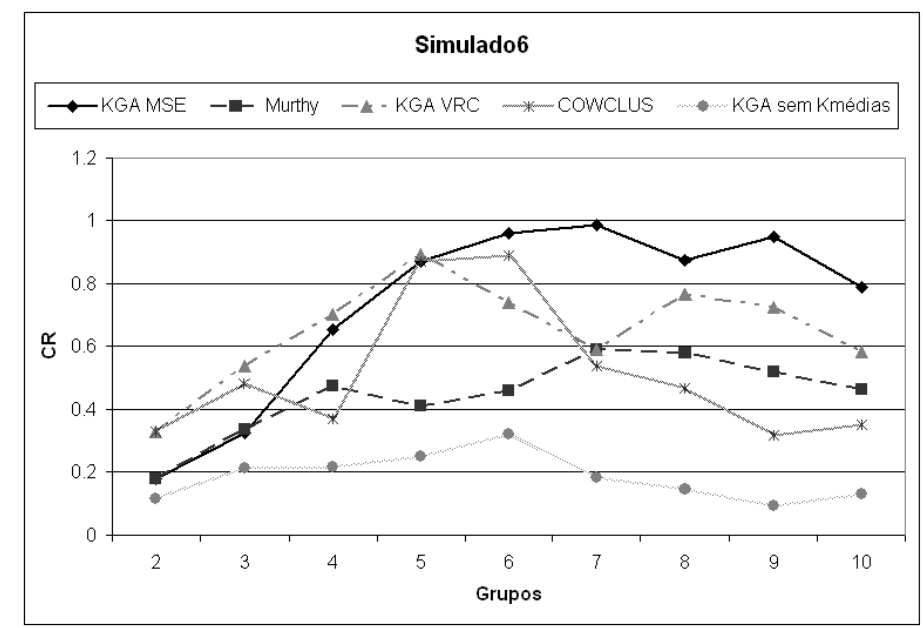

Figura 5.17: CR dos resultados obtidos para a base Simulado6.

Os índices CR obtidos para a base Simulado6 são bem parecidos com os índices obtidos para a base Gaussiana3, como é apresentado na Figura 5.17, com a diferença que os algoritmos com aptidão baseada em VRC que utilizam $k$-médias tiveram índices mais altos que os outros, quando o número de grupos é pequeno. Apesar disso, o KMGA MSE obteve os maiores índices CR na maioria dos casos. O algoritmo COWCLUS obteve um agrupamento próximo ao real quando agrupou a base Simulado6 em 6 grupos, mas não mostrou o mesmo desempenho em outros agrupamentos. Os experimentos que não utilizaram $k$-médias ainda continuaram a obter os índices mais baixos.

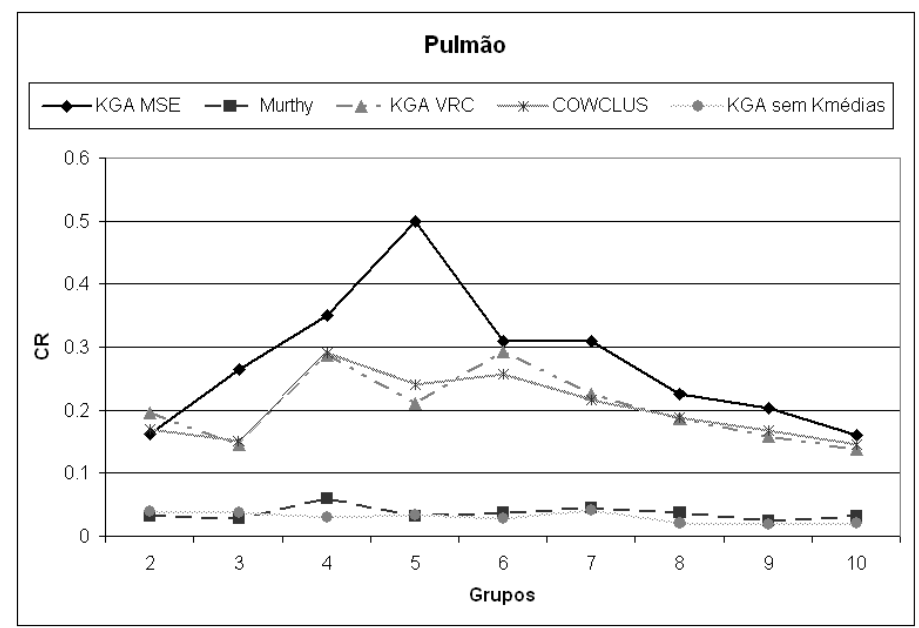

Figura 5.18: CR dos resultados obtidos para a base Pulmão. 
Assim como nas bases anteriores, o algoritmo KMGA MSE obteve os maiores índices CR para a Pulmão, seguido pelos algoritmos COWCLUS e KMGA VRC, como mostra a Figura 5.18. Mesmo aplicando $k$-médias apenas no último indivíduo, o algoritmo COWCLUS obteve índices próximos aos do algoritmo KMGA VRC, o que mostra que, para essa base e função de aptidão, o uso do $k$-médias em todos os indivíduos pode ser desnecessário. Deve ser observado, no entanto, que os algoritmos que não usam $k$-médias tiveram em baixos índices CR.

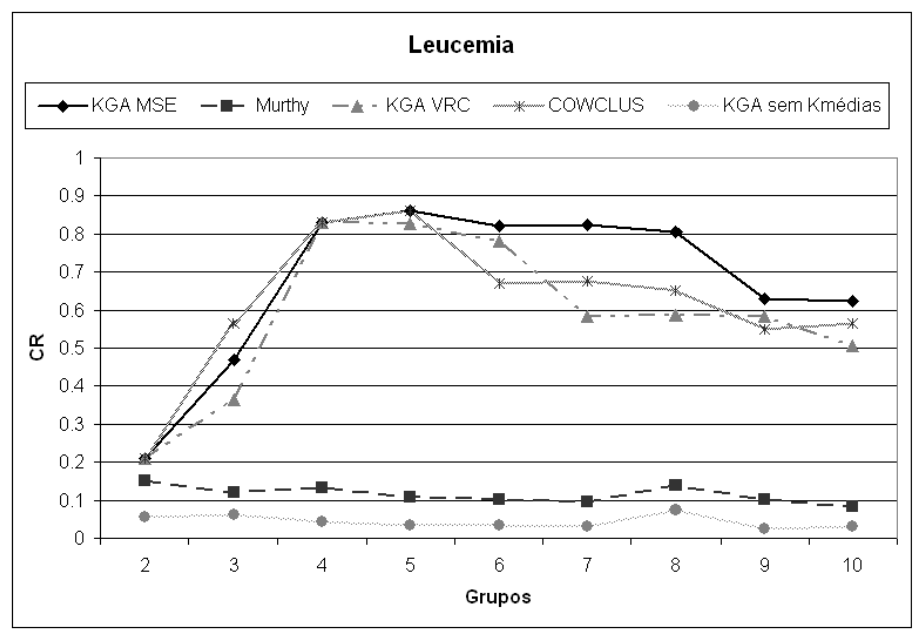

Figura 5.19: CR dos resultados obtidos para a base Leucemia.

Os algoritmos que utilizaram $k$-médias para ajustar seus grupos obtiveram índices CR altos no agrupamento da base Leucemia, como ilustra a Figura 5.19. O algoritmo COWCLUS obteve índices CR maiores do que KMGA VRC na maioria dos agrupamentos, mostrando o bom desempenho do algoritmo mesmo sem o uso de $k$-médias em todos os indivíduos. O algoritmo KMGA MSE continua a obter os maiores índices CR na maioria dos agrupamentos, e os algoritmos Murthy e AG sem $k$-médias não obtiveram bons resultados, segundo o critério CR.

A Figura 5.20 mostra que os algoritmos em que houve a aplicação de $k$-médias tiveram resultados muito próximos no agrupamento da base Proteínas. Os índices obtidos por esses algoritmos foram mais altos que os obtidos pelos algoritmos que não utilizaram $k$-médias. Porém, os índices CR foram muito baixos de maneira geral para essa base.

Os resultados mostram ainda que a utilização de $k$-médias para o ajuste fino dos agrupamentos produzidos pelos algoritmos estudados fez com os agrupamentos ficassem mais semelhantes à estrutura real dos dados. Isso acontece mesmo quando o algoritmo é aplicado apenas ao último indivíduo.

Em razão dos experimentos terem sido executados em diferentes computadores, com diferentes arquiteturas e sistemas operacionais, não é possível fazer uma 


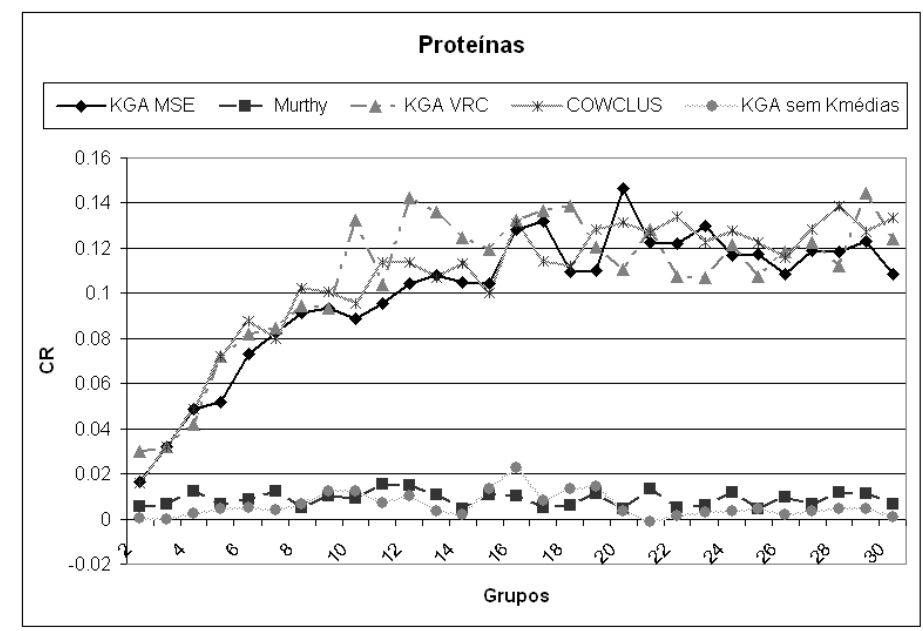

Figura 5.20: CR dos resultados obtidos para a base Proteínas.

comparação precisa do tempo de execução de cada algoritmo. O que se pode afirmar é que a utilização de $k$-médias apenas no último indivíduo aumentou o tempo de execução em décimos de segundo, enquanto sua utilização em todos os indivíduos fez com que o algoritmo tivesse um tempo de processamento até 100 vezes maior.

\subsection{KMGA com número de grupos não estabelecido}

Como descrito na Seção 2.4 as técnicas de agrupamento particionais dividem os padrões das bases de dados em um número $k$ de grupos pré-definido. Dessa forma, é preciso especificar qual será o valor de $k$ antes de particionar a base de dados. Porém, o número total de grupos ou classes pode ser desconhecido para uma determinada base de dados. Uma das abordagens para determinar $k$ consiste em executar o algoritmo uma vez para cada valor de $k$ em um intervalo pré-definido, como nas seções anteriores, e comparar os resultados. Outra abordagem define o número de grupos por meio de uma técnica de otimização, nessa dissertação, AGs. Nessa seção, é investigada a segunda abordagem.

Dentre os AGs que avaliam o número de grupos, publicados por outros autores, podem ser citados o algoritmo CGA, proposto por Hruschka et al. (2004), e o algoritmo GCA, utilizado por Cole (1998). No trabalho desenvolvido por Hruschka et al. (2004), o algoritmo CGA é capaz de formar agrupamentos com números de grupos distintos, sendo executado com diferentes características, descritas na Seção 4.5.1. Cole (1998) estudou vários métodos de agrupar dados em um número desconhecido de grupos, implementando diferentes versões do algoritmo CGA. Esses algoritmos foram implementados neste trabalho e seus resultados foram comparados com o algoritmo KMGA. Como os algoritmos CGA, GCA e KMGA 
apresentam várias versões, as características dos algoritmos implementados para esse estudo são descritas nas seções 5.11.1, 5.11.2 e 5.11 .3 .

\subsubsection{CGA}

O algoritmo CGA possui quatro versões (Hruschka et al., 2004). A versão utilizada nesse trabalho é a versão CGA-IV, que mantém as características do algoritmo CGA-I apresentadas na Tabela 5.15 e o operador de cruzamento ilustrado pela Figura 4.9. O uso de $k$-médias em todos os agrupamentos gerados pelo AG e aptidão baseada em Silhueta também são características do CGA-IV, sendo também implementadas neste trabalho. O cálculo da Silhueta baseado em centróides do algoritmo não foi feito, pois Hruschka et al. (2004) afirma que o uso de centróides nesse cálculo foi responsável pela perda de informações detalhadas sobre os grupos, o que fez com que o desempenho do algoritmo não melhorasse. Portanto, esse cálculo foi feito por meio das distâncias entre os padrões. A função de aptidão do CGA-IV é dada pela Equação 5.5 .

$$
s(i)=\frac{b(i)}{a(i)+\epsilon}
$$

em que $b$ é calculado pela Equação 2.23, $a$ é calculado pela Equação 2.22 e $\epsilon$ é o termo necessário para o cálculo de $s(i)$ quando $a=0$.

\subsubsection{GCA}

Cole (1998) estudou variações do algoritmo GCA, de sua autoria. A versão utilizada nesse experimento faz uso da representação Grupo-Número, da seleção proporcional à aptidão e do operador de cruzamento uniforme. Cole (1998) utilizou duas funções de aptidão: aptidão baseada na soma da distância quadrática entre os padrões de um mesmo grupo (WGSS, do inglês Weighted within-Group Sum of Squares), descrita pela Equação 2.27, e aptidão baseada na soma das distâncias entre os padrões e o centróide do grupo a que pertencem.

Neste trabalho, as duas funções foram estudadas, porém a aptidão baseada na soma das distâncias entre os padrões e o centróide de seu grupo mostrou forte tendência a selecionar os indivíduos com o maior número de grupos possível. Por isso essa função foi descartada e somente os resultados selecionados pela função baseada em WGSS foram considerados.

\subsubsection{KMGA}

O algoritmo KMGA, descrito na seção 5.2, foi adaptado para permitir que indivíduos de uma mesma população representassem agrupamentos com diferentes 
números de grupos. O algoritmo foi executado com quatro diferentes critérios de seleção:

1. Seleção com aptidão baseada em VRC, como descrito na Seção 5.5 .

2. Seleção com aptidão baseada em Silhueta, como descrito na Seção 5.6.

3. Seleção com aptidão baseada em VRC e Silhueta, como descrito na Seção 5.8 .

4. Seleção com aptidão baseada em VRC ou Silhueta.

A última aptidão, que é nova, é baseada nos resultados obtidos nos experimentos descritos nas outras seções. Por meio deles, foi visto que o critério Silhueta obteve agrupamentos mais próximos dos reais do que os outros critérios internos estudados. Porém, o critério Silhueta não mostrou ser um bom critério para discriminar o número de grupos real de um agrupamento. O contrário ocorreu com o critério VRC, que obteve bons resultados na escolha do número de grupos. Por esses motivos, nessa nova função de aptidão, o indivíduo $i$ é considerado mais apto que o indivíduo $j$ se o resultado da VRC de $i$ for maior que a VRC de $j$, caso $i$ e $j$ representem agrupamentos com diferentes números de grupos. Se $i$ e $j$ não apresentarem um número diferente de grupos, $i$ será mais apto que $j$ se a Silhueta de $i$ for maior que a Silhueta de $j$.

Os operadores de cruzamento e mutação também foram modificados para indivíduos com números de grupos distintos. O cruzamento por centróides coloca os centróides de ambos os pais em um vetor de tamanho $v=c_{1}+c_{2}$, em que $c_{1}$ é o número de centróides do primeiro pai e $c_{2}$ é o número de centróides do segundo pai. Em seguida, o primeiro filho recebe entre 2 e $v-2$ centróides aleatórios do vetor e o segundo filho recebe os centróides restantes.

A mutação permite que o número de grupos no indivíduo seja alterado, adicionando ou removendo padrões dos grupos. Se o padrão modificado for o último do grupo, o grupo é eliminado. Se o novo valor do padrão modificado for maior que o número de grupos, um novo grupo é gerado.

\subsubsection{Experimentos}

Nos experimentos realizados, na inicialização dos algoritmos é selecionado aleatoriamente um número de grupos entre 2 e $k$ para cada indivíduo da população. $\mathrm{O}$ valor de $k$ para a maioria das bases foi 10, com exceção da base Proteínas, em que o valor de $k$ foi 30 . Em seguida, os padrões são adicionados aleatoriamente aos grupos representados pelos indivíduos. Todas as populações foram compostas por 
30 indivíduos e o critério de parada para os algoritmos foi de 100 gerações ou 10 gerações sem aumento na aptidão. Cada algoritmo foi executado 30 vezes nesse experimento e os valores apresentados nessa seção são as médias dos resultados obtidos.

Os resultados obtidos são apresentadas nas tabelas 5.15, 5.16, 5.17, 5.18, 5.19 $\mathrm{e}$ 5.20. Nelas são apresentadas as bases de dados agrupadas, o número de grupos do indivíduo mais apto, o valor obtido pelo critério CR desse indivíduo, a média dos índices CR da população final, o desvio padrão, o número de gerações executadas e o tempo total em segundos.

\begin{tabular}{|l|r|r|r|r|r|r|}
\hline Base & Grupos & CR & Média & Desvio & Gerações & Tempo \\
\hline Gaussiana3 & 6 & 0,56240 & 0,38330 & 0,12760 & 33 & 20,31200 \\
\hline Simulado6 & 7 & 0,52888 & 0,53240 & 0,06932 & 35 & 40,15000 \\
\hline Pulmão & 6 & 0,29760 & 0,24802 & 0,04456 & 28 & 201,82600 \\
\hline Leucemia & 7 & 0,69632 & 0,68722 & 0,03503 & 27 & 217,34000 \\
\hline Proteínas & 24 & 0,12847 & 0,12697 & 0,00672 & 40 & 485,87900 \\
\hline
\end{tabular}

Tabela 5.15: Características dos resultados obtidos com CGA.

Como pode ser visto na Tabela 5.15, o algoritmo CGA não conseguiu encontrar a partição ótima para a base Gaussiana3 na maioria das execuções, apresentando em um baixo índice CR. Os índices CR dos resultados selecionados para as outras bases estão acima da média da população final, dentro do desvio padrão. Os índices CR para as bases Pulmão e Leucemia foram altos se comparados aos outros algoritmos dessa seção. O algoritmo não encontrou o número de grupos real das bases, mas conseguiu encontrar valores próximos dos mesmos, com exceção da base Gaussiana3. Ele foi concluído entre as gerações 27 e 40, o que fez o seu tempo de execução total ficar próximo da média dos algoritmos utilizados nesse experimento.

\begin{tabular}{|l|r|r|r|r|r|r|}
\hline Base & Grupos & CR & Média & Desvio & Gerações & Tempo \\
\hline Gaussiana3 & 10 & 0,46721 & 0,42313 & 0,13480 & 30 & 4,70532 \\
\hline Simulado6 & 10 & 0,63334 & 0,46338 & 0,16399 & 23 & 3,70823 \\
\hline Pulmão & 9 & 0,18203 & 0,15945 & 0,06296 & 24 & 18,856 \\
\hline Leucemia & 10 & 0,53499 & 0,48171 & 0,12059 & 23 & 22,14742 \\
\hline Proteínas & 29 & 0,11313 & 0,10408 & 0,01483 & 27 & 20,53672 \\
\hline
\end{tabular}

Tabela 5.16: Características dos resultados obtidos com GCA.

A Tabela 5.16 mostra os resultados obtidos pelo algoritmo GCA. Nela é possível ver que a aptidão baseada em WGSS não selecionou indivíduos com estrutura próxima da real para a base Gaussiana3 e Pulmão, mas obteve bons índices CR para as bases Simulado6 e Leucemia. O número de grupos encontrados para 
todas as bases é próximo do limite máximo do experimento, longe do número de grupos real. O CR dos indivíduos com melhores WGSS está acima da média dos indivíduos da população final para a maioria das bases de dados. Uma análise das populações finais mostra a existência de indivíduos com bons índices CR e pequena diferença de WGSS para o indivíduo com melhor WGSS. O tempo de execução foi pequeno na maioria dos casos, pois o algoritmo $k$-médias não é utilizado.

\begin{tabular}{|l|r|r|r|r|r|r|}
\hline Base & Grupos & CR & Média & Desvio & Gerações & Tempo \\
\hline Gaussiana3 & 3 & 1 & 0,70615 & 0,2672 & 10 & 5,57193 \\
\hline Simulado6 & 5 & 0,86728 & 0,62338 & 0,20432 & 16 & 12,58241 \\
\hline Pulmão & 10 & 0,13792 & 0,18062 & 0,03696 & 26 & 278,28130 \\
\hline Leucemia & 10 & 0,49613 & 0,60458 & 0,08421 & 28 & 363,68431 \\
\hline Proteínas & 30 & 0,11112 & 0,11631 & 0,01062 & 26 & 573,45830 \\
\hline
\end{tabular}

Tabela 5.17: Características dos resultados obtidos pelo KMGA com aptidão por VRC.

O algoritmo KMGA com aptidão por VRC foi capaz de determinar corretamente o número de grupos apenas para a base Gaussiana3, mas obteve um valor próximo ao real para a base Simulado6. Ele também obteve valores baixos no agrupamento das outras bases, a maioria abaixo da média da população. O número de grupos encontrado é alto e distante do número real para essas bases. O tempo total de execução do algoritmo foi 1,50 vezes maior que o algoritmo CGA e 17 vezes maior que o tempo de execução do algoritmo GCA, aproximadamente.

\begin{tabular}{|l|r|r|r|r|r|r|}
\hline Base & Grupos & CR & Média & Desvio & Gerações & Tempo \\
\hline Gaussiana3 & 3 & 1 & 0,71341 & 0,27809 & 10 & 4,6800 \\
\hline Simulado6 & 3 & 0,34489 & 0,23316 & 0,09819 & 11 & 5,97001 \\
\hline Pulmão & 2 & 0,16291 & 0,17268 & 0,01327 & 10 & 56,6823 \\
\hline Leucemia & 2 & 0,20174 & 0,210272 & 0,00246 & 14 & 95,19421 \\
\hline Proteínas & 3 & 0,03191 & 0,03201 & 0,00624 & 11 & 92,08234 \\
\hline
\end{tabular}

Tabela 5.18: Características dos resultados obtidos pelo KMGA com aptidão por Silhueta.

A Tabela 5.18 mostra que o algoritmo KMGA com aptidão baseada em Silhueta não apresentou bom desempenho ao selecionar o número de grupos dos agrupamentos. Apesar do agrupamento correto da base Gaussiana3, o algoritmo obteve valores CR abaixo da média da população para as bases Pulmão e Leucemia. O número de grupos foi baixo para todas as bases. Seu tempo de execução total foi aproximadamente $1 / 5$ do tempo do algoritmo KMGA com aptidão baseada em VRC, apresentando um número de gerações semelhante ao algoritmo anterior para a maioria das bases. 


\begin{tabular}{|l|r|r|r|r|r|r|}
\hline Base & Grupos & CR & Média & Desvio & Gerações & Tempo \\
\hline Gaussiana3 & 3 & 1 & 0,72282 & 0,27803 & 10 & 4,84632 \\
\hline Simulado6 & 5 & 0,90662 & 0,38771 & 0,22772 & 16 & 8,95121 \\
\hline Pulmão & 2 & 0,19623 & 0,19223 & 0,03668 & 10 & 67,40932 \\
\hline Leucemia & 4 & 0,82967 & 0,53768 & 0,24642 & 10 & 87,31342 \\
\hline Proteínas & 3 & 0,03183 & 0,03313 & 0,00891 & 13 & 102,68721 \\
\hline
\end{tabular}

Tabela 5.19: Características dos resultados obtidos pelo KMGA com aptidão por VRC e Silhueta.

Apesar do algoritmo com aptidão baseada em Silhueta e VRC ter obtido valores baixos para o número de grupos, ele foi capaz de encontrar o agrupamento ótimo para a base Gaussiana3 e os maiores valores de CR do experimento para as bases Simulado6 e Leucemia. O número de grupos é muito próximo ao obtido pelo KMGA com aptidão baseada em Silhueta, ou seja, menor que a estrutura real dos dados, porém um pouco acima do encontrado pelo KMGA Silhueta. Os valores de CR para as bases Pulmão e Proteínas também foram próximos do obtido por esse algoritmo. O tempo total de execução do algoritmo foi próximo ao do KMGA Silhueta. O número de gerações também foi baixo.

\begin{tabular}{|l|r|r|r|r|r|r|}
\hline Base & Grupos & CR & Média & Desvio & Gerações & Tempo \\
\hline Gaussiana3 & 4 & 0,54156 & 0,5858 & 0,21164 & 99 & 52,90821 \\
\hline Simulado6 & 6 & 0,44375 & 0,43634 & 0,14686 & 99 & 77,14141 \\
\hline Pulmão & 7 & 0,24389 & 0,22329 & 0,05647 & 99 & 1000,70001 \\
\hline Leucemia & 7 & 0,59861 & 0,59549 & 0,11876 & 99 & 1283,91201 \\
\hline Proteínas & 9 & 0,07142 & 0,06708 & 0,02081 & 99 & 1275,98143 \\
\hline
\end{tabular}

Tabela 5.20: Características dos resultados obtidos pelo KMGA com aptidão por VRC ou Silhueta.

Como pode ser visto na Tabela 5.20, o algoritmo KMGA com aptidão baseada em VRC ou Silhueta não selecionou indivíduos com CR maior que os selecionados pelos outros algoritmos, com exceção da base Pulmão. O número de grupos também foi próximo do real para a maioria das bases e seu tempo de execução total chega a ser 13 vezes maior que outras versões do KMGA utilizadas nesses experimentos.

Os resultados apresentados nessa seção mostram que a seleção do número de grupos feita por diferentes algoritmos obteve desempenhos distintos para cada uma das bases de dados estudadas. Dentre os algoritmos estudados, o CGA foi o que obteve melhores resultados para as bases Pulmão e Proteínas e o algoritmo KMGA, com aptidão baseada em VRC e Silhueta, os melhores resultados para as bases Gaussiana3, Simulado6 e Leucemia.

Apesar de ambos os algoritmos CGA e KMGA utilizarem Silhueta como fun- 
ção de aptidão, a aptidão do algoritmo CGA, dada pela Equação 5.5 , apresentou um desempenho melhor em relação a seleção do número de grupos do que a função de aptidão utilizada pelo KMGA, dada pela Equação 2.24 .

O uso conjunto de critérios de aptidão pode melhorar o desempenho obtido pelos algoritmos estudados, conforme os resultados do algoritmo KMGA com aptidão baseada em VRC e Silhueta. A população final gerada por esse algoritmo ao agrupar algumas bases apresentou indivíduos com aptidão muito próxima ou igual a máxima obtida, mas com erros (MSE) menores e valores de CR maiores. Por esse motivo, os valores de MSE dos agrupamentos poderia ser um bom critério de desempate para seleção de indivíduos com valores de aptidões semelhantes.

Mesmo que o número de grupos não seja estabelecido, é importante limitar o número máximo de grupos formados pelos cruzamentos estudados. Se o algoritmo formar agrupamentos com um número muito grande de grupos, esses grupos se tornam muito pequenos. Isso pode fazer com que a aptidão do agrupamento aumente até o ponto em que haverá apenas grupos com um único padrão.

\subsection{Análise de desempenho do KMGA e comparação com outras abordagens similares}

Várias versões do algoritmo KMGA, desenvolvido nesse trabalho, foram investigadas e seus resultados estudados e apresentados em outras seções do Capítulo 5. Elas mostram que os algoritmos que utilizaram o critério de validação Silhueta resultaram em agrupamentos mais próximos da estrutura real dos dados, segundo o critério CR, quando o número de grupos formados é fixo. Porém, os mesmos resultados mostram que o critério Silhueta pode aglomerar grupos próximos ou sobrepostos em um único grupo, especialmente se o número de grupos formados for menor que o número real da base. Esse efeito foi descrito pelos autores como aglomeração de grupos nas seções anteriores.

O critério VRC, quando usado em conjunto com o critério Silhueta, obteve bons resultados na seleção de agrupamentos com diferentes números de grupos, como pode ser visto na Seção 5.11 . Além disso, o critério produz valores baixos para agrupamentos afetados pela aglomeração de grupos, causado pela seleção por Silhueta.

O algoritmo KMGA com função de aptidão mista, apresentado na Seção 5.8 , foi desenvolvido com o objetivo de possibilitar o uso do critério Silhueta como função de aptidão do AG e detectar os agrupamentos afetados pela aglomeração de grupos provocado por ele. O resultado obtido por esse algoritmo depende dos valores das variáveis $c_{1}$ e $c_{2}$ de sua aptidão, dada pela Equação 5.2. Se o valor 
de $c_{1}$ for muito superior ao valor de $c_{2}$, o algoritmo não é capaz de discriminar os agrupamentos afetados pela aglomeração de padrões nas bases de dados estudadas. Caso o valor de $c_{2}$ seja igual ao superior ao valor de $c_{1}$, o algoritmo perde a capacidade de encontrar agrupamentos com a estrutura tão próximas da real quanto os agrupamentos formados apenas com a utilização do índice Silhueta.

Durante os experimentos, os valores de $c_{1}$ e $c_{2}$ foram escolhidos empiricamente para cada base de dados e foi constatado que as combinações de valores que obtiveram os resultados com melhor $\mathrm{CR}$ são diferentes para cada base. Isso aconteceu porque os critérios VRC e Silhueta avaliam características distintas dos agrupamentos validados e a estrutura destes agrupamentos varia entre diferentes bases de dados. Os dados apresentados nas tabelas 5.4 e 5.8 mostram que o aumento dos índices de um dos critérios VRC ou Silhueta não implica no aumento do outro. Além disso, os mesmos dados apresentam vários casos em que a seleção de índices maiores para um critério resultou em índices abaixo da média para o outro.

Portanto, encontrar bons valores para as variáveis $c_{1}$ e $c_{2}$ é uma tarefa que depende diretamente da estrutura dos a serem agrupados. Se a estrutura for desconhecida, essa tarefa pode ser penosa. Por esse motivo, os autores propõem novas funções de aptidão baseadas em VRC e Silhueta. As funções de aptidão propostas são:

- Versão 1 (V1) - Essa função de aptidão é baseada no valor da Silhueta do agrupamento, que é recompensada se o valor do VRC do agrupamento estiver acima da média da população ou penalizada se estiver abaixo. A Equação 5.6 é utilizada para calcular a aptidão de cada indivíduo $i$ da população.

$$
A p t(i)=\sum_{j=1}^{n} s(j) / n \times(V R C(i) / \overline{V R C})
$$

em que $n$ é o número de padrões na base de dados, $s(j)$ é a Silhueta do padrão $j$, dada pela Equação 2.24, e $\overline{V R C}=\sum_{i=1}^{p} V R C(i) / p$, sendo $p$ o tamanho da população.

- Versão 2 (V2) - Essa versão também é baseada no valor da Silhueta, mas apenas penaliza os indivíduos que representam agrupamentos com VRC abaixo da média da população. Se $V R C(i)<\overline{V R C}$, a função de aptidão é dada pela Equação 5.6. Caso contrário, a aptidão é calculada por $\operatorname{Apt}(i)=$ 
$\sum_{j=1}^{n} s(j) / n$

- Versão 3 (V3) - Nessa versão, a aptidão é o valor da Silhueta do agrupamento. O indivíduo que representa o agrupamento com menor VRC da população é descartado.

- Versão 4 (V4) - Essa função de aptidão penaliza os indivíduos cujos agrupamentos apresentem VRC com valores menores que o desvio padrão da média da população. Sendo $d v$ o desvio padrão dos valores de VRC dos indivíduos, se $V R C(i)-\overline{V R C}<-d v$, então a aptidão do indivíduo $i$ é dada pela Equação 5.7. Caso $V R C(i)-\overline{V R C} \geq-d v$, a aptidão do indivíduo é calculada por $A p t(i)=\sum_{j=1}^{n} s(j) / n$, ou seja, a Silhueta do agrupamento.

$$
\operatorname{Apt}(i)=\frac{\sum_{j=1}^{n} s(j) / n}{(\overline{V R C}-V R C(i)) / d v}
$$

Como a Equação 5.2 foi a primeira a ser desenvolvida, ela será chamada de Versão 0 (V0). Caso vários indivíduos da mesma população apresentarem a maior aptidão, o indivíduo com menor MSE é escolhido. Se o valor do MSE for o mesmo para todos, o indivíduo cuja aptidão foi calculada primeiro é o escolhido.

O algoritmo KMGA foi executado da maneira descrita nas seções 5.5, 5.6 e 5.8 utilizando as funções de aptidão V1, V2, V3 e V4. Os resultados obtidos com o KMGA V1 foram muito semelhantes aos obtidos pelo KMGA V0, ambos foram capazes de evitar a aglomeração de grupos nas bases Simulado6 e Leucemia. O KMGA V1 foi capaz de encontrar a estrutura real da base Simulado6, o que aconteceu com poucas versões do KMGA. Porém, os algoritmos KMGA V0 e V1 obtiveram um desempenho muito inferior ao obtido pelo algoritmo KMGA com aptidão baseada em Silhueta ao agrupar a base de dados Pulmão.

Os algoritmos KMGA V2 e V3 não foram capazes de evitar o efeito de aglomeração de grupos, apesar de suas execuções resultarem em uma pequena redução do mesmo. Essas versões obtiveram um desempenho um pouco melhor no agrupamento da base Pulmão, mas muito inferior ao obtido pelo algoritmo KMGA com aptidão baseada em Silhueta.

Os resultados da execução do algoritmo KMGA V4 apresentaram uma redução do efeito de aglomeração de grupos superior à obtida pelas versões V2 e V3, mas inferior às versões V0 e V1. Eles também apresentam um desempenho próximo ao obtido pelo algoritmo KMGA com aptidão baseada em Silhueta ao agrupar a base de dados Pulmão. 
Os resultados sugerem ainda que a base Simulado6 é formada de grupos próximos que são agrupados juntos quando os agrupamentos são selecionados pelo critério Silhueta. Esses agrupamentos apresentam baixo índice de VRC. A base Pulmão contém um grupo com uma quantidade maior de padrões do que os outros. O critério Silhueta apresenta bom desempenho ao selecionar agrupamentos dessa base, mas o critério VRC não.

Além da função de aptidão, a utilização de um algoritmo particional, $k$-médias nesse projeto, para ajuste dos grupos foi estudada. Segundo os resultados obtidos e apresentados na Seção 5.10, os experimentos que não utilizaram $k$-médias não obtiveram um bom desempenho no agrupamento das bases de dados. Os experimentos que empregaram $k$-médias apenas na última geração obtiveram resultados próximos aos que usaram $k$-médias em todos os indivíduos.

Assim, os experimentos com KMGA V1, V2, V3 e V4 foram refeitos sem o uso de $k$-médias durante a execução do AG. $\mathrm{O}$ algoritmo $k$-médias foi aplicado apenas na população final e os agrupamentos resultantes substituíram o agrupamento representado pelo indivíduo apenas se sua aptidão fosse maior do que a aptidão do agrupamento a ser substituído. Os resultados obtidos por esses experimentos foram próximos aos experimentos que usaram $k$-médias em todos os indivíduos, como é o caso do algoritmo COWCLUS apresentado na Seção 5.10 .

Todos experimentos foram executados duas vezes, a primeira utilizando cruzamento por margens e a segunda com cruzamento por centróides. Em quase todos eles, os resultados obtidos com cruzamento por centróides apresentaram índices CR maiores. Por esse motivo, os experimentos feitos utilizando cruzamento por centróides foram escolhidos para a análise feita nessa seção.

As versões V0 e V4 do algoritmo KMGA obtiveram os melhores resultados. Por isso, os índices CR desses algoritmos foram comparados com os resultantes das versões anteriores e são apresentados nas figuras 5.21, 5.22, 5.23 e 5.24 . Os índices do critério CR para a base de dados Proteínas foram muito semelhantes em todos os experimentos e, por esse motivo, não são apresentados. A versão V4 do algoritmo KMGA que aplicou $k$-médias apenas na população final do AG também foi comparada. O CR dos resultados obtidos é apresentada nessas figuras como KMGA V4.1.

Conforme a Figura 5.21, com exceção dos algoritmos KMGA MSE e KMGA VRC, todas a outras versões do algoritmo KMGA obtiveram resultados muito próximos ao agrupar a base de dados Gaussiana3. Todas as versões conseguiram encontrar o agrupamento real dos dados.

A Figura 5.22 apresenta o CR obtido para cada número de grupos gerados 


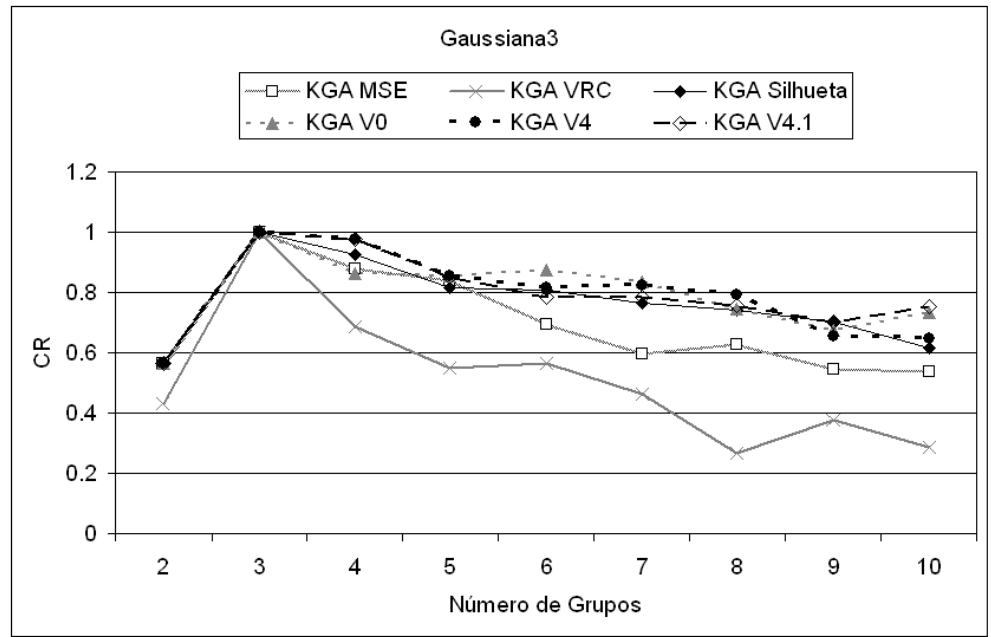

Figura 5.21: CR dos resultados obtidos com KMGA para a base Gaussiana3.

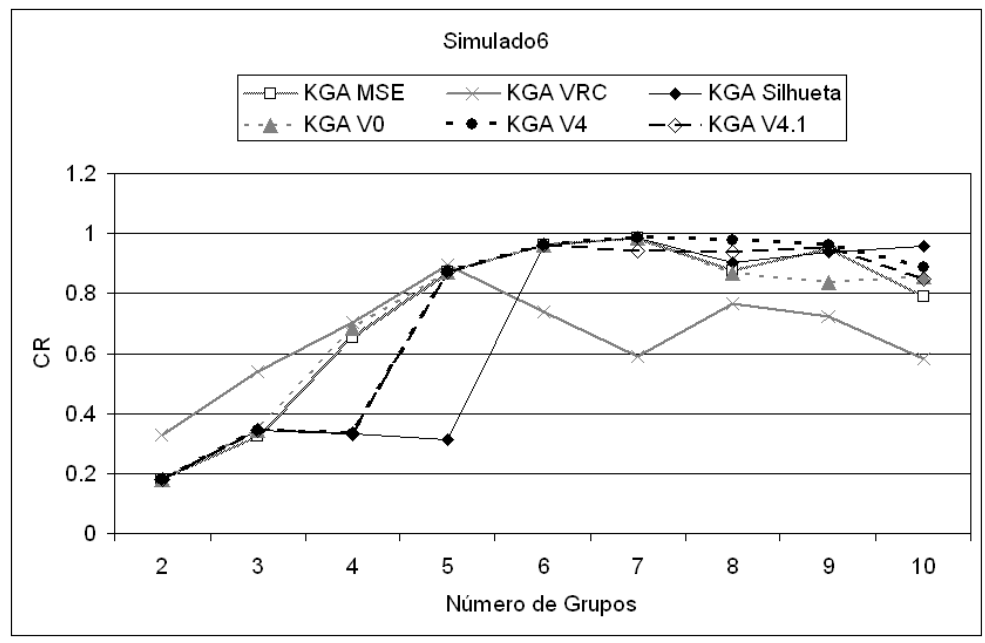

Figura 5.22: CR dos resultados obtidos com KMGA para a base Simulado6.

para a base Simulado6. Nela é possível ver que o algoritmo KMGA Silhueta apresentou valores baixos de CR para os agrupamentos com 4 e 5 grupos. O efeito de aglomeração de grupos foi detectado nos algoritmos KMGA V4 e KMGA V4.1. A análise dos agrupamentos obtidos mostra aglomeração de grupos em todos os casos. Apesar do algoritmo KMGA VRC não sofrer esse efeito, ele não obteve bons índices para os agrupamentos com mais de 5 grupos. Os algoritmos KMGA MSE e KMGA V0 sofreram uma pequena redução dos índices CR nos agrupamentos com mais de 6 grupos. É possível que essa redução tenha relação com o uso de VRC na função de aptidão, para o algoritmo KMGA V0.

Os resultados da Figura 5.23 apresentam os índices CR obtidos com o agrupamento da base Pulmão. Os maiores índices foram obtidos pelo algoritmo KMGA com aptidão baseada em Silhueta, seguido dos algoritmos KMGA V4 e KMGA 


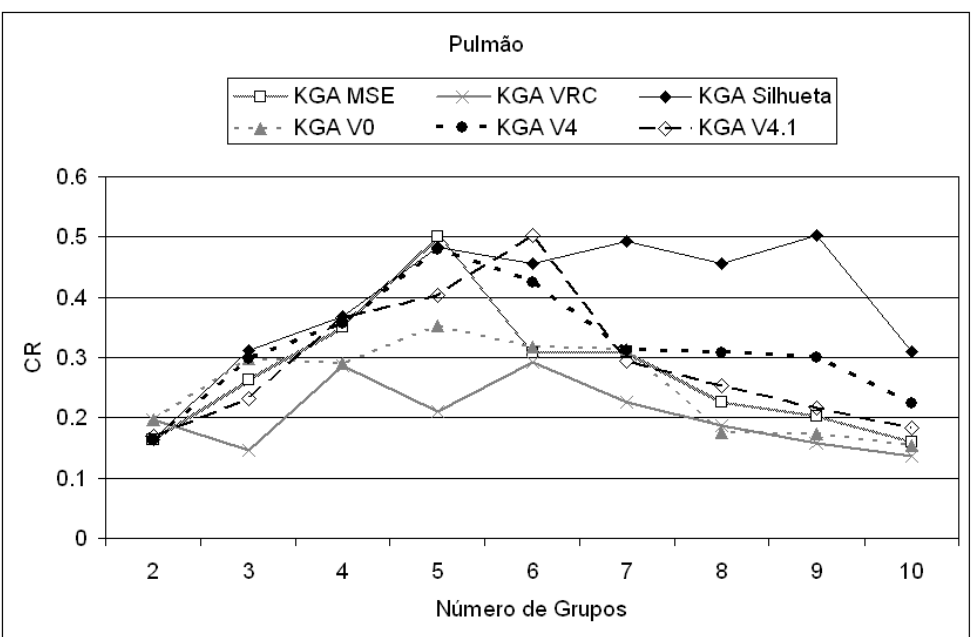

Figura 5.23: CR dos resultados obtidos com KMGA para a base Pulmão.

V4.1. O algoritmo KMGA MSE obteve um bom índice para o agrupamento com 5 grupos, porém o mesmo não ocorre com os outros agrupamentos produzidos pelo algoritmo. Os algoritmos KMGA VRC e KMGA V0, cujas aptidões são fortemente influenciadas pelo critério VRC, não geraram agrupamentos com bons valores.

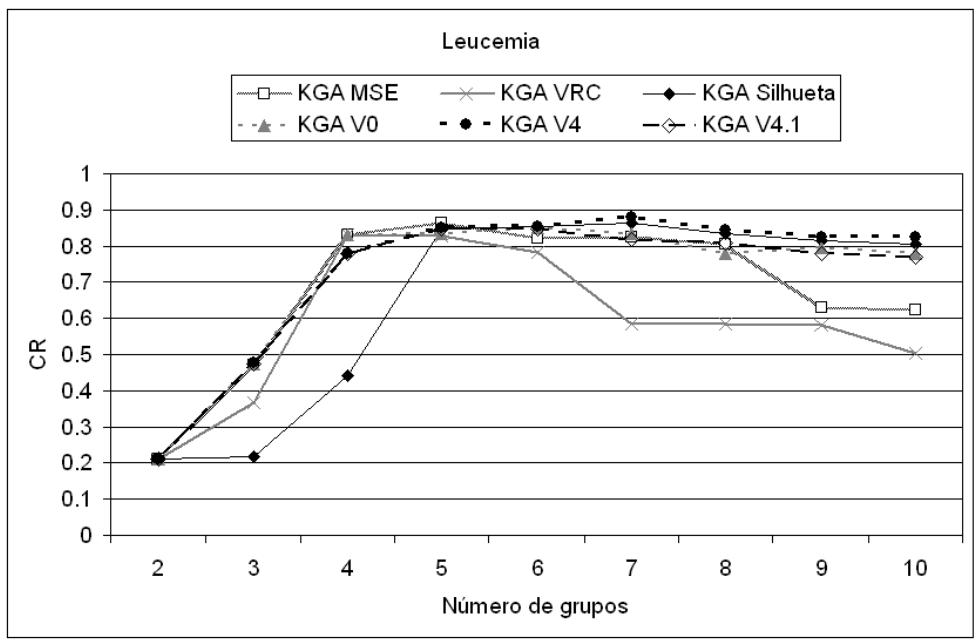

Figura 5.24: CR dos resultados obtidos com KMGA para a base Leucemia.

Os valores obtidos pelo critério CR dos agrupamentos da base Leucemia são apresentados na Figura 5.24. O algoritmo KMGA Silhueta executou aglomeração de grupos nos agrupamentos de 3 e 4 grupos e o algoritmo KMGA VRC obteve os piores índices na maioria dos agrupamentos. Os algoritmos KMGA que utilizaram aptidões baseadas em ambos os critérios obtiveram resultados próximos e com valores acima de 0.7 na maioria dos casos. O algoritmo KMGA MSE obteve resultados semelhantes aos KMGAs, que utilizaram aptidões baseadas em ambos 
os critérios, com queda nos agrupamentos de 9 e 10 grupos.

Os resultados obtidos permitem uma comparação entre as versões do algoritmo KMGA desenvolvidas nesse projeto. A versão V4.1 foi escolhida como a versão de melhor desempenho, por ter obtido bons índices CR nas quatro bases estudadas e por possuir tolerância a aglomeração de grupos. Além disso, o tempo de execução total do algoritmo foi de 3 a 30 vezes menor que o das outras versões do KMGA.

\subsubsection{KMGA comparado com abordagens similares}

Maneiras distintas de construir a população inicial do algoritmo foram estudadas. Elas consistem em inserir agrupamentos resultantes de técnicas de agrupamento hierárquico ou $k$-médias na população inicial. Porém, essas mudanças não surtiram aumento no índice CR final do algoritmo, apenas aumentaram ou reduziram seu tempo de execução. Esse aumento foi causado pela execução do algoritmo que irá gerar os indivíduos da população inicial. Em alguns casos, o algoritmo convergiu rapidamente para as soluções resultantes desses algoritmos, o que fez com que o AG executasse um número menor de gerações e, conseqüentemente, finalizasse em um tempo menor.

O uso de múltiplas medidas de dissimilaridade, apresentado na Seção 5.7, resultou na melhoria dos índices dos critérios de validação da maioria dos agrupamentos. As três medidas selecionadas com maior freqüência pelo experimento foram a distância Euclidiana, correlação de Pearson e distância Manhattan. Por isso, essas medidas foram escolhidas para serem utilizadas pelo $k$-médias na população final da execução do KMGA V4.1. Essa versão aprimorada pelo uso do $k$-médias com várias medidas de dissimilaridade é chamada de KMGA versão 5 (V5) e suas características são iguais às do algoritmo KMGA V4.1, com exceção da aplicação de $k$-médias.

No algoritmo KMGA V5, o k-médias é aplicado com três variações nos agrupamentos representados pela população final, uma com a distância Euclidiana, outra com a correlação de Pearson e a terceira com distância Manhattan. Os indivíduos da população final passam a representar os agrupamentos resultantes dessa aplicação apenas se esses forem mais aptos do que os agrupamentos representados antes da aplicação de cada $k$-médias. Isso fez com que o desempenho do algoritmo KGMA V5 fosse igual ou superior ao do algoritmo KMGA V4.1, uma vez que ambos executam os mesmos procedimentos antes da aplicação do $k$-médias.

Experimentos com características semelhantes aos apresentados nas seções 5.5 . 5.6 e 5.8 foram realizados com o algoritmo KMGA V5. Os agrupamentos obtidos foram validados com o critério $\mathrm{CR}$ e comparados com agrupamentos resultantes 
dos algoritmos $k$-médias, GAG (descrito na Tabela 4.5), COWCLUS (descrito na Tabela 4.4), o AG desenvolvido por Murthy (descrito na Tabela 4.3) e os algoritmos hierárquicos single-link e complete-link. Esses resultados são apresentados nas figuras 5.25 5.26, 5.27, 5.28 e 5.29. Este experimento foi executado 30 vezes para cada algoritmo e cada resultado apresentado é a média dos valores obtidos nas 30 repetições.

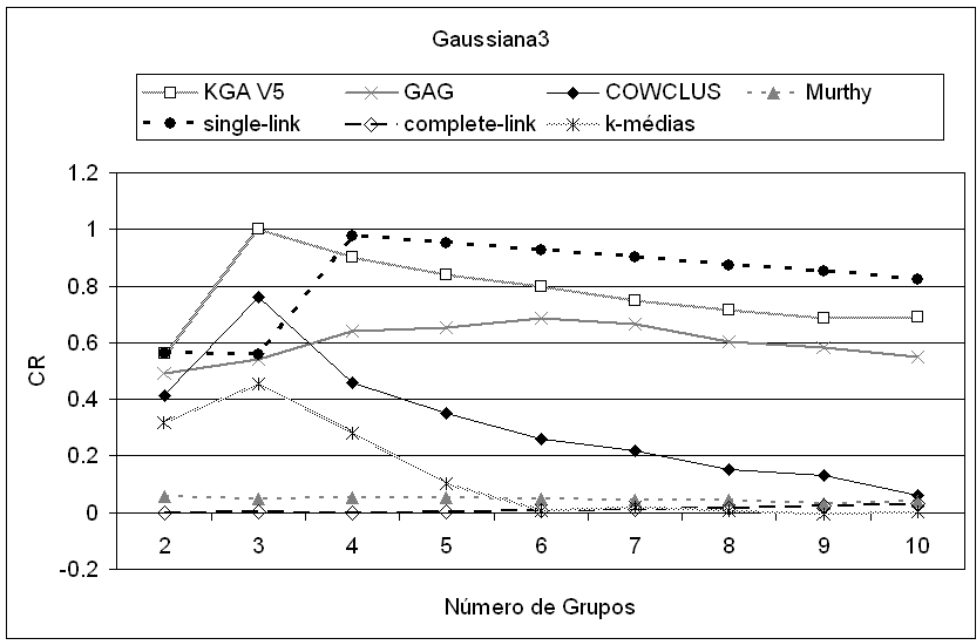

Figura 5.25: CR obtida com vários algoritmos de agrupamento para a base Gaussiana3.

A Figura 5.25 apresenta os índices CR dos agrupamentos para a base de dados Gaussiana3. Nela é possível visualizar que o algoritmo KMGA V5 obteve uma desempenho superior aos outros algoritmos na maioria dos agrupamentos. A única exceção é o algoritmo hierárquico single-link, que obteve os melhores índices para quase todos os agrupamentos, mas não conseguiu encontrar o agrupamento real da base. Outros algoritmos que não conseguiram encontrar o agrupamento real da base foram o GAG e o AG utilizado por Murthy. O pior desempenho foi obtido pelo algoritmo complete-link.

Segundo os resultados apresentados na Figura 5.26, o algoritmo KMGA V5 obteve mais agrupamentos com índices altos do que qualquer uma das outras técnicas separadamente. Apesar disso, o algoritmo apresentou aglomeração de padrões ao agrupar a base em 4 grupos. O desempenho do algoritmo singlelink não foi bom para essa base, a maioria dos agrupamentos resultantes dele não apresentaram bons índices CR. O pior desempenho foi obtido pelo algoritmo Murthy. O limite de 10 gerações sem melhoria na aptidão, imposto a todos os AGs do experimento, não permitiu que algoritmo aprimorasse os agrupamentos iniciais.

Apesar do desempenho ruim do algoritmo complete-link nas bases de dados 


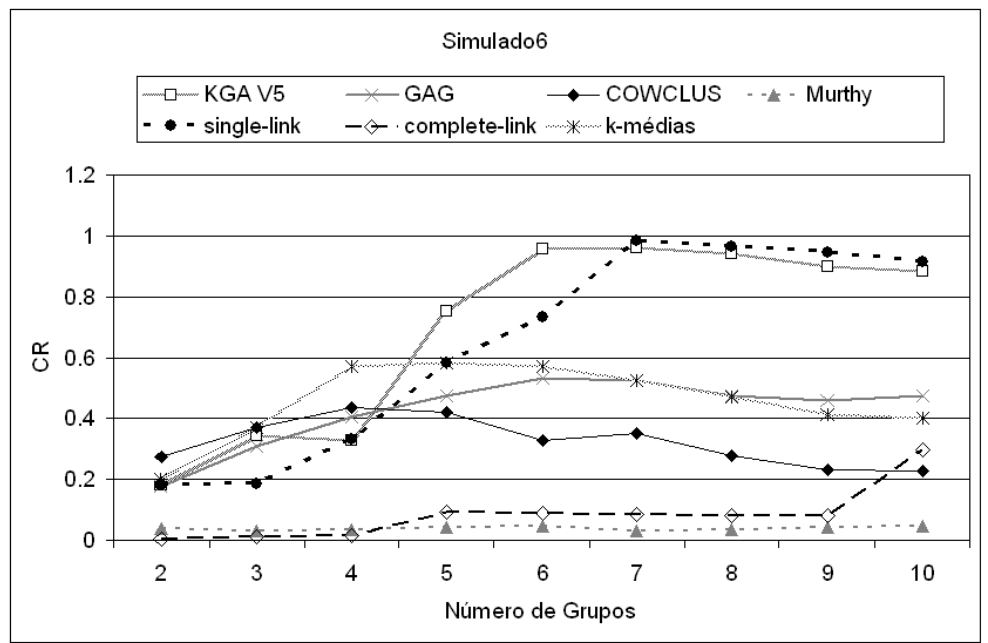

Figura 5.26: CR obtida com vários algoritmos de agrupamento para a base Simulado6.

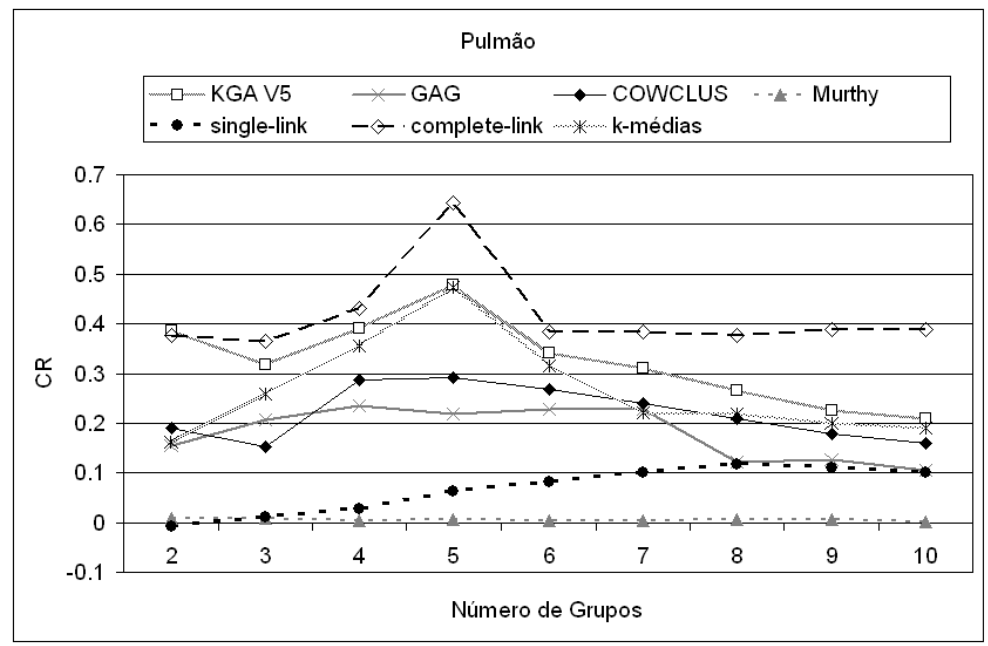

Figura 5.27: CR obtida com vários algoritmos de agrupamento para a base Pulmão.

Gaussiana3 e Simulado6, ele obteve o melhor desempenho na base de dados Pulmão, seguido pelo algoritmo KMGA V5. O algoritmo single-link gerou agrupamentos com baixos valores de CR, um desempenho muito abaixo do obtido nas bases anteriores.

O algoritmo KMGA V5 obteve os melhores agrupamentos da base Leucemia considerando os diferentes números de grupos, segundo os resultados na Figura 5.28. Ele também obteve um índice próximo do melhor no agrupamento com 3 grupos. Os algoritmos $k$-médias e COWCLUS geraram bons agrupamentos, em geral, e os algoritmos single-link e Murthy obtiveram os piores desempenhos.

A base Proteínas também foi agrupada pelos algoritmos comparados. Nesse 


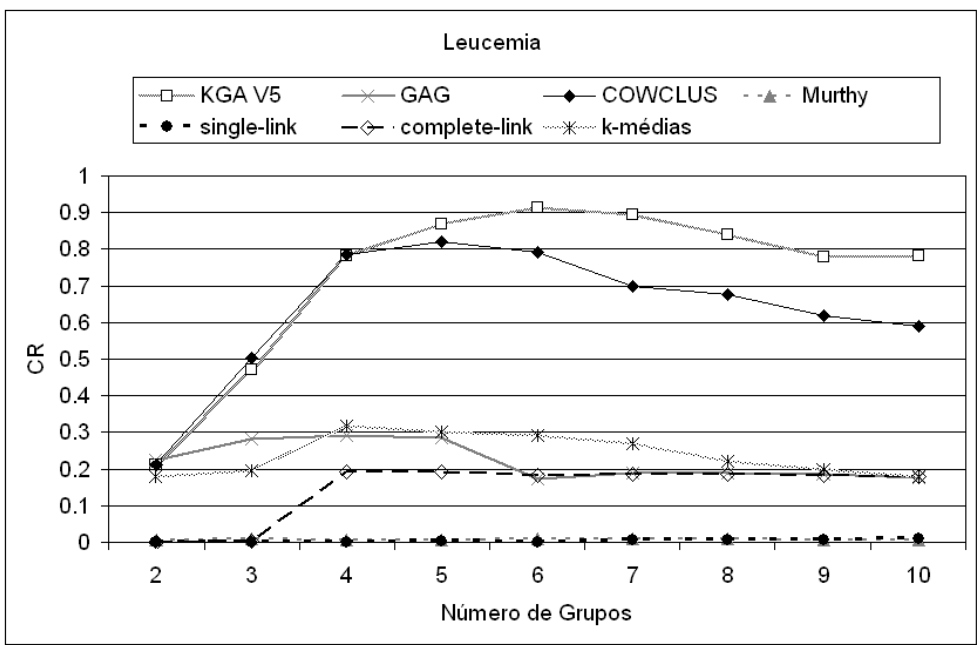

Figura 5.28: CR obtida com vários algoritmos de agrupamento para a base Leucemia.

experimento, o valor do critério CR foi baseado na estrutura de 4 grupos da base Proteínas, diferentemente dos outros experimentos feitos, em que o critério teve como base a estrutura de 27 grupos. Isso foi feito para avaliar o desempenho do critério KMGA de uma nova maneira nesse trabalho, avaliando a capacidade do algoritmo obter uma estrutura diferente das estudadas anteriormente. Os valores do índice CR dos agrupamentos resultantes são apresentadas na Figura 5.29.

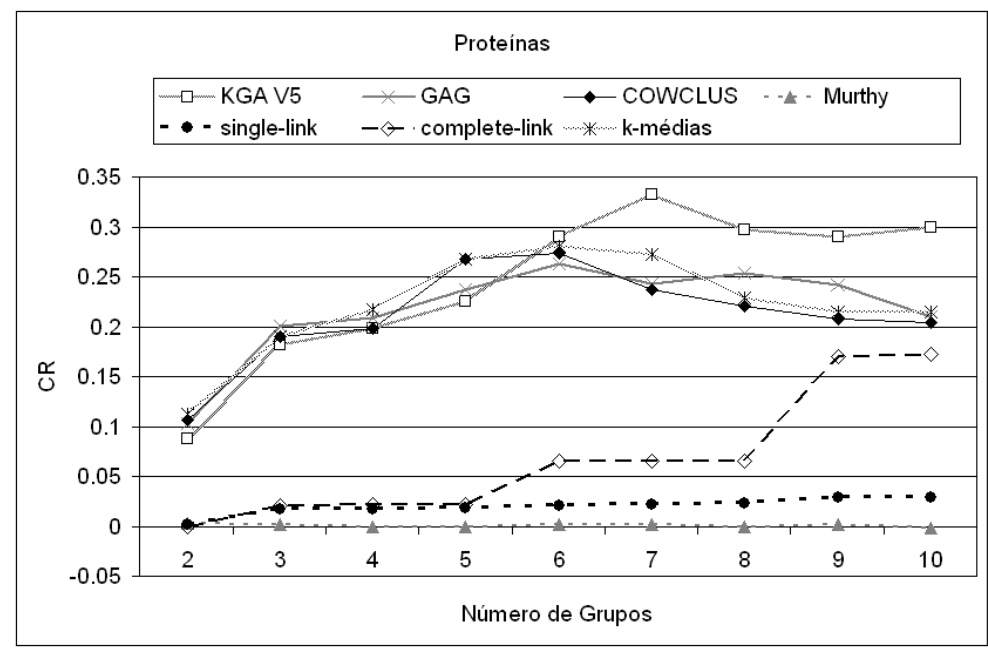

Figura 5.29: CR obtida com vários algoritmos de agrupamento para a base Proteínas.

Os algoritmos de agrupamento hierárquicos single-link e complete-link e o AG utilizado por Murthy não obtiveram bons resultados ao agrupar a base de dados Proteínas, como é apresentado na Figura 5.29. O algoritmo KMGA V5 obteve o maior valor CR do experimento e foi o algoritmo com a maior média dos índices do 
critério. Os outros algoritmos apresentaram resultados muito próximos. Nenhum agrupamento foi validado com valor igual ou acima de 0.4 , o que indica que a estrutura de 4 grupos da base Proteínas não é de fácil agrupamento para os algoritmos utilizados.

O tempo de execução total dos algoritmos é apresentado no gráfico em escala logarítmica na Figura 5.30. Nele, é possível verificar que os menores tempos de execução foram obtidos pelos algoritmos hierárquicos, sendo que para algumas bases, esses foram menores que 1 segundo. Porém, o desempenho desses algoritmos foi baixo em várias das bases de dados estudadas.

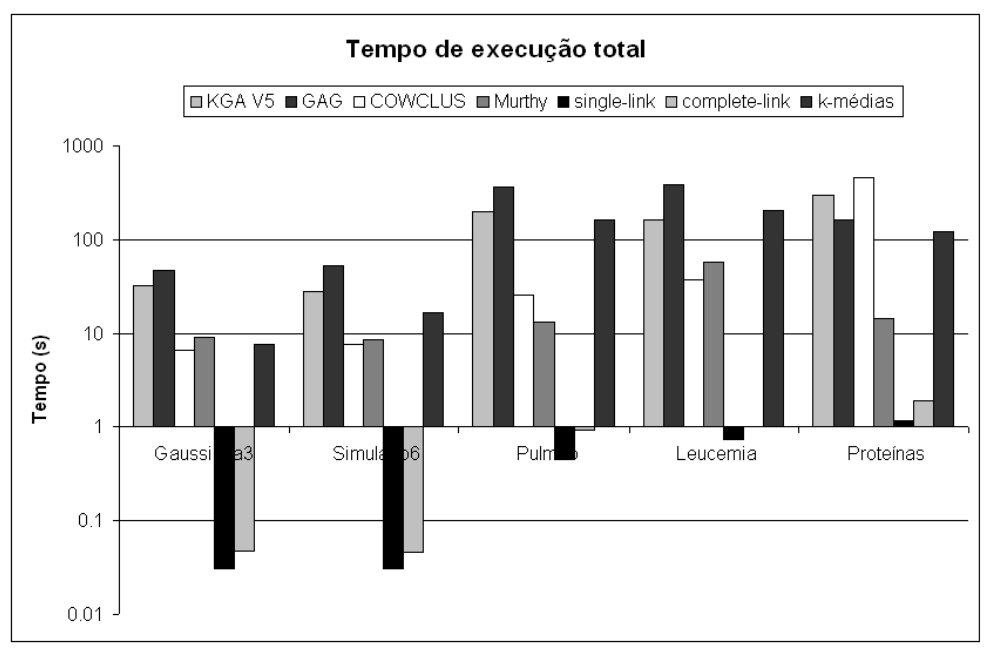

Figura 5.30: Tempo de execução total dos algoritmos.

Após os algoritmos hierárquicos, os algoritmos mais rápidos foram os algoritmos COWCLUS e o AG utilizado por Murthy. Esses algoritmos obtiveram um desempenho que vai de fraco a médio em comparação aos outros algoritmos. Além disso, o algoritmo COWCLUS apresentou o maior tempo de execução do experimento para a base Proteínas.

Os algoritmos KMGA V5 e $k$-médias exibiram tempos de processamento próximos e foram os algoritmos que obtiveram os melhores resultados na média. $\mathrm{O}$ maior tempo de execução foi obtido pelo algoritmo GAG, que, na média, executou um número muito maior de gerações do que os outros AGs analisados. O algoritmo não obteve resultados de destaque em nenhuma das bases.

Os resultados obtidos comprovam experimentalmente que o algoritmo KMGA V5 é capaz de obter agrupamentos próximos da estrutura real das bases de dados estudadas. Seu desempenho permaneceu bom em todas as bases, o que não ocorreu com os outros algoritmos. Seu tempo de execução foi próximo de outros algoritmos encontrados na literatura que utilizam AG e $k$-médias. 


\subsection{Considerações Finais}

Nessa seção foram apresentados os experimentos desenvolvidos no decorrer do projeto e uma análise dos resultados obtidos. O estudo de características importantes do uso de AG para o agrupamento de dados possibilitou o desenvolvimento de um novo algoritmo de agrupamento, o KMGA. A análise dos resultados mostra que o KMGA apresenta bom desempenho e estabilidade no agrupamento das bases estudadas, representando assim uma alternativa promissora para aplicações de agrupamento de dados.

Os resultados mostram ainda que o desempenho de diferentes técnicas de agrupamento e validação varia com a estrutura da base de dados agrupada. A comparação de diferentes algoritmos de agrupamento permite um melhor conhecimento das características das bases de dados. AGs podem ser utilizados em conjunto com outras técnicas de agrupamento, aprimorando os resultados obtidos, como foi apresentado nessa seção. 


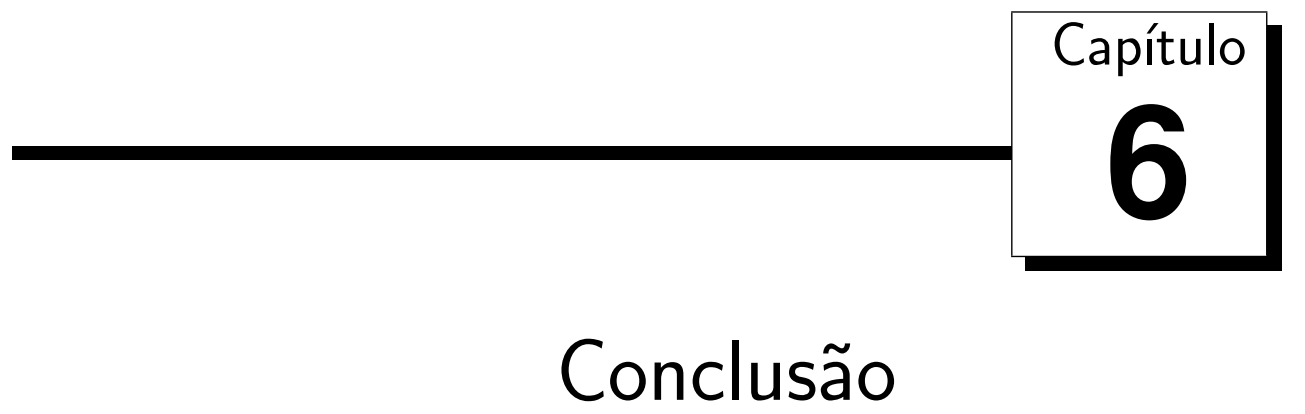

A análise de expressão gênica é uma área de pesquisa em expansão em Bioinformática. Para dar conta da demanda por análises confiáveis dos dados gerados, em geral não rotulados, é necessário o desenvolvimento de ferramentas computacionais que possibilitem a classificação não supervisionada de dados. Algoritmos de agrupamento têm sido utilizados com freqüência nessas ferramentas, mas nem sempre têm encontrado resultados que atendam às necessidades dos pesquisadores das áreas biológicas. AGs por serem algoritmos de busca global que, por meio de operadores probabilísticos, permitem ampliar a quantidade de possíveis soluções resultantes dos algoritmos de agrupamento, são candidatos potenciais para a melhora dos resultados obtidos, como comprovam os trabalhos publicados nos últimos anos.

Nesse contexto se enquadra o trabalho desenvolvido pelo candidato, que investigou alternativas para combinação de um algoritmo particional, o algoritmo $k$-médias, com AGs. O candidato inclusive propôs novas abordagens para essa combinação.

Os objetivos do trabalho apresentado nessa dissertação foram:

1. O estudo do uso de AGs em conjunto com algoritmos de agrupamento: o principal objetivo deste projeto foi o estudo de um algoritmo híbrido de agrupamento; capaz de efetuar uma busca global no espaço de soluções de forma a encontrar o agrupamento com melhor índice, segundo um critério pré-estabelecido.

2. A aplicação dos algoritmos estudados em análise de dados de expressão gênica: um dos objetivos deste trabalho consistiu na exploração de algoritmos de agrupamento em dados de expressão gênica; esses algoritmos devem ser capazes de agrupar genes de acordo com sua função ou 
agrupar amostras para identificar tipos e sub-tipos de patologias, por exemplo, tipos e sub-tipos de câncer.

3. Fazer uma análise comparativa do desempenho obtido por diferentes técnicas de agrupamento baseadas em AGs: sob esse aspecto, o objetivo do trabalho foi realizar experimentos com diferentes técnicas de agrupamento em conjunto com AGs e estudar o desempenho obtido por essas combinações.

Durante o estudo da utilização de AGs com algoritmos de agrupamento, foram pesquisados os trabalhos publicados na área. As características mais relevantes dos algoritmos de agrupamento, AGs e a utilização de ambos em algoritmos híbridos foram classificadas e descritas nos capítulos 2, 3 e 4 dessa dissertação. A classificação dos algoritmos híbridos foi feita segundo o tipo de agrupamento resultante: particionais, hierárquicos e baseados em Redes Neurais. No início desse texto são descritos conceitos importantes na análise de expressão gênica, área de aplicação dos algoritmos estudados.

$\mathrm{Na}$ fase experimental, a pesquisa deu ênfase no estudo de técnicas particionais, pela estrutura simples do agrupamento resultante e pela sensibilidade dos algoritmos desse grupo aos valores dos parâmetros livres. Várias versões do algoritmo particional KMGA, proposto pelo candidato, foram estudadas. os resultados obtidos por essas versões foram comparados entre si e com outros algoritmos encontrados na literatura.

Algumas conclusões relacionadas com as características dos algoritmos estudados são apresentadas a seguir:

- Representação - A representação foi composta principalmente das representações Grupo-Número e baseada em centróides. Em alguns experimentos, apenas uma dessas representações foi usada, o que permitiu uma comparação de desempenho entre elas.

Tal comparação permitiu algumas conclusões interessantes. Por exemplo, armazenar o número do grupo a que cada padrão pertence necessita de pouca memória e tem baixo custo adicional de processamento. A representação Grupo-Número evita o re-cálculo das distâncias entre os padrões e os centróides dos grupos, necessário todas as vezes que é preciso determinar o grupo de um padrão.

Nos algoritmos em que o $k$-médias foi aplicado em todos indivíduos, o armazenamento dos centróides teve custo computacional muito baixo, uma 
vez que seus valores já foram calculados. Porém, esse armazenamento foi necessário apenas quando o cruzamento por centróides foi utilizado. Nos algoritmos KMGA V4.1 e V5, k-médias é aplicado apenas nas populações finais, o que torna necessário o cálculo dos centróides para esse tipo de cruzamento. Isso aumentou de $10 \%$ a $15 \%$, aproximadamente, o tempo de execução do algoritmo.

- Função de Aptidão - Várias funções de aptidão foram utilizadas, dentre elas, funções baseadas em MSE, VRC e Silhueta. A função de melhor desempenho varia com a base de dados agrupada, com o conhecimento prévio do número de grupos e com os valores escolhidos para os parâmetros livres da função.

O estudo dos resultados obtidos nos experimentos, especialmente os descritos nas seções 5.5.1 e 5.6.1, mostra que é difícil estabelecer relações entre os critérios estudados. Esses avaliam características distintas das estruturas dos agrupamentos, sendo que essas podem ter maior presença ou não, dependendo da base de dados. Portanto, a presença de uma característica avaliada por um critério não implica na necessidade da presença de características avaliadas por outros.

A funções de aptidão baseadas em MSE avaliaram melhor agrupamentos com formatos hiper-esféricos, assim como funções baseadas em Silhueta. As funções baseadas em silhueta tiveram desempenhos melhores dos que as outras ao determinar a estrutura real dos dados. Porém, essas funções tendem a causar a aglomeração de grupos sobrepostos, especialmente quando o número de grupos do agrupamento é igual ou menor que o real. Por esse motivo, essas funções resultam em melhores estruturas quando o número de grupos é alto.

Funções de aptidão baseadas em VRC não sofreram do mesmo problema de aglomeração de dados que as baseadas em Silhueta. Quando utilizada em conjunto com Silhueta, elas também foram eficientes na busca pelo número real de grupos das bases. Porém, quando o número de grupos é determinado, essas funções resultaram em índices de validação abaixo das demais.

O uso conjunto de critérios de validação obteve bons resultados, permitindo o bom desempenho do critério Silhueta e evitando o efeito de aglomeração de grupos. Mesmo assim, ainda é preciso ajustar a contribuição de cada critério na aptidão dos indivíduos, pois cada base de dados apresenta características que são detectadas em diferentes níveis por cada critério. Esse ajuste pode 
ser feito por meio de parâmetros.

- Inicialização - Nesse projeto, os agrupamentos iniciais foram gerados aleatoriamente ou por meio de um algoritmo de agrupamento hierárquico (single-link ou complete-link). A variação da forma de inicialização não provocou alteração significativa nos resultados obtidos.

- Seleção - Foram estudados os métodos de seleção por Roleta e por Torneio. A seleção por Torneio preservou melhor a variabilidade dos indivíduos nos experimentos executados.

- Cruzamento - O cruzamento de um simples ponto é eficiente apenas quando a representação é feita por centróides ou qualquer representação em que a estrutura dos grupos não possa ser severamente prejudicada durante o cruzamento.

O cruzamento com número desconhecido de grupos, feito por Hruschka et al. (2004), pode modificar o número de grupos durante a execução, o que faz com que os indivíduos filhos tenham um número de grupos diferentes dos pais. Isto é um problema quando o número de grupos é fixo. Além disso, seu desempenho foi pior que o cruzamento por centróides na maioria das bases estudadas.

O cruzamento baseado em margens só é aplicável para problemas com um número fixo de grupos. O desempenho desse cruzamento foi bom apenas nos experimentos em que foi utilizado em conjunto com $k$-médias. Ele resultou em agrupamentos com baixos índices de validação em outros casos.

O cruzamento por centróides foi o de melhor desempenho nas bases de dados estudadas. Esse cruzamento forma grupos hiper-esféricos, pois os padrões mais próximos do centróide sempre vão pertencer ao grupo representado por este. Essa característica pode ser prejudicial no agrupamento de grupos com formatos diferentes.

- Mutação - Não houve estudo de mutações distintas. As mutações descritas na literatura são muito próximas da utilizada e, por esse motivo, foi dada prioridade no estudo de outras características dos AGs.

- $\boldsymbol{K}$-médias - O estudo do uso de $k$-médias em conjunto com AG mostra que a aplicação do algoritmo aumentou os índices de validação para as bases de dados utilizadas. Algoritmos que aplicaram $k$-médias apenas nos agrupamentos da população final, como COWCLUS, KMGA V4.1 e V5, 
resultaram em índices de validação muito próximos aos dos algoritmos que aplicaram em todas as populações.

AGs com $k$-médias resultaram em agrupamentos com maiores índices de validação do que os obtidos pelo $k$-médias sozinho. Um fator importante para esse resultado é a qualidade dos grupos que são usados no início da execução do $k$-médias. Os grupos selecionados pelo AG são de maior qualidade que os selecionados aleatoriamente, pois recebem grupos de gerações anteriores. Os agrupamentos que sofreram aglomeração de grupos não resultaram em agrupamentos melhores que os obtidos por $k$-médias.

- Algoritmos Distribuídos - Os experimentos executados com os AGDs implementados resultaram em populações de maior diversidade. Porém, as características dos indivíduos migrantes não foram absorvidas pelos indivíduos com maior aptidão. Funções de aptidão mais sensíveis ao contexto desses algoritmos podem resolver esse problema.

- Tempo de Execução - O tempo de execução dos algoritmos variou de acordo com as características dos mesmos. Como foi apresentado na Seção 5.3. o uso de AGs pode melhorar o desempenho de algoritmos de agrupamento sem que haja um grande aumento no tempo de execução total ou até redução do mesmo. Porém, AGs complexos, como os que aplicam técnicas para ajuste de agrupamentos em todos indivíduos, têm seu tempo de execução aumentado várias vezes e nem sempre obtêm bons resultados.

- Medidas de Similaridade - O uso de diferentes medidas de dissimilaridade selecionadas pelo AG permitiu um aumento de desempenho na maioria dos casos. Contudo, a variação dos índices obtidos não foi maior do que $5 \%$ na maioria dos experimentos, seja para mais ou para menos.

Três das cinco bases de dados utilizadas são compostas de expressão gênica. As bases Proteínas e Pulmão são bastante heterogênias, o que dificultou seus agrupamentos pelos algoritmos estudados. A base de dados Leucemia, quando agrupada, resultou em altos índices do critério CR, refletindo a forte semelhança entre os agrupamentos obtidos e o real. Um algoritmo que tenha como objetivo agrupar bases como essas deve ser capaz de avaliar diferentes características. AGs com funções de aptidão multi-objetivo ou baseadas em vários critérios podem ser capazes de fazê-lo.

Os algoritmos desenvolvidos foram comparados com diversos outros propostos na literatura e suas características aprimoradas. A versão final do algoritmo 
KMGA apresentou um bom desempenho e um bom tempo de execução em comparação com outros algoritmos.

Possíveis trabalhos futuros envolvem: o agrupamento de bases de dados não utilizadas nos experimentos, a fim de comprovar a eficiência do algoritmo estudado; o estudo de novas funções de aptidão que possibilitem determinar melhor a estrutura dos dados e o número de grupos; o estudo do uso de novos critérios de validação de agrupamentos na execução do AG, com o objetivo de avaliar novas características das estruturas dos dados; e o estudo de funções de aptidão mais adequadas aos AGDs. 


\section{Referências Bibliográficas}

Balakrishnan, K. and Honavar, V. (1995). Evolutionary Design of Neural Architectures: A Preliminary Taxonomy and Guide to Literature. Technical report, Department of Computer Science, Iowa State University, Ames, Iowa.

Baldi, P. and Brunak, S. (1998). Bioinformatics: The Machine Learning Approach. Adaptative Computation and Machine Learning. MIT Press.

Barbara, D. (2000). An introduction to cluster analysis for data mi-

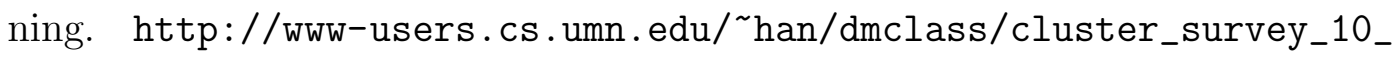
02_00.pdf [Acessado em 12/11/2003].

Bayram, E., II, P. S., Harris, R., Xiao, Y.-D., Clauset, A. J., and Schmitt, J. D. (2004). Genetic algorithms and self-organizing maps: a powerful combination for modeling complex qsar and qspr problems. In Journal of Computer-Aided Molecular Design, volume 18, pages 483 - 493. Springer Science+Business Media B.V., Formerly Kluwer Academic Publishers B.V.

Beasley, D., Bull, D. R., and Martin, R. R. (1993). An overview of genetic algorithms: Part 2, research topics. University Computing, 15(4):170-181.

Belew, R. K. and Booker, L. B., editors (1991). Solving Partitioning Problems with Genetic Algorithms. Morgan Kaufmann.

Ben-Dor, A., Friedman, N., and Yakhini, Z. (2001). Class discovery in gene expression data. In RECOMB, pages 31-38. http://citeseer.nj.nec.com/ 387748.html.

Bezdek, J. C., Boggavaparu, S., Hall, L. O., and Bensaid, A. (1994). Genetic algorithm guided clustering. Procedings of the First IEEE Conference on Evolutionary Computation, pages 34-40.

Bhattacharjee, A., Richards, W. G., Staunton, J., Li, C., Monti, S., Vasa, P., Ladd, C., Beheshti, J., Bueno, R., Gillette, M., Loda, M., Weber, G., Mark, 
E. J., Lander, E. S., Wong, W., Johnson, B. E., Golub, T. R., Sugarbaker, D. J., and Meyerson, M. (2001). Classification of human lung carcionmas by mrna expression profiling reveals distinct adenacarcinomas sub-classes. In Proceedings of the National Academy of Sciences, 98(24):13790-13795.

Calinski, T. and Harabasz, J. (1974). A dendrite method for cluster analysis. Communications in statistics, 3(1):1-27.

Cantú-Paz, E. (1998). A survey of parallel genetic algorithms. In Calculateurs Paralleles, volume 10, pages 141-171, Department of Computer Science and Illinois Genetic Algorithms Laboratory. Reseaux et Systems Repartis.

Cantú-Paz, E. (1999). Migration policies and takeover times in genetic algorithms. In GECCO, page 775 .

Cantú-Paz, E. (2000). Markov chain models of parallel genetic algorithms. In Transactions on Evolutionary Computation, volume 4, pages 216-226. IEEE.

Chan, V., Hozentas, N., and Park, V. (2000). Gene Expression. University of Waterloo.

Chen, X., Gui, W., Cen, L., and Hu, Z. (2004). A multi-population genetic algorithm based on chaotic migration strategy and its application to inventory programming. In Proceedings of the 5th World Congress on Intelligent Control and Automation, Hangzhou, P.R. China, pages 2159-2162. IEEE.

Cole, R. M. (1998). Clustering with Genetic Algorithms. PhD thesis, Department of Computer Science, University of Western Australia.

Cowgill, M. C., Harvey, R. J., and Watson, L. T. (1998). A genetic algorithm approach to cluster analysis. Technical report, Virginia Polytechnic Institute \& State University, Blacksburg, VA, USA.

Denzinger, J. and Kidney, J. (2003). Improving migration by diversity. In The 2003 Congress on Evolutionary Computation, volume 1, pages 700-707. IEEE.

Ding, C. H. and Dubchak, I. (2001). Multiclass protein folder recognition using support vector machines and neural networks. Bioinformatics, 17:4:349-358.

Dubes, R. and Jain, A. K. (1976). Clustering techniques: the user's dilemma. Pattern Recognition, 8:247 - 260. 
Duda, R., Hart, P., and Stork, D. (2001). Pattern Classification. John Wiley \& Sons.

Eisen, M. B., Spellman, P., Brown, P., and Botstein, D. (1998). Cluster analysis and display of genome-wide expression patterns. In Proc. Natl. Acad. Sci. USA, volume 95 , pages $14863-14868$.

Estivill-Castro, V. (2002). Why so many clustering algorithms - a position paper. SIGKDD Explorations, 4(1):65-75.

Faceli, K., de Carvalho, A. C. P. L. F., and Souto, M. C. P. (2005a). Algoritmos de agrupamento de dados. Technical Report 249, ICMC-USP.

Faceli, K., de Carvalho, A. C. P. L. F., and Souto, M. C. P. (2005b). Validação de algoritmos de agrupamento. Technical Report 254, ICMC-USP.

Fränti, P., Kaukoranta, T., and Nevalainen, O. (1997a). On the splitting methos for vq codebook generation. Optical Engineering, 36:3043-3051.

Fränti, P. and Kivijärvi, J. (2000). Randomised local search algorithm for the clustering problem. Pattern Analysis and Applications, 3:358-369.

Fränti, P., Kivijärvi, J., Kaukoranta, T., and Nevalainen, O. (1997b). Genetic algorithms for large scale clustering problems. The Computer Journal, 40:547554 .

Garai, G. and Chaudhuri, B. (2004). A novel genetic algorithm for automatic clustering. Pattern Recognition Letters, 25:173-187.

Gesú, V. D., Giancarlo, R., Bosco, G. L., Raimondi, A., and Scaturro, D. (2005). Genclust: A genetic algorithm for clustering gene expression data. $B M C B i-$ oinformatics, 6(289):1-11.

Golub, T., D.K. Slonim and, P. T., Huard, C., Gaasenbeek, M., Mesirov, J., Coller, H., Loh, M., Downing, J., Caligiuri, M., Bloomfield, C., and Lander, E. (1999). Molecular classification of cancer: Class discovery and class prediction by gene expression. Science, 286(5439):531-537.

Gordon, A. (1999). Classification. Chapman \& Hall/CRC.

Greene, W. A. (2003). Unsupervised hierarchical clustering via a genetic algorithm. In Proceedings of the 2003 Congress on Evolutionary Computation, pages 998-1005. IEEE Press. 
Halkidi, M., Batistakis, Y., and Vazirgiannis, M. (2001). On clustering validation techniques. Intelligent Information Systems Journal, 17(2-3):107-145.

Hall, L., Ozyurt, B., and Bezdek, J. (1999). Clustering with a genetically optimized approach. In Transations on Evolutionary Computation, volume 3, pages 103-112, Department of Computer Science and Engineering, University of South Florida, Department of Computer Science and Engineering, University of West Florida. IEEE.

Handl, J., Knowles, J., and Kell, D. B. (2005). Computational cluster validation in post-genomic data analysis. Bioinformatics, 21(15):3201-3212.

Hartigan, J. A. (1985). Statistical theory in clustering. Journal of Classification, 2:63-76.

Haykin, S. (1999). Neural Networks: A Comprehensive Foundation. Prentice Hall.

He, Q. (1999). A review of clustering algorithms as applied in IR. Technical Report UIUCLIS-1999/6+IRG, Information Retrieval Group, University of Illinois.

Hiroyasu, T., Miki, M., and Negami, M. (1999). Distributed genetic algorithms with randomized migration rate. In International Conference on Systems, Man and Cybernetics, volume 1, pages 689 - 694. IEEE.

Hruschka, E. R., Campello, R. J. G. B., and de Castro, L. N. (2004). Improving the efficiency of a clustering genetic algorithm. In Advances in Artificial Intelligence - IBERAMIA 2004: 9th Ibero-American Conference on AI, Puebla, Mexico, November 22-25. Proceedings, volume 3315, page 861. Springer-Verlag $\mathrm{GmbH}$, Lecture Notes in Computer Science.

Hubert, L. J. and Arabie, P. (1985). Comparing partitions. Journal of Classification, 2:193-218.

Jain, A. and Dubes, R. (1988). Algorithms for Clustering Data. Prentice Hall.

Jain, A. K., Murty, M. N., and Flynn, P. J. (1999). Data clustering: a review. ACM Computing Surveys, 31(3):264-323.

Jiang, D., Tang, C., and Zhang, A. (2003). Cluster analysis for gene expression data: A survey. IEEE Transactions on Knowledge and Data Engineering. 
Jin, H.-D., Leung, K.-S., Wong, M.-L., and Xu, Z.-B. (2003). An efficient selforganizing map designed by genetic algorithms for the traveling salesman problem. In Systems, Man and Cybernetics, Part B, IEEE Transactions on, volume 33, pages $877-888$. IEEE.

Johnson, R. A. and Wichern, D. W. (1982). Applied multivariate statistical analysis. Prentice Hall, Englewood Cliffs, NJ.

Kaufman, L. and Rousseeuw, P. J. (1990). Finding Groups in Data: An Introduction to Cluster Analysis. John Wiley \& Sons.

Kivijärvi, J., Fränti, P., and Nevalainen, O. (2003). Self-adaptive genetic algorithm for clustering. Journal of Heuristics, 9(2):113 - 129.

Lin, W.-Y., Lee, W.-Y., and Hong, T.-P. (2002). On self-adaptive multipopulation genetic algorithms. In International Conference on Systems, Man and Cybernetics, volume 6. IEEE.

Ma, P. and Chan, K. (2003). Discovering clusters in gene expression data using evolutionary approach. Proceedings on 15th IEEE International Conference on Tools with Artificial Intelligence, 3-5:459 - 466.

Ma, Z. (2005). A genetic som clustering algorithm for intrusion detection. In Advances in Neural Networks - ISNN 2005: Second International Symposium on Neural Networks, Chongqing, China, May 30, volume 3498, page 421, Department of Computer Science and Engineering, Chongqing University, Chongqing 400044, China. Lecture Notes in Computer Science, Springer-Verlag GmbH.

Maulik, U. and Bandyopadhyay, S. (2000). Genetic algorithm-based clustering technique. Pattern Recognition, 33:1455 - 1465.

Mitchell, M. (1999). An introduction to Genetic Algorithms. MIT Press.

Mitchell, T. (1997). Machine Learning. McGraw Hill.

Monti, S., Tamayo, P., Mesirov, J., and Golub, T. (2003). Consensus clustering: A resampling based mathod for class discovery and visualization of gene expression microarray data. Machine Learning, 52:91-118.

Murphy, D. (2002). Gene expression studies using microarrays: Principles, problems, and prospects. Advan. Physiol. Educ., 26(4):256-270. 
Murthy, C. A. and Chowdhury, N. (1996). In search of optimal clusters using genetic algorithms. Pattern Recogn. Lett., 17(8):825 - 832.

Ng, R. T., Sander, J., and Sleumer, M. C. (2001). Hierarchical cluster analysis of SAGE data for cancer profiling. In Workshop on Data Mining in Bioinformatics (BIOKDD01), pages 65-72.

Noda, E., Coelho, A., Ricarte, I., Yamakami, A., and Freitas, A. (2002). Devising adaptive migration policies for cooperative distributed genetic algorithms. In International Conference on Systems, Man and Cybernetics, volume 6, pages 438-443. IEEE.

Oei, C. K., Goldberg, D. E., and Chang, S. J. (1991). Tournament selection, niching, and the preservation of diversity. Technical Report 91011, University of Illinois at Urbana-Champaign (IlliGAL).

Ohtsuka, A., Kamiura, N., Isokawa, T., and Matsui, N. (2002). On detection of confused blood samples using self organizing maps and genetic algorithm. In Neural Information Processing, 2002. ICONIP '02. Proceedings of the 9th International Conference on, volume 5, pages 2233 - 2238, Department of Computer Science and Illinois Genetic Algorithms Laboratory.

Pan, H., Zhu, J., and Han, D. (2003). Genetic algorithms applied to multi-class clustering for gene expression data. Genomics, Proteomics and Bioinformatics, 1(4):279-287.

Peña, J. M., Lozano, J. A., and Larrañaga, P. (1999). An empirical comparison of four initialization methods for the k-means algorithm. Pattern recognition letters, 20:1027-1040.

Raghavan, V. V. and Birchand, K. (1979). A clustering strategy based on formalism of reproductive process in a natural system. In Proceedings of the Second International Conference on Information Storage and Retrieval, pages 10-22.

Rousseeuw, P. J. (1987). Silhouettes: a graphical aid to the interpretation and validation of cluster analysis. Journal of Computational and Applied Mathematics, 20:53-65.

Setúbal, J. C. and Meidanis, J. (1997). Introduction to Computational Molecular Biology. PWS Publishing Company. 
Slonim, D. K., Tamayo, P., Mesirov, J. P., Golub, T. R., and Lander, E. S. (2000). Class prediction and discovery using gene expression data. In $R E C O M B$, pages 263-272.

Stuart, A. (1983). Kendall's tau. Encyclopedia of Statistical Sciences, 4(367369):3201-3212.

Tan, L., Taniar, D., and Smith, K. (2002). A new parallel genetic algorithm. In International Symposium on Parallel Architectures, Algorithms and Networks, pages $284-289$. IEEE.

Tanaka, M., Furukawa, Y., and Tanino, T. (1996). Weight tuning and pattern classification by self organizing map using genetic algorithm. In Proceedings of IEEE International Conference on Evolutionary Computation, pages $602-$ 605. May, 20-22.

Tseng, L. and Yang, S.B., . (2001). A genetic approach to the automatic clustering problem. Pattern Recognition, 34:415-424.

Ward, J. H. (1963). Hierarchical grouping to optimize an objective function. Journal of the American Statistical Association, 58:236-244.

Wu, F.-X., Zhang, W. J., and Kusalik, A. J. (2003). A genetic k-means clustering algorithm applied to gene expression data. In Advances in Artificial Intelligence: 16th Conference of the Canadian Society for Computational Studies of Intelligence, AI 2003, Halifax, Canada, June 11-13. Proceedings, volume 2671, pages 520 - 526. Springer-Verlag GmbH.

Yang, Y. H., Dudoit, S., Luu, P., and Speed, T. P. (2001). Normalization for cDNA microarray data. In SPIE BiOS 2001, San Jose, California.

Yeoh, E. J., Ross, M. E., Shurtleff, S. A., Williams, W. K., Patel, D., Mahfouz, R., Behm, F. G., Raimondi, S. C., Relling, M. V., Patel, A., Cheng, C., Campana, D., Wilkins, D., Zhou, X., Li, J., Liu, H., Pui, C. H., Evans, W. E., Naeve, C., Wong, L., and Downing, J. R. (2002). Classification, subtype discovery, and prediction of outcome in pediatric acute lymphoblastic leukemia by gene expression profiling. Cancer Cell, 1(2).

Yeung, K., Haynor, D., and Ruzzo, W. (2000). Validating clustering for gene expression data. Technical Report UW-CSE-00-01-01, University of Washington, Department of Computer Science and Engeneering. 
Zeger, K. and Gersho, A. (1989). Stochastic relaxation algorithm for improved vector quantiser design. Electronics Letters, 25:896-898.

Zeng, Y., Tang, J., Garcia-Frias, J., and Gao, G. (2002). An adaptive metaclustering approach: Combining the information from different clustering results. In IEEE Computer Society Bioinformatics Conference (CSB'02), page 276, Stanford, California.

Zhang, T., Ramakrishnan, R., and Livny, M. (1996). BIRCH: an efficient data clustering method for very large databases. In Proceedings of the 1996 ACM SIGMOD International Conference on Management of Data, pages 103-114, Montreal, Canada. 